\title{
Innovation in Three Government Labs: Individual and Institutional Factors
}

\author{
by \\ Michael Rosenblatt, B.A., M.A. \\ A thesis submitted to the Faculty of Graduate Studies and Research \\ in partial fulfillment of \\ the requirements for the degree of \\ Doctor of Philosophy \\ School of Public Policy and Administration \\ Carleton University \\ Ottawa, Ontario \\ March 2004
}

Copyright (C) 2004 Michael Rosenblatt 


\author{
National Library \\ of Canada \\ Acquisitions and \\ Bibliographic Services \\ 395 Wellington Street \\ Ottawa ON K1A ON4 \\ Canada
}

Bibliothèque nationale

du Canada

Acquisisitons et services bibliographiques

395 , rue Wellington Ottawa ON K1A 0N4 Canada
Your file Votre référence ISBN: 0-612-94213-9 Our file Notre référence ISBN: 0-612-94213-9
The author has granted a nonexclusive licence allowing the National Library of Canada to reproduce, loan, distribute or sell copies of this thesis in microform, paper or electronic formats.

The author retains ownership of the copyright in this thesis. Neither the thesis nor substantial extracts from it may be printed or otherwise reproduced without the author's permission.
L'auteur a accordé une licence non exclusive permettant à la Bibliothèque nationale du Canada de reproduire, prêter, distribuer ou vendre des copies de cette thèse sous la forme de microfiche/film, de reproduction sur papier ou sur format électronique.

L'auteur conserve la propriété du droit d'auteur qui protège cette thèse. $\mathrm{Ni}$ la thèse ni des extraits substantiels de celle-ci ne doivent être imprimés ou aturement reproduits sans son autorisation.
In compliance with the Canadian Privacy Act some supporting forms may have been removed from this dissertation.

While these forms may be included in the document page count, their removal does not represent any loss of content from the dissertation.
Conformément à la loi canadienne sur la protection de la vie privée, quelques formulaires secondaires ont été enlevés de ce manuscrit.

Bien que ces formulaires aient inclus dans la pagination, il n'y aura aucun contenu manquant. 


\begin{abstract}
This thesis examines innovation in three federal government laboratories: Canada Centre for Remote Sensing; CANMET Materials Technology Laboratory; and the CANMET Energy Technology Centre; at both the individual and institutional levels. Through the individual lens we cover three themes: characteristics of innovators and champions; hierarchy; and barriers faced and promotion methods used to advance innovation. Through the institutional lens we examine four themes: publicness; political direction and interest; recognition and rewards preference; and work environment.

Our main contribution related to individual factors is to extend understandings of these themes, which tends to be derived from theories and research on the private sector, to innovators and champions in government labs. We also extend institutional factors to study innovation in government labs. For both the individual and the institutional levels, we modify existing theories and definitions found in the literature to apply to government labs. We create and administer a survey and focus groups to yield new primary evidence to test our hypotheses.

Our findings related to individual factors indicate that innovators are competent and cosmopolitans, but not risk-takers. A majority of champions did not possess the characteristics of taking ownership of innovations, risk-taking or motivating others to work on an innovation. We found clear differences between innovators and noninnovators, and champions and non-champions on these characteristics. Our results suggest that elites and technical specialists are innovators and champions and more successful than non-elites and non-technical specialists, although our findings were not statistically significant. The main barrier to innovation was resources. The rational and participative championing processes were used most frequently.

Related to institutional factors, we found that the level of cost recovery varies between the labs in our study. Where cost recovery imperatives are stronger, there is more advocacy towards, and more products created for, the private sector. The main impact of implemented innovations was not financial. Political interest and direction did not have an impact on the day-to-day workings of the labs. We found that innovation awards were not a motivator of innovation, and the nomination process was problematic. Innovators did not identify an intrinsic rewards preference. Feedback in all the labs was mostly positive. Finally, most respondents were satisfied and involved with their jobs, and there were not differences between innovators and non-innovators.
\end{abstract}




\section{Acknowledgements}

Michael Rosenblatt would like to thank thesis supervisor Professor Bruce Doern and committee members Professors Keith Newton and Gene Swimmer for their assistance in bringing this thesis to completion, and Professors David Siegel and Jonathan Malloy for reviewing the thesis. The time, patience and assistance of the Directors and their assistants in the labs in this study are also greatly appreciated.

Michael would like to thank his wife Melanie and his parents Sidney and Christine, Michael and Connie for their love, understanding, assistance and support. Finally, a special thank you goes to mentors Barry Kay and Barbara Carroll. 


\section{Table of Contents}

INTRODUCTION - Defining Innovation

- Individual Factors Related to Innovation

10

- Institutional Factors Related to Innovation

PART I INDIVIDUAL FACTORS

CHAPTER 1 CHARACTERISTICS OF INNOVATORS AND CHAMPIONS

Theme 1: Characteristics of Innovators and Champions

- $\quad$ Competence: Experience; Technical

- Cosmopolitans: Professional and Academic

Activities

- $\quad$ Risk Taking

- What is Championing?

- Characteristics of Champions: Taking Ownership and Motivating Others

- $\quad$ Risk Taking

Theme 2: Hierarchy and Innovation; Elites and Technical Specialists

- Positional Power: The Authorization to Make

Decisions and Compel Compliance

$$
\begin{array}{ll}
\circ & \text { Elites } \\
\circ & \text { Expertise: The Technical (Staff, } \\
& \text { Functional) Specialist }
\end{array}
$$

Theme 3: Overcoming Innovation Barriers; the Rational;

Participative; and Renegade Processes

- Chapter Summary

PART II INSTITUTIONAL FACTORS

CHAPTER 2 INSTITUTIONAL FACTORS RELATED

TO INDIVIDUAL INNOVATION IN

GOVERNMENT LABS

- National Systems Of Innovation 
Institutional Theme 2: Political Direction; Interest and Innovation 74

Institutional Theme 3: Recognition and Rewards Preference 77

- Intrinsic and Extrinsic Motivation $\quad 78$

- Feedback 86

Institutional Theme 4: Work Environment; Job Satisfaction and 89 Involvement

- Chapter Summary $\quad 93$

PART III RESULTS

CHAPTER $3 \quad$ RESULTS: INDIVIDUAL FACTORS 96

- Identification of Innovators and Number of 96 Implemented Innovations

- Demographic Factors Gender and Age $\quad 97$

Theme 1 Results: Characteristics Of Innovators; Competence 98

- Competence Components: Experience; $\quad 99$ Technical Expertise; and Education

- Overall Competence 102

- Cosmopolitanism: Professional and Academic 105 Activities

- Risk Takers 111

- Champions and Non-Champions 113

- Gender and Championing 114

- Success Championing 115

- To Whom are Champions Promoting 116 Innovations?

- Categories of Respondents: Innovators, 118 Champions, Non-Innovators, and NonChampions

- Characteristics Of Champions 119

- Risk Taking 120

- Innovation Ownership 122

- Motivating Others 124

Theme 2 Results: Hierarchy and Innovation and Championing 126

- Success Advocating 128

- Other Characteristics of Elites 129

- The Technical Specialist 130 
- Success Advocating and Other Characteristics of Technical Specialists

Theme 3 Results: Championing Methods Used And Barriers Faced

- What Problems Did You Encounter?

- Chapter Summary

\section{CHAPTER 4 RESULTS: INSTITUTIONAL FACTORS}

- Natural Resources Canada (NRCan) and the 140 Labs

- CANMET Materials Technology Laboratory (MTL)

- CANMET Energy Technology Centre (CETC)

- Canada Centre For Remote Sensing (CCRS)

- Program Review \& S\&T Management

Institutional Theme 1 Results: Publicness; Cost Recovery 156

- Publicness: Market Influence and Product 165 Mix

- Impact of Cost Recovery: Short Term 168

Institutional Theme 2 Results: Political Interest and Direction

172

- Political Direction

Institutional Theme 3 Results: Recognition and Rewards Preference

- Rewards Preferences of Innovators and Champions

- Feedback

Institutional Theme 4 Results: Work Environment; Job Satisfaction and 185 Involvement

- Job Involvement

- Chapter Summary

\section{CHAPTER 5 CONCLUSIONS}

- Conclusions for Individual Factors

- Conclusions for Institutional Factors 


\section{List of Appendices}

Appendices

- Methodology

223

- Survey Instrument

231

- Focus Group Questions

237 


\section{Abbreviations}

$\begin{array}{ll}\text { CCAF } & \text { Climate Change Action Fund } \\ \text { CCRS } & \text { Canada Centre for Remote Sensing } \\ \text { CETC } & \text { CANMET Energy Technology Centre } \\ \text { CGDI } & \text { Canadian Geospatial Data Infrastructure } \\ \text { MTL } & \text { CANMET Materials Technology Laboratory } \\ \text { NRC } & \text { National Research Council } \\ \text { NRCan } & \text { Natural Resources Canada } \\ \text { OECD } & \begin{array}{l}\text { Organization for Economic Co-operation and } \\ \text { Development }\end{array} \\ \text { PERD } & \text { Program on Energy Research and Development }\end{array}$




\section{INTRODUCTION}

The purpose of this thesis is to examine innovation in three Canadian federal government laboratories at both the individual and the institutional levels. The three labs in our study are: Canada Centre for Remote Sensing; CANMET Materials Technology Laboratory; and CANMET Energy Technology Centre. All three labs are part of the same federal Department, Natural Resources Canada (NRCan). ${ }^{1}$

The Canada Centre for Remote Sensing (CCRS) is responsible for the reception, processing, archiving and dissemination of remotely sensed data for Canada, and coordinates a research program to develop and apply remote sensing technology to sustainable development and environmental protection; geospatial information applications; and provides electronic access to spatial databases. ${ }^{2}$ The CANMET Materials Technology Laboratory (MTL) works with the minerals, metals and energy industries to find safer, cleaner and more efficient methods to develop and use Canada's mineral and energy resources. ${ }^{3}$ MTL is the largest research facility in Canada dedicated to metals, ceramics, and concrete technology. ${ }^{4}$ The CANMET Energy Technology Centre (CETC) provides energy science and technology for the economic, environmental and social well being of Canadians, ${ }^{5}$ such as health and safety improvements. ${ }^{6}$ We will describe the labs in more detail in chapter four.

\footnotetext{
${ }^{1}$ Please see the methodology appendix for a complete description of the criteria for selection of the labs.

${ }^{2}$ Canada Centre for Remote Sensing, "About Us," accessed at the CCRS Website, January 2004, [http://www.ccrs.nrcan.gc.ca/ccrs/org/org_e.html]

3 CANMET, CANMET Annual Report 1993-94, (Ottawa: Supply and Services Canada, 1994), "Mission and Mandate" and CANMET, CANMET'95 New Directions, (Ottawa: Supply and Services Canada, 1995), foreword.

${ }^{4}$ Natural Resources Canada, CANMET Building the future, (Ottawa: Public Works and Government Services Canada, 2001), 10.

${ }^{5}$ CANMET Energy Technology Centre, CETC /ETB Business Plan 2002/03-2004/05, (Not published, 2003), i.
} 
In our study we follow Fariborz Damanpour's prescription that research should consider more than one dimension of innovation, including variables that take into account individual, organizational, and environmental factors. ${ }^{7}$ We also agree that innovation is a complex construct with individual and institutional factors affecting it. ${ }^{8}$ We will examine two main streams of literature: the first discusses innovation at the individual level and comes from a variety of disciplines. The second stream relates to institutional factors, and comes from literature about government laboratories in Canada and the United States. This focuses our scope on individual and institutional factors related to innovation, rather than on the innovation process, the innovations themselves, or broader science and technology or economic policy. While other steams of literature such as that on the New Public Management may indirectly relate to innovation, we do not attempt to build on this literature per se. ${ }^{9}$

Through the individual lens we will cover three analytical themes: characteristics of innovators and champions; hierarchy; and barriers faced and promotion methods used to advance innovation. Our main contribution related to individual factors is to extend existing understandings of these themes, which tends to be derived from theories and research on the private sector, to innovators and champions in government labs. At the individual level, we will develop hypotheses using the literature and test them with our survey results.

\footnotetext{
${ }^{6}$ Natural Resources Canada, CANMET Making an impact on Canada, (Ottawa: Public Works and Government Services Canada, 1997), 13.

${ }^{7}$ Fariborz Damanpour, "Organizational Innovation: a Meta-Analysis of Effects and Determinants and Moderators," in Academy of Management Journal Vol 34, no. 3 (1991), 583.

${ }^{8}$ Fariborz Damanpour, Kathryn Szabat and William Evan, "The Relationship Between Types of Innovation and Organizational Performance," in Journal of Management Studies Vol 26, no. 3 (November 1989), 587. ${ }^{9}$ For example, please see Peter Aucoin, The New Public Management: Canada in Comparative Perspective (Montreal: McGill-Queen's University Press, 1997).
} 
To make this contribution, we will examine the individual level literature and choose a few important characteristics, hierarchical levels, championing methods and barriers faced related to innovators and champions, and re-postulate the theories to apply to innovators and champions in government labs. In the process, we provide new groupings of these characteristics into manageable categories. Second, we will create and administer a survey and conduct focus groups. They will both be used to obtain quantitative and qualitative evidence on the characteristics and hierarchical level of innovators and champions in government labs, as well as championing methods and barriers faced. We will use this evidence to test our hypotheses and observe similarities and differences between factors found in the literature and our results.

Through the institutional lens we will examine four main analytical themes: publicness; political direction and interest; recognition and rewards preference; and work environment. Our main contribution related to institutional factors will be to examine these four themes and extend them in several ways. First, while some institutional factors have been used to examine government labs, these factors are not always applied to the study of innovation. Also, in some cases we are using concepts from the literature, but amending the factors to apply to the study of innovation in government labs.

For example, the theme of publicness has been discussed in government lab literature, related to cost recovery. However, there are few studies of the actual impact of cost recovery on government labs, or innovation. Political interest and direction are less well documented, and we will provide a definition, as well as qualitative evidence related to its extent and impact on the labs related to innovation. 
Our second overall contribution related to institutional factors is to provide a new survey instrument, focus group questions and methodologies to test the extent and impact of these institutional factors. Finally, we will provide quantitative and qualitative evidence to test our hypotheses, and observe similarities and differences between factors identified in the literature and our results. At the institutional level, we will compare our results across the three labs in our study.

The structure of the thesis reflects the core task of examining individual and institutional factors related to innovation, and is organized into three main parts. Part I deals with the conceptual discussion of innovation at the individual level. Part II deals with innovation at the institutional level through a focused look at key institutional characteristics. In Part III we present our results for both individual and institutional factors. The remaining part of this Introduction sketches out the broad rationale for, and content of, this dual framework structure and methodologies broadly employed. It also indicates the basic detailed chapter structure.

\section{Defining Innovation}

Before we can discuss innovation further, we need to define it. One difficulty in studying and defining innovation is that it is almost always viewed as a positive event, ${ }^{10}$ often equated with goodness in an unquestioning way. ${ }^{11}$ This was not always so: historically innovation was cast as a negative. "The positive connotation of innovation, as a valuable improvement is itself a new idea." ${ }^{2}$ As global competition increases,

\footnotetext{
${ }^{10}$ George Downs and Lawrence Mohr, "Conceptual Issues in the Study of Innovation," in Administrative Science Quarterly Vol 21, (December 1976), 700.

"Peter Frost and Carolyn Egri, "The Political Process of Innovation," in Research in Organizational Behavior Vol 13, (1991), 273.

${ }^{12}$ Randall Morck, The Economic Determinants of Innovation (Ottawa: Public Works and Government Services Canada, 2001), 1.
} 
innovation becomes even more important as organizations, which generate and implement more good ideas about better, more efficient ways of working have a distinct advantage. ${ }^{13}$ Innovative organizations will fare better. "Innovation represents today's competitive advantage, supported by strong mainstream capabilities in quality, efficiency, speed and flexibility." 14 Innovations may be rare, but their consequences are important. ${ }^{15}$

Our literature review identified that innovation appears to assume different meanings at the individual and organizational levels of analysis. ${ }^{16}$ The term innovation itself is contentious and problematic. "It is often used loosely and interchangeably with terms such as creativity, invention and change. The concept is often deployed with such imprecision and variation that it can seem to mean almost anything." ${ }^{17}$ There seem to be three main issues of contention: what we include in our definition of innovation; how "new" an innovation has to be; and if implementation is necessary to be considered an innovation.

Statistics Canada defines innovation fluidly as "new goods or services differ significantly in character or intended use from previously produced goods or services" 18 or: improved goods; services; or processes whose performance has been significantly

\footnotetext{
${ }^{13}$ Peter Monge, Michael Cozzens and Noshir Contractor, "Communication and Motivational Predictors of the Dynamics of Organizational Innovation," in Organizational Science Vol 3, no. 2 (May 1992), 250.

${ }^{14}$ Benn Lawson and Danny Samson, "Developing innovation capability in organizations: a dynamic capabilities approach," in International Journal of Innovation Management Vol 5, no. 3 (September 2001), 381.

${ }^{15}$ Henrich Greve and Alva Taylor, "Innovations as catalysts for organizational change: shifts in organizational cognition and search," in Administrative Science Quarterly 45, (2000), 56.

${ }^{16}$ Alan Meyer and James Goes, "Organizational assimilation of innovations: a multilevel contextual analysis," in Academy of Management Journal Vol 31, no. 4 (1988), 918.

${ }^{17}$ John Storey, "The management of innovation problem," in International Journal of Innovation Management Vol 4, no. 3, (September 2000), 348.

${ }^{18}$ Statistics Canada, 2000 Workplace and Employee Survey (Ottawa: Public Works and Government Services Canada, 2000), 30.
} 
enhanced or upgraded. ${ }^{19}$ Statistics Canada's definition seems to conform to OECD's Oslo manual: "[a] technological product innovation is the implementation/ commercialization of a product with improved performance characteristics... A technological process innovation is the implementation/ adoption of new or significantly improved production or delivery methods., ${ }^{20}$ Others include in the definition of innovation the process of change to introduce a new idea, method or device, ${ }^{21}$ and also the process by which something new (or "reinvented") is adopted and diffused. ${ }^{22}$

Another issue in the definition of innovation is how "new" an innovation needs to be. This may be the difference between innovation and invention. "It seems important ...to separate the idea of invention form the idea of innovation. Invention implied bringing something new into being: innovation implies bringing something new into use." 23 As James Iain Gow points out, "[i]t is important to remember also that innovation is not invention; the latter involves true creation, whereas in the case of innovation the change is only new to the organization, it may have been tried elsewhere. 24

The terms innovation and "technological change" are often used interchangeably. Some innovations are radical departures ${ }^{25}$ from previous techniques; others are incremental improvements on existing products, processes or services. If someone took an existing idea and applied it to a new or significantly improved product, process or

\footnotetext{
${ }^{19}$ Statistics Canada, Survey of Innovation 1999 (Ottawa: Public Works and Government Services Canada, 1999), 4.

${ }^{20} \mathrm{OECD}$, Oslo manual: proposed guidelines for collecting and interpreting technological innovation data (Paris France: Organisation for Economic Co-operation and Development, 1997), 18.

${ }^{21}$ Conference Board of Canada, Members Briefing Measuring Innovation: is it doable? (Ottawa: Conference Board of Canada, January 1997), 1.

${ }^{22}$ Richard Merritt and Anna Merritt, editors, Innovation in the Public Sector (Beverly Hills: Sage, 1985), 11 .

${ }^{23}$ Lawrence Mohr, "Determinants of innovation in organizations," in The American Political Science Review Vol 63, (1969), 112.

${ }^{24}$ James Iain Gow, Innovation in the Public Service (Ottawa: CCMD, 1992), v.

${ }^{25}$ Radical innovations can usher in a "new techno-economic paradigm".
} 
service, this is consistent with the OCED's Oslo manual, which describes the first portable cassette player as an innovation, even though the tape recorder and miniearphones existed previously, because the result was an overall product that had not existed before. ${ }^{26}$ The ideas must be different from what's been done before, and useful. ${ }^{27}$ Another definitional issue is whether implementation of a new product, process or service is necessary for it to be considered an innovation. In the OECD definition, implementation is an integral part of innovation, where "...innovations comprise implemented technologically new products and processes...."28 (our emphasis). Similarly: innovation is defined as the successful introduction of means or ends that are new to that situation. ${ }^{29}$ However, the length of time to implement can vary, ${ }^{30}$ and it usually results from a management decision. ${ }^{31}$ In our definition, innovation includes the creation of a new product, process or service ${ }^{32}$ that has been implemented within the last two years. ${ }^{33}$ The ideas for the innovations may come from other organizations or existing products.

Difficulties defining innovation are also reflected in innovation measurement strategies. 'Literature related to the measurement of innovation at an institutional level

\footnotetext{
${ }^{26}$ OECD, 1997, 48.

${ }^{27}$ Teresa Amabile, "Motivating creativity in organizations: on doing what you love and loving what you do," in California Management Review Vol 40, no. 1 (Fall 1997), 40.

${ }^{28}$ OECD, 1997, 47.

${ }^{29}$ Lawrence Mohr, 1969, 112.

30 James Iain Gow, 1992, 2.

${ }^{31}$ Katherine Klein and Joann Speer Sorra, "The challenge of innovation implementation," in Academy of Management Review Vol 21, no. 4 (1996), 1055.

${ }^{32}$ There may be differences between "hard" innovations such as lasers, robots, CAD/CAM systems and "soft" innovations such as organizational design and human resource management, but we will not specifically differentiate between them in this dissertation, both types qualify as innovations.

${ }^{33}$ This includes products, processes and services that have been created within a reasonable time frame that people should remember the details of its creation, but not too short so that innovations have had a chance to be implemented.
} 
often focuses on patent data. ${ }^{34}$ This measurement strategy is clearly defined, but faces the problems that not all patented innovations are implemented, and not all innovations are patented. Other literature on innovation measurement looks at spending on Research and Development (R\&D). ${ }^{35}$ One limitation of this approach is that R\&D may not be necessary for innovation. One organization may not conduct R\&D and yet be innovative, while another may spend a great deal on R\&D and not innovate.

Our measurement strategy is to use our definition of innovation, and if an individual is innovating, we expect s/he would be creating and implementing new ideas. On this basis, through our survey instrument, we will ask respondents if they have worked on an implemented innovation in the last two years to divide respondents into "innovators" and "non-innovators".

One difference between this dissertation and other studies is that we are focusing on the innovator rather than on the innovation. Why might one want to study innovation focusing on the individual as the unit of analysis? The individual is the starting point of innovation. ${ }^{36}$ It seems possible for an individual to be unable to innovate successfully because institutional and environmental factors work against him/her. However, the reverse is not necessarily true. If other factors promote innovation, there may not be

\footnotetext{
${ }^{34}$ For example, please see Manuel Trajtenberg, Is Canada missing the 'Technology Boat'? Evidence from Patent Data CSLS-Industry Canada conference on Canada in the $21^{\text {st }}$ Century: A Time for Vision, (1999) or Mohammed Rafiquzzaman and Lori Whewell, Recent Jumps in Patenting Activities: Comparative Innovative Performance of Major Industrial Countries, Patterns and Explanations Industry Canada Working Paper \#27, (1998).

${ }^{35}$ For example, please see Frances Anderson, An overview of Statistical Indicators of regional innovation in Canada: a provincial comparison (Ottawa: Statistics Canada, 1998) or Statistics Canada, Estimates of Canadian research and development expenditures (GERD), Canada, 1992 to 2003, and by province 1992 to 2001 (Ottawa: Statistics Canada, 2003) or Industry Canada, Science and Technology Advice: A Framework to Build On (Ottawa: Industry Canada, 2002).

${ }^{36}$ The Conference Board of Canada, Investing in innovation, $3^{\text {rd }}$ Annual Innovation Report (Ottawa: Conference Board of Canada, 2001), 21.
} 
innovation without innovative individuals. However, since institutional factors likely influence innovation, they will be considered as well.

When one speaks of a government lab, one may think only of a facility consisting of a laboratory with test equipment, beakers, etc. In such a place one would likely find researchers, scientists, engineers and technicians. However, this excludes labs that do not conduct Science and Technology (S\&T) on a workbench. Some labs may not have a work area as such, but rather exist as a network of computers, while others provide funding, research or monitoring, with or without a physical lab. We consider government labs in the broadest sense, including the S\&T function (physical lab), policy, funding and administrative sides. As a result, our primary research includes all employees who work in the lab, (scientists, technicians) as well as management, policy analysts and administrative assistants, etc., in three Canadian federal government labs. ${ }^{37}$

Another interesting area for study in individual innovation is the promotion of innovation, by individuals called "champions". We will devise questions to separate survey respondents into champions and "non-champions". Champions are not necessarily innovators, as a non-innovator can be a champion. ${ }^{38}$ We will discuss champions in detail in chapter one, but the identification of innovators and champions in our survey instrument gives us four potential categories of respondents:

\begin{tabular}{|c|c|}
\hline Innovator & Non-Innovator \\
Champion & Champion \\
\hline Innovator & Non-Innovator \\
Non-Champion & Non-Champion \\
\hline
\end{tabular}

\footnotetext{
${ }^{37}$ Canada Centre for Remote Sensing; CANMET Materials Technology Laboratory; and CANMET Energy Technology Centre.

${ }^{38}$ They could promote someone else's innovation and still be considered a champion.
} 


\section{Individual Factors Related to Innovation}

In chapter one, we will review the literature relevant to individual innovation, and in chapter three we will present our results. We will examine three broad themes related to individual innovation: the characteristics of innovators and champions; hierarchy and innovation; and the promotion methods champions use and the barriers they face. The literature raises the question: are the characteristics of innovators/non-innovators and champions/non-champions different? Studies often proceed from the starting point that there are indeed differences on several characteristics between innovators and noninnovators and champions and non-champions, and identifies what these characteristics may be. Some studies are theoretical, others are case studies, but unfortunately only a few have empirical tests of differences in characteristics.

Out of a long list of potential characteristics found in the literature, we need to choose those we think are relevant to the study of innovators and champions in government labs. We also need to re-define some concepts to fit government labs, and to create a methodology to find out if the innovators and champions in our study have these characteristics. We want to answer two broad questions, first: do the innovators/champions in our study possess the characteristics we have chosen from the literature? Second: are the characteristics of champions and innovators in our study different from characteristics of non-champions and non-innovators? In chapter one, we will choose the characteristics we will examine, and compose hypotheses to test for differences between innovators and non-innovators and champions and non-champions.

The second theme we are interested in is the level in the hierarchy of innovators and champions. Is there a relationship between hierarchy, innovation and championing? 
Diana $\mathrm{Day}^{39}$ suggests that while innovators can come from any level of the organization, different types of innovators occupy different levels in the hierarchy and there is a relationship between hierarchy and the success of innovators and champions. In the first chapter, we will describe different hierarchical levels, and propose hypotheses to test their potential link to innovation.

The third theme related to individual factors is the promotion method used and the barriers faced by champions. Research by Jane Howell and Christopher Higgins ${ }^{40}$ describes a few different methods champions can use to promote innovations in private firms, as well as the barriers faced. There are not any recent studies of championing in government labs, so we are led to the question: what methods of promoting innovations do champions in government labs use, and what barriers do they face? We will amend championing methods found in the private sector literature to fit government labs, and create hypotheses to test if these methods of championing are used.

\section{Institutional Factors Related to Innovation}

In the second part of the dissertation, starting in chapter two, we examine institutional factors related to individual innovation. In chapter four, we present our findings. Most authors seem to agree that institutional factors have an effect on the innovativeness of an individual. Where they differ is in the amount of impact institutional factors have. Some identify institutional arrangements as the most important factor in describing innovation, although most agree that individual factors have some

\footnotetext{
${ }^{39}$ Diana L. Day, "Raising radicals: different processes for championing innovative corporate ventures," in Organization Science Vol 5, no. 2 (May 1994).

${ }^{40}$ Jane M. Howell and Christopher A. Higgins, "Champions of Change: Identifying, Understanding and Supporting Champions of Technological Innovations," in Organizational Dynamics (Summer 1990).
} 
importance as well. ${ }^{41}$ Unfortunately, there are few recent studies of innovation in government labs to be found in literature. Unfortunately, there are also some difficulties in moving from individual factors related to innovation to institutional factors.

As with the individual innovation literature, we sorted through the many different institutional themes found in the literature related to government labs, and narrowed it down to focus on four themes including: publicness; political interest and direction; recognition and rewards preference; and work environment. The first institutional theme that we will examine is "publicness", which "refers to the degree of external control or influence exerted by governmental actors.. ${ }^{42}$ The obverse is the degree of control/influence exerted by non-governmental actors.

Private sector focused institutional studies use the firm as the unit of analysis to study innovation, which is motivated by profit. As government organizations are not in direct competition and are not required to make a profit, what happens in the public sector? The Canadian federal government's Program Review in the 1990's extended efforts begun in the 1980 's designed to encourage labs to recover/share costs through partnerships and the sale of products and services. Cost recovery may act as a motivator of innovation.

One way to examine the theme of publicness is to look at cost recovery/sharing. One shortcoming of the literature is that there has not been much discussion of the extent of cost recovery/sharing in Canadian federal government labs, or its impacts. An overall research questions is: does cost recovery/sharing have an impact on innovation in the lab? To answer this question, we first need to find out how important cost

${ }^{41}$ Victor A. Thompson, Bureaucracy and Innovation (University: University of Alabama Press, 1976), 7.

${ }^{42}$ Michael Crow and Barry Bozeman, Limited by Design: R\&D Laboratories in the U.S. National Innovation System (New York: Columbia University Press, 1998), 109. 
recovery/sharing is to the lab, and second if there are any impacts on innovation? All labs will likely have some levels of cost sharing/recovery, but we need to identify ways to measure if cost recovery/sharing is important, by looking at a lab's mandate, documentation and financial information. We will take the results and make a judgment on the importance of cost recovery in the lab. A focus group will give us their perspective of the importance of cost recovery/sharing, which may be different from the documentation. They will also describe if the funding source (public/private) has an impact on innovation.

To identify the impact cost recovery is having on innovation, we consulted studies by Crow and Bozeman ${ }^{43}$ and others, and extracted two separate potential effects. First, cost recovery/sharing is expected to have an impact on the products that the lab produces. We will use lab documentation and focus groups to determine the mix of goods, and ask: what effects market influences have on the balance between public and private goods? The logic is that if cost recovery is very important, the lab's output of innovations will be balanced towards proprietary products to be sold to the private sector, and less innovations for the public good. In a lab where cost recovery is less important we expect innovative output balanced towards the public good.

Second, in labs where cost recovery/sharing is very important, their innovative activities are likely orientated towards innovations that will yield a financial impact. This would occur when the lab tries to recover or share money from their innovations. Similarly, in labs where cost recovery/sharing is very important we would expect they would advocate more towards the private sector. Comparing the results for each lab should allow us to describe the impact that cost recovery/sharing is having on innovation

${ }^{43}$ Michael Crow and Barry Bozeman, 1987, 1998. 
in the labs. Our contribution will be to describe the publicness and the extent of cost recovery/sharing in three Canadian federal government labs. We will extend our knowledge by using qualitative measures of asking our focus groups what the main impacts of cost recovery (if any) are on the lab and innovation?

Our second institutional theme is political interest and direction. Political interest is the interest shown in the lab by political figures such as a Minister, Deputy Minister, etc., through requests for briefing notes, site visits, etc. Political direction is oversight, scrutiny and stopping (or promotion) of innovations for political reasons. To capture these dimensions, our contribution is to create a new matrix, which provides a high level overview of political interest and direction to capture the relative differences, if any, between the labs. We decided to use a qualitative method of asking our focus groups to describe the political direction and interest in the lab to allow us to place the labs on this matrix.

Our matrix allows us to show the relative levels of political interest and direction in all three labs. If the labs have different levels of political interest and direction, we can see if this has an impact on innovators and champions in the lab. We will ask focus group participants to describe their perception of the impacts of political interest and direction. This provides qualitative evidence of the levels of political interest and direction in the labs, and its influence on innovation. Political interest and direction are unique institutional features of public sector innovation, but neither has previously been studied in relation to innovation in government labs. Our contribution is to define and describe these concepts, and provide new qualitative evidence. 
Our third institutional theme is recognition and rewards preference. In government labs, as money awards cannot easily be used as a motivator of innovation, what can the organization do to motivate and reward innovators? Two types of rewards we will study are innovation awards and feedback, both of which are widely used in government labs. We will find out what focus groups' opinions are of innovation awards and feedback. We also want to find out the nature of feedback given to innovators in government labs, as positive feedback may be positively related to innovation.

One might expect that extrinsic types of rewards such as prestige, money and recognition motivate people to innovate. However, studies by Teresa Amabile ${ }^{44}$ found that innovators are intrinsically rather than extrinsically motivated. (I.e.: motivated by self-satisfaction rather than awards) As this is not a dissertation in psychology, we will only look at motivation in terms of rewards preference related to a successful innovation. This is not meant to be a proxy for motivation. In chapter two, we will create hypotheses to identify differences in rewards preferences of innovators/non-innovators and champions/ non-champions.

The last theme related to institutional factors we will examine in this dissertation is the work environment in the labs, in particular how satisfied and involved respondents are with their jobs. This leads to the question: what is the level of job satisfaction and involvement in the labs, and does it relate to innovation? We will use the literature as the basis of our hypotheses related to job satisfaction and involvement. It is possible innovators may be more job satisfied and involved than non-innovators.

${ }^{44}$ Teresa Amabile, 1997, and Teresa Amabile, Karl G. Hill, Beth A. Hennessey and Elizabeth M. Tighe, 1994. 
This dissertation is relevant as federal policy such as Canada's Innovation Strategy is interested in the future role of government labs to help turn Canada into an innovative country, on the lookout for opportunities to improve our economic prospects and quality of life. The role of the government is to promote an environment conducive for innovation and to conduct research in areas private industry can or will not, and to protect the public interest. ${ }^{45}$ Are Canada's government labs up to the task? "Government research laboratories were born out of the need to build the nation, undertaking such activities as geological surveys, the establishment of standards, meteorology, health surveillance and natural resources development." ${ }^{, 46}$ Government labs have played an important role in Canadian history in the areas of science, technology and innovation. ${ }^{47}$ Canada has been recognized for the strengths of its government labs. Many significant breakthroughs have come from the labs to make important contributions to industrial development and public welfare. ${ }^{48}$

As an integral part of the government's strategy to keep Canada competitive, federal labs have been required to fill many roles, including providing support to industry to fill technology-adoption gaps, ${ }^{49}$ and to help direct technology. ${ }^{50}$ However, the role of government labs should not be limited to only considering their outputs, as they have many other indirect effects, such as supporting Canadian scientific societies (chemists,

\footnotetext{
${ }^{45}$ Industry Canada, Achieving Excellence Investing in People, Knowledge and Opportunity (Ottawa: Public Works and Government Services Canada, 2002),10.

${ }^{46}$ Jacek Warna, Government Research Laboratories Finding the Right Chemistry for the Future (Ottawa: Conference Board of Canada, 1999), 1.

${ }^{47}$ Jeff Kinder, "The Doubling of Government Science" in How Ottawa spends 2003-04: Regime Change and Policy Shift, (Don Mills: Oxford University Press, 2003), 217.

${ }^{48}$ U. Kumar and V. Kumar, Incubating technology: best practices (Not published, Fall 1997), 25.

${ }^{49}$ The Impact Group, The Roles of the Federal Government in Performing Science and Technology: the Canadian Context and Major Forces (Not published, March 1999), 5.

${ }^{50}$ Henry Lambright, "Government and technological innovation: weather modification as a case in point," in Public Administration Review Vol 32, (January-February 1972), 1.
} 
geophysics, etc). ${ }^{51}$ Although, some critics feel that government should be a facilitator of innovation rather than a "doer". A recent survey by Decima research on behalf of NRCan supports this sentiment. When it comes to leadership in developing S\&T, relatively few believe the federal government is playing the lead role, but this is consistent with the public's expectation that government's role should be to support the activities of others rather than undertake the work itself. ${ }^{52}$

Government labs can also conduct basic research. Basic research can lead to significant advances in knowledge and social gains, and is often the source of new instrumentation and methods that are vital to the advancement of science and technology. In addition, the basic research system provides the training required for the next generation of researchers, engineers and technicians. ${ }^{53}$ Basic research is likely to generate substantial external economies, but profit opportunities are not likely to draw a socially desirable quantity of resources into basic research. ${ }^{54}$ Because of the risks or small return involved, public labs can push the envelope ${ }^{55}$ of innovation to complete work that the private sector cannot or will not. ${ }^{56}$ Deciding the role of federal labs has always been a balancing act between basic and applied research. ${ }^{57}$ It is the tension between cost recovery, public good and applied research that makes government labs interesting to study.

\footnotetext{
${ }^{51}$ The Impact Group, 1999, 27.

52 Decima Research, Canadian's Attitudes Towards Natural Resource Issues 2002 (Not published, May 2002), 6 .

${ }^{53}$ Roberto Gualtieri, "Science Policy and Basic Research in Canada", in How Ottawa Spends 1994-95: Making Change, (Ottawa: Carleton University Press, 1994), 303.

${ }^{54}$ Richard Nelson, "The simple economics of basic scientific research," in Journal of political economy Vol 67, (1959), 302.

55 Jacek Warna, 1999, 1.

${ }^{56}$ Federal Partners in Technology Transfer, Report on Activities Spring 1999 to Spring 2000 (Ottawa: Public Works and Government Services Canada, 2000), 14.

${ }^{57}$ Jacek Warna, 1999, 3.
} 
We end the dissertation by presenting conclusions drawn from three separate lines of evidence: literature and government document review; a survey; and focus groups to arrive at overall results and to describe and compare the labs. The survey along with the focus groups yields new primary research about innovation in government labs. The use of both an individual and an institutional lens has not, to the best of our knowledge, been used to study government labs before. The contribution is also based on overall conclusions regarding what policies might enhance innovation and also ways in which innovation may be different in government labs. We now begin our examination of individual factors. 
PART I INDIVIDUAL FACTORS 


\section{CHAPTER 1: CHARACTERISTICS OF INNOVATORS \& CHAMPIONS}

In this chapter we examine literature related to individual innovation, institutional innovation literature will be discussed in the next chapter. We begin by contextualizing the literature review through a discussion of some of its shortcomings. We then discuss our first theme: characteristics of innovators and champions. Next, we consider the theme of hierarchy $y^{58}$ and its relationship to innovation and championing. We conclude this chapter by discussing barriers faced and promotion methods used to advance innovation.

The literature on individual innovation is vast, and comes from a wide variety of disciplines, as the study of innovation does not yet have a school of its own. This is both a strength and weakness. Authors from different disciplines add unique perspectives and insights, but unfortunately seldom seem to build on the work of others outside of their discipline. Also, relatively few scholars appear to study innovation exclusively, most look at innovation in the context of other issues. This has prevented a coherent body of literature examining innovation from emerging, but rather a patchwork of studies and theories. This dissertation has its roots in public policy and administration, although we have tried to consider and use theories from a variety of disciplines.

One of the key difficulties in the study of innovation is what George Downs and Lawrence Mohr identify as "instability"; where what is found to be important in one study of innovation is found to be unimportant in another. ${ }^{59}$ As Richard Wolfe points

\footnotetext{
${ }^{58}$ Hierarchy is sometimes considered an institutional factor because it can examine how the lab operates in relationship to its "parent" Department, Agency or Council. Our examination of hierarchy is different, focusing on the hierarchical levels of champions and innovators in the lab, rather than each lab's relationship to NRCan.

${ }^{59}$ George Downs and Lawrence Mohr, "Conceptual Issues in the Study of Innovation," in Administrative Sciences Quarterly Vol 21, (December 1976), 701.
} 
out, the most consistent theme found in innovation literature is that its research results have been inconsistent. One explanation is that the empirical instability and theoretical confusion results from the belief that a unitary theory of innovation exists. Several adequate, circumscribed, theories of innovation exist but each applies under different conditions. ${ }^{60}$ Different theories and levels of analysis have not yielded clarity. Perhaps innovation is best explained by a number of different theories. Another explanation for variation of the results could be problems with the level of analysis. ${ }^{61}$

One specific shortcoming of the literature that has implications for a dissertation examining innovation in government labs is that few studies focus on the public sector. Most of what we know about individual innovation factors comes from research that focuses on the private sector. This is important because there may be differences in the characteristics of employees in the public and private sectors. Characteristics have not been defined in terms directly relevant to government labs. Also, the literature yields a long list of characteristics of innovators and champions, which are ungrouped and difficult to manage.

Some of the possible characteristics of innovators include: a belief they are creative; a tolerance for ambiguity; high competence; ${ }^{62}$ being a "cosmopolitan"; a risk taker; having technical expertise and industry knowledge. Ideally, we would examine many characteristics, but time and space allow us to focus only on a few important

\footnotetext{
${ }^{60}$ Richard Wolfe, "Organizational innovation: review, critique and suggested research directions," in Journal of Management Studies Vol 31, no. 3 (May 1994), 406.

${ }^{61}$ Augustus Abbey and John Dickson, "R\&D work climate and innovation in semiconductors," in Academy of Management Journal Vol 26, no. 2 (1983), 362.

${ }^{62}$ Robert Keller and Winford Holland, "Communicators and innovators in research and development organizations," in Academy of Management Journal Vol 26, no. 4 (December 1983), 742.
} 
qualities. ${ }^{63}$ We chose to examine three characteristics of innovators including: competence; cosmopolitanism; ${ }^{64}$ and risk taking. Competence and risk taking were included because they were mentioned frequently as characteristics of innovators. Cosmopolitanism was chosen because it has not been studied in depth, and also because it encompasses many sub-concepts related to innovation. We will discuss the characteristics of champions later in this chapter.

Another shortcoming of the literature is characteristics, descriptions of hierarchy, and methods of championing have rarely been empirically tested, even on the private sector, and few have descriptions of how to measure them. For some of the characteristics of innovators and champions, we will modify private sector definitions to fit the study of innovators and champions in government labs. We will also provide new groupings of characteristics into manageable categories. As we present the characteristics of innovators and champions, we will indicate theories drawn from the literature, and our hypotheses for innovators and champions in the government labs in our study.

\section{Theme 1: Characteristics of Innovators and Champions}

The main research question related to innovators and champions raised in the literature is: are the characteristics of innovators/non-innovators and champions/nonchampions different? Overall, there appears to be differences on several characteristics, although some studies are theoretical, others are case studies, and few have empirical tests of differences in characteristics. This leads us to pose two questions: do the innovators/champions in our study possess characteristics identified in the literature?

\footnotetext{
${ }^{63}$ We excluded personality traits such as charisma because they are difficult to measure and their relationship to innovation is less clear.

${ }^{64}$ Cosmopolitans are people who have links and orientations outside the organization, contrasted with

"locals" who operate within their organization.
} 
Second, are the characteristics of champions and innovators in our study different from characteristics of non-champions and non-innovators? From these questions, we hypothesize:

\begin{tabular}{|l|l|}
\hline Hypothesis 1: & $\begin{array}{l}\text { Innovators possess three characteristics we have chosen from the } \\
\text { literature: competence; cosmopolitanism; and risk taking. }\end{array}$ \\
\hline Hypothesis 2: & $\begin{array}{l}\text { There are clear differences in the characteristics of innovators and non- } \\
\text { innovators, innovators have higher levels of competence, participate } \\
\text { more in cosmopolitan activities, and are more risk-loving than non- } \\
\text { innovators. }\end{array}$ \\
\hline
\end{tabular}

We will make hypotheses about characteristics of champions later in this chapter.

Hypothesizes related to differences in characteristics are generally: innovators (champions) will have higher levels of the characteristic than non-innovators (nonchampions), however some non-innovators (non-champions) will possess the characteristic as well. We expect to see differences between innovators (champions) and non-innovators (non-champions), but the differences will not likely be absolute. This limitation is inherent in the examination of individual characteristics.

To test our hypotheses, we will create and administer a new survey instrument and focus groups to find evidence of the characteristics and hierarchical level of innovators and champions in government labs, as well as championing methods used. If the innovators/champions in our study possess these characteristics and noninnovators/non-champions do not, we can conclude that their characteristics differ, and innovators/champions in the government labs in our survey possess the same characteristics identified in the literature.

If innovators (champions) and non-innovators (non-champions) both possess, or both do not possess a characteristic, then we can conclude that this is not a characteristic unique to innovators (champions) in our survey. There may be differences between 
characteristics of innovators (champions) identified in the literature, and the characteristics of innovators (champions) in the government labs in our study. We begin with the characteristic of competence, which innovators are expected to possess.

\section{Competence: Experience; Technical Expertise; and Education}

Innovation often begins with the search for a solution, and competence allows one to approach the problem knowing what has been tried out previously. Unfortunately, there is no single measure of competence identified in the literature, so we chose to measure three components that together make up competence: experience; technical expertise; and education.

Personal experience can reduce the uncertainty about a new situation, and allows a person to believe they can succeed in implementing an innovation. ${ }^{65}$ Jay Galbraith agrees ${ }^{66}$ that experience is a key part of innovation. Unfortunately, the literature lacks a measurement strategy relevant to government labs, so we need to create one. We propose to measure experience by the length of time one has worked in the industry, at the lab, and at the same job. We also consider having a similar job with another organization as experience.

Being in the industry for a long time helps one see different ways of tackling problems and overcoming obstacles. Using this knowledge one can get to the heart of the problem and focus efforts where they are most likely to succeed. Successful innovators need an in-depth knowledge of the industry gained through experience. ${ }^{67}$ The length of

\footnotetext{
${ }^{65}$ James Farr and Cameron Ford, "Individual Innovation" in Innovation and Creativity at work psychological and organizational structures, Edited by Michael West and James Farr, (Toronto: John Wiley \& Sons, 1990), 67.

${ }^{66}$ Jay Galbraith, "Designing the Innovating Organization," in Organizational Dynamics Vol 11, no. 1 (Winter 1982), 22.

${ }^{67}$ Jay Galbraith, Winter 1982, 22.
} 
time at the lab and in the same job are also important, as successful innovation is likely increased by knowing one's job, the organization and its people. Through our survey, we will identify those who have been in the industry for more than four years, at the lab for more than four years and in the same job for more than three years, or had a similar job in another organization as experienced.

Richard Woodman, John Sawyer and Ricky Griffin ${ }^{68}$ identified that technical expertise is a component of competence, which plays a role in the ability of the individual to be creative. If one has technical expertise, including the skills and abilities to tackle the problem, one is more likely to be innovative. Expertise is the foundation of all creative work, which can be viewed as the set of cognitive pathways that may be followed for problem solving. ${ }^{69}$ Expertise includes the repertoire of knowledge used to solve problems, including factual information and strategies and skills for manipulating declarative knowledge. ${ }^{70}$ Unfortunately, the literature did not furnish a measurement strategy, so we propose to measure technical expertise by asking how often respondents were approached to solve difficult technical problems in (or near) their field and whose technical expertise allows them to influence the acceptance/rejection of innovations in the lab.

Robert Keller and Winford Holland's findings ${ }^{71}$ indicate education is also related to innovation, where the more formal education one has, the more likely one is to innovate. This would seem to apply to innovators in government labs as it would to

\footnotetext{
${ }^{68}$ Richard Woodman, John Sawyer and Ricky Griffin, "Toward a theory of organizational creativity," in Academy of Management Review Vol 18, no. 2 (1993), 301.

${ }^{69}$ Teresa Amabile, Fall 1997, 42.

${ }^{70}$ Mary Ann Glynn, "Innovative genius: a framework for relating individual and organizational intelligences to innovation," in Academy of Management Review Vol 21, no. 4 (1996), 1084.

${ }^{71}$ Robert Keller and Winford Holland, December 1983, 748.
} 
innovators in the private sector. One may notice that this characteristic is directional as opposed to exclusive. While innovators are predicted to have more formal education than non-innovators, most non-innovators likely have some formal education. Keller and Holland's findings also noted that innovation is improved by communication. ${ }^{72}$

To explore the link between competence and innovation, we will add the components of experience, technical expertise and education together into a single measure of competence. In accordance with the literature, in relation to our first hypothesis (innovators will possess certain characteristics), we expect innovators will be competent. For our second hypothesis (clear differences in characteristics), innovators in our study will have higher levels of competence than non-innovators. We have redefined the concept of competence to fit with innovators and champions in government labs. We identified, grouped and suggested measurement strategies for three components of competence (experience, technical expertise, and education). We now examine cosmopolitanism, another characteristic of innovators.

\section{Cosmopolitans: Professional and Academic Activities}

Innovative individuals are likely to be "cosmopolitans": people who have links and orientations outside the organization. ${ }^{73}$ Cosmopolitans are contrasted with "locals" who operate within their organization. Cosmopolitanism is related to innovativeness, as "...the presence of a cosmopolitan innovator - one who by dint of having richer experiences, more formal training, or a larger set of informal contacts in other jurisdictions is more change oriented - can facilitate organizational change."74

\footnotetext{
${ }^{72}$ Robert Keller and Winford Holland, December 1983, 742.

${ }^{73}$ James Iain Gow, 1992, v.

${ }^{74}$ Robert K. Yin, "Production Efficiency Versus Bureaucratic Self-interest: Two Innovative Processes?" in Policy Sciences Vol 8, (1977), 385.
} 
Cosmopolitanism is a broad concept that contains several components such as journal readership, and holding office in professional associations, but unfortunately the literature does not place the components into larger groups. Building on the literature, we propose to use the same components, but aggregate them into two larger groups: professional and academic activities.

One way for cosmopolitans to be orientated outside of their organization is to participate in professional activities such as holding office in work related organizations and attending work related professional meetings. ${ }^{75}$ These associations can lead to frequent contacts with others in the same industry. Even in competitive industries, this can allow a cosmopolitan to develop a network of contacts. ${ }^{76}$ In government labs, scientists must keep pace with the latest advances in their fields, so they should be provided with opportunities to forge strong ties among their peers. ${ }^{77}$ Through relationships one can learn ways to solve problems and advance innovation.

In a country with a relatively small scientific and research community like Canada, cosmopolitanism can be even more important as many government labs may not have all of the scientific or research resources they need "in-house". To mitigate this problem, cosmopolitans may participate in a formal or informal network to exchange information and give and receive support ${ }^{78}$ from others in the international, national and local scientific community. This can lead to increased linkages through exchanges,

\footnotetext{
75 Thomas Robertson and Yoram Wind, "Organizational Cosmopolitanism and Innovativeness," in Academy of Management Journal Vol 26, no. 2 (1983), 335.

${ }^{76}$ John Czepiel, "Patterns of Interorganizational Communications and the Diffusion of a Major Technological Innovation in a Competitive Industrial Community," in Academy of Management Journal Vol 18, no. 1 (1975), 22.

${ }^{77}$ Natural Resources Canada, "NRCan's S\&T Management Framework", (March 1996) accessed at the NRCan Website, December 2001, [http://www.nrcan.gc.ca/dmo/scitech/documents/stmf/stfm_e.html], page 8.

${ }^{78}$ Bruce Doern and Richard Levesque, The National Research Council in the Innovation Policy Era, Changing Hierarchies, Networks, and Markets (Toronto: University of Toronto Press, 2002), 26.
} 
meetings, conferences, etc. The linkages are important to find out what others in similar (or different) fields are doing. This may also mean increased contacts and consultation with counterparts in universities as well as the private sector. This network of communication between the government, industry and universities is sometimes described as a "triple helix" of innovation. ${ }^{79}$

Alan Topalian found that innovators: “....act as the 'eyes and ears' of their organizations using networks of outside experts and facilitators to distil opportunities and threats that should be addressed. They are able to bring together the resources to take up innovation, making best use of internal intellectual assets. ${ }^{\prime 80}$ Similarly, others have found a positive link between professional training and outside professional activities to innovation. ${ }^{81}$ Through our survey instrument, we will see if respondents engaged in the following professional activities: attending work related professional meetings; held an office in a work related professional association; and had frequent contact with colleagues or other organizations in the same industry.

Our second cosmopolitan group identifies academic activities orientated outside the lab, which have been found to be positively related to innovation. ${ }^{82}$ Academic activities such as attending conferences allow people to network, share ideas with peers, and discuss solutions to problems. ${ }^{83}$ In a study of innovators at General Motors: "[i]n addition to asking questions, initiators remained open to new information. They went to technical conferences and shows. They enjoyed talking to customers. They read lots of

${ }_{79}$ Loet Leydesdorff, and Henry Etzkowitz, "Triple Helix of innovation," in Science and Public Policy Vol 25 , no. 6 (1998), 358.

${ }^{80}$ Alan Topalian, "The role of innovation leaders in developing long-term products," in International Journal of Innovation Management Vol 4, no. 2 (June 2000), 152.

${ }^{81}$ Jon Pierce and Andre Delbecq, "Organizational Structure, Individual Attitudes and Innovation," in Academy of Management Review (January 1977), 30.

${ }^{82}$ Thomas Robertson and Yoram Wind, 1983, 335.

${ }^{83}$ John Storey, September 2000, 363. 
technical and other journals. They saw outsiders as people they could learn from. ${ }^{" 84} \mathrm{We}$ will identify participation in academic activities such as submitting articles, reading work related journals, presenting a paper at a work related conference, or attending an international meeting/conference.

There is not a lot of recent empirical evidence about cosmopolitanism and innovation. A 1981 study of the adoption of administrative and technological innovations in hospitals by John Kimberly and Michael Evanisko found that hospitals that adopted administrative innovations had cosmopolitan administrators. ${ }^{85}$ More recent evidence about cosmopolitanism and its relationship to innovation comes from a Canadian public sector case study, which found that the most creative public servants appear to have diversity in work experience, training and credentials that introduce new perspectives into an organization, and base their worldview someplace outside the organization. $^{86}$

To test our first hypothesis (innovators possess this characteristic), we will create an equally weighted index comprised of both professional and academic activities, and cross-tabulate to see if cosmopolitanism is a characteristic that innovators possess. For our second hypothesis (clear differences in characteristics) we expect that innovators in our study will be cosmopolitans, participating in professional and academic activities more than non-innovators. We will also ask focus groups about the importance of cosmopolitan activities. To the best of our knowledge, cosmopolitanism has not

\footnotetext{
${ }^{84}$ Alan Frohman, "Personal Initiative Sparks Innovation," in Research Technology Management (MayJune 1999), 34.

${ }^{85}$ John Kimberly and Michael J. Evanisko, "Organizational Innovation: The Influence of Individual, Organizational and Contextual Factors on Hospital Adoption of Technological and Administrative Innovations," in Academy of Management Journal Vol 24, (1981), 107.

${ }^{86}$ Peter Buker, Always Better Continuously Innovative Public Sector Organizations in Canada, (Toronto: Institute of Public Administration of Canada, 2003), New Directions \#11, 64.
} 
previously been used as a concept to study innovators in Canadian federal government labs, so our contribution is both a new grouping of the cosmopolitan concept, (into professional and academic activities) and also an empirical test of cosmopolitanism as a characteristic of innovators in government labs.

\section{Risk Taking}

To innovate, an innovator must assume some or all of the risk of failure. It is almost a truism that innovation, by being something outside the norm, requires risk taking. ${ }^{87}$ As Jay Galbraith identifies; "[t]he psychological attributes of successful entrepreneurs include great need to achieve and take risks. Prospective innovators have an irreverence for the status quo." ${ }^{88}$ Risk taking is important to innovation, however this may be a characteristic that differs between the two sectors, as public sector employees may be less able to take risks as senior civil servants and politicians may be concerned about bureaucrats taking risks and embarrassing the Minister. ${ }^{89}$

However, while the public sector as a whole may be less likely to encourage risk taking behavior, it seems necessary for any innovator to take risks to advance an innovation. Related to our first hypothesis, innovators in our study are expected to be risk-lovers. For our second hypothesis (differences in characteristics), we expect that innovators are more risk-loving than non-innovators. To this point, we have identified the characteristics of innovators we will examine including: competence; cosmopolitanism; and risk taking. In our next section, we will describe champions and their characteristics.

\footnotetext{
${ }^{87}$ Peter Buker, 63.

${ }^{88}$ Jay Galbraith, Winter 1982, 22.

${ }^{89}$ Kenneth Kernaghan, Brian Marson and Sanford Borins, The New Public Organization, (Toronto: IPAC, 2000), 176 .
} 


\section{What is Championing?}

A crucial factor in the advancement of an innovation is the champion who promotes it. Championing is the recognition, pushing, and demonstrating of a new technical idea, approach or procedure for management approval. ${ }^{90}$ Champions and innovators are related, but one does not necessarily need to be an innovator to be a champion, as it is possible to champion someone else's innovation. Stephen Markham and Lynda Aiman-Smith define a champion as someone who recognizes a new technology or market opportunity as having significant potential; adopts the project as his or her own; generates support (including resources) from others in the organization; and advocates vigorously for the project. ${ }^{91}$

One of the main activities of a champion is to sell the merits of an innovation, and get management interested in the project. ${ }^{92}$ No idea takes root within an organization purely on its own merits: it has to be sold. ${ }^{93}$ Even if one has been handed the innovation by management, while the assignment gives legitimacy, it often contains no promises about resources or support required for implementation. ${ }^{94}$ The champion must secure resources, (money, equipment, personnel) for its development, which is a separate activity from the promotion of the merits of an innovation. Situations often arise where good ideas are promoted, but with limited funds available, only some innovations can be allocated resources.

\footnotetext{
${ }^{90}$ Alan L. Frohman, "The Performance of Innovation: Managerial Roles," in California Management Review Vol. XX, no. 3 (Spring 1978), 7.

${ }^{91}$ Stephen Markham and Lynda Aiman-Smith, "Product champions: truths, myths and management," in Research Technology Management (May-June 2001), 44.

${ }^{92}$ Alok K. Chakrabarti, "The Role of Champion in Product Innovation," in California Management Review Vol XVII, (Winter 1974), 58.

${ }^{93}$ Thomas Davenport, Laurence Prusak and James Wilson, "Who's bringing you hot ideas and how are you responding?" in Harvard Business Review (February 2003), 60.

${ }^{94}$ Rosabeth Moss Kanter, "When a thousand flowers bloom: structural, collective and social conditions for innovation in organization," in Research in Organizational Behavior, Vol 10, (1988), 184.
} 
The champion is key to the successful advancement of an innovation. Without champions, projects rarely become corporate ventures and have a higher probability of fizzling out. ${ }^{95}$ Champions are leaders and active innovators, seeking new opportunities, questioning the status quo and formulating creative solutions. ${ }^{96}$ Innovations are lost without champions who believe in new products and also understand the gritty tasks of actually building them. ${ }^{97}$

Peter Frost and Carolyn Egri ${ }^{98}$, Houston Carr and Jack Hogue come to similar conclusions. "A strong advocate or champion is needed to implement change. If you are about to introduce a new technology into your organization, and you are not a true champion of the idea who is ready to take the offense and to defend it when required, you should find such a person - or your venture may be doomed." 999 The absence of champions can mean that organizations may have lots of ideas but few innovations. ${ }^{100}$ The champion is a zealot who believes in the innovation ${ }^{101}$ and helps drive it forward ${ }^{102}$ by communicating benefits to be derived and legitimizing time and effort devoted to innovation. $^{103}$

While these studies provided a relatively clear picture of the activities of a champion, we need to identify champions in our study.

\footnotetext{
${ }_{95}$ Diana L. Day, May 1994, 148.

${ }^{96}$ Jane M. Howell and Christopher A. Higgins, "Champions of Change: Identifying, Understanding and Supporting Champions of Technological Innovations," in Organizational Dynamics (Summer 1990), 43.

${ }^{97}$ Don Frey, "Learning the Ropes, My Life as a Product Champion," in Harvard Business Review (September-October, 1991), 46.

${ }_{98}$ Peter Frost and Carolyn Egri, 1991, 270.

${ }^{99}$ Houston H. Carr and Jack T. Hogue, "It Takes a Champion," in Journal of Systems Management (August 1989), 15.

100 Jane M. Howell and Christopher A. Higgins, 1990, 55.

101 Thomas Peters and Robert Waterman, In Search of Excellence Lessons from America's Best Run Companies, (New York: Warner Books, 1982), 208.

${ }^{102}$ Diana L. Day, May 1994, 153.

${ }^{103}$ Alan Topalian, June 2000, 154.
} 
We identify champions as those who: promote an innovation to their clients; colleagues; supervisor or manager/director; and attempt to secure resources (money, equipment, personnel) for the innovation. It is not necessary to be successful to be a champion.

\section{Characteristics of Champions: Taking Ownership of Innovations and Motivating Others}

For the characteristics of champions, our review found similar shortcomings to the individual innovator literature. Most studies focus on private sector champions. One shortcoming of champion research is that being a champion is usually a positive connotation, so champions associate themselves with successful innovations, but distance themselves from failed ones. ${ }^{104}$ A question in our survey will identify successful and failed champions by asking how successful they thought they were in advancing an innovation.

Some characteristics of champions include: taking ownership in an innovation; motivating others; taking risks; and having technical expertise. Other research suggests champions have a varied career experience, a long tenure in organizations, an in-depth knowledge of the industry and experience in many different divisions and locations. ${ }^{105}$ We decided to focus on three characteristics that seemed to be relevant to champions in government labs including: taking ownership of an innovation; motivating others; and taking risks. This leads us to make two hypotheses:

\footnotetext{
${ }^{104}$ Stephen K. Markham and Abbie Griffin, "The Breakfast of Champions: Associations Between Champions and Product Development Environments, Practices and Performance," in Journal of Product Innovation Management Vol 15, (1998), 437.

${ }^{105}$ Jane M. Howell and Christopher A. Higgins, 1990, 44.
} 


\begin{tabular}{|l|l|}
\hline Hypothesis 3: & $\begin{array}{l}\text { Champions possess three characteristics we have chosen from the } \\
\text { literature: taking ownership of innovations; motivating others; and } \\
\text { taking risks. }\end{array}$ \\
\hline Hypothesis 4: & $\begin{array}{l}\text { There are clear differences in the characteristics of champions and non- } \\
\text { champions, champions have higher levels of taking ownership of } \\
\text { innovations, motivating others and taking risks than non-champions. }\end{array}$ \\
\hline
\end{tabular}

Research has found one of the distinguishing characteristics of a champion is that s/he takes personal ownership of an innovation and works hard to advance it. They gain satisfaction by having it "done their way"106 and overcoming opposition. "Such a person must have a reasonable amount of support from others in the organization, and must be deeply committed to the idea and ready to defend it against every onslaught by those who prefer the status quo."107 Management style and institutional culture can play a role in determining whether employees take ownership of innovations. Employees who participate in the decision making process may feel a greater sense of ownership than others who are excluded or do not participate.

Stephen Markham found that champions achieved distinctiveness by accepting risk, vigorously supporting or advocating the project and helping the project through critical times and overcoming opposition or leading coalitions. ${ }^{108}$ Champions energize others and generate support for the idea. ${ }^{109}$ We expect champions take ownership of innovations more than non-champions. It was unclear how champions in the literature were identified to take ownership of innovations, so we decided to ask respondents if they thought an innovation they worked on "belonged to them" or was "their baby".

\footnotetext{
${ }^{106}$ Jay Galbraith, Winter 1982, 23.

${ }^{107}$ Houston H. Carr and Jack T. Hogue, August 1989, 15.

${ }^{108}$ Stephen K. Markham, "A Longitudinal Examination of How Champions Influence Others to Support Their Projects," in Journal of Product Innovation Management Vol 15, (1998), 497.

${ }^{109}$ Stephen K. Markham and Lynda Aiman-Smith, 2001, 47.
} 
Motivating others to work on an innovation is another characteristic of champions. When a champion tries to advance an innovation, s/he often seeks support for the innovation and encourages others to work with them. ${ }^{110}$ If a champion is not also the innovator, s/he can encourage the innovator to become a champion, or alternatively take on the champion role. As there appears to be a teamwork environment in many government and private labs ${ }^{111}$, it seems reasonable to expect that champions should try to motivate others to work on innovations. For our third hypothesis (champions possess this characteristic), we expect champions motivate others to work on an innovation. For our fourth hypothesis (clear differences in characteristics) we expect champions motivate others more often than non-champions. It also seems reasonable that management style and organization culture could also influence whether champions motivate others. Along with motivating others, the main characteristic of a champion is to take risks.

\section{Risk Taking}

Being a risk-taker is a key quality of a champion. "Essentially, the champion must be a man willing to put himself on the line for an idea of doubtful success. He is willing to fail. But he is capable of using any and every means of informal sales and pressure in order to succeed." ${ }^{\prime 12}$ Along with being a risk taker, it is also important to be able to accept failure and continue to work on an innovation, because some suggest that most champions fail most of the time, ${ }^{113}$ and there is reason to believe that the bolder the

\footnotetext{
${ }^{110}$ Jane M. Howell and Christopher A. Higgins, "Champions of Technological Innovation," in Administrative Science Quarterly 35, (1990), 321.

"11 Robert Keller, "Predictors of the performance of project groups in R\&D organizations," in Academy of Management Journal Vol 29, no. 4 (1986), 714.

${ }^{112}$ Donald A. Schon, "Champions for Radical New Inventions," in Harvard Business Review Vol 41, (1963), 84.

${ }^{113}$ Thomas Peters and Robert Waterman, 1982, 209.
} 
innovation the greater the risk. ${ }^{114}$ It is not clear how we should identify risk takers, so we need to come up with a way to measure risk taking in government labs. To identify risk takers, we will ask respondents if they have tried to secure resources for an innovation that they believed had only a slight chance of being a technical or marketplace success. As risk taking appears to be important to championing, for our third hypothesis, (champions possess this characteristic) we expect that champions are risk-takers. For our fourth hypothesis (differences in characteristics) we will find out if: more champions are risk-takers than non-champions.

Summary: characteristics of innovators and champions

\begin{tabular}{|l|c|c|c|c|}
\hline \multicolumn{1}{|c|}{ Characteristics } & Innovator & $\begin{array}{c}\text { Non- } \\
\text { innovator }\end{array}$ & Champion & $\begin{array}{c}\text { Non- } \\
\text { champion }\end{array}$ \\
\hline $\begin{array}{l}\text { Competence } \\
\text { Experience } \\
\text { Technical expertise } \\
\text { - Education }\end{array}$ & More & Less & N/A & N/A \\
\hline $\begin{array}{l}\text { Cosmopolitanism } \\
\text { Professional } \\
\text { activities } \\
\text { Academic activities }\end{array}$ & More & Less & N/A & N/A \\
\hline Risk taking & More & Less & More & Less \\
\hline Taking ownership & N/A & N/A & More & Less \\
\hline Motivating others & N/A & N/A & More & Less \\
\hline
\end{tabular}

The previous table displays the characteristics of innovators and champions we will examine and our expectations on the possession of these characteristics. In the next section, we look at our second theme: hierarchy and its relationship to innovation and championing.

${ }^{114}$ Alan Altshuler, "Public Innovation and Political Incentives," Harvard University, (Fall 1997), 2. 


\section{Theme 2: Hierarchy and Innovation; Elites and Technical Specialists}

The second theme related to individual innovation is the level in the hierarchy of innovators and champions. In some studies, the theme of hierarchy is treated somewhat differently. Hierarchy is sometimes considered an institutional factor because it can examine how the lab operates in relationship to its "parent" Department, Agency or Council, or the government. It can also examine how the lab reacts to internal and external institutional factors. Bruce Doern and Richard Levesque's study of the National Research Council is an example of this type of application of hierarchy to innovation. ${ }^{115}$ Our examination of hierarchy is different, focusing on the hierarchical levels of individual champions and innovators in the lab, rather than institutional relationships. Innovators and champions appear at different times and play different roles. Donald Schon was one of the first to identify different types of champions, proposing a distinction between a lower organizational level "product champion", who proposes and promotes new ideas and "management" who decides their fate. ${ }^{116}$ Some research has found significant differences between 'idea-havers'-those who come up with ideas and 'idea-exploiters' those who do something with the ideas they have generated. ${ }^{117}$

Unfortunately, this dichotomy does not consider that managers could also promote an innovation. Building on Schon, Modesto Maidique and Diana Day distinguish between two types of champions: a "business innovator" (sometimes called an organizational sponsor); and a "product champion". A business innovator is a person within the managerial structure responsible for the overall progress of the project, while a

\footnotetext{
${ }^{115}$ Bruce Doern and Richard Levesque, The National Research Council in the Innovation Policy Era, Changing Hierarchies, Networks, and Markets (Toronto: University of Toronto Press, 2002)

${ }^{116}$ Donald A. Schon, $1963,86$.

${ }^{117}$ Edward Roberts, "Managing Invention and Innovation," in Research Technology Management Vol 31, no.1 (1988), 16.
} 
product champion was anyone who made a decisive contribution to the innovation by actively and enthusiastically promoting its progress. ${ }^{118}$ The organizational sponsor is responsible for securing resources and legitimacy. A successful organizational sponsor may be an ex-product champion, who's been there and knows how to shield an innovation from the organization's tendency towards negation. ${ }^{119}$

This view of championing roles allows for champions to come from different levels in the organization, correcting a shortcoming in earlier work where "champions and their innovations emerge from the depths of the organization, when, in fact, champions may emerge from any level and location within the firm." ${ }^{120}$ People at all hierarchical levels, can create new ideas, execute and commercialize new products. ${ }^{121}$ This boils down to the question: is there a relationship between hierarchy, innovation and championing?

Sometimes, innovations championed by staff (non-management) are known as a "bottom-up". However, it is unclear if this process describes innovation in most organizations. "Part of the controversy concerning the bottom-up view stems from the myth that one person with an idea makes heroic efforts to take the idea from conception to final commercialization. In fact, such a process is relatively rare."122 Unfortunately, there is little empirical evidence to support or refute this. When a manager champions, this is called a top-down approach. Some projects require a top down approach, such as costly, high profile ventures or those that represent substantial risks for the organization

\footnotetext{
${ }^{118}$ Modesto A. Maidique, "Entrepreneurs, Champions, and Technological Innovation," in Sloan Management Review Vol 21, no. 2 (Winter 1980), 61.

${ }_{119}$ Thomas Peters and Robert Waterman, 1982, 208.

${ }^{120}$ Diana L. Day, May 1994, 148.

${ }^{121}$ Brian Guthrie and Jacek Warda, The Road to Global Best: Leadership, Innovation and Corporate Culture (Ottawa: The Conference Board of Canada, May 2002), 1.

${ }^{122}$ Diana L. Day, May 1994, 149.
} 
or a threat to the status quo. ${ }^{123}$ While a top down approach gives an incomplete picture of innovation, it seems to be the focus of most research. ${ }^{124}$

One project may have multiple champions, which often ensures that a project moves from one stage of development to another. ${ }^{125}$ This means that different champions can play different roles at different stages. Even with a possibility of more than one champion, often one person stands out. ${ }^{126}$ Gordon Brunner agrees: "[w]hen we look back at our blockbuster business successes, we've consistently been able to identify one or a very few technologists who really made a huge contribution."127

We will examine two factors related to hierarchy: power ${ }^{128}$ and expertise. Power is needed to facilitate, orchestrate and shape product innovations. ${ }^{129}$ The advancement of an innovation involves give and take. "Contests and struggles for collaboration are often part and parcel of the innovation process. It is often played out through the exercise of power." $" 130$ To relate hierarchy to innovation, we are interested in positional power.

\section{Positional Power: The Authorization to Make Decisions and Compel Compliance}

We will consider two components of positional power related to innovation: the authorization to make decisions; and the ability to ensure compliance. One's position can give the authority to make decisions that effect an innovation such as: the awarding or removal of funds; and the allocation (or removal) of equipment. This can also include the

\footnotetext{
${ }^{123}$ Diana L. Day, May 1994, 152.

${ }^{124}$ Nigel King, "Innovation at work: the research literature," in Innovation and Creativity at work psychological and organizational structures, Edited by Michael West and James Farr, (Toronto: John Wiley \& Sons, 1990), 29.

${ }^{125}$ Stephen K. Markham and Lynda Aiman-Smith, May-June 2001, 46.

${ }^{126}$ Diana L. Day, May 1994, 148.

${ }^{127}$ Gordon Brunner, "The tao of innovation," in Research Technology Management (January-February $2001), 51$.

${ }^{128}$ Power is defined as any force that results in behavior that would not have occurred if it had not been present.

${ }^{129}$ Cynthia Hardy, "Sustained product innovation in large, mature organizations: overcoming innovation to organization problems," in Academy of Management Journal Vol 39, no. 5 (1996), 1146.

${ }^{130}$ Peter Frost and Carolyn Egri, 1991, 236.
} 
ability to hire/fire, promote or punish employees and assign personnel to work on an innovation. Usually, as one progresses to higher levels, one has a greater control of these allocations. While lower level employees can be champions, eventually they need to secure resources from someone with the positional power to deny or approve the request.

Closely related to the authorization to make decisions is the ability to compel compliance of subordinates. Subordinates can be instructed to advance an innovation, using hierarchical authority. ${ }^{131}$ Jurgen Hauschildt and Edgar Kirchmann found that positional (hierarchical) power could be used to help protect an innovation from opposition and establish it in the face of resistance. ${ }^{132}$ John Storey found that innovators and subordinates required special protection, like "air-cover". They were seen as vulnerable should that cover be removed. ${ }^{133}$ A lower level champion usually does not have the positional power to shield him or herself or the innovation.

While managers may have the authority to make decisions and the ability to compel compliance, they are rarely in a position where they have access to all of the information and resources an innovation needs. They must trade, broker and work with peers, superiors and subordinates. ${ }^{134}$ To get support, John Kotter identifies types of power a manager can use, the most important of which related to innovation is the belief in a manager's expertise ${ }^{135}$, which includes knowledge, skills and attitudes. ${ }^{136}$ The

\footnotetext{
${ }^{131}$ Jeffrey Pfeffer, "Understanding Power in Organizations," in Managing Strategic Innovation and Change, Edited by Michael Tushman and Philip Anderson, (New York: Oxford University Press, 1997), 225.

${ }^{132}$ Jurgen Hauschildt and Edgar Kirchmann, "Teamwork for innovation - the 'troika' of promoters," in R\&D Management Vol 31,no. 1 (2000), 41.

${ }^{133}$ John Storey, September 2000, 362.

${ }^{134}$ Rosabeth Moss Kanter, "The middle manager as innovator," in Harvard Business Review (July-August 1982), 98.

${ }^{135}$ John P. Kotter, "Power, dependence, and effective management," in Harvard Business Review (JulyAugust 1977), 129.
} 
recommendations of a manager with technical expertise are likely taken more seriously than those from one who is not as technically proficient.

\section{Elites}

To study links between hierarchy and innovation, we require a modified description of "management", because some managers have authority related to innovation and some do not. Also, champions can appear to be management when they are not. We consider those who have the authority to make decisions related to an innovation, such as the removal/approval of funding and personnel as part of the "elite", rather than management. A champion can appear to be part of the elite, and may be consulted on the advancement of an innovation. If the champion does not control resources and compliance, $\mathrm{s} / \mathrm{he}$ is not part of the elite. There is no definition of elite in the literature relevant to government labs, and so we propose to define:

elites as employees and managers who could: assign subordinates to work on an innovation; allocate funds greater than $\$ 10000$ towards an innovation; and allocate equipment to be used to work on an innovation.

This definition includes the components of positional power (allocate funds and equipment) and also ability to compel compliance (assign subordinates) and is relevant to government labs.

We are interested in two types of elites: those who are innovating, and elites who are not innovating. The study of elites is important because they often set a direction for the organization that determines the innovative environment, including the types of innovations accepted. "Scholars regularly cite leadership as an essential element in the

${ }^{136}$ Michael K. Badawy, "The role of the technical manager Why managers fail," in The Human Side of Managing Technical Innovation Edited by Ralph Katz, (New York: Oxford University Press, 1997), 230. 
success of public agencies."137 Innovation requires a clear vision from management and a passion for change. ${ }^{138}$ Leadership is important because almost all organizations are somewhat hierarchical, and as a result decision-making power accrues to the leaders. ${ }^{139}$ Elites can define strategy and core values, and provide a role model or rewards and recognition for innovators. ${ }^{140}$ Some research has found a direct relationship between what the elites value and what the organization accomplishes. ${ }^{141}$ If elites set up a positive environment for innovation, we would expect more innovation.

Public sector research has found that leadership is not by itself enough to make an organization innovative. However, no cases were found where leaders did not take an active role in promoting innovations. This means that it is not enough to allow employees to innovate; the leaders must promote and encourage innovation. ${ }^{142}$ It is possible to overrate the importance of the individual, and by emphasizing the effect of leadership; we may overlook other factors, ${ }^{143}$ such as organizational structure. ${ }^{144}$ Organizations matter, ${ }^{145}$ and structure imposes constraints on the individual. ${ }^{146}$ This is why we are studying both individual and organizational factors.

An elite has the positional power to be an effective champion to advance or protect an innovation because s/he has the authority to make decisions about its

\footnotetext{
${ }^{137}$ Hal Rainey and Paula Steinbauer, 1999, 18.

${ }^{138}$ Brian Guthrie and Jacek Warda, May 2002, 2.

${ }^{139}$ Nigel King, 1990, 28.

${ }^{140}$ Michael Tushman and David Nadler, "Organizing for Innovation," in California Management Review Vol XXVIII, no. 3 (Spring 1986), 91.

${ }^{141}$ Jerald Hage and Robert Dewar, "Elite Values Versus Organizational Structure in Predicting Innovation," in Administrative Science Quarterly Vol 18, (1973), 279.

142 Peter Buker, 2003, 58.

${ }^{143}$ Stanley Lieberson and James O'Connor, 'Leadership and Organizational Performance: A Study of Large Corporations," in American Sociological Review Vol 37, no.2 (1972), 129.

${ }_{144}$ Marshall W. Meyer, "Leadership and Organizational Structure," in American Journal of Sociology Vol 81 , no. 3 (1975), 516 .

${ }^{145}$ Cynthia Hardy, 1996, 1146.

${ }^{146}$ Daniel Brass, "Being in the Right Place: A Structural Analysis of Individual Influence in an Organization," in Administrative Science Quarterly 29, (1984), 518.
} 
advancement and the ability to compel compliance of subordinates. This brings us to hypothesize:

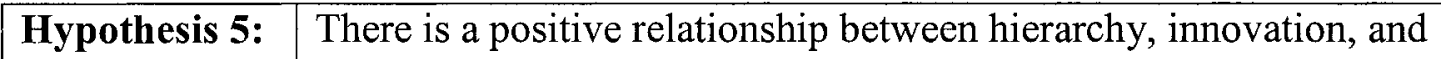
championing, a higher proportion of elites are innovators, and champions compared to non-elites.

Hypothesis 6: $\quad$ There is a positive relationship between hierarchy and success championing where elites are more successful champions than nonelites.

Through our survey instrument, we will examine the link between hierarchy and innovation by determining if elites are innovators and champions. We will also ask how successful elites and non-elites considered their promotion efforts to be. This allows us to compare those who are innovating and/or championing an innovation, if they are elites, and how successful they think they have been.

\section{Expertise: The Technical (Staff, Functional) Specialist}

So far, we have examined power based upon level in the hierarchy. Another type of power related to innovation comes from expertise. William Evan and Guy Black identify the "staff specialist" as a major source of innovation. Staff specialists' positional power and influence are based upon expertise rather than their level in the hierarchy. Evan and Black's study found that approximately $67 \%$ of proposals were generated by staff specialists, suggesting a frequent source of new ideas. Even if they are not generating ideas, staff specialists may evaluate them, by investigating their merit and feasibility. ${ }^{147}$ Staff, functional and technical specialist are all describing the same individual: one who has influence because $\mathrm{s} / \mathrm{he}$ possesses technical expertise acquired through either education or experience. ${ }^{148}$

\footnotetext{
${ }^{147}$ William M. Evan and Guy Black, "Innovation in business organizations: some factors associated with success or failure of staff proposals," in The Journal of Business Vol 40, (1967), 520.

${ }^{148}$ To simplify, we will refer to technical, staff and functional specialists as "technical specialists".
} 
The role of technical specialists is described well, but there is no measurement strategy appropriate for government labs. So while we embrace the concept, we need to create survey questions to identify technical experts in government labs.

We define technical specialists as those who were approached by others in the lab to solve difficult technical problems in (or near) their field and whose technical expertise allows them to influence the acceptance/rejection of proposed innovations in the lab.

With technical expertise, they can innovate and defend an idea on its technical merits. This allows for the advancement of their innovations over others championed by individuals who lack technical expertise. To promote an innovation, a champion must be persistent, competent, credible, and knowledgeable about the company, and the market. ${ }^{149}$ This leads us to hypothesize:

\begin{tabular}{|l|l|}
\hline Hypothesis 7: & $\begin{array}{l}\text { There is a positive relationship between hierarchy, innovation, and } \\
\text { championing, a higher proportion of technical specialists are innovators, } \\
\text { and champions compared to non-technical specialists. }\end{array}$ \\
\hline Hypothesis 8: & $\begin{array}{l}\text { There is a positive relationship between hierarchy and success } \\
\text { championing where technical specialists are more successful } \\
\text { championing than non-technical specialists. }\end{array}$ \\
\hline
\end{tabular}

Unfortunately, there is a danger in relying on a specialist, because their knowledge can become narrow and their capabilities may prevent them from using other knowledge to innovate. ${ }^{150}$ Further, specialists may only concern themselves with the success of their personal project to the detriment of the organization.

Robert Thornton found: "[p]ower did not seem to accrue to an individual merely because of his position in the organization channel except at quite high echelons. Thus, power possessed at lower echelons, for example at the technical specialist level, might

\footnotetext{
${ }^{149}$ Alok K. Chakrabarti, Winter 1974, 61.

${ }^{150}$ D. Hamberg, "Invention in the industrial research laboratory," in Journal of Political Economy (April 1963), 106.
} 
not be available to intermediate supervisors." 151 While a manager has more positional power than subordinates, it is unlikely they are experts in all the functions under their control, and they can find themselves at a disadvantage to the experts. ${ }^{152}$ The higher a manager is in the organization the more dependent he or she becomes on key subordinates, ${ }^{153}$ and the areas in which s/he is vulnerable increases and becomes more complex rather than the reverse. ${ }^{154}$

Superior-subordinate relations are inherently asymmetric in their distribution of formal power. The president starts out with more positional power than his subordinates. But subordinates also have sources of power, such as familiarity and intimate knowledge of the company and its operations. ${ }^{155}$ A technical specialist can make an effective champion if $\mathrm{s} /$ he is close to the problems the organization is trying to solve, by being involved in the day-to-day operations and having a keen sense of what's happening. They may also have contact with colleagues in the industry, and this leads to knowledge of how others are tackling similar problems.

If technical specialists can control access to those who have specialized knowledge or if they restrict (gate keep) the flow of information, they acquire additional power to the extent that they can exclude superiors from information. "Thus dependence together with the manipulation of the dependency relationship is the key to the power of lower participants." ${ }^{\prime 156}$ Many managers are aware of this strategy and try to build their

\footnotetext{
${ }^{151}$ Robert L. Thornton "Decisions to Innovate," in Personnel Administration (May June 1970), 44.

${ }^{152}$ Michael Lawless and Linda L. Price, "An agency perspective on new technology champions," in Organization Science Vol 3, no. 3 (August 1992),344.

${ }^{153}$ John Gabarro, "Socialization At The Top - How CEOs and Subordinates Evolve Interpersonal Contracts," in Organizational Dynamics (Winter 1979), 4.

154 John P. Kotter, July-August 1977, 127.

${ }^{155}$ John Gabarro, 1979, 12.

${ }^{156}$ David Mechanic, "Sources of Power of Lower Participants in Complex Organizations," in Administrative Science Quarterly Vol 7, (1962), 356.
} 
own information networks to counteract it. Because of the asymmetries of positional power, lower level participants may find themselves at such a disadvantage that they consider going outside of the normal role structure of the organization. As David Mechanic observes: "[1] ower participants do not usually achieve control by using the role structure of the organization, but rather by circumventing, sabotaging and manipulating it." $^{\prime 157}$

What is important is that "the power to attain personal, group, or organizational goals should not be restricted to downward influence in organizations. Although the supervisor and the worker may use different methods of influence, each can help or hinder the other's attempts to fulfill important goals."158 We will consider both innovative elites and technical specialists as possible champions and sources of innovation. Elites have positional power to move their ideas forward, but may lack technical expertise. The technical specialist has expertise, but is not usually able to allocate the resources necessary to bring an innovation to fruition.

How can a champion who does not possess positional power (not elite or technical specialist) advance an innovation? Champions must try to use their power and influence to find others at higher levels to get support. ${ }^{159}$ However, persuasion has a downside, as it requires a lot of time, skill and information and a receptive audience. ${ }^{160}$ The power of persuasion is linked to "personal" power, which arises from sources such as their past record of performance -charisma or force of personality, and persuasiveness. ${ }^{161}$

\footnotetext{
${ }^{157}$ David Mechanic, 1962, 356.

${ }^{158}$ Warren Schilit and Edwin Locke, "A Study of Upward Influence in Organizations," in Administrative Science Quarterly Vol 27, (1982), 304.

${ }^{159}$ Diana L. Day, May 1994, 150.

${ }^{160}$ John P. Kotter, July-August 1977, 128.

${ }^{161}$ John Gabarro, Winter, 1979, 12.
} 
Some individuals, regardless of their hierarchal position seem to wield substantial influence over the decision making process. They have considerable personal power, but no authority. ${ }^{162}$ However, Baldridge and Burnham ${ }^{163}$ and David Mechanic's studies both found that personal power may result from positional power rather than from personal characteristics. $^{164}$

In this section, we identified that positional power came from the authorization to make decisions and compel compliance. Positional power can also come from technical expertise. We defined elites and technical specialists. To the best of our knowledge, the application of hierarchy, as we have defined it, has not been used previously to study government labs, so our contribution is a definition and measurement strategy of the concept of elites and technical specialists in government labs and an empirical test of the theory. In the next section, we discuss the barriers to innovation faced by champions.

\section{Theme 3: Overcoming Barriers; the Rational; Participative; and Renegade Processes}

The third and final theme we will examine related to individual innovation factors is the overcoming of barriers to innovation. Overcoming opposition is an important role of a champion. "Enthusiastic, visionary champions push their ideas through the organization, resolving turf disputes, overriding established norms, and ignoring anguished cries of 'it won't work!' from those who stand to lose with the new system."165 Almost any innovation faces some, perhaps massive opposition. ${ }^{166}$ John Story observed;

\footnotetext{
162 David Mechanic, 1962, 349.

${ }^{163}$ Victor Baldridge and Robert Burnham, "Organizational Innovation: Individual, Organizational, and Environmental Impacts," in Administrative Science Quarterly Vol 20, (June 1975), 169.

${ }^{164}$ David Mechanic, 1962, 350.

${ }^{165}$ Cynthia Mathis Beath, "Supporting the Information Technology Champion," in MIS Quarterly (September 1991), 356.

${ }^{166}$ Jurgen Hauschildt and Edgar Kirchmann, 2000, 41.
} 
"[i]nnovation was clearly viewed as a contested terrain."167 Management and colleagues may be skeptical an innovation will work, or indifferent that it will yield the benefits the champion claims or simply resist change. If an organization did not seek out new ideas, it loses its competitive edge, but without some resistance the consequences could be disastrous. ${ }^{168}$

Champions may have to overcome preferences for other activities, especially if others see the proposed innovation as a threat to resources allocated to their own project, ${ }^{169}$ or if other projects have a better chance of success or a better fit with the research agenda. Opposition a champion faces is not necessarily related to the innovation itself, but "[i]nnovation for some managers was seen as a fight for resources. It involves competition between projects and even between change and the status quo."170 Innovations designed to solve a specific technical problem or serve a small target market, or are unlikely to yield a substantial monetary return may be rejected in favor of others that appear to have a larger monetary or prestige payback.

Opposition to an innovation is not necessarily negative. "In overcoming the political obstacles to change, the innovator is forced to justify the merits of proposed change as well as perhaps adopting the innovation to meet the needs of a wider constituency, thereby enhancing its potential benefits." $" 171$ When an innovation receives scrutiny by critics, underlying assumptions are tested and it may be improved. ${ }^{172}$ A critic should question assumptions and improve the innovation, but not quash every new idea.

\footnotetext{
${ }^{167}$ John Storey, September 2000, 358.

${ }^{168}$ Donald A. Schon, 1963, 82.

169 Alan L. Frohman, Spring 1978, 6.

${ }^{170}$ John Storey, September 2000, 361.

${ }_{171}$ Peter Frost and Carolyn Egri, 1991, 281.

${ }^{172}$ Andrew Van de Ven, Douglas Polley, Raghu Garud and Sankaran Venkataraman, The innovation journey, (New York: Oxford University Press, 1999), 99.
} 
Other barriers to innovation include: inertia in putting forward an idea; fear of criticism; feeling that the idea will not be well received or acted upon; ${ }^{173}$ a lack of resources (time and money); short-termism; and fear of failure. ${ }^{174}$ Difficulties specific to the public sector include: bureaucratic attitudes; turf fights and resistance; coordination and logistics; union and management opposition; inadequate resources; and legislative constraints. ${ }^{175}$ Champions are important because they take ownership and risks and motivate others to advance innovation past these barriers. However, an innovation is not necessarily a triumph, as it may overestimate the opposition. Even if champions faced little opposition, they still are champions. In our survey and focus groups, we will ask respondents to identify the main barriers in advancing an innovation.

Jane Howell and Christopher Higgins identified three different processes champions use to promote innovations: rational, participative and renegade processes. ${ }^{176}$ While these were used to describe innovation in the private sector, they have not to the best of our knowledge been applied to government labs. Our contribution will be to see if champions in government labs use any of these three processes. The rational and participative processes are the way many envision innovation, where small numbers of individuals ${ }^{177}$ gather information, generate new ideas, demonstrate them and finally implement the innovation. ${ }^{178}$ The innovation journey "consists of entrepreneurs who,

\footnotetext{
173 Alok K. Chakrabarti, Winter 1974, 58.

${ }^{174}$ John Storey, 2000, 358.

${ }^{175}$ Kenneth Kernaghan, Brian Marson and Sandford Borins, 2000, 81.

${ }^{176}$ Jane M. Howell and Christopher A. Higgins, 1990, 41.

${ }^{177}$ Edward Roberts and Alan Fusfeld, "Staffing the Innovative Technology-based organization," in $\underline{\text { Sloan }}$ Management Review (Spring 1981), 22.

${ }^{178}$ Alan L. Frohman, Spring 1978, 5.
} 
with support and funding of upper managers or investors, undertake a sequence of events that create and transform a new idea into an implemented reality."179

The rational process is where a champion receives approval prior to implementation of an innovation. "By using the rational process - by far the most common approach to innovation - the champion plays within the organization's rules and procedures. Standard approval processes are followed and executive approval is obtained before the technology is implemented." 180

In his study of innovators, Robert Thornton described the rational process:

...an image of technical competence is very important to airline specialists. For this reason, specialists are very eager to present to their bosses ideas which represent up to the minute developments. When they hear of a new concept, therefore, these specialists will be anxious to inform their superiors of it. In the process, the technician tends to become personally involved, presenting the new ideas as his own position. Thus he will frequently become an excellent 'inside salesman' for the idea. ${ }^{181}$

This is the least risky process, since the champion works within organizational rules, and receives management approval before proceeding.

At General Motors, the rational process was described where proposals were sent to bosses first, and if not receptive, bosses were asked what they didn't like about the idea, and the innovators worked to address the problem. They continued on in spite of obstacles and treated the need to get 'buy-in' and approvals as opportunities to test their ideas and plans. ${ }^{182}$ As John Storey points out, while innovation theory casts the innovator as heroic and admired, in practice to be innovative can invite resistance and reprisal. ${ }^{183}$

\footnotetext{
${ }^{179}$ Yu-Ting Cheng and Andrew Van de Ven, "Learning the Innovation Journey: Order Out of Chaos?" in Organization Science Vol 7, no. 6 (November-December 1996), 593.

${ }^{180}$ Jane M. Howell and Christopher A. Higgins, 1990, 48.

181 Robert L. Thornton, "Decisions to Innovate," in Personnel Administration (May June 1970 ), 43.

182 Alan Frohman, 1999, 32.

183 John Storey, $2000,352$.
} 
Using the rational process still involves taking risks. The innovators at General Motors continued on because they believed the results would speak for themselves to convince senior managers of the worth of the innovation. ${ }^{184}$ Through our survey instrument, we will ask champions who worked on an implemented innovation if they presented the innovation to a supervisor or Director. Respondents who did are using the rational process.

Innovation is a risk for the organization, but how it responds defines whether or not it is an innovative organization. The organization may respond adaptively or defensively. ${ }^{185}$ If management is sympathetic and open to new ideas, the rational process is effective in promoting innovation. "In order for the champion to be effective, management has to be responsive. One obvious way is through the creation of an environment that supports championing." 186 Since the rational process involves receiving approval before proceeding, if management is not receptive, an innovation may be quashed before it gets off the ground. To increase the success rate, the participative process may be used.

The participative process involves the champion presenting information to colleagues to build support before proposing the innovation to management for approval. This method likely has a higher success rate, because increasing buy-in strengthens the champion's position. The participative approach is similar to the rational process, except the champion gains support before seeking approval. The champion can try to link the

\footnotetext{
${ }^{184}$ Alan Frohman, 1999, 33.

${ }^{185}$ William M. Evan and Guy Black, 1967, 525.

${ }^{186}$ William A. Fischer, Willard Hamilton, Curtis P. McLaughlin and Robert W. Zmud, "The elusive product champion," in Research Management (May-June 1986), 15.
} 
innovation proposal to the vision statement to get management buy-in, ${ }^{187}$ or tailor the innovation to fit their organization's specific needs. ${ }^{188}$ This is why champions try to develop relationships, convincing others about ideas and gathering resources. ${ }^{189}$ If they are unable to convince others of an innovation's worth, they may not be able to turn it into a product, process or service. We will ask champions who worked on an implemented innovation if they consulted with internal colleagues, and if it was important to have internal colleagues' support? Respondents who answered affirmatively to both questions are using the participative process.

The renegade process is where the champion bypasses the approval process. "In the renegade process, the champion generates and implements ideas without receiving permission from the formal organization, and usually in violation of explicit management directives." 190 Without approval for implementation (from the rational process), nor the groundswell of support from the participative process, the renegade is operating alone, likely against orders or in secret. This is a risky type of innovation, for both the renegade and the organization. For a renegade, the risks are clear: if s/he is caught deliberately disobeying a management decision; s/he can face punishment or dismissal. For the organization, there is a risk that the renegade can be using scarce resources on the innovation. Also, if renegades are working on their own projects rather than assigned duties, other priorities may slip, leading to missed deadlines, etc.

Why would a champion choose the renegade process? Renegades justify their activities because the organization is not listening to their ideas and if given a chance, the

\footnotetext{
${ }^{187}$ Jane M. Howell and Christopher A. Higgins, 1990, 50.

188 Thomas Davenport, Laurence Prusak and James Wilson, February 2003, 60.

${ }^{189}$ Stephen K. Markham and Lynda Aiman-Smith, May-June 2001, 49.

190 Jane M. Howell and Christopher A. Higgins, 1990, 50.
} 
innovations will be successful, and once successful, their transgressions will be forgiven. ${ }^{191}$ Renegades appear to be loyal to the innovation, and see its merits as more important than the rules and culture of the organization. "Systems and procedures developed in large companies are designed to maintain the status quo and avoid risks. The regular screening mechanisms require a hierarchy of management and chain of command. The champion goes beyond his formal organizational role, over the hierarchical chain, to where positive decision making is possible." 192 If the renegade process is used often, it may be a sign the organization is not receptive to new ideas.

The renegade process is somewhat difficult to measure, so we will use several questions as proxies. Champions who identified that having internal colleagues' support was unimportant, and that they would be likely to go over a supervisor's head if they disagreed about the potential of an innovation, and who thought that it would be likely that senior management would accept an innovation created without formal management approval are proxies of the renegade process. The three types of innovative process can be considered as a continuum. If a champion proposed an innovation using the rational approach and failed, s/he could then use the renegade process and implement the innovation anyway. Alternatively, the champion could try to build support using the participative process. Champions could shift championing methods, depending on the risk level they are willing to accept and the receptivity of management.

Recent evidence from the public sector suggests that tactics most commonly used in North America could be broadly described as persuasion - demonstrating the benefits, demonstration projects and marketing - and accommodation - consulting, with

\footnotetext{
191 Jane M. Howell and Christopher A. Higgins, 1990, 50.

${ }^{192}$ Alok K. Chakrabarti, 1974, 58.
} 
innovators attempting to persuade or accommodate their opponents rather than appealing to their superiors to use their authority to overcome opponents. ${ }^{193}$ This would seem to indicate a rational process, while consultation and accommodation indicates the participative process at work. As there are many barriers to going over the boss's head and almost no financial rewards for doing so, renegading does not seem as likely to be used in the public sector.

While the championing methods we are discussing have not been applied to government labs before, as government labs usually have many hierarchical levels, and constrained budgets, this leads us to expect that the rational and the participative process would be used more often, where champions would speak to their colleagues or bosses about an innovation, receive permission to move forward and advance the innovation. This leads us to hypothesis 9:

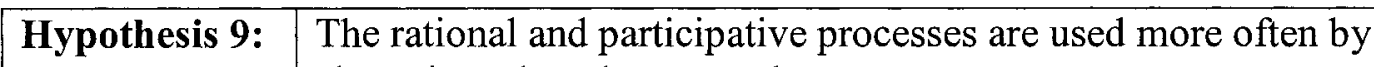 champions than the renegade process.}

In sum, all three approaches: the rational; participative; and the renegade involve selling management on the value of an innovation. The rational process is the least risky, while the renegade process is the most risky and uncertain. The championing methods we discussed were derived from literature focused on the private sector; and we are extending them to government labs. Through our survey we will try to determine which of the processes respondents used, and how successful they were.

\section{Chapter Summary}

In this chapter, we have covered three analytical themes related to individual level innovation including: characteristics of innovators and champions; hierarchy; and;

\footnotetext{
${ }^{193}$ Kenneth Kernaghan, Brian Marson and Sandford Borins, 2000, 83.
} 
barriers faced and promotion methods used to advance innovation. In the first theme, we identified potential characteristics of innovators: competence; cosmopolitanism; and risktaking. We defined championing and will ask champions to rate their success to identify successful and failed champions. The characteristics of champions we will examine are: risk taking; personal ownership of an innovation; and motivating others. In our second theme of hierarchy, we identified a potential positive relationship between hierarchy and innovation through elites and technical specialists. In our final theme, we described the rational; participative; and renegade championing processes, and possible barriers that champions could face. In the next chapter, we move away from individual factors to look at institutional factors related to innovation. 
PART II INSTITUTIONAL FACTORS 


\section{CHAPTER 2: INSTITUTIONAL FACTORS RELATED TO INDIVIDUAL INNOVATION IN GOVERNMENT LABS}

This thesis intends to study both individual and institutional factors related to innovation in government labs. However, there are some difficulties moving from the individual to the institutional level of analysis. To help clarify our journey, thus far we have identified the characteristics of innovators and champions that we will study, as well as their hierarchical level. We have discussed methods that champions could use and barriers they may face. In the first chapter, we purposely did not discuss the labs as institutions, in order to allow individual factors to be considered independent of organizational factors.

To move to the institutional level we want to consider institutional factors identified in the literature as having an effect on innovation. As with individual factors, there are two distinct bodies of literature, one focuses on the private sector and another on government labs. Some believe the distinction between the public and private sectors is important because each stands for alternate approaches to problem solving, with business typifying efficiency and rationality, while government is associated with a ponderous and often ineffective administrative style. ${ }^{194}$

Most organizational theory seems to indicate that innovation thrives in dynamic, flexible enterprises and not in rigid bureaucracies. If nothing else, bureaucratic administration may lack the prerequisites for innovation, namely creative thinking, idea experimentation and inventiveness. This leads to the belief that some of the most important institutional features related to innovation are the opposite of those most

\footnotetext{
${ }^{194}$ Bruce Buchanan, "Red-tape and the service ethic," in Administration and Society (February 1975), 424.
} 
frequently built into public organizations. ${ }^{195}$ This view of government may be outdated, and government is changing and modernizing. ${ }^{196}$ Hal Rainey and Paula Steinbauer point out that while government organizations have virtually an archetypical status as cumbersome, bungling entities, many of them perform well. ${ }^{197}$ David Roessner adds: "[t]he answer to the question of whether there is anything intrinsic to public sector organizations that relegates them to lives less innovative than their private sector counterparts appears to be, theoretically yes; empirically maybe and maybe not." ${ }^{\prime 198}$

An examination of the literature related to government labs will provide the institutional factors we will use to examine innovation in the government labs in our study. However, we also need to situate our discussion in the broader context of Canadian Science and Technology (S\&T) Policy. The purpose of this dissertation is not to examine Canadian S\&T policy in detail, but it is important that we consider current S\&T policy themes, which could affect government labs as institutions.

Over the past twenty years, most countries including Canada have assessed the role, function and performance of government labs. ${ }^{199}$ In Canada, this assessment has taken the form of various: Councils; Committees; Task Forces; Advisory Panels; and Reviews. $^{200}$ These assessments looked broadly at the state of government Science and

\footnotetext{
${ }^{195}$ Lloyd A. Rowe and William Boise, "Organizational Innovation: Current Research and Evolving Concepts," in Public Administration Review Vol 34, (May/June 1974), 287.

${ }^{196}$ Nada Teofilovic," The reality of innovation in government," in Innovation Journal Vol 7, no.3 (2002), 1.

${ }^{197}$ Hal Rainey and Paula Steinbauer, "Galloping Elephants: Developing Elements of a Theory of Effective Government Organizations," in Journal of Public Administration Research and Theory Vol 9, no.1 (1999), 2. ${ }^{198}$ David Roessner, "Incentives to Innovate in Public and Private Organizations," in Administration and Society Vol 9, no. 3 (November, 1977), 360.

${ }_{199}$ OECD, The changing role of government research laboratories (Washington: Organisation for Economic Co-operation and Development, 1989), 33.

${ }^{200}$ For a review of commissions, committees, etc, related to Science and Technology policy in Canada, please see Bruce Doern and Jeff Kinder, "One Size Does Not Fit All: Canadian Government Laboratories as Diverse and Complex Institutions," Journal of Canadian Studies, (in press), or The Impact Group, The
} 
Technology (S\&T) including government labs. In some cases, studies examined the way government labs should be organized, financed and managed, as well as how their research should be exploited. Committees sometimes examined government labs with a particular mindset. For example, the National Advisory Board on Science and Technology appointed by the Conservative Government in 1987 reflected the government's market-based approaches in their report. ${ }^{201}$

In Canada, current reviews of the role of government labs have indicated a shift in focus from past practices of using government scientific institutions to build the nation and its capabilities, towards dealing with challenges facing government science and the public interest related to structural pressures such as globalization, innovation, and governance. ${ }^{202}$ This shift threatened to weaken the underlying logic of the existence of government labs, including the provision of public goods such as basic infrastructure, support of policy goals, strengthening of regulatory mandates, and the protection of society. $^{203}$

In response to these challenges, government labs tried to assert their roles in these areas. Historically, “...government has continually responded to contemporary demands, has helped build capacities in industry, universities, and communities, and has adjusted operations to maintain service, relevancy and preparedness." ${ }^{204}$ Another line of argument might have also been successful. Perhaps, "[i]t would have been simpler to

Roles of the Federal Government in Performing Science and Technology: the Canadian Context and Major Forces (Not Published, March 1999).

${ }^{201}$ Doern and Kinder, "One size does not fit all: Canadian Government Laboratories as diverse and complex institutions," Journal of Canadian Studies (in press), 16.

${ }^{202}$ John de la Mothe, "Government Science and the Public Interest," in Risky Business: Canada's Changing Science-Based Policy and Regulatory Regime, Bruce Doern and Ted Reed Editors, (Toronto: University of Toronto Press, 2000), 32.

${ }^{203}$ John de la Mothe, $2000,31$.

${ }^{204}$ John de la Mothe, 2000, 32. 
take the more positive line that government research bodies were set up because they seemed to be the best answer to providing the stimulus needed to promote the priority aims and options defined by governments."205

The question that we are still grappling with is what should the role of government labs be? The result of recent Science and Technology policies is a new pressure placed on government labs to become market sensitive and serve commercial innovation goals. ${ }^{206}$ To serve commercial innovation goals, government labs need to collaborate more with private industry, to insure that more emphasis is placed upon the end-users needs. ${ }^{207}$ As such government labs can be sure that the products they are producing are wanted by industry. This momentum has been accelerated by a decline in the performance of S\&T by the federal government since the early 1980 's. ${ }^{208}$ This has been coupled with an increase in research in the private and university sector.

Government-performed science and technology remains important, and government labs are cast as catalytic players whose purpose is to foster commercial innovation and economic development. ${ }^{209}$ Although, the more responsive to commercial needs the labs become the more of a tension it creates for the labs in meeting public good goals. "Society does not expect private sector labs to behave like their public sector counterparts. Nor should it expect public sector labs to behave like private sector organizations." 210

\footnotetext{
205 OECD, 1989, 33.

${ }^{206}$ Bruce Doern and Jeff Kinder, in press, 31.

207 OECD 39.

208 John De la Mothe, 2000, 31.

${ }^{209}$ Bruce Doern and Jeff Kinder, in press, 1.

210 The Impact Group, 1999, 27.
} 
One general shortcoming of Science and Technology Policy is that government labs are rarely studied/considered as institutions. ${ }^{211}$ Unfortunately, S\&T policy often groups labs by sector (government, university or industry), using stereotypes of roles of labs in each sector. ${ }^{212}$ Crow and Bozeman's experience indicates that R\&D laboratories are very diverse organizations with unique cultures, different technical capabilities, organizational structure, resources, market interaction, political and bureaucratic environment, and adaptability. ${ }^{213}$ While Crow and Bozeman were discussing studies of American labs, Doern and Kinder argue that this assessment is relevant to Canada, as it is important for S\&T policy frameworks to consider the diverse and changing configurations of government research laboratories. $^{214}$

In spite of these shortcomings, the question of how best to organize the government's research infrastructure remains. "The government of Canada had put in place an impressive knowledge infrastructure consisting of a network of federal laboratories, testing establishments, survey groups, and the like, at the same time there was a growing question of how best to organize for science given the available resources." 215 Part of the answer to the question lies in how much responsibility the government wants to take to organize and shape the overall innovative framework. ${ }^{216}$

\footnotetext{
${ }^{211}$ Michael Crow and Barry Bozeman, 1998, 5.

${ }^{212}$ Bruce Doern and Jeff Kinder, in press, 5.

213 Crow and Bozeman, 1998, 5.

${ }^{214}$ Bruce Doern and Jeff Kinder, in press, 6.

215 John De la Mothe, 2000, 32.

${ }^{216}$ Christopher Freeman and Luc Sote, The Economics of Industrial Innovation (Cambridge: MIT Press, 1997), 190.
} 


\section{National Systems of Innovation}

One possible way to move forward S\&T and innovation policy is through the organization of research institutions into a network, sometimes called a "national system of innovation". A national system of innovation can be defined as "...the complex network of agents, policies and institutions supporting the process of technical advance in the economy." ${ }^{217}$ The components of this system include industry, universities and government labs. ${ }^{218}$ Its focus can be narrow or wide. The narrow focus is on organizations and institutions directly involved in the process of scientific and technology research. A broader perspective includes these and other political, economic and social institutions affecting these activities. ${ }^{219}$

Even without an "official" national system of innovation, Canada's government labs are part of a network of other government labs, universities and industry. "Within the complex institutional jigsaw puzzle that makes up the research system in OECD countries, the government research establishments act as a link, an intermediary, between the field of science and knowledge, the social and economic field, and the policymaking and regulatory field." 220 The point of a national system of innovation should be to encourage linkages and collaboration amongst various players to put scarce resources such as funding and information to the best possible use. In this way, government labs could be seen to make a more a more visible, effective and systematic contribution to innovation and the technological development of the economy. ${ }^{221}$

\footnotetext{
${ }^{217}$ Crow and Bozeman, 1998, 42.

${ }^{218}$ Donald Mcfetridge, "The Canadian System of Industrial Innovation" in National Innovation Systems: a comparative analysis Richard Nelson, Editor, (New York: Oxford University Press, 1993), 299.

${ }^{219}$ Crow and Bozeman, 1998, 42.

${ }^{220}$ OECD, 1989, 33.

${ }^{221}$ OECD, 1989, 37.
} 
For the network (system) to be successful, it is necessary to understand the institutional design of government laboratories, and the roles they play in the national and regional systems of innovation. ${ }^{222}$ To increase chances for success, it would seem that all players in the system should work together to achieve clearly defined and agreed upon outcomes. "The importance of the interaction is that it makes an innovation system more than the sum of its parts. Each organization contributes to the effectiveness of the others." 223 Unfortunately not all of the potential players in this system appear to have the same desired outcomes, and can even have difficulty working together. ${ }^{224}$

A recent study by Bruce Doern and Richard Levesque ${ }^{225}$ examines innovation in the National Research Council (NRC), bringing together three levels of analysis: hierarchies; markets; and networks. ${ }^{226}$ Their findings indicate that in the last ten years NRC has changed on all three levels. Examined under the hierarchy lens, the NRC has changed as: a corporate entity; a budgetary system; a system of personnel management and finally as a set of rules and procedures related to innovation. As a network, internally the NRC has been an organization of networks for a long time. NRC also comprises part of regional and national networks of innovation. Markets have had an influence on the NRC, and it now operates with more importance attached to partnerships with business and intellectual property rights and strategies. ${ }^{227}$

Within literature looking at government labs, we have identified a few shortcomings. First, relatively few studies deal directly with innovation. The literature

\footnotetext{
${ }^{222}$ Bruce Doern and Jeff Kinder, in press, 28.

${ }^{223}$ Donald McFetridge, 1993, 299.

${ }^{224}$ OECD, 1989, 65.

${ }^{225}$ Bruce Doern and Richard Levesque, 2002, 26.

${ }^{226}$ Hierarchies are defined in the classical bureaucratic sense. Markets are modes of exchange within which goods and services are traded voluntarily. Networks involve exchanges of information and support.

${ }^{227}$ Bruce Doern and Richard Levesque, 2002, 151-153.
} 
describes factors that would seem to be relevant to innovation in government labs, but have not been discussed in that context. An example of this kind of factor that we will study in this dissertation includes political interest and direction. Political interest and direction are described as a difference between the public and private sector, yet its extent and effect on innovation in government labs is unknown. Our contribution will be to take factors found in government lab literature and refine them to study innovation, and offer primary qualitative and quantitative research on its extent and impacts.

Second, studies of innovation in the public sector tend to be case studies, and few provide empirical evidence. Many focus on government programs as the unit of analysis, rather than on individuals, or the institution (Agency, Department, Lab, etc.) Their evidence may not be appropriate to extrapolate, and it is unclear how well government labs are described by these findings. Finally, our literature review also discovered that few studies look at innovation in Canadian government labs.

While the literature identifies many institutional factors that may be related to innovation, we have narrowed the list to four main analytical themes including: publicness; political direction and interest; recognition and rewards preference; and work environment. Publicness refers to the degree of external control or influence exerted by governmental actors." 228 Publicness encompasses the concepts of: funding (including cost recovery/sharing) and market influence. Publicness was chosen because it lies at the heart of the institutional factors effecting innovation in government labs: the tensions that arise from cost recovery/sharing; the uneasiness between private and public funding; and the balance between public and private goods.

${ }^{228}$ Michael Crow and Barry Bozeman, 1998, 109. 
Political interest and direction, and work environment were chosen because they represent factors found in the literature that can be expanded to describe innovation in government labs. Recognition and rewards preference was chosen because it has been a popular subject in both public administration and private sector focused literature, although recognition has not to the best of our knowledge been applied to the study of innovation in government labs. All institutional factors we are looking at were identified in the literature as important. ${ }^{229}$ We begin by looking at the concept of publicness.

There is a significant amount of literature devoted to institutional innovation in the private sector, with the firm as the unit of analysis. Our task is to see if any of the concepts identified in the private sector literature might be useful to include in our study of government labs. As Richard Wolfe notes, "[f]ew issues have been characterized by as much agreement among organizational researchers as the importance of innovation to organizational competitiveness and effectiveness. ${ }^{, 230}$ However, while public organizations may be encouraged by clients and elected overseers to be more efficient or effective, they do not usually face competition, and are therefore rarely forced to abandon familiar routines. ${ }^{231}$ Theoretically a lack of competition could inhibit innovation, although how it relates in practice is unclear. ${ }^{232}$

The motivation for private sector organizations to innovate is theorized to come from the search for competitive advantage to increase profit or market share. What happens in the public sector where these are not necessarily motivations? First, one must

\footnotetext{
${ }^{229}$ Other institutional factors such as size and centralization were also identified as potentially important, but it was not clear how they could be measured or their relationship to innovation.

${ }^{230}$ Richard Wolfe, May 1994, 405.

231 Alan Altshuler, Fall 1997, 1.

232 James Perry and Hal Rainey, "The public-private distinction in organization theory: a critique and research strategy," in Academy of Management Review Vol 13, no. 2 (1988), 191.
} 
define what one means by the public sector. Most studies follow the "core" perspective, which "...implies that there are essential differences between public and private organizations and those differences are elegantly captured in a simple distinction based on legal type (government owned vs. privately owned)."233 Based upon this distinction, one major theoretical difference is that the public sector values are aimed at consensus while private sector values are aimed at profit. ${ }^{234}$

Although profits are required for businesses to exist, they may not be the only objective. Other advantages of business activities include: products; services; employment; and all of the 'hidden hand' effects of community and social contribution. ${ }^{235}$ A less positive interpretation of the private sector suggests, "firms produce abundant examples of waste, inefficiency, blundering, and fraud, even in the most reputable and admired firms. This raises the issue of whether market exposure actually causes business firms to perform more effectively than non-market government agencies." 236

The disadvantage of the core approach is that it does not handle exceptions, such as government labs, which can be both privately and publicly funded. To correct this shortcoming, the "dimensional" approach suggests an organization can be a mix of private or public to varying degrees - some organizations are "more public" than others. ${ }^{237}$ The dimensional approach is better suited to study government labs, since they are publicly owned, but no longer wholly funded by taxpayer. As Doern and Kinder

\footnotetext{
${ }^{233}$ Barry Bozeman and Stuart Bretschneider, "The Publicness Puzzle in Organization Theory: A Test of Alternative Explanations of Differences Between Public and Private Organizations," in Journal of Public Administration Research and Theory Vol 4, no.2 (April 1994), 198.

${ }^{234}$ Michael Murray, "Comparing Public And Private Management: an exploratory essay," in Public Administration Review (July/August 1975), 365.

${ }^{235}$ Michael Murray, 1975, 365.

${ }^{236}$ Hal Rainey and Paula Steinbauer, 1999, 7.

${ }^{237}$ Barry Bozeman and Stuart Bretschneider, April 1994, 199.
} 
caution, government laboratories have not been properly examined as real functioning institutions in any thorough manner. They tend to be examined through the general rubric of the basic dichotomy between the public and private sector. ${ }^{238}$

\section{Institutional Theme 1: Publicness; Profit and Cost Recovery}

While public sector organizations may not be required to make a profit, "cost recovery" may act to encourage innovation. The federal government's 1990's Program Review continued earlier efforts to encourage federal institutions to: streamline programs; reduce costs; increase efficiency; and improve accountability. ${ }^{239}$ Government labs are required by Parliament to show fiscal responsibility. Without a yardstick like profit, it may be difficult to show that innovations can be effective. This makes departures from current practice difficult and controversial, regardless of potential efficiencies. ${ }^{240}$

It is misleading to say that the public sector has no profit objective. Cost benefit analysis is used in the public sector, and efficiency in government is often discussed. ${ }^{241}$ Cost benefit analysis can be difficult, as costs are usually immediate, while benefits, if known, could accrue several years in the future. "Furthermore, because public programs are largely funded by individuals who do not receive the direct benefit of these programs, there is a demand for equity, accountability, and responsiveness, in addition to a demand

\footnotetext{
${ }^{238}$ Bruce Doern and Jeff Kinder, "Federal government laboratories as complex institutions: the changing mix of hierarchies, networks and markets," (Not published, March 2001), 44.

${ }^{239}$ Natural Resources Canada, "NRCan's S\&T Management Framework", (March 1996), accessed at the NRCan Website, December 2001, [http://www.nrcan.gc.ca/dmo/scitech/documents/stmf/stfm_e.html], page 1.

${ }^{240}$ Alan Altshuler, 1997, 1.

${ }^{241}$ Michael Murray, 1975, 365.
} 
for economic efficiency." ${ }^{242}$ Expenses must be kept in check, and sometimes full or partial costs recovered. Many government labs want to make a small surplus, if it can be used to fund new activities, or to grow in size and scope. ${ }^{243}$

The purpose of cost recovery is: "[t]o shift the cost from taxpayers at large to the users who benefit most directly from the S\&T activities. ${ }^{244}$ There are many different types of cost recovery, from full-cost pricing, direct reception and retention of generated revenues or recovered costs, to multi-year financing of major projects. The revenue stream comes from full or partial cost recovery, the sale of products and intellectual property licenses. Cost recovery works where the public and private sectors have common needs, and where collaborative arrangements are beneficial and consistent with the public good. ${ }^{245}$

While in principle government labs have to respond to cost-recovery imperatives, the level of cost-recovery is not the same in all labs. "The diversity of government laboratories undercuts stereotyping. Some government laboratories pay little heed to prospects for commercial benefit but others provide $R \& D$ products designed for short term transfer to private developers. ${ }^{, 246}$ Cost recovery and commercialization attempts "can tip the balance away from targeted basic research towards short term commercial

\footnotetext{
${ }^{242}$ Bradley Wright, "Public-Sector Work Motivation: A Review of the Current Literature and a Revised Conceptual Model," in Journal of Public Administration Research and Theory Vol 11, no. 4 (October 2001), 567.

${ }^{243}$ Robert K. Yin, "Production Efficiency Versus Bureaucratic Self-Interest: Two Innovative Processes?" in Policy Sciences Vol 8, (1977), 388.

${ }^{244}$ Natural Resources Canada, "Compendium of science and Technology Management Practices," NRCan website, accessed January 2002, [http://www.nrcan.gc.ca/dom/scitech/documents/compendium/ compen_e.html], page 36 .

${ }^{245}$ Natural Resources Canada, "Framework for revenue Generation, external funding and collaborative activities", NRCan website, accessed March 2003, [http://www.nrcan.gc.ca/dmo/scitech/revgen/ revgen_e.htm], page 6 .

${ }^{246}$ Michael Crow and Barry Bozeman, "A new typology for R\&D Laboratories: implications for policy analysis," in Journal of Policy Analysis and management Vol 6, no. 3 (1987), 329.
} 
research, which is best suited to the private sector., ${ }^{247}$ To maintain the balance, government has looked to partnerships to produce funding and expertise, and defray risk. Partnerships can yield many benefits, such as expediting knowledge transfer and the commercialization of research results. ${ }^{248}$

Relationships with industry allow the lab to complete their public funding, but may force an adaptation of research themes to these relationships. ${ }^{249}$ The implication of these linkages is that the public's confidence in the independence of government science and the protection of the public interest could be compromised. Support for industrial innovation can create tension with other public good roles of government science. ${ }^{250}$ Federal laboratories have always had to strike a balance between the public and private good, ${ }^{251}$ however, cost recovery imperatives might shift the balance too far towards the private good. Labs want to ensure the maximum economic and social return on investment, however "... a pressing priority in a global knowledge-based economy is to capitalize on new, marketable technology by lifting it out of federal laboratories and into the commercial realm of everyday use." 252 This is clearly a signal that research commercialism is important and desirable.

Based upon the literature, one of our overall research questions related to publicness as an institutional factor is: does cost recovery/sharing have an impact on innovation in the lab? To answer this question, we first need to find out how

\footnotetext{
${ }^{247}$ Jacek Warna, November 1999, 3.

248 Jeff Kinder, 2003, 218.

${ }^{249}$ P.B. Joly and V. Mangematin, "Profile of public laboratories, industrial partnerships and organization of R\&D: the dynamics of industrial relationships in a large research organization," in Research Policy Vol 25 , (1996), 902.

250 Jeff Kinder, 2003, 218.

${ }^{251}$ Federal Partners in Technology Transfer, Report on Activities Spring 1999 to Spring 2000 (Ottawa:

Public Works and Government Services Canada, 2002), 22.

${ }^{252}$ Federal Partners in Technology Transfer, Annual Report 2001-02 Building Technology Transfer

Capacity in Federal Laboratories (Ottawa: Public Works and Government Services, 2002), 10.
} 
important cost recovery/sharing is to the lab, and second if there are any impacts on innovation. If we only measure impacts of cost recovery/sharing without knowing its importance, we might mistakenly assume causality. In other words, impacts may turn up even in labs where cost recovery is less important and may be absent in labs where cost recovery/sharing is very important. We need to know the importance of cost recovery/sharing before we can measure its effects.

Cost recovery sharing is itself a political intervention, and since it is a departmental goal, all three labs in our study will have some levels of cost recovery/sharing. We will use two measures to determine if cost recovery/sharing is important, and identify to what extent there are differences between the labs. First, if it is a priority, the evidence we expect to find is: cost recovery/sharing and partnerships are identified in the lab's mandate or documentation. If cost recovery/sharing appears, this is one measure that cost recovery/sharing is important, if not it is an indication it is less important. Second, another measure of the importance of cost recovery/sharing is the percentage of the lab's total budget that comes from private funding.

Michael Crow and Barry Bozeman ${ }^{253}$ created a matrix to measure what they described as the "publicness" of a lab. This included looking at the percentage of financing that comes from private sources, as well as the types of products the lab produces. We will use financial information to determine the percentage of government financing of the laboratory's total budget to measure the publicness of a lab. This assumes government financing equates to some extent with public influence. Crow and Bozeman divide the results of the percentage of research funded by the government into three categories of publicness: high (76-100\%), moderate (26-75\%) and low (0-25\%).

${ }^{253}$ Michael Crow and Barry Bozeman, 1987, 330. 
Our preliminary examination of financial evidence from the labs suggests that to compare the labs in our study we will use Crow and Bozeman's concept, but modify their scale. If the percentage of financing from non-government sources is above fifteen percent, cost recovery/sharing is very important, if it is between ten to fifteen percent it is important, and below ten percent it is less important.

We will take the results of our two measures and consider them together to make a judgment on the importance of cost recovery in the lab. While mandates are important, we will put more emphasis on the financial information in the rating of the importance of cost recovery in the lab. For example, if Lab A has cost sharing/ recovery identified in its mandate or documentation, and above fifteen percent of the budget comes from private sources, we will judge that cost recovery is very important in this lab.

If in Lab B, cost recovery/sharing is not identified in the mandate or documentation, but between ten to fifteen percent of the budget comes from private sources, cost recovery/sharing imperatives can be identified as important. If cost sharing/ recovery are not in the mandate or documentation and if less than $10 \%$ of the lab's total budget comes from private sources, cost sharing/recovery imperatives can be described as less important. A focus group will give us a perspective as to the importance of cost recovery/sharing and will describe if the funding source (public or private) has an impact on innovation.

\begin{tabular}{|l|c|c|}
\hline $\begin{array}{c}\text { Description of cost } \\
\text { recovery/ sharing } \\
\text { importance }\end{array}$ & $\begin{array}{c}\text { Cost recovery/sharing } \\
\text { identified in mandate or } \\
\text { documentation? }\end{array}$ & $\begin{array}{c}\text { Percentage of budget } \\
\text { from private sources }\end{array}$ \\
\hline Very Important & Yes & Above $15 \%$ \\
\hline Important & Yes & Between $10 \%-15 \%$ \\
\hline Less Important & No & Less than $10 \%$ \\
\hline
\end{tabular}


To this point, we have described how we will identify the importance of cost recovery imperatives in the lab. While cost recovery imperatives have been discussed in government lab literature, it tends to be at a theoretical level and evidence seems to be limited to case studies. To the best of our knowledge, the importance of cost recovery in Canadian federal government labs has not been described before. Our contribution is to provide more concrete evidence of the extent of cost sharing/recovery. Cost recovery may be very important in some labs, and unimportant in others. However, we have not yet answered the question: is cost recovery/sharing having an impact on innovation in the $l a b$ ?

To find the impact cost recovery is having on innovation, we identified two potential effects. First, cost recovery/sharing is expected to influence the products that the lab produces. Crow and Bozeman identify the level of "market influence", measured by the extent to which the product is appropriable. There are three levels of market influence on a lab: little market influence; where the principal output is for the public good; balanced: (market and non market products) and proprietary (heavy market influence). ${ }^{254}$ We will use lab documentation and focus groups to determine the mix of goods, and ask what effects market influences have on the balance between the public and private goods? We make the following hypotheses:

\begin{tabular}{|l|l|}
\hline Hypothesis 10: & $\begin{array}{l}\text { In a lab where cost recovery/sharing is very important, it will } \\
\text { produce more balanced/ proprietary innovations, to serve cost } \\
\text { recovery imperatives. If cost recovery/sharing is less important, we } \\
\text { expect to see more public good innovations. }\end{array}$ \\
\hline Hypothesis 11: & $\begin{array}{l}\text { In labs where cost recovery is important, the main impact of an } \\
\text { implemented innovation would be financial, and there is more } \\
\text { advocacy to the private sector than in labs where cost } \\
\text { recovery/sharing is less important. }\end{array}$ \\
\hline
\end{tabular}

${ }^{254}$ Michael Crow and Barry Bozeman, 1987, 336. 
For hypothesis 10 , the logic is that if cost recovery is very important, the lab's output of innovations will be balanced towards proprietary products to be sold (shared) with the private sector, and less innovations for the public good. In a lab where cost recovery is less important we expect more goods produced for the public good. It is important to note that all labs produce some proprietary, balanced and public goods.

Related to hypothesis 11 , financial impacts of innovations would seem to be more important where the lab was strongly motivated to recover or share money from its innovations. Similarly, in labs where cost recovery/sharing is very important, advocacy would be directed towards industry clients who have the funds available to finance innovations. At this point, we have identified measures of the extent of cost recovery and its potential impacts. Combining the two dimensions, and comparing the results for each lab should allow us to describe the impact that cost recovery/sharing is having on innovation in the labs.

We have introduced the concept of publicness and outlined our study of it through cost recovery/ sharing, identifying its importance to the lab and its potential effects. Government labs are faced with shaping a future balancing basic research for the public good, with producing marketable innovations. They have no profit motive in the private sector sense, yet due to budgetary and political pressure, they are often required to recover (all or some) costs. They occupy a middle ground, as they are not completely public organizations, nor are they private. They have to work in partnership with industry, yet advance public policy goals. The interplay of these forces makes government labs interesting to study. In the next section, we examine political direction and interest. 


\section{Institutional Theme 2: Political Direction; Interest and Innovation}

Our second theme relates to political direction and interest in government labs. One difference between government labs and private firms is in political direction and interest, “...reflected in their differing political influences, degree of market exposure, and public scrutiny, as well as in their internal structures and organizational processes." 255 Political influences are important because innovations can be "... undermined by decisions made by senior executives and ministers - i.e. the rug can be pulled from under projects at any time.,"256 Successfully innovating public sector organizations seemed to be less worried about political interference in the day-to day operations. ${ }^{257}$ Unlike private enterprise, reasons for quashing innovation in the public sector may not be related to the probability of success or profitability, but rather politics. A ban on cloning research in American government labs is an example.

Political direction also involves the balancing of multiple vague, and sometimesconflicting goals and priorities set by political officials outside the lab. ${ }^{258}$ This makes priority setting and planning difficult. ${ }^{259}$ Even when priorities and goals are clear, timelines are often short, while institutional responses can be long. ${ }^{260}$ However, while scholars agree the public sector faces difficulty in balancing goals, how this affects innovation is unclear ${ }^{261}$ and it is hard to say how such observations should be tested

\footnotetext{
${ }^{255}$ Fariborz Damanpour and William Evan, "Organizational Innovation and Performance: The Problem of Organizational Lag," in Administrative Science Quarterly Vol 29, (1984), 407.

${ }^{256}$ Donald Hall, "You've got to conform to create: the implications of corporate culture on innovation in the Canadian Federal Public Service," in The Innovation Journal (Feb 2002), 6.

${ }^{257}$ Peter Buker, 2003, 66.

${ }^{258}$ Hal Rainey and Paula Steinbauer, 1999, 20.

${ }^{259}$ Myron Fottler, "Is Management Really Generic," in Academy of Management Review Vol 6, no. 1 (1981), 10.

260 Joseph Bower, "Effective public management," in Harvard Business Review (March-April 1977), 137.

${ }^{261}$ Hal Rainey, "Public Agencies and Private Firms Incentive Structures, Goals and Individual Roles," in Administration and Society Vol 15, no. 2 (August 1983), 213.
} 
empirically. We decided to use a qualitative method of asking our focus groups to use a low to high scale to describe the political direction in the lab. Low represents little political direction and high represents a lot of political direction.

Another dimension of political direction is oversight. Effective agencies will have oversight authorities that are supportive, delegative, and attentive to agency mission accomplishment, and emphasize effective performance. Yet the authorities also will tend to be supportive, providing resources and authorization necessary to support good performance. ${ }^{262}$ Recent research about successful Canadian public organizations identifies that while they were subject to a "head office", they attributed part of their innovative success to the freedom they had from direct political direction. This was especially true in Ottawa, where it was perceived that too much time and effort was spent dealing with political issues, protecting the minister and avoiding mistakes. ${ }^{263}$ Although we studied it in its own section, it is also clear that cost recovery is itself a political intervention. To measure political direction, we will ask focus groups if innovations are scrutinized, delayed, or stopped (promoted) by political figures such as a Minster, Assistant or Deputy Minister, or Standing or Senate Committees, etc.

Political interest is related to political direction. As a part of a federal department, government labs should expect some interest, such as requests for site visits, briefings, briefing notes and materials, questions in the House of Commons/Senate, Standing or Senate Committee, etc. from political figures. ${ }^{264}$ Political interest could be either a promoter or an inhibitor of innovation. Political interest could enhance a lab's ability to innovate if the interest led to increased funding or regulatory changes to accomplish

\footnotetext{
${ }^{262}$ Hal Rainey and Paula Steinbauer, 1999, 14.

${ }^{263}$ Peter Buker, 2003, 66.

${ }^{264}$ Minister, Member of Parliament, Deputy Minister, etc.
} 
innovative goals. On the other hand, political interest could mire the lab and its innovation in political wrangling and prevent the advancement of the innovation. We will ask focus groups to rate the level of political interest in the lab on a low to high scale, with low representing little political interest in their lab and high representing lots of political interest in their lab.

To capture political interest and direction together, our contribution is to create a new matrix, which provides a high level overview of political interest and direction, to capture the relative differences, if any, between the labs.

Political Interest

\begin{tabular}{|l|c|c|c|}
\hline \multicolumn{1}{|c|}{ Political Direction } & $\begin{array}{c}\text { Low } \\
\text { interest in } \\
\text { lab's activities } \\
\text { and outputs }\end{array}$ & $\begin{array}{c}\text { Medium } \\
\text { interest in } \\
\text { lab's activities } \\
\text { and outputs }\end{array}$ & $\begin{array}{c}\text { High } \\
\text { interest in } \\
\text { lab's activities } \\
\text { and outputs }\end{array}$ \\
\hline $\begin{array}{l}\text { Little direction in lab's activities. Innovations are } \\
\text { not often scrutinized, delayed, or stopped } \\
\text { (promoted) for political reasons. }\end{array}$ & & & \\
\hline $\begin{array}{l}\text { Medium } \\
\text { Some direction in lab's activities. Innovations are } \\
\text { sometimes scrutinized, delayed or stopped } \\
\text { (promoted) for political reasons. }\end{array}$ & & & \\
\hline $\begin{array}{l}\text { High } \\
\text { Lots of direction in lab's activities. Innovations } \\
\text { are often scrutinized, delayed or stopped } \\
\text { (promoted) for political reasons. }\end{array}$ & & & \\
\hline
\end{tabular}

We will ask focus group participants to place their lab on this matrix, and we will describe our results in chapter three.

Political interest and direction can also come from media attention. One of the primary concerns of most civil servants is to avoid negative publicity for the Minister or the Department. Innovation can be dangerous because a new process or service that fails can attract attention. “...[A] paramount dread of government officials is newsworthy failure. Old programs may be inadequate, but their familiarity insulates them from much 
media attention. Even when they do attract scrutiny, responsible officials can plausibly defend themselves with the argument that they have simply been following standard practice. ${ }^{265}$ Because of this pressure, it is possible that innovation is more risky for the bureaucrat than for the entrepreneur, ${ }^{266}$ although recent case studies of successful Canadian public organizations have found that when innovations failed, they were viewed as learning experiences. ${ }^{267}$ Perhaps not surprisingly, as negative publicity can be detrimental to an organization, positive publicity can help. ${ }^{268}$ We will ask focus group participants if their lab or innovations have received media attention. In the next section we look at recognition and rewards.

\section{Institutional Theme 3: Recognition and Rewards Preference}

The third theme we will examine relates to recognition and rewards preferences of innovators. What motivates people is important, to the point that it is identified as one of the "big" questions of public management. ${ }^{269}$ Public sector organizations will not achieve their goals if employee motivation is low. ${ }^{270}$ There are two types of motivations: intrinsic and extrinsic, which may be related to innovation. Other than knowing that people are differently motivated, why might we want to differentiate between the two types of motivation? Some reasons are to understand and predict behavior. ${ }^{271}$ A great

\footnotetext{
${ }^{265}$ Alan Altshuler, 1997, 1.

${ }^{266}$ Victor Thompson, 1968, 5.

${ }^{267}$ Peter Buker, 2003, 63.

${ }^{268}$ Hal Rainey and Paula Steinbauer, 1999, 15.

${ }^{269}$ Robert Behn, "The Big Questions of Public Management," in Public Administration Review Vol 55, no. 4 (July/August 1995), 315.

${ }^{270}$ Monica Belcourt and Simon Taggar, Making Government the Best Place to Work: Building Commitment (Toronto: IPAC, New Directions, No 8, 2002), vii.

${ }^{271}$ Teresa M. Amabile, Karl G. Hill, Beth A. Hennessey and Elizabeth M. Tighe, "The Work Preference Inventory: Assessing Intrinsic, Extrinsic Motivational Orientations," in Journal of Personality and Social Psychology Vol 66, no. 5 (1994), 951.
} 
deal of social psychological research has documented striking differences in task performance between intrinsically and extrinsically motivated individuals. ${ }^{272}$

As this is not a dissertation in psychology, we will look at motivation in terms of rewards preferences related to a successful innovation. This is not meant to be a proxy for motivation. We are interested to find out if there are differences in rewards preferences of innovators/non-innovators and champions/non-champions.

\section{Intrinsic and Extrinsic Motivation}

What is intrinsic motivation? "One is said to be intrinsically motivated to perform an activity when he receives no apparent rewards except the activity itself. This intrinsic motivation might be either innate or learned."273 It can also be related to personal satisfactions ${ }^{274}$ including: challenge; enjoyment; personal enrichment; interest; and self-determination. ${ }^{275}$ Intrinsic factors are associated with work itself such as craftsmanship, and frequently for the sake of personal satisfaction. ${ }^{276}$ Empirical evidence on R\&D professionals has shown that intrinsic rewards are held in high regard and that extrinsic motivators such as individual rewards are less important, or may even be viewed as counterproductive tools for motivation. ${ }^{277}$ This research has confirmed, “....it's the

\footnotetext{
${ }^{272}$ Teresa M. Amabile, Karl G. Hill, Beth A. Hennessey and Elizabeth M. Tighe, 1994, 951.

${ }^{273}$ Edward L. Deci, "Effects of externally motivated rewards on intrinsic motivation," in Journal of Personality and Social Psychology Vol 18, (1971), 105.

${ }^{274}$ Edward E. Lawler and Douglas Hall, "Relationship of job characteristics to job involvement, satisfaction, and intrinsic motivation," in Journal of Applied Psychology Vol 54, no. 4 (1970), 311.

${ }^{275}$ Teresa M. Amabile, Karl G. Hill, Beth A. Hennessey and Elizabeth M. Tighe, 1994, 951.

${ }^{276}$ William M. James, "Best HR Practices for today's innovation management," in Research Technology Management (January-February, 2002), 58.

${ }^{277}$ Chao Chen, Cameron Ford and George Farris, "Do Rewards Benefit the Organization? The Effects of Reward Types and the Perceptions of Diverse R\&D Professionals," in IEEE Transactions on Engineering Management, Vol 46, no. 1 (February 1999), 49.
} 
work that motivates technologists and researchers to an ever-higher level of

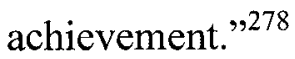

Intrinsic motivation also arises from the desire to solve a problem. For the intrinsically motivated, the satisfaction of finding a solution encourages them to work on a project. This links to innovation, because the innovative process often begins as a search for a solution to a problem. "Because a positive sense of challenge in the work is one of the most important predictors of creativity, it is imperative to match people to work that utilizes their skills, stretches their skills, and is clearly valued by the organization." ${ }^{279}$ It is the intellectual stimulation and excitement of seeing ideas turned into action that motivate some. ${ }^{280}$

An organization can influence intrinsic motivation by setting up a rewards system that mixes internal motivations, such as the opportunity to pursue one's own ideas, with promotions and recognition. ${ }^{281}$ Intrinsically motivated employees can be assigned to work on interesting problems, which necessitate creativity and resourcefulness. ${ }^{282}$ Motivation can also come from access to important equipment and facilities. The ability to work on a specific piece of equipment, especially if it is rare or "state of the art" may provide a motivation to innovate. These capitalize on intrinsic motivation and can lead to increased innovation. The motivation of employees should be of key importance, as

\footnotetext{
${ }^{278}$ William M. James, 2002, 58.

${ }^{279}$ Teresa Amabile, 1997, 55.

${ }^{280}$ Thomas Davenport, Laurence Prusak and James Wilson, February 2003, 63.

281 Jay Galbraith, Winter 1982, 19.

${ }^{282}$ Edward Deci, "The Effects of Contingent and Noncontingent Rewards and Controls on Intrinsic Motivation," in Organizational Behavior and Human Performance no. 8 (1972), 218.
} 
"[e]fforts to improve the performance of government organizations hinge in part on the ability to successfully motivate public employees. $" 283$

Extrinsic differs from intrinsic motivation because it focuses on benefits received by the actor that are not part of the task, but related to the attempted or successful completion of the job. Extrinsic motivation is described as "...the motivation to work primarily in response to something apart from the work itself, such as reward or recognition or the dictates of other people. ${ }^{, 284}$ In its extreme form, extrinsic motivation comes solely from rewards (money, fame, etc). Organizations use multiple extrinsic motivations to encourage employees to work harder and follow the rules. ${ }^{285}$ The difference between intrinsic and extrinsic rewards is that the former is inherent in the job, and the latter tends to be materialistic. ${ }^{286}$

Positive extrinsic motivations come in the forms of money, recognition and feedback, goal setting, flextime, job enlargement, job enrichment and participation. ${ }^{287}$ Extrinsic motivation is important for an organization, because incentives and rewards have a major impact on motivation and individual and group behavior. ${ }^{288}$ Many believe that rewards systems are powerful motivators ${ }^{289}$, and therefore, key to successful innovative behavior. ${ }^{290}$

\footnotetext{
${ }^{283}$ David Houston, "Public Service Motivation: A Multivariate Test," in Journal of Public Administration Research and Theory Vol 10, no. 4 (2000), 713.

${ }^{284}$ Teresa M. Amabile, Karl G. Hill, Beth A. Hennessey and Elizabeth M. Tighe, 1994, 950.

${ }^{285}$ William M. James, 2002, 58.

${ }^{286}$ Chao Chen, Cameron Ford and George Farris, 1999, 48.

${ }^{287}$ James Perry and Lyman Porter, "Factors Affecting the Context for Motivation in Public Organizations," in Academy of Management Review Vol 7, no. 1 (1982), 94.

${ }^{288}$ Thomas Kuczmarski, Innovation Leadership Strategies for the Competitive Edge (Chicago: NTC Business Books, 1996), 147.

${ }^{289}$ Michael Tushman and David Nadler, Spring 1986, 85.

${ }^{290}$ Benn Lawson and Danny Samson, September 2001, 393.
} 
One way to motivate innovators is to recognize and reward them. ${ }^{291}$ One key difference between the public and private sectors is that the private sector has more flexibility to reward innovators. It is generally agreed that no matter what progressive norms the public-sector embraces to support innovation, existing systems of financial compensation work against them by denying the one overt controllable factor. ${ }^{292}$

While the private sector has more flexibility to reward, some have found differences in the motivations of the individuals who work in each sector. ${ }^{293}$ As Brian Clegg points out many creative people are not involved in business for philosophical pleasure, but for reward. ${ }^{294}$ This may lead us to the conclusion that "profit-seeking firms are likely to be dominated by economic-orientated employees while public-service organizations, both public and non-profit are likely to be dominated by service orientated employees."295 Ran Lachman found that CEO's in the public sector were less satisfied with both their extrinsic rewards and their intrinsic rewards. ${ }^{296}$

This may be evidence of a public-service ethic. "...[S]ome individuals have strong norms and emotions about performing public service. This 'public service ethic' is thought to attract certain individuals to government service and foster work behaviors that are consistent with the public interest." 297 Compared with the private sector,

\footnotetext{
${ }^{291}$ Geoffrey Nicholson, "Keeping Innovation Alive," in Research Technology Management (May-June 1998), 3.

${ }^{292}$ Peter Buker, 2003, 70.

${ }^{293}$ Philip Crewson, "Public-Service motivation: building empirical evidence of incidence and effect," in Journal of Public Administration and Research Vol 7, no. 4 (October 1997), 16.

${ }^{294}$ Brian Clegg, Creativity and Innovation for Managers (Boston: The Institute of Management, 1999), 36.

${ }^{295}$ Philip Crewson, October 1997, 16.

${ }^{296}$ Ran Lachman, "Public and Private Sector Differences: CEO's Perceptions of Their Role Environments," in Academy of Management Journal (September 1985), 677.

${ }^{297}$ Gene Brewer, Sally Coleman Selden and Rex Facer, "Individual Conceptions of Public Service Motivation," in Public Administration Review Vol 60, no. 3 (May/June 2000), 254.
} 
government employees generally have been found to rate intrinsic rewards more highly ${ }^{298}$ than private sector workers, whereas private employees focus more on extrinsic rewards in the form of high pay, status and prestige, etc. ${ }^{299}$ However, other research has not found differences in motivation between the two sectors. ${ }^{300}$ These findings are not conclusive, as they are not entirely consistent and the causal direction remains uncertain. ${ }^{301}$

In lieu of money rewards, recognition may be more important in the public sector. The Canadian federal government "... has an award plan for inventors and innovators. The objective is to encourage public servants working in scientific and technological areas to commercialize their inventions. A second objective is to encourage these inventors to remain in the public service. ${ }^{, 302}$ This appears to be at odds with some government policies for encouraging spin off companies as a way of commercializing technologies that do not have a suitable receptor capacity in Canada. ${ }^{303}$ In the public sector, one usually has to apply to win an innovation award, and it is possible that the documentation of success will raise morale and improve team spirit. ${ }^{304}$ Other public sector evidence found that employee recognition programs, and rewards, all contribute to employee pride. ${ }^{305}$

Organizations are attracted to use recognition as an extrinsic motivator, since an awards program is relatively inexpensive to set up and can be repeated frequently.

\footnotetext{
${ }^{298}$ Mak Khojasteh, "Motivating the private vs. public sector managers," in Public Personnel Management Vol 3, (Fall 1993), 398.

299 David Houston, $2000,717$.

${ }^{300}$ James Perry and Lois Recascino Wise, "The Motivational Basis of Public Service," in Public

Administration Review (May June 1990), 368.

${ }^{301}$ Bradley Wright, October 2001, 566.

${ }^{302}$ Sandford Borins, "Public-service awards programs: an exploratory analysis," in Canadian Public Administration Vol 43, no. 3 (2000), 328.

${ }^{303}$ Federal Partners in Technology Transfer, 2002, 3.

${ }^{304}$ Sandford Borins, 2000, 333.

${ }^{305}$ Peter Buker, 2003, 69.
} 
Awards could motivate people to innovate, as it seems likely that both intrinsically and extrinsically motivated individuals would like recognition for accomplishments.

However, it is possible that the award may be more relevant to extrinsically motivated individuals because they may choose to work in an environment where there are extrinsic strong motivations such as rewards and money. ${ }^{306}$

While the literature discusses differences in motivations, it is unclear on how to measure these differences in the context of government labs. While we cannot identify respondents as intrinsically or extrinsically motivated, we can create a survey question to identify a respondent's rewards preference, related to a successfully implemented innovation. When asked if they played a major role in the development of an innovation that turned out to be successful, how they would prefer to be rewarded?

Respondents who identify rewards such as "formal recognition, name on the patent, monetary incentive, or an innovation award" are identifying an extrinsic rewards preference. Those who identify "no reward necessary, given time to work on their own research projects, informal recognition or new machinery or equipment" are identifying an intrinsic rewards preference.

Many theorists appear to treat intrinsic and extrinsic motivation as separate, distinct concepts, but are they completely exclusive? "The common implication is that the two work in opposition." ${ }^{307}$ There are reasons why this may in fact not be so. It is likely that at different times and circumstances, people act according to different motivations. An individual who is intrinsically motivated could also respond to extrinsic rewards, such as recognition. Individual creativity suggests a balance between

\footnotetext{
${ }^{306}$ Teresa M. Amabile, Karl G. Hill, Beth A. Hennessey and Elizabeth M. Tighe, 1994, 951.

${ }^{307}$ Teresa M. Amabile, Karl G. Hill, Beth A. Hennessey and Elizabeth M. Tighe, 1994, 952.
} 
commitment to a task, some freedom, some intrinsic rewards, but some extrinsic rewards as well. ${ }^{308}$

In their study on extrinsic incentives and performance, Arie Kruglanski, Irith Friedman and Gabriella Zeevi looked for differences in performance of differently motivated individuals, and found that intrinsically motivated individuals obtained superior performance in the absence of extrinsic incentives. ${ }^{309}$ Others such as Amabile have found that those who are primarily intrinsically motivated will be more creative than extrinsically motivated individuals, and are more strongly driven than others by the enjoyment and sense of challenge in their work. ${ }^{310}$ They will choose assignments that allow them to develop new skills, be creative and become involved in their work. ${ }^{311}$

This is not to say they are not paid, but their motivation stems from satisfactions not money or rewards. "If the goal is excellence, no artificial incentive can ever match the power of intrinsic motivation. People who do exceptional work may be glad to be paid, but they do not work to collect a paycheck. They work because they love what they do. ${ }^{9312}$ Some research indicates that intrinsically motivated people work harder, produce better quality work and are more creative. ${ }^{313}$ The motivation to engage in the work is primarily for its own sake because it is interesting or satisfying. The literature leads us to expect that innovators are intrinsically motivated. While we do not profess to be able to

\footnotetext{
${ }^{308}$ Victor Thompson, Bureaucracy and Innovation (Urbana Illinois, 1968), 11.

${ }^{309}$ Arie W. Kruglanski, Irith Friedman and Gabriella Zeevi, "The effects of extrinsic incentive on some qualitative aspects of task performance," in Journal of Personality Vol 39, (1971), 607.

${ }^{310}$ Teresa Amabile, Fall 1997, 40.

311 Teresa M. Amabile, Karl G. Hill, Beth A. Hennessey and Elizabeth M. Tighe, 1994, 951.

312 Alfie Kohn, "Why Incentive Plans Cannot Work," in Harvard Business Review (September-October $1993), 62$.

${ }^{313}$ Eleanor Glor, "Key factors influencing innovation in government," in The Innovation Journal (March 2001), 10.
} 
determine the motivations of respondents, we can identify their rewards preferences, related to successful innovation. In agreement with the literature, we hypothesize:

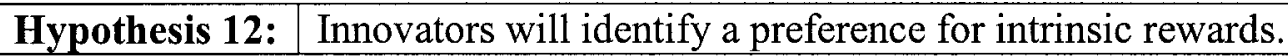

Those who win the award may be designated as "heroes". The purpose of designating a hero is to: make success attainable and human; provide role models; and motivate employees. ${ }^{314}$ By recognizing innovators as heroes, others may attempt to emulate their behavior, encouraging more innovation. John Storey found the idea of an individual hero innovator was popular among managers. ${ }^{315}$ However, the culture of some organizations will resist the creation of individual heroes. Some individuals resist recognition, perhaps because they are shy, or don't want the resentment of others. Also, heroes may emerge who have views contrary to those of management, or assume that their success places them above the rules or allows them to take unnecessary risks. ${ }^{316}$

Heroes recognized for individual behavior may undermine a team spirit, as other members who contributed to the innovation may feel unappreciated. ${ }^{317}$ William Fischer et al found that of competing product teams, surprisingly, the successful team had almost a $50 \%$ turnover rate because members felt they had not been adequately rewarded for their performance, while the losing team had a much smaller turnover rate. ${ }^{318}$ This conforms to Alfie Kohn's assessment: “...not receiving a reward one had expected to receive is also indistinguishable from being punished. Whether the incentive is withdrawn or withheld deliberately, or simply not received by someone who had hoped to

\footnotetext{
${ }^{314}$ Alan L. Wilkins, Lee Tom Perry, and Alan G. Checketts, "Please Don't Make Me A Hero: A ReExamination of Corporate Heroes," in Human Resource Management Vol 29, no. 3 (Fall 1990), 328.

315 John Storey, 2000, 362.

${ }^{316}$ Alan L. Wilkins, Lee Tom Perry, and Alan G. Checketts, Fall 1990, 329.

${ }^{317}$ Alan L. Wilkins, Lee Tom Perry, and Alan G. Checketts, Fall 1990, 334.

${ }^{318}$ William A. Fischer, Willard Hamilton, Curtis P. McLaughlin and Robert W. Zmud, May-June $1986,15$.
} 
get it, the effect is identical. And the more desirable the reward, the more demoralizing it is to miss out." 319

Awards can also create a problem if those who win are seen as "favorites" of management. This can create resentment among those who do not win. In the public sector, it was found that awards can have demoralizing consequences if they are given to the undeserving; and the message of an award given to the undeserving is that no effort is required for innovative work and results in cynicism. ${ }^{320}$ One-way to ensure the proper functioning of the awards system is for management to be scrupulously fair and transparent. Criteria used to determine awards winners should be known and generally agreed to. In sum, it is unclear how recognition relates to innovation, as people may want recognition, but if they do not receive it they may be de-motivated. Our contribution will be to find out through our survey and focus groups how innovation awards are perceived in government labs.

\section{Feedback}

Extrinsic motivation can also come in the form of feedback from supervisors and colleagues. Feedback is related to recognition, as positive feedback should function similarly to recognition as a motivator. Feedback could also be used in a continuous and a more (or less) formal way. Almost everyone likes being told that they are doing a good job. The purposeful use of positive feedback can help motivate intrinsically motivated

\footnotetext{
319 Alfie Kohn, September-October 1993, 58.

${ }^{320}$ Peter Buker, 2003, 69.
} 
individuals as well. ${ }^{321}$ Edward Deci's findings indicate that one who is intrinsically motivated and receives positive feedback will be more motivated to perform the task. ${ }^{322}$

Related to innovation, it appears that positive feedback, used sparingly, could be a major source of motivation and recognition related to innovation. ${ }^{323}$ As Brian Clegg notes: “... it can make a huge difference to ensure that a staff member gets appropriate recognition for creativity. This can range from a pat on the back and congratulations to making sure everyone knows just whose idea it was."324 Even intrinsically motivated individuals need encouragement. "Positive outcomes can also result from reward, recognition, and feedback that directly increase the person's involvement in the work itself... ${ }^{9325}$ A purposeful use of feedback towards the goals of innovation could spur on an individual and help overcome fear of promoting new ideas. "[I]nnovation leaders also have a responsibility to ensure that there is appropriate feedback on performance and its contribution to corporate success.",326

However, there are dangers in giving too much positive feedback as one may become dependant on it, leading to a decrease in motivation. ${ }^{327}$ Even if it did not decrease motivation, it is possible positive feedback loses its effectiveness with repeated use. It is also possible that feedback could only be positive when individuals conformed to existing methods of tackling problems or proposing ideas, which could decrease creativity.

\footnotetext{
${ }^{321}$ Greg Oldham, "The Motivational Strategies Used by Supervisors: Relationships to Effectiveness Indicators," in Organizational Behavior and Human Performance Vol 15, (1976), 67.

${ }^{322}$ Edward L. Deci, 1971, 108.

${ }^{323}$ Edward Roberts and Alan Fusfeld, Spring 1981, 31.

${ }^{324}$ Brian Clegg, Creativity and Innovation for Managers (Boston: The Institute of Management, 1999), 37.

${ }^{325}$ Teresa Amabile, 1997, 45.

${ }^{326}$ Alan Topalian, June 2000, 167.

${ }^{327}$ Edward Deci, 1972, 224.
} 
One empirical measure of feedback comes from the 2002 Canadian Public Service Survey ${ }^{328}$ which found that $68 \%$ of the public service respondents received useful feedback, and $30 \%$ did not. Other recent evidence suggests that "[e]mployees want to be recognized for their contributions. They want feedback on their performance, with employer discussions of their strengths and a pat on the back when performance merits it." ${ }^{329}$ As positive feedback is one of the few mechanisms that the public sector can use to motivate employees, there is likely positive feedback being given. We hypothesize:

\section{Hypothesis 13: $\quad$ Positive feedback is positively related to innovation.}

Feedback does not need to be positive to be a motivator. The threat of negative feedback could motivate employees, where a small amount of negative feedback could serve as a challenge. ${ }^{330}$ However, to avoid negative feedback, an employee could do the job to minimum standards. It is difficult to see how any significant amount of negative feedback could be positively related to innovation.

The critical component of extrinsic motivations seems to be the how an individual perceives the motivation. ${ }^{331}$ One may be motivated to perform effectively to the extent one believes that performance is important to achieving goals the individual sees as important. ${ }^{332}$ The effects of the different types of extrinsic motivations may not be the

\footnotetext{
${ }^{328}$ Public Service Survey 2002 Question 19. “ I receive useful feedback from my immediate supervisor on my job performance" Public service Survey website: [http://www.survey-sondage.gc.ca/] accessed January 2004.

${ }^{329}$ Monica Belcourt and Simon Taggar, 2002, 6.

${ }^{330}$ Edward Deci, 1972, 224.

${ }^{331}$ Teresa Amabile, William DeJong and Mark Lepper, "Effects of Externally Imposed Deadlines on Subsequent Intrinsic Motivation," in Journal of Personality and Social Psychology Vol 34, no.1 (1976), 97. ${ }^{332}$ Victor Vroom, "Ego-involvement, job satisfaction and job performance," in Personnel Psychology Vol 15, (1962), 173.
} 
same $\mathrm{e}^{333}$, different rewards can have different effects. In our survey, we examine how often feedback is received and how it is perceived.

In this section we have explored our third institutional theme of recognition and rewards preference. We looked briefly at intrinsic and extrinsic motivation, and questions to identify the rewards preference related to a successful innovation. We have also identified feedback and recognition as important motivators of innovation. In the next section, we examine our final institutional factor of work environment.

\section{Institutional Theme 4: Work Environment; Job Satisfaction and Involvement}

We will also examine how job involvement and satisfaction relate to innovation. Most people approach their jobs with a desire to have some responsibility, and interest in their work. Most like recognition for achievements, and many would like the opportunity to advance. "The attainment of these aspirations and expectations produces feelings of satisfaction. The lack of attainment, or the frustration of these objectives, causes people to be dissatisfied with their jobs." ${ }^{334}$ Job satisfaction is also a matter of degree where a person's work environment fulfills his or hers needs, the greater the job satisfaction. ${ }^{335}$ Job satisfaction may be determined by the extent to which self-evaluation is increased by high performance and decreased by low performance. ${ }^{336}$

Attempting to understand job satisfaction "... has been motivated by utilitarian reasons (e.g., increased productivity and organizational commitment, lower absenteeism and turnover, and ultimately, increased organizational effectiveness) as well as

\footnotetext{
${ }^{333}$ Edward L. Deci, 1971, 107.

${ }^{334}$ Paul Wernimont, "Intrinsic and extrinsic factors in job satisfaction," in Journal of Applied Psychology Vol 50, (1966), 49.

${ }^{335}$ Mark Ellickson, "Determinants of Job Satisfaction of Municipal Government Employees," in Public Personnel Management Vol 31, no. 3 (fall 2002), 344.

${ }^{336}$ Victor Vroom, 1962, 160.
} 
humanitarian interests ( i.e., employees deserve to be treated with respect and have their psychological and physical well-being maximized). ${ }^{.337}$ Canadian research has identified that continuous innovation requires an underlying sustained structure of happy employees. $^{338}$

There have been sporadic empirical comparisons of job satisfaction in the public and private sectors, but the results have been mixed. Dennis Organ may have an explanation: "[w]hen people answer questions about their satisfaction-with work, pay, supervision, promotion-they think about fairness. They compare what they might reasonably have expected and what they actually experience." ${ }^{, 339}$ Satisfaction may be relative rather than absolute. Some research has found that "on every significant dimension, no important differences were found between public and private sector managers. The two groups show virtually identical personality traits... ${ }^{340}$ Similarly, others have found bureaucrats were more energetic, less dependent, and no more power hungry than businessmen. ${ }^{341}$

Some research has found that the largest differences between the private and public sectors were in the satisfaction with rewards related to performance. Private sector managers were much more satisfied than public sector managers. ${ }^{342}$ Bruce Buchanan found that "[s]everal studies conducted in a variety of public and private organizations have displayed a striking consistency in results: business executives typically report more

\footnotetext{
${ }^{337}$ Mark Ellickson, 2002, 343.

${ }^{338}$ Peter Buker, 2003, 68.

${ }^{339}$ Dennis Organ, "The subtle significance of job satisfaction," in The Human Side of Managing Technical Innovation Edited by Ralph Katz, (New York: Oxford University Press, 1997), 22.

${ }^{340}$ James Driscoll, Gary Cowger and Robert Egan, "Private Managers \& Public Myths - Public Managers \& Private Myths," in Sloan Management Review (Fall 1979), 55.

${ }^{341}$ James Guyot, "Government Bureaucrats are Different," in Public Administration Review Vol 22, (1962), 202.

${ }^{342}$ Ester Solomon, "Private and Public Sector Managers: An Empirical Investigation of Job Characteristics and Organizational Climate," in Journal of Applied Psychology Vol 71, no. 2 (1986), 253.
} 
positive attitudes toward their organizations than comparable government executives. ${ }^{\$ 43}$ It may be premature to discount the significance of public-private differences and their implications for management training and practice. ${ }^{344}$ While there are theoretical reasons why the two sectors may be different, empirical evidence is mixed.

One shortcoming of research is that few studies have focused on public sector job satisfactions in the Canada. However, two recent Canadian federal public service surveys provide a snapshot of the overall career satisfaction. In $2002,78 \%$ of all respondents ${ }^{345}$ were satisfied with their careers in the public service. ${ }^{346}$ This is an increase from $69 \%$ who were satisfied with their careers in 1999 . There were some (20\%) who were not satisfied with their careers, down from ( $29 \%$ in) $1999 .{ }^{347}$ Related to job satisfaction ${ }^{348}$, in the 2002 survey, $32 \%$ strongly agreed that their organization was a good place to work, and 52\% mostly agreed. Using our survey instrument, we will ask respondents their level of job satisfaction. We will compare the satisfactions of innovators and non-innovators, hypothesizing:

\begin{tabular}{|l|l}
\hline Hypothesis 14: & Innovators are more satisfied with their job than non-innovators.
\end{tabular}

Job involvement is a description of how important work is to an individual. It is the internalization of values about the goodness of work or the importance of work in the

\footnotetext{
${ }^{343}$ Bruce Buchanan, "Government Managers, Business Executives and Organizational Commitment," in Public Administration Review (July-August, 1974), 339.

${ }^{344}$ Hal Rainey, Robert Backoff and Charles Levine, "Comparing Public and Private Organizations," in Public Administration Review (March/April 1976), 233.

${ }^{345}$ The total number of respondents in 2002 was 94135 and 103420 in 1999.

${ }^{346}$ Question 89 in the 2002 Public Service Survey.

${ }^{347}$ Public Service Commission of Canada, 2002 Public Service Employee Survey "Organizational Report for government of Canada" accessed January 2002, [http://www.survey-sondage.gc.ca/2002/resultsresultats/00/result-e.htm]

${ }^{348}$ Question 88 in the 2002 Public Service Survey.
} 
worth of the person. ${ }^{349}$ It can also be defined as the degree to which a person's work performance affects his or her self-esteem. For a job-involved person, work is a very important part of his/her life. For a non-job involved person, work is not as important in his or her life. The core of his or her self-image is not greatly affected by the kind or quality of his or her work. ${ }^{350}$

Victor Vroom used the concept of ego-involvement to describe job involvement, where a person is ego-involved in a task or job to whatever extent his self-esteem is affected by his perceived level of performance. Ego-involvement is a different description of job-involvement. Vroom's findings substantiated his hypotheses, finding: "[p]ersons who are ego-involved in their jobs are rated higher in job performance than those who are not ego-involved in their jobs." $" 351$ His reasoning was that ego-involved persons would link their self-esteem to their evaluation of their performance, and as such they would be more highly motivated to perform effectively than those who are not egoinvolved. Recent studies of ego involvement came to similar findings:

...for the professional-not only the Michael Jordans but also the highly skilled specialists in the laboratory-there is an even more compelling reason why in-role performance will not suffer because of dissatisfaction. The reason is ego-involvement. For the ego-involved professional, poor or even mediocre performance is intrinsically painful. It arouses feelings of guilt, embarrassment, and self-reproach. ${ }^{352}$

\footnotetext{
349 Thomas Lodahl and Mathilde Kejner, "The definition and measurement of job involvement," in $\underline{\text { Journal }}$ of applied Psychology Vol 49, no. 1 (1965), 24.

${ }^{350}$ Thomas Lodahl and Mathilde Kejner, 1965, 25.

${ }^{351}$ Victor Vroom, 1962, 176.

${ }^{352}$ Dennis Organ, 1997,21.
} 
While this makes sense, it may not always appear in empirical results because "...people are a mix of motives, exhibiting combinations of values over a lifetime and focusing on different motives at various points in their careers."

Job satisfaction and involvement are related, but not the same, since it is possible to have one without the other. "Although both constructs refer to the specific job, distinctions between the emotional state of liking one's job (job satisfaction) and the cognitive belief state of psychological identification with one's job (job involvement) have been advanced for some time. ${ }^{354}$ Although, it is possible for some persons to be highly satisfied, but not involved, and for others to be highly involved but not satisfied. ${ }^{355}$ Some research has identified that people can distinguish between job satisfaction and job involvement. ${ }^{356}$ Related to job involvement, we hypothesize:

\section{\begin{tabular}{|l|l|}
\hline Hypothesis 15: & Innovators are more job involved than non-innovators.
\end{tabular}}

We will test the link between job involvement, and innovation through our survey.

\section{Chapter Summary}

In this chapter, we looked at four main analytical themes related to institutional factors including: publicness; political direction and interest; recognition and rewards preference; and work environment. Under the theme of publicness, we considered that government labs lack a profit motive in the private sector sense, but cost recovery/sharing may also act as a motivator of innovation. We discussed ways to identify the importance of cost recovery/sharing, and its potential effects on innovation. In our theme of political

\footnotetext{
353 James Perry and Lois Recascino Wise, May June 1990, 369.

${ }^{354}$ Paul Brooke, Daniel Russell and James Price, "Discriminant Validation of Measures of Job Satisfaction, Job Involvement, and Organizational Commitment," in Journal of Applied Psychology Vol 73, no. 2 (1998), 139.

${ }^{355}$ Peter Weissenberg and Leopold Gruenfeld, "Relationship between job satisfaction and job involvement," in Journal of Applied Psychology (1968), 469.

${ }^{356}$ Paul Brooke and Daniel Russell, 1998, 143.
} 
interest and direction, we considered if they might have a bearing on innovation. In our third theme, we described intrinsic and extrinsic motivation and proposed questions to identify the rewards preference of respondents. We also considered innovation awards and feedback as types of recognition that may be related to innovation. In our final theme of work environment, we identified the factors of job satisfaction and involvement, proposing both are positively related to innovation.

We have now completed our literature review of institutional factors. We have set out four analytical themes related to institutional factors and made hypotheses. We will present our findings related to institutional hypotheses in chapter four. In the next chapter, we return to the individual level of analysis as we present our findings related to individual innovation factors. 
PART III RESULTS 


\section{CHAPTER 3: RESULTS: INDIVIDUAL FACTORS}

We now present the results of our survey and focus groups ${ }^{357}$ examining three analytical themes of individual factors related to innovation: characteristics of innovators and champions; hierarchy; and; barriers faced and promotion methods used to advance innovation. Our results are based upon 88 survey respondents. ${ }^{358}$ This is a relatively small sample, so we must be cautious in our analysis. Throughout this chapter, we present the combined results for all three labs, and where appropriate we describe the results for individual labs. In some instances due to a small number of cases, we may not break out the results by lab.

\section{Identification of Innovators and Number of Implemented Innovations}

To identify the innovators in our survey, we asked: "in the last two years, of the innovations you have worked on, how many have been implemented (i.e.: created and

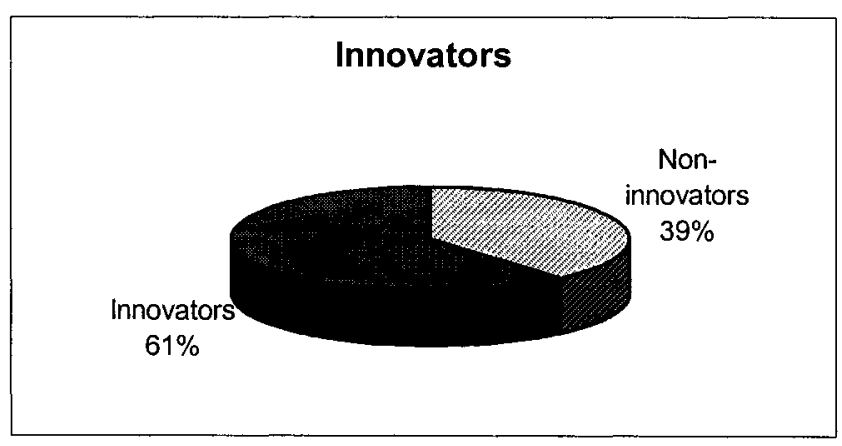

put into use by either the $1 \mathrm{~b}^{359}$ or its customers/partners)." To be identified as an innovator, the respondent had to have worked on at least one implemented innovation. Of the 88 respondents, $61 \%$ are innovators, $39 \%$ are non-innovators.

\footnotetext{
${ }^{357}$ Please see the methodology appendix for a complete discussion of the selection of the labs and respondents

35821 respondents from Materials Technology Laboratory, 24 from Canada Centre for Remote Sensing and 43 from CANMET Energy Technology Centre.

${ }^{359}$ The questionnaire text contains the official name of the lab ie: Canada Centre for Remote Sensing, not "lab".
} 
The percentage of innovators in both CANMET labs is similar, although MTL had slightly less respondents (52\%) innovating, compared with CETC (58\%). The percentage of innovators was the highest in CCRS (75\%). This does not indicate one lab is more innovative than another, but in our survey there were different

\begin{tabular}{|c|l|c|c|}
\hline \multicolumn{4}{|c|}{ Innovators and Non-innovators } \\
\hline $\mathrm{N}=88$ & \multicolumn{1}{|c|}{ Lab } & Non-innovators & Innovators \\
\hline 43 & CETC & $42 \%$ & $58 \%$ \\
\hline 21 & MTL & $48 \%$ & $52 \%$ \\
\hline 24 & CCRS & $\mathbf{2 5 \%}$ & $\mathbf{7 5 \%}$ \\
\hline & Chi Square 2.786 & Sig 0.248 & \\
\hline
\end{tabular}
percentages of innovative respondents in each lab. With a chi square of $2.786(\mathrm{p}<0.248)$, the differences are not statistically significant.

In all the labs, of innovators, almost half $(46 \%)$ had worked on only one implemented innovation in the last two years, while another $35 \%$ had worked on two implemented innovations. The majority $(82 \%)$ of innovators worked on

\begin{tabular}{|c|c|}
\hline \multicolumn{2}{|c|}{ Implemented Innovations } \\
\hline Number Implemented & $\begin{array}{c}\text { Percentage of } \\
\text { Innovators }\end{array}$ \\
\hline 1 & $46 \%$ \\
\hline 2 & $35 \%$ \\
\hline 3 & $11 \%$ \\
\hline $\begin{array}{c}\text { Over 4 implemented } \\
\text { innovations }\end{array}$ & $7 \%$ \\
\hline
\end{tabular}

fewer than three implemented innovations. The largest number of implemented innovations was seven.

\section{Demographic Factors: Gender and Age}

In our survey, we asked questions about two demographic factors: gender and age. Where relevant, we will include these demographics to add insight into the findings. Our findings indicate that a higher percentage of men are innovators compared to women. About two thirds (65\%) of men are innovators, while slightly less than half $(48 \%)$ of the females are innovators. Our chi square of $2.057(\mathrm{p}<0.152)$ indicates 


\begin{tabular}{|l|c|c|}
\hline \multicolumn{3}{|c|}{ Gender and Innovation } \\
\hline $\mathrm{N}=87$ & Male & Female \\
\hline Non-innovators & $35 \%$ of male & $52 \%$ of female \\
\hline Innovators & $65 \%$ of male & $48 \%$ of female \\
\hline Chi Square 2.057 & Sig 0.152 & $\mathrm{T} 1.388$ Sig 0.175 \\
\hline
\end{tabular}

that the differences between the genders of innovators are not statistically significant.

The relationship between age and innovation indicates that most innovators are between 40-59 years old. Before and after these ages, smaller percentages of respondents innovate, although our chi square of $3.495(\mathrm{p}<0.479)$ is not statistically significant.

\begin{tabular}{|c|c|c|}
\hline \multicolumn{3}{|c|}{ Age and Innovation } \\
\hline $\mathbf{N}=\mathbf{8 7}$ & Non-innovator & Innovator \\
\hline Age & & \\
\hline Under 30 & $\mathbf{1 5 \%}$ of non-innovator & $\mathbf{8 \%}$ of innovator \\
\hline $\mathbf{3 0}-\mathbf{3 9}$ & $\mathbf{1 2 \%}$ & $\mathbf{2 1 \%}$ \\
\hline $40-49$ & $\mathbf{3 5 \%}$ & $\mathbf{3 2} \%$ \\
\hline $\mathbf{5 0 - 5 9}$ & $\mathbf{3 5 \%}$ & $\mathbf{3 0 \%}$ \\
\hline Over 59 & $\mathbf{3 \%}$ & $\mathbf{9 \%}$ \\
\hline Chi Square 3.495 & Sig 0.479 & \\
\hline
\end{tabular}

\section{Theme 1 Results: Characteristics of Innovators; Competence}

Our first theme is the characteristics of innovators, which brings us to hypothesis 1: innovators possess three characteristics: competence; cosmopolitanism; and risktaking. We will test the null hypothesis (Ho) that innovators do not possess the characteristics: competence; cosmopolitanism; and risk taking. We will only test our hypotheses on the overall characteristic, not the individual components.

Hypothesis 2: there are clear differences in the characteristics of innovators and non-innovators, innovators have higher levels of competence, participate more in cosmopolitan activities, and are more risk-loving than non-innovators. We will test the null hypothesis (Ho) that there are no differences in the characteristics of innovators and non-innovators, using a chi square. If the results are statistically significant, we will 
reject the null hypothesis. We will now examine each of the three characteristics and their components.

As mentioned in the first chapter, competence is a prerequisite for innovation. One who possesses knowledge and skills should be able to tackle problems, and create new products, processes and services. We measure competence components including: experience; technical expertise; and education. Competence is expected to be a characteristic of innovators, and innovators should possess higher levels of competence components (experience, technical expertise and education) than non-innovators. We will look at each of the components and their relationship to innovation, and then add the components together to create an overall measure of competence.

\section{Competence Components: Experience; Technical Expertise and Education}

Through our survey, we identify being in the industry for more than four years, at the lab for more than four years, in the same job for more than three years, or had a similar job in another organization as sub-components of experience. We coded experience into three categories: high; medium; and low. ${ }^{360}$ The results are that overall $69 \%$ of respondents have high, $13 \%$ medium and $18 \%$ low experience. There were some differences between the labs, with MTL having the largest percentage $(76 \%)$ in the high category, and CCRS having the largest percentage (25\%) in the low category. Our chi square of $1.401(\mathrm{p}<0.844)$ indicates that the differences between the labs are not statistically significant.

\footnotetext{
${ }^{360}$ For each of the four sub-components of experience, we assigned a value of one if the respondent had the characteristic. For example, if the respondent was at the lab for more than four years, they would be assigned a value of one, and if not, zero. We repeated this procedure for all four sub-components, and the highest score a respondent could have is four. We recoded experience into three categories: "low", total scores on all four sub-components of 0 or 1 , "medium" a total score of two, and "high" for scores of 3 or greater.
} 


\begin{tabular}{|l|c|c|c|}
\hline \multicolumn{4}{|c|}{ Experience } \\
\hline \multicolumn{1}{|c|}{ N=88 } & Low & Medium & High \\
\hline CETC & $16 \%$ of CETC & $14 \%$ of CETC & $70 \%$ of CETC \\
\hline MTL & $14 \%$ of MTL & $10 \%$ of MTL & $76 \%$ of MTL \\
\hline CCRS & $25 \%$ of CCRS & $13 \%$ of CCRS & $63 \%$ of CCRS \\
\hline Overall & $18 \%$ & $13 \%$ & $69 \%$ \\
\hline Chi Square 1.401 & Sig 0.844 & & \\
\hline
\end{tabular}

Related to innovation, we found that $78 \%$ of innovators have high experience, $11 \%$ medium and $11 \%$ low. This compares to $56 \%$ of non-innovators with high, $15 \%$ medium and $29 \%$ low experience. Innovators have higher levels of experience than noninnovators.

\begin{tabular}{|c|c|c|c|}
\hline \multicolumn{4}{|c|}{ Innovation and Experience } \\
\hline $\mathbf{N}=\mathbf{8 8}$ & Low & Medium & High \\
\hline Non-innovators & $\mathbf{2 9 \%}$ & $\mathbf{1 5 \%}$ & $\mathbf{5 6 \%}$ \\
\hline Innovators & $\mathbf{1 1 \%}$ & $\mathbf{1 1 \%}$ & $\mathbf{7 8 \%}$ \\
\hline Chi Square 5.502 & Sig 0.064 & & \\
\hline
\end{tabular}

Our chi square $5.502(p<0.064)$ indicates a statistically significant difference.

Our second component of competence is technical expertise. We identify technical expertise by asking how often respondents were approached to solve difficult technical problems in (or near) their field and if their technical expertise allowed them to influence the acceptance/rejection of innovations in the lab. ${ }^{361}$ We took responses to both questions and added them into a technical expertise variable, which we then recoded into low, medium and high levels of technical expertise. ${ }^{362}$

\footnotetext{
${ }^{361}$ Respondents who were approached "rarely" (who answered one or two) were coded as 1, respondents approached "sometimes" were coded as 2 , and those approached "often or very often" (4 or 5) were coded as 3. Respondents who answered that their technical expertise allowed them to influence the acceptance/rejection of proposed innovations were coded as one, those who did not were coded as a zero. ${ }^{362}$ Respondents with total scores of three or four were coded as "high", scores of two "medium" and scores of one "low".
} 


\begin{tabular}{|l|c|c|c|}
\hline \multicolumn{4}{|c|}{ Technical Expertise } \\
\hline \multicolumn{1}{|c|}{ N=85 } & Low & Medium & High \\
\hline CETC & $26 \%$ of CETC & $35 \%$ of CETC & $39 \%$ of CETC \\
\hline MTL & $21 \%$ of MTL & $26 \%$ of MTL & $53 \%$ of MTL \\
\hline CCRS & $17 \%$ of CCRS & $17 \%$ of CCRS & $65 \%$ of CCRS \\
\hline Overall & $22 \%$ & $28 \%$ & $49 \%$ \\
\hline Chi Square 4.176 & Sig 0.383 & & \\
\hline
\end{tabular}

We found that overall almost half (49\%) of respondents had high technical expertise, $28 \%$ had medium and $22 \%$ had low. There were differences between the labs, although our chi square $4.176 \mathrm{p}<0.383$ was not statistically significant.

\begin{tabular}{|c|c|c|c|}
\hline \multicolumn{5}{|c|}{ Innovation and Technical Expertise } \\
\hline $\mathrm{N}=85$ & Low & Medium & High \\
\hline Non-innovators & $\mathbf{3 0 \%}$ & $\mathbf{3 6 \%}$ & $\mathbf{3 3 \%}$ \\
\hline Innovators & $17 \%$ & $\mathbf{2 3} \%$ & $\mathbf{6 0 \%}$ \\
\hline Chi square 5.610 & Sig 0.061 & & \\
\hline
\end{tabular}

Looking at the relationship between innovation and technical expertise, we found that the majority of innovators $(60 \%)$ had high technical expertise, almost a quarter $(23 \%)$ had medium and $17 \%$ had low. This compares to a third of non-innovators with high technical expertise, $36 \%$ with medium and $30 \%$ with low. Innovators have higher levels of technical expertise, and our chi square $5.610 \mathrm{p}<0.061$ is significant.

The third component of competence is education. We asked respondents the level of education they had completed. When we grouped educational attainment, overall the majority (56\%) of respondents had a Masters or $\mathrm{PhD}, 29 \%$ had an Undergraduate or Professional degree, and 15\% had College or High school.

\begin{tabular}{|l|c|c|c|}
\hline \multicolumn{4}{|c|}{ Highest Level of Education Completed } \\
\hline N=88 & College and HS & $\begin{array}{c}\text { Undergrad and } \\
\text { Prof }\end{array}$ & Masters and PhD \\
\hline CETC & $14 \%$ & $44 \%$ & $42 \%$ \\
\hline MTL & $24 \%$ & $9 \%$ & $67 \%$ \\
\hline CCRS & $\mathbf{8 \%}$ & $21 \%$ & $71 \%$ \\
\hline Overall & $15 \%$ & $29 \%$ & $56 \%$ \\
\hline Chi Square 11.359 & Sig 0.23 & & \\
\hline
\end{tabular}


CCRS had the highest percentage of respondents with a Masters/PhD (71\%) and CETC had the lowest (42\%). However, CETC had the largest percentage (44\%) in the Undergrad and Professional category. MTL had the largest percentage (24\%) in the College/High school category. Our chi square of $11.359 \mathrm{p}<0.23$ is not statistically significant.

Of innovators, the majority $(65 \%)$ had a Masters or $\mathrm{PhD}, 30 \%$ had a Bachelor or

\begin{tabular}{|l|c|c|c|}
\hline \multicolumn{4}{|c|}{ Innovation and Education } \\
\hline $\mathbf{N}=\mathbf{8 8}$ & H.S and College & $\begin{array}{c}\text { Bachelors and } \\
\text { Professional }\end{array}$ & Masters and PhD \\
\hline Non-innovators & $\mathbf{2 9 \%}$ & $\mathbf{2 9 \%}$ & $\mathbf{4 1 \%}$ \\
\hline Innovators & $\mathbf{5 \%}$ & $\mathbf{3 0 \%}$ & $\mathbf{6 5 \%}$ \\
\hline Chi Square 10.132 & Sig 0.006 & & \\
\hline
\end{tabular}

Professional designation, and 5\% had College/High school. Comparatively, a higher percentage of non-innovators have High school/College (29\%), about the same Bachelors and Professional (29\%), but fewer Masters and PhD's (41\%). Our results suggest that innovators have more formal education, and our chi square of $10.132(\mathrm{p}<0.006)$ indicates that the results are statistically significant.

\section{Overall Competence}

We have examined three components of competence: experience, technical expertise, and education. Now we will add them together to create a competence variable, ${ }^{363}$ with three categories: high; medium; and low innovative competence. The competence we are describing is based solely on factors related to innovation examined in the survey. Those with high competence possess these factors, while those who do not still need to acquire them. We are not saying those who fall into the low category are

\footnotetext{
${ }^{363}$ Experience variable was coded low-high (1-3), technical expertise low-high (1-3) and education lowhigh (1-3). Coded scores for each respondent were added together. Totals of 3-5 were coded as "low", scores of 6-7 as "medium" and 8-9 as "high".
} 
incompetent, but rather they have not yet accumulated experiences and competence related to innovation.

\begin{tabular}{|l|c|c|c|}
\hline \multicolumn{4}{|c|}{ Innovative Competence } \\
\hline N=85 & Low & Medium & High \\
\hline CETC & $\mathbf{2 3 \%}$ & $\mathbf{3 7 \%}$ & $\mathbf{4 0 \%}$ \\
\hline MTL & $\mathbf{2 1 \%}$ & $\mathbf{2 6 \%}$ & $\mathbf{5 3 \%}$ \\
\hline CCRS & $\mathbf{9 \%}$ & $\mathbf{4 3 \%}$ & $\mathbf{4 8 \%}$ \\
\hline Overall & $\mathbf{1 9 \%}$ & $\mathbf{3 6 \%}$ & $\mathbf{4 5 \%}$ \\
\hline Chi Square 3.180 & Sig 0.528 & & \\
\hline
\end{tabular}

Overall, $19 \%$ of respondents have a low innovative competence, $36 \%$ have medium and $45 \%$ have a high. There are some differences between the labs, where MTL has the highest percentage of high innovative competent respondents (53\%) while CETC had the least (40\%). CETC had the smallest percentage (9\%) in the low category, and CETC had the most $(23 \%)$. Our chi square $3.180 \mathrm{p}<0.528$ is not statistically significant.

On the overall competence variable our findings indicate that of innovators, $9 \%$ had low innovative competence, $35 \%$ had medium and $56 \%$ had high innovative competence. Of non-innovators, $33 \%$ had low innovative competence, $40 \%$ had medium and $27 \%$ had high innovative competence. Our chi square $9.827 \mathrm{p}<0.007$ is statistically significant.

\begin{tabular}{|l|c|c|c|}
\hline \multicolumn{4}{|c|}{ Innovation and Competence } \\
\hline $\mathbf{N}=\mathbf{8 8}$ & Low & Medium & High \\
\hline Non innovators & $\mathbf{3 3 \%}$ & $\mathbf{4 0 \%}$ & $\mathbf{2 7 \%}$ \\
\hline Innovators & $\mathbf{9 \%}$ & $\mathbf{3 5 \%}$ & $\mathbf{5 6 \%}$ \\
\hline Chi Square 9.827 & Sig 0.007 & & \\
\hline
\end{tabular}

We can now test hypothesis 1: competence is a characteristic innovators possess. We want to find out if significantly more than $50 \%$ of innovators have medium or high competence. Using the full range of values that can be taken by this variable (from a low score of 3 to a maximum score of 9), we want to find out if a statistically significant 
percentage of innovators have medium or high innovative competence (i.e. scores greater than 5). The null hypothesis (Ho), says that competence is not a characteristic that innovators possess, and so the percentage of innovators with medium or high competence is less than $50 \%$. From our data, we found that $91 \%$ (47) of our innovators had competence levels above 5 .

$Z=0.91-0.5=0.41 /$ Standard Error

$\frac{0.41}{\sqrt{\frac{\text { standard deviation }}{52 \text { innovators }}}}=\frac{0.41}{\sqrt{\frac{(0.5)(0.5)}{52 \text { innovators }}}}=\frac{0.41}{0.069}=5.94$

We can look up the $Z$ value of $5.94=0.4999$. Our original test was to see if greater than $50 \%$ of innovators did not possess this characteristic, so $0.5-0.4999=0.0001$. This indicates that the probability of drawing this sample by chance is unlikely $(\mathrm{p}<0.0001)$, therefore we can reject the null hypothesis. Competence is a characteristic of innovators.

For hypothesis 2: there are clear differences in the characteristics of innovators and non-innovators, we can use the null hypothesis that there are no differences in the characteristics of innovators and champions. If this is true, a chi square test should not be statistically significant. Our chi square results $(9.827 \mathrm{p}<0.007)$ indicate that the relationship is statistically significant, so we can reject the null hypothesis. Innovators in our study have higher levels of competence than non-innovators. 
Summary of Expectations and Results: Competence

\begin{tabular}{|c|c|c|c|c|c|}
\hline & \multicolumn{5}{|c|}{ Possession of Characteristics } \\
\hline & \multicolumn{3}{|c|}{ Expectations } & \multicolumn{2}{|c|}{ Results } \\
\hline Characteristics & Innovator & & n-innovator & Innovator & Non-innovator \\
\hline Competence & & & & & \\
\hline - Experience & & & & & \\
\hline - Technical expertise & & & & & \\
\hline - Education & More & & Less & More & Less \\
\hline \multicolumn{3}{|c|}{$\begin{array}{l}\text { Hypothesis } 1 \text { : innovators in our study will } \\
\text { possess the characteristic of competence. }\end{array}$} & \multicolumn{3}{|c|}{$\begin{array}{l}\text { Results: we can reject the null hypothesis that } \\
\text { innovators do not posses the characteristic of } \\
\text { competence. }\end{array}$} \\
\hline \multicolumn{3}{|c|}{$\begin{array}{l}\text { Hypothesis 2: there are clear differences in } \\
\text { the characteristics of innovators and non- } \\
\text { innovators, innovators have higher levels of } \\
\text { competence. }\end{array}$} & \multicolumn{3}{|c|}{$\begin{array}{l}\text { Results: we can reject the null hypothesis that } \\
\text { there are no differences between innovators and } \\
\text { non-innovators in the characteristic of } \\
\text { competence. }\end{array}$} \\
\hline
\end{tabular}

We found innovators are competent, possessing the characteristics of experience, technical expertise and education. There are clear differences between innovators and non-innovators. In the next section, we look at a second characteristic of innovators: cosmopolitanism.

\section{Cosmopolitanism: Professional and Academic Activities}

"Cosmopolitan" is a description of an individual who is orientated outside the organization. Individuals orientated internally are described in the literature as "locals". To explore cosmopolitanism and its relationship to innovation, we divided cosmopolitanism into two categories: professional and academic. Through our survey we will see if respondents engaged in the following professional activities: attending workrelated professional meetings; held an office in a work related professional association; and had frequent contact with colleagues or other organizations in the same industry. ${ }^{364}$

\footnotetext{
${ }^{364}$ For each of the three components, we created a dichotomous variable, equal to one if the respondent had participated in the activity in the last two years. For example, if the respondent had attended a work related professional meeting, they were coded as a "one", if not, a "zero". This was repeated for the three variables. All three were equally weighted and added together. We then recoded the result into "low" (totals of 0 ), medium (totals of 1-2) and "high" (total of 3).
} 
These were added together, and grouped into low, medium and high participation in professional activities. Most respondents (70\%) had medium levels of participation in

\begin{tabular}{|l|c|c|c|}
\hline \multicolumn{4}{|c|}{ Cosmopolitan Professional Activity Participation } \\
\hline N=88 & Low & Medium & High \\
\hline CETC & $16 \%$ & $77 \%$ & $7 \%$ \\
\hline MTL & $19 \%$ & $43 \%$ & $\mathbf{3 8 \%}$ \\
\hline CCRS & $\mathbf{8 \%}$ & $\mathbf{8 3} \%$ & $\mathbf{8 \%}$ \\
\hline Overall & $15 \%$ & $\mathbf{7 0 \%}$ & $\mathbf{1 5 \%}$ \\
\hline Chi Square 14.251 & Sig 0.007 & & \\
\hline
\end{tabular}

professional activities. Equal percentages (15\%) had high and low participation. In all three labs, focus groups identified that cosmopolitan activities are important. Several participants noted that everybody is encouraged to attend at least one conference per year. Conferences are important, not only to learn, but to promote the services of the lab. ${ }^{365}$ As another put it: "shows and expo's also give fantastic exposure to needs and questions and also to the other scientists out there." ${ }^{366}$ Many participated in activities orientated outside their lab.

Comparing across the labs, MTL had the largest percentage in the high category (38\%), yet also had the highest in the low category (19\%). CCRS had by far the largest percentage $(83 \%)$ in the medium category. Our chi square of $14.251(\mathrm{p}<0.007)$ indicates that the differences between the labs are statistically significant. One explanation of the differences in the labs may be the relatively higher percentage (48\%) of MTL respondents holding office in professional associations, compared with $9 \%$ of CETC and $8 \%$ of CCRS respondents. MTL focus groups indicated that due to the nature of their business, participation in professional associations was important.

\footnotetext{
${ }^{365}$ Materials Technology Laboratory focus group participants

${ }^{366}$ Energy Technology Centre focus group participants
} 


\begin{tabular}{|l|c|c|c|}
\hline \multicolumn{4}{|c|}{ Cosmopolitan Professional Activities and Innovation } \\
\hline $\mathbf{N}=\mathbf{8 8}$ & Low & Medium & High \\
\hline Non-innovators & $\mathbf{1 8 \%}$ & $\mathbf{7 6 \%}$ & $\mathbf{6 \%}$ \\
\hline Innovators & $\mathbf{1 3 \%}$ & $\mathbf{6 7 \%}$ & $\mathbf{2 0 \%}$ \\
\hline Chi Square 3.559 & Sig 0.169 & & \\
\hline
\end{tabular}

Of innovators, $20 \%$ have high levels of participation in professional activities, $67 \%$ have medium participation. This compares with $6 \%$ of non-innovators with high participation and $76 \%$ with medium. Our chi square of $3.559(\mathrm{p}<0.169)$ is not statistically significant.

The second category of cosmopolitan activities includes participation in academic activities such as submitting articles, reading work related journals, presenting a paper at a work related conference, or attending an international meeting/ conference.

\begin{tabular}{|l|c|c|c|}
\hline \multicolumn{4}{|c|}{ Cosmopolitan Academic Activity Participation } \\
\hline N=88 & Low & Medium & High \\
\hline CETC & $14 \%$ & $\mathbf{4 4 \%}$ & $\mathbf{4 2 \%}$ \\
\hline MTL & $24 \%$ & $14 \%$ & $62 \%$ \\
\hline CCRS & $13 \%$ & $33 \%$ & $54 \%$ \\
\hline Overall & $16 \%$ & $34 \%$ & $50 \%$ \\
\hline Chi Square 6.057 & Sig 0.195 & & \\
\hline
\end{tabular}

Our results indicate that half of respondents had high levels of participation in academic activities. Just over a third had medium, and 16\% had low levels of participation. MTL had the largest percentage of respondents in the high category $(62 \%)$, and the largest percentage in the low category (24\%). CETC had the smallest percentage in the high category (42\%), but the largest in the medium category (44\%). With chi square of 6.057 $\mathrm{p}<0.195$, the differences are not statistically significant.

To compare innovators and non-innovators, $56 \%$ of innovators had high academic activity participation, $39 \%$ had medium and $6 \%$ had low participation. Of noninnovators, $41 \%$ had high academic activities participation, $27 \%$ medium and $32 \%$ low 
participation. With a Chi square of $11.224 \mathrm{p}<0.004$, our results are statistically significant.

\begin{tabular}{|l|c|c|c|}
\hline \multicolumn{4}{|c|}{ Cosmopolitan Academic Activities and Innovation } \\
\hline $\mathrm{N}=\mathbf{8 8}$ & Low & Medium & High \\
\hline Non innovators & $\mathbf{3 2 \%}$ & $\mathbf{2 7 \%}$ & $\mathbf{4 1 \%}$ \\
\hline Innovators & $\mathbf{6 \%}$ & $\mathbf{3 9 \%}$ & $\mathbf{5 6 \%}$ \\
\hline Chi Square 11.224 & Sig $\mathbf{0 . 0 0 4}$ & & \\
\hline
\end{tabular}

Interestingly, in our two cosmopolitan sub-categories, a much larger percentage of respondents participated in academic cosmopolitan activities, compared to professional cosmopolitan activities. One reason may be that for Research Scientists and others, several of the academic cosmopolitan activities such as published articles, are important for promotion. "Articles, work related-meetings, holding office in professional associations, etc, are all required for promotions. It's pretty hard to get promoted without a publication. Not impossible, but difficult." ${ }^{367}$ Cosmopolitan activities are also important to the greater scientific community as demonstrations of scientific output.

Thus far, we have looked at two subcategories of cosmopolitanism, and found that both appear positively related to innovation, although only academic activities was statistically significant. As we proposed that cosmopolitanism is made up of these two components together, we can amalgamate both into an overall cosmopolitan variable. ${ }^{368}$ Overall the results show that $51 \%$ of respondents have high cosmopolitan characteristics, a quarter have medium and $24 \%$ have low.

\footnotetext{
${ }^{367}$ Materials Technology Laboratory focus group participant

368 To do this, we took the low (1), medium (2) and high (3) coded responses from both variables and weighed them equally and added them together. For example, if a respondent was in the medium category of participation in professional activities (2) and in the high category (3) of academic activity participation, added together their score would be 5 . We recoded all of the summed results into high, medium and low levels, where low $=$ total score of 2 or 3 , medium $=4$, high $=$ total of 5 or 6 .
} 


\begin{tabular}{|l|c|c|c|}
\hline \multicolumn{4}{|c|}{ Overall Cosmopolitanism } \\
\hline N=88 & Low & Medium & High \\
\hline CETC & $\mathbf{2 1 \%}$ & $\mathbf{3 7 \%}$ & $\mathbf{4 2 \%}$ \\
\hline MTL & $\mathbf{3 3 \%}$ & $\mathbf{5 \%}$ & $\mathbf{6 2 \%}$ \\
\hline CCRS & $\mathbf{2 1 \%}$ & $\mathbf{2 1 \%}$ & $\mathbf{5 8 \%}$ \\
\hline Overall & $\mathbf{2 4 \%}$ & $\mathbf{2 5 \%}$ & $\mathbf{5 1 \%}$ \\
\hline Chi Square 8.650 & Sig 0.070 & & \\
\hline
\end{tabular}

MTL has the highest percentage of respondents in the high category, but also the highest percentage (33\%) in the low category. Our chi square of $8.650 \mathrm{p}<0.070$ is statistically significant. There were no substantial differences between genders and levels of cosmopolitanism, nor a clear pattern between cosmopolitanism and age.

When we relate overall cosmopolitanism to innovation, $57 \%$ of innovators had high cosmopolitan characteristics, $26 \%$ medium and $17 \%$ low. For non-innovators, $41 \%$ had high cosmopolitan characteristics, $24 \%$ medium and $35 \%$ low.

\begin{tabular}{|l|c|c|c|}
\hline \multicolumn{4}{|c|}{ Overall Cosmopolitanism and Innovation } \\
\hline $\mathrm{N}=\mathbf{8 8}$ & Low & Medium & High \\
\hline Non innovators & $\mathbf{3 5 \%}$ & $\mathbf{2 4 \%}$ & $\mathbf{4 1 \%}$ \\
\hline Innovators & $\mathbf{1 7 \%}$ & $\mathbf{2 6 \%}$ & $\mathbf{5 7 \%}$ \\
\hline Chi Square 4.156 & Sig 0.125 & & \\
\hline
\end{tabular}

We can now test hypothesis 1: innovators possess the characteristic of cosmopolitanism. We will use the null hypothesis (Ho) innovators do not possess the characteristic of cosmopolitanism. We want to find out if significantly more than $50 \%$ of innovators have medium or high cosmopolitanism. Using the full range of values that can be taken by this variable (2-6) we want to find out if a significant percentage of innovators have innovative competence scores greater than 3 . The null hypothesis (Ho), says that cosmopolitanism is not a characteristic that innovators possess, and so less than $50 \%$ of innovators will have this characteristic. From our data, we found that ( $83 \%)$ of our innovators had competence scores above 3. 
$\mathrm{Z}=0.833-0.5=0.333 /$ Standard Error

$\frac{0.33}{\sqrt{\frac{\text { standard deviation }}{54 \text { innovators }}}}=\frac{0.33}{\sqrt{\frac{(0.5)(0.5)}{54 \text { innovators }}}}=\frac{0.33}{0.0680}=4.85$

We look up the $Z$ value of $4.85=0.4999$. Our original test was to see if greater than $50 \%$ of innovators did not possess this characteristic, so $0.5-0.4999=0.0001$. This indicates that the probability of drawing this sample by chance is unlikely $(p<0.0001)$, therefore we can reject the null hypothesis. Cosmopolitanism is a characteristic of innovators.

For hypothesis 2: there are clear differences in the characteristics of innovators and non-innovators, innovators participate more in cosmopolitan activities, the null hypothesis is that there are no differences in the characteristics of innovators and noninnovators. If this is true, a chi square will not be statistically significant. Our chi square of $4.156 \mathrm{p}<0.125$ is not statistically significant, so we cannot reject the null hypothesis. Our findings are directionally as expected.

Summary of Expectations and Results: Cosmopolitanism

\begin{tabular}{|c|c|c|c|c|c|}
\hline & \multicolumn{5}{|c|}{ Possession of Characteristics } \\
\hline & \multicolumn{3}{|c|}{ Expectations } & \multicolumn{2}{|c|}{ Results } \\
\hline Characteristics & Innovator & & n-innovator & Innovator & Non-innovator \\
\hline $\begin{array}{l}\text { Cosmopolitanism } \\
\text { - Professional activities } \\
\text { - Academic activities }\end{array}$ & $\begin{array}{l}\text { More } \\
\text { More } \\
\text { More }\end{array}$ & & $\begin{array}{l}\text { Less } \\
\text { Less } \\
\text { Less }\end{array}$ & $\begin{array}{c}\text { More* } \\
\text { More* } \\
\text { More }\end{array}$ & $\begin{array}{c}\text { Less* } \\
\text { Less* } \\
\text { Less }\end{array}$ \\
\hline \multicolumn{3}{|c|}{$\begin{array}{l}\text { Hypothesis 1: innovators in our study will } \\
\text { be cosmopolitans. }\end{array}$} & \multicolumn{3}{|c|}{$\begin{array}{l}\text { Results: we can reject the null hypothesis that } \\
\text { innovators in our study are not cosmopolitans. }\end{array}$} \\
\hline \multicolumn{3}{|c|}{$\begin{array}{l}\text { Hypothesis 2: there are clear differences in } \\
\text { the characteristics of innovators and non- } \\
\text { innovators, innovators will participate more } \\
\text { in professional and academic activities more } \\
\text { than non-innovators. }\end{array}$} & \multicolumn{3}{|c|}{$\begin{array}{l}\text { Results: *we cannot reject the null hypothesis } \\
\text { that innovators in our study participate in } \\
\text { professional and academic activities more than } \\
\text { non-innovators. }\end{array}$} \\
\hline
\end{tabular}


While innovators in our study are cosmopolitans, we cannot say there are statistically significant differences between innovators and champions. In the next section, we examine the third characteristic of innovators: risk taking.

\section{Risk Takers}

As innovation is often risky and uncertain, we expect to find that innovators are risk takers more than non-innovators. We divided risk-taking behavior into two categories: risk taking potential; and actual risk takers. To identify risk taking potential we asked respondents if they believed that the probability of success of an innovation was $50 / 50$, how likely would they be to advocate/promote its technical or other merits to their manager/director or clients? We recoded the variable into high, medium and low categories. ${ }^{369}$ Our results indicate that $19 \%$ of respondents have high risk taking potential, $32 \%$ medium and $50 \%$ low risk taking potential.

\begin{tabular}{|l|c|c|c|}
\hline \multicolumn{4}{|c|}{ Risk Taking Potential } \\
\hline N=85 & Low & Medium & High \\
\hline CETC & $49 \%$ & $\mathbf{2 4 \%}$ & $\mathbf{2 7 \%}$ \\
\hline MTL & $\mathbf{4 8 \%}$ & $\mathbf{4 3 \%}$ & $\mathbf{9 \%}$ \\
\hline CCRS & $\mathbf{5 2 \%}$ & $\mathbf{3 5 \%}$ & $\mathbf{1 5 \%}$ \\
\hline Overall & $\mathbf{4 9 \%}$ & $\mathbf{3 2} \%$ & $\mathbf{1 9 \%}$ \\
\hline Chi Square 4.403 & Sig 0.354 & & \\
\hline
\end{tabular}

There were some differences between the labs, with CETC having the largest percentage $(27 \%)$ of respondents in the high risk taking potential category, although the other labs made up the difference in the medium category. Our chi square $4.403 p<0.354$ indicates that the differences are not statistically significant. When we look at the relationship between risk taking and innovation, somewhat surprisingly, only $17 \%$ of innovators were potential high risk takers.

\footnotetext{
${ }^{369}$ Respondents who were "very likely" (5) to advocate the innovation were coded as "high" risk taking potential, "likely" (4) as "medium", and less than 4 as "low" risk taking potential.
} 


\begin{tabular}{|l|c|c|c|}
\hline \multicolumn{4}{|c|}{ Innovation and Risk Taking } \\
\hline $\mathbf{N}=\mathbf{8 5}$ & Low & Medium & High \\
\hline Non innovators & $\mathbf{5 0 \%}$ & $\mathbf{2 8 \%}$ & $\mathbf{2 2 \%}$ \\
\hline Innovators & $\mathbf{4 9 \%}$ & $\mathbf{3 4 \%}$ & $\mathbf{1 7 \%}$ \\
\hline Chi Square 0.471 & Sig 0.790 & & \\
\hline
\end{tabular}

Another 34\% were medium potential risk takers, but almost half (49\%) were low potential risk takers. This compares with a slightly larger percentage $(22 \%)$ of noninnovators in the high risk taking potential category, and similar percentages in the medium and low categories. With a chi square of $0.471 \mathrm{p}<0.790$, the result is not statistically significant.

To identify the actual risk takers, we asked if respondents had tried to secure resources, equipment or personnel for an innovation that they considered to only have a slight chance of being a success? Of innovators, only $16 \%$ took the risk of advocating for an innovation they considered having a slight chance of success. We can now test Hypothesis 1: innovators are risk takers. Our null hypothesis (Ho) is that less than $50 \%$ of innovators possess this characteristic. Since the percentage of innovators who are risk takers $(16 \%)$ is well below $50 \%$, we cannot reject the null hypothesis that the innovators in our study are not risk takers.

To test our second hypothesis, that there are differences in characteristics of innovators and non-innovators, we use the null hypothesis that there are no differences in the characteristics of innovators and champions. If this is true, a $\mathrm{T}$ test should not be statistically significant. Our T test $1.732(\mathrm{p}<0.090)$ indicates a statistically significant difference between innovators and non-innovators, so we can reject the null hypothesis. There are differences in risk taking between innovators and non-innovators. 
Summary of Expectations and Results: Risk-taking

\begin{tabular}{|l|c|c|c|c|}
\hline & \multicolumn{3}{|c|}{ Possession of Characteristics } \\
\hline \multicolumn{1}{|c|}{ Characteristics } & Innovator & Non-innovator & \multicolumn{1}{c|}{ Results } \\
\hline Risk Takers & \multicolumn{1}{|c|}{ More } & \multicolumn{1}{c|}{ Less } & Inconclusive & Inconclusive \\
\hline $\begin{array}{l}\text { Hypothesis 1: innovators in our study posses } \\
\text { the characteristic of risk-taking. }\end{array}$ & $\begin{array}{l}\text { Results: we cannot reject the null } \\
\text { hypothesis that innovators are not risk- } \\
\text { lovers. Most innovators were not risk- } \\
\text { takers. }\end{array}$ \\
\hline $\begin{array}{l}\text { Hypothesis 2: there are clear differences in } \\
\text { the characteristics of innovators and non- } \\
\text { innovators, innovators are more risk-taking } \\
\text { than non-innovators. }\end{array}$ & $\begin{array}{l}\text { Results: we can reject the null } \\
\text { hypothesis that there are no differences } \\
\text { between innovators and non-innovators. }\end{array}$ \\
\hline
\end{tabular}

In this section, we have identified $61 \%$ of respondents as innovators. Most innovators had worked on one or two implemented innovations. We have examined three characteristics of innovators. We have tested our first hypothesis that innovators possess the characteristics of competence, cosmopolitanism and risk taking, and found that innovators are competent and cosmopolitans, as expected. Our results do not indicate innovators are risk takers.

We have tested our second hypothesis, that there are clear differences in the characteristics of innovators and non-innovators, finding that innovators have higher overall innovative competence, and are more risk loving than non-innovators. While innovators appear to participate in cosmopolitan activities more than non-innovators, the differences between innovators and non-innovators are not statistically significant.

\section{Champions and Non-Champions}

Continuing our first theme, we will now identify champions and examine their characteristics. To be considered a champion, within the last two years the respondents had to have advocated the technical merits of an innovation to someone both inside and outside the lab, and tried to secure resources for an innovation either inside or outside the 
lab. We identified just over half (56\%) of respondents as champions, $44 \%$ are nonchampions. Of champions, most (61\%) had worked

on at least one implemented innovation. Comparatively, of non-champions, $54 \%$ had worked on at least one implemented innovation, although the results (Chi

\section{Champions}

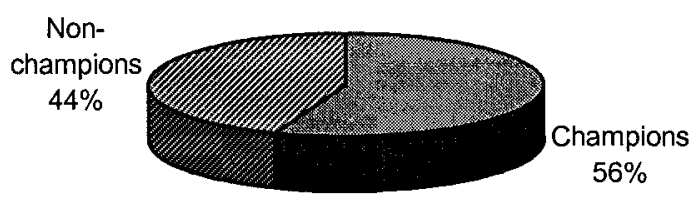

Square $1.670 \mathrm{p}<0.196$ ) are not significant.

It is interesting that MTL had the smallest percentage of innovators, but the

largest percentage of champions $(62 \%)$, and CCRS had the most innovators, but the fewest

champions. The chi square

\begin{tabular}{|l|c|c|}
\hline \multicolumn{3}{|c|}{ Champions } \\
\hline N=88 & Non-champions & Champions \\
\hline CETC & $44 \%$ & $56 \%$ \\
\hline MTL & $38 \%$ & $62 \%$ \\
\hline CCRS & $50 \%$ & $50 \%$ \\
\hline Chi Square 0.644 & Sig 0.725 & \\
\hline
\end{tabular}

of $0.644 \mathrm{p}<0.725$ is not statistically significant.

\section{Gender and Championing}

When we look at the gender of champions, males are as likely to be champions as females. Of males, $56 \%$ were champions, while $52 \%$ of female respondents were champions. When we use a $\mathrm{T}$ test to compare the means of both groups, our results $(T=0.289 \mathrm{p}<0.775)$ do not indicate a statistically significant difference between genders, which suggests equal opportunity championing. 


\section{Success Championing}

Thirteen percent of champions described that they had been unsuccessful or very unsuccessful at advocating/promoting the merits of an innovation - meaning they are failed champions. ${ }^{370}$ Sixty three percent of champions reported being somewhat successful, and $24 \%$ were successful or very successful. Added together, it appears that the vast majority ( $87 \%$ ) of champions had some success promoting the merits of an innovation. The focus groups provided an explanation: people won't write a proposal if they don't think it will succeed. "Those who do propose something are generally successful, because they know the rules of the game. ${ }^{371}$

Both CETC and CCRS had $29 \%$ of respondents who thought they were successful at advocating the technical or other merits of an innovation. MTL had a smaller percentage in the successful category (13\%), but the differences in percentages between the labs was made up in the somewhat category (73\%), although our chi square $1.946 \mathrm{p}<$ 0.746 indicates the results are not statistically significant. MTL focus group participants suggested it could be we're a bit more realistic about our success rate, or that every proposal that's made is modified and could be improved. ${ }^{372}$ Overall, most champions in all labs had success promoting their innovations.

\footnotetext{
${ }^{370}$ Our fears that no respondents would not identify themselves as failed champions did not materialize.

${ }^{371}$ Materials Technology Laboratory focus group participants

${ }^{372}$ Materials Technology Laboratory focus group participants
} 
As one participant

described: "we've got

a system in pace that

only talks about

success and a culture

of success to find it

wherever we can."

\section{Success Advocating Innovations}

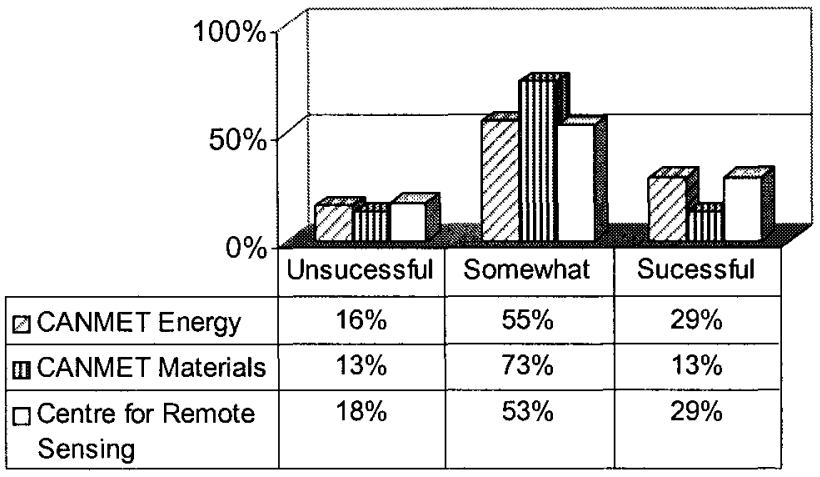

There were minor differences in the gender of the champion and the success rates in promoting innovations, as $13 \%$ of male innovators were unsuccessful, compared to $9 \%$ of females, $61 \%$ of males had some success, compared to $64 \%$ of females and $25 \%$ of males were very successful, compared to $27 \%$ of females. Our chi square $(0.917$ $\mathrm{p}<0.632)$ indicates that the results are not statistically significant.

\section{To Whom are Champions Promoting Innovations?}

Overall, most advocacy

(51\%) went to current

clients in the private sector,

$31 \%$ to the government

sector and $18 \%$ to current

\section{Advocate to Current Clients}

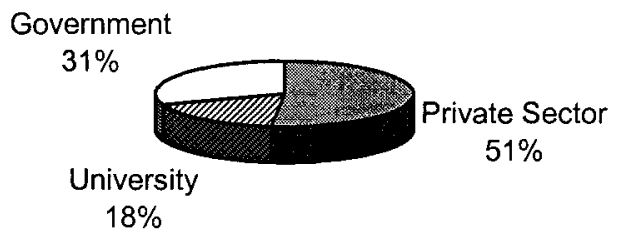

clients in the university

sector. Respondents could advocate to more than one sector. Advocacy, to both current and potential clients is of key importance. "We're supposed to be spending a fair amount

\footnotetext{
${ }^{373}$ Canada Centre for Remote Sensing focus group participants
} 
of our time, not only innovating, but getting approval for new projects, both internally and externally., 374

For potential clients, the overall picture looks similar, with the bulk of advocacy towards the private sector.

The focus on industry was

identified because of

funding and knowledge of

their wants and needs. "We

\section{Advocate to Potential Clients}

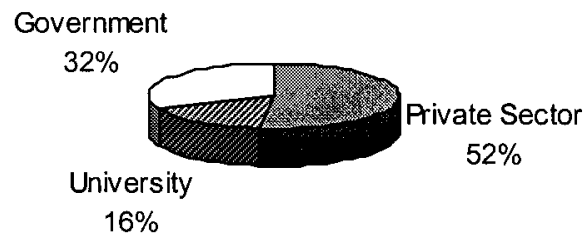

spent a lot of time with industry over the years, so we have a fix on what industry

needs. ${ }^{975}$ Part of advocacy is to create linkages between the lab and industry. ${ }^{376}$ When working in partnerships, the lab can become part of a private-public sector network. As MTL documentation advises: "[n]etworking is one of our strengths. We provide linkages that allow your business to take advantage of he knowledge base stored in universities, government research facilities and industry." 377

In the focus groups, participants described the distribution of advocacy to potential clients as about right. As one participant explained: "you're seeing a bit of a shift, but the lab is very driven by resources and revenues, so we are seeing a bit of a reflection of where is there potential. If we became eligible for more government funding programs, if we could apply to these things, then we might see more of a shift. If there are no resources to be gained, then you don't go there." ${ }^{378}$ Asked why advocacy to

\footnotetext{
${ }^{374}$ Materials Technology Laboratory focus group participants

${ }^{375}$ Materials Technology Laboratory focus group participants

${ }^{376}$ Natural Resources Canada, CANMET Building the future (Ottawa: Public Works and Government Services Canada, 2001), 5.

${ }^{377}$ Natural Resources Canada, 2001, 5.

${ }^{378}$ Materials Technology Laboratory focus group participants
} 
the university sector was smaller than government or industry, the response was that "Abase is tight, there are no government programs to which we're eligible, the universities don't have money, then industry is where we're directed to."379 Universities are not often an end user, and are often seen as a competitor.

\section{Categories of Respondents: Innovators; Champions; Non-Innovators; and Non- Champions}

Are champions also innovating? It is possible to innovate and not champion, where one might discover an innovation, but not promote it. The flip side is not to innovate, but to promote someone else's innovation. Thirty eight percent of respondents were innovators and champions, the largest category in our study. We found $24 \%$ of respondents who had worked on at least one implemented innovation, but who are not promoting both inside and outside the lab. Some innovate, but do not promote.

Another interesting group is respondents who are champions, but not innovators they have promoted the merits of an innovation both inside and outside the lab, and tried to secure resources for the innovation, but did not work on an implemented innovation. This group is $18 \%$ of the total respondents, who were championing innovations of others, or championing an innovation that had not yet been implemented. This suggests that there are many possible opportunities for promoting innovations of others. There are a fifth $(20 \%)$ of respondents who are neither champions nor innovators. One concern in the development of the survey instrument was that everyone would identify himself or herself as an innovator or a champion, but as $20 \%$ of our respondents are non-innovators, non-champions, this did not occur.

\footnotetext{
${ }^{379}$ Materials Technology Laboratory focus group participants
} 
Overall, this paints a picture

where the largest category is

innovators and champions,

followed by innovators and

champions. We expect that

innovators would champion

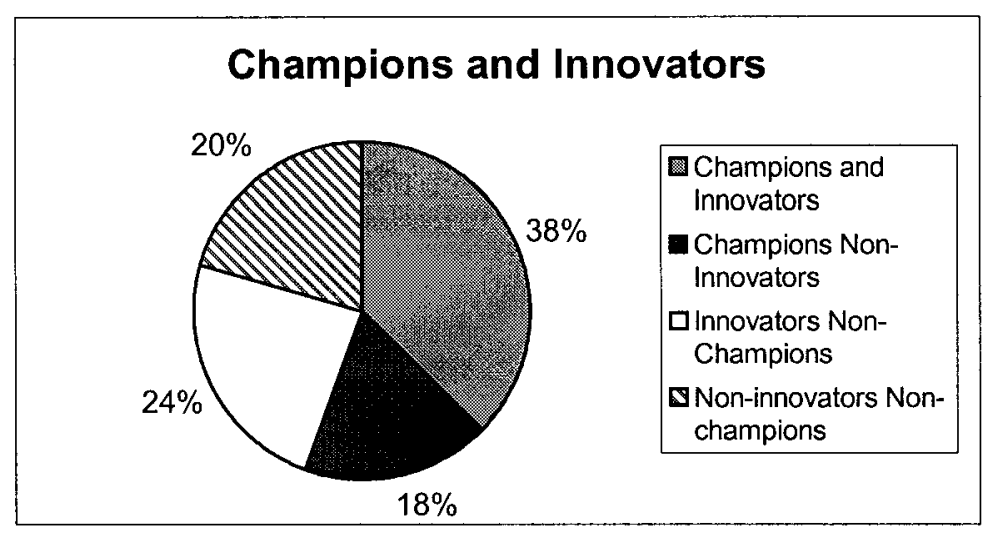

innovations. "Why would they be doing their work if they weren't going to promote

it? ${ }^{\bullet 380}$ We will now examine some characteristics of champions.

\section{Characteristics of Champions}

From our literature review, the characteristics of champions that we decided to examine include: risk taking; taking personal ownership of an innovation; and motivating others to work on innovation. The level in the hierarchy of the champion was also indicated to be important, and will be addressed under the theme of hierarchy and innovation, later in this chapter. This brings us to Hypothesis 3: champions possess three characteristics we have chosen from the literature: taking ownership of innovations; motivating others; and taking risks. We will test this hypothesis using the null hypothesis that champions do not take ownership of innovations; motivate others; and take risks.

We will also examine Hypothesis 4: there are clear differences in the characteristics of champions and non-champions, champions have higher levels of taking ownership of innovations, motivating others and taking risks than non-champions. We will use a chi square or a $\mathrm{T}$ test to see if the results are statistically significant.

${ }^{380}$ Energy Technology Centre Focus Group participants 
Risk Taking

We have previously discussed risk taking as a characteristic of innovators.

Similar to innovators, our hypothesis is that champions are risk lovers, and non-

champions are not. We decided to divide risk-taking into: potential risk takers; and actual risk takers. Risk taking potential was identified as how likely a respondent would be to advocate the merits of an innovation with a $50 / 50$ chance of success. We coded respondents into low medium and high levels of risk taking potential. ${ }^{381}$

\begin{tabular}{|l|c|c|c|}
\hline \multicolumn{4}{|c|}{ Potential Risk Taking and Championing } \\
\hline $\mathrm{N}=85$ & Low & Medium & High \\
\hline Non-champions & $\mathbf{6 6 \%}$ & $\mathbf{2 6 \%}$ & $\mathbf{8 \%}$ \\
\hline Champions & $\mathbf{3 6 \%}$ & $\mathbf{3 6 \%}$ & $\mathbf{2 8 \%}$ \\
\hline Chi Square 8.734 & Sig 0.013 & & \\
\hline
\end{tabular}

Surprisingly, only $28 \%$ of champions were potential high-risk takers, although our chi square of $8.734 \mathrm{p}<0.013$ is significant. When we look at actual risk taking, the bulk of champions ( $84 \%$ ) did not try to secure resources for an innovation they considered had a slight chance of success. Our null hypothesis is that less than $50 \%$ of champions possess this characteristic. As only $16 \%$ of champions took a risk, and this is well below $50 \%$, we cannot reject the null hypothesis, and it appears risk-taking is not a characteristic of champions in our study.

One explanation for these results is maybe champions don't waste time with innovations they don't believe will come to fruition. "This is reflecting the awareness of fiscal limitations and workload. If you have a submission of things to do that have a good chance of success, why would you put your time into something that doesn't have

\footnotetext{
${ }^{381}$ Respondents who were very likely (5) to advocate the innovation were coded as "high" risk taking potential, likely (4) as "medium", and less than 4 as "low" risk taking potential.
} 
as good a chance?"382 Risk takers were considered important, as they are creating flagship programs once in a while. ${ }^{383}$

When we compare the characteristics of champions and non-champions, looking at all the potential high-risk takers, almost all (81\%) were champions. Almost all nonchampions $(92 \%)$ were non-risk takers. We can test the null hypothesis that there are no differences in the characteristics of champions and non-champions. If this is true, the results should not be statistically significant. Our chi square $5.181 \mathrm{p}<0.023$ is statistically significant, so we can reject the null hypothesis. There are clear differences in the characteristics of champions and non-champions.

Summary of Expectations and Results: Risk Taking

\begin{tabular}{|c|c|c|c|c|c|}
\hline & \multicolumn{5}{|c|}{ Possession of Characteristics } \\
\hline & \multicolumn{3}{|c|}{ Expectations } & \multicolumn{2}{|c|}{ Results } \\
\hline Characteristics & Champion & Non & -champion & Champion & Non-champion \\
\hline Risk Takers & More & & Less & Inconclusive & Inconclusive \\
\hline \multicolumn{3}{|c|}{$\begin{array}{l}\text { Hypothesis 3: Champions in our study are } \\
\text { risk-takers. }\end{array}$} & \multicolumn{3}{|c|}{$\begin{array}{l}\text { Results: we cannot reject the null hypothesis } \\
\text { that this is not a characteristic of champions. } \\
\text { Champions in our study are not risk takers. }\end{array}$} \\
\hline \multicolumn{3}{|c|}{$\begin{array}{l}\text { Hypothesis 4: There are clear differences in } \\
\text { the characteristics of champions and non- } \\
\text { champions, champions take risks more than } \\
\text { non-champions. }\end{array}$} & \multicolumn{3}{|c|}{$\begin{array}{l}\text { Results: we can reject the null hypothesis that } \\
\text { there are not differences in the characteristics of } \\
\text { champions and non-champions. Champions } \\
\text { take more risks than non-champions. }\end{array}$} \\
\hline
\end{tabular}

\footnotetext{
${ }^{382}$ Materials Technology Laboratory focus group participants

${ }^{383}$ Energy Technology Centre focus group participants
} 


\section{Innovation Ownership}

One quality of a

champion is that they

take ownership of an

innovation. We

expect that champions

take ownership more

\section{Innovation Ownership}

Don't Know

$13 \%$

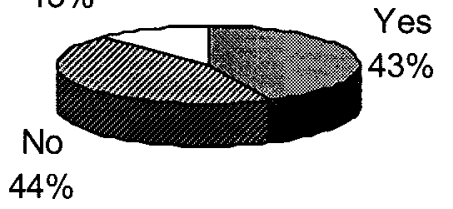

than non- champions.

Overall $43 \%$ of respondents took ownership of an innovation, $44 \%$ did not, and $13 \%$ were not sure. The focus groups were of different opinions on the issue of innovation ownership. There was a clear sense that it is rare to identify innovations with an individual as most innovations are a team affair, and that a project leader may feel that it's his baby, but it's still a team. ${ }^{384}$ However, most allowed for the possibility of one person claiming an innovation as his/her own. There is a lead scientist and a project leader for every project, so it's possible. Also "while there can be many people, there can be one who stands out." $" 385$

We asked champions if any of the innovations that they were involved with they considered to "belong to them" or "be their baby"? Overall, 53\% of champions took ownership of an innovation. This compares to $31 \%$ of non-champions who took ownership of innovations. Many champions considered innovations to be theirs, even if they worked in a team.

\footnotetext{
${ }^{384}$ Materials Technology Laboratory focus group participants

${ }^{385}$ Energy Technology Centre focus group participants
} 


\begin{tabular}{|l|c|c|}
\hline \multicolumn{3}{|c|}{ Innovation Ownership and Championing } \\
\hline $\mathbf{N}=\mathbf{8 8}$ & Non-champions & Champions \\
\hline No ownership & $69 \%$ of non-champions & $\mathbf{4 7 \%}$ of champions \\
\hline Took ownership & $\mathbf{3 1} \%$ of non-champions & $\mathbf{5 3 \%}$ of champions \\
\hline Chi Square 4.398 & Sig 0.036 & $\mathrm{~T}=\mathbf{2 . 1 2 7}$ Sig 0.036 \\
\hline
\end{tabular}

To test hypothesis 3: champions possess the characteristic of innovation ownership, we will use the null hypothesis (Ho), says that taking ownership of an innovation is not a characteristic that champions possess, and so the percentage of champions with this characteristic is less than $50 \%$. From our data, we found that $53 \%(26)$ of our champions took ownership.

$Z=0.53-0.5=0.03 /$ Standard Error $\frac{0.03}{\sqrt{\frac{\text { standard deviation }}{49 \text { champions }}}}=\frac{0.03}{\sqrt{\frac{0.25}{49}}}=\frac{0.03}{0.071}=0.422$

This converts to a value of 0.0948 . Our original test was to see if greater than $50 \%$ of champions did not possess this characteristic, so $0.5-0.0948=0.4052$. This indicates that the probability of drawing this sample by chance is likely $(\mathrm{p}<0.4052)$, so we cannot reject the null hypothesis. We cannot be sure that taking ownership is a characteristic of champions.

For hypothesis 4: there are clear differences in the characteristics of champions and non-champions, our null hypothesis is that there are not clear differences in the characteristics of champions and non-champions. If this is true, our T test will not be statistically significant. The result of our T test $(2.127 \mathrm{p}<0.036)$ is statistically significant, so we can reject the null hypothesis that there are no differences between champions and non-champions. 


\section{Summary of Expectations And Results: Taking Ownership}

\begin{tabular}{|l|c|c|c|c|}
\hline & \multicolumn{3}{|c|}{ Possession of Characteristics } \\
\hline \multicolumn{1}{|c|}{ Characteristics } & \multicolumn{1}{|c|}{ Expectations } & \multicolumn{2}{c|}{ Results } \\
\hline Taking ownership & More & \multicolumn{1}{c|}{ Less } & Champion & Non-champion \\
\hline $\begin{array}{l}\text { Hypothesis 3: Champions possess the } \\
\text { characteristic of taking ownership of } \\
\text { innovations }\end{array}$ & $\begin{array}{l}\text { Results: we cannot reject the null hypothesis } \\
\text { that champions do not take ownership of } \\
\text { innovations. }\end{array}$ \\
\hline $\begin{array}{l}\text { Hypothesis 4: There are clear differences } \\
\text { in the characteristics of champions and } \\
\text { non-champions, champions have higher } \\
\text { levels of taking ownership of innovations. }\end{array}$ & $\begin{array}{l}\text { Results: we can reject the null hypothesis that } \\
\text { there are no differences in the characteristics } \\
\text { of champions and non-champions. } \\
\text { Champions take ownership more than non- } \\
\text { champions. }\end{array}$ \\
\hline
\end{tabular}

\section{Motivating Others}

Championing theory suggests that champions motivate others, generate enthusiasm and support to advance an innovation. We asked "how often respondents found themselves trying to motivate others within the lab to work on an innovation that they're involved with." We divided champions into, "often motivators", who had often or very often tried to motivate someone else to work on an innovation, and "not-often motivators", who tried less frequently to motivate others. We can test hypothesis 3 : champions possess the characteristic of motivating others, using a null hypothesis that champions are not often motivators. If this is true, less than $50 \%$ of the champions would be frequent motivators. Our results indicate that $37 \%$ of champions were often motivators. As this is less than $50 \%$ of champions, we cannot reject the null hypothesis.

For hypothesis 4: there are clear differences in the characteristics of champions and non-champions, champions have high levels of motivating others, we found that $37 \%$ were often motivators, while $15 \%$ of non-champions tried often to motivate others. Our null hypothesis is that there are no differences between the characteristics of champions and non-champions. Our $\mathrm{T}$ test $(\mathrm{T}=2.274 \mathrm{p}<0.025)$ of the differences between 
champions and non-champions is statistically significant, so we can reject the null hypothesis that there are no differences between champions and non-champions.

While champions try to motivate others more often than non-champions, it is still a smaller percentage than one might have expected. As one focus group participant noted "I'm shocked that it's not very often. I was expecting one big curve going upwards." 386 Another provided a potential explanation: "There are projects that are very innovative, very successful, where the project leader works over lunch, doesn't take coffee breaks, once he has his target defined, he is very innovative creative, and so on, but may not motivate others." ${ }^{387}$ Some may not see motivation as part of their job.

Summary of Expectations and Results: Motivating Others

\begin{tabular}{|c|c|c|c|c|}
\hline & \multicolumn{3}{|c|}{ Possession of Characteristics } \\
\hline & \multicolumn{3}{|c|}{ Expectations } \\
\hline Characteristics & Champion & Non-champion & \multicolumn{1}{c|}{ Champion } & Non-champion \\
\hline Motivating others & \multicolumn{1}{|c|}{ More } & \multicolumn{1}{|c|}{ Less } & Inconclusive & Inconclusive \\
\hline $\begin{array}{l}\text { Hypothesis 3: Champions possess the } \\
\text { characteristic of motivating others }\end{array}$ & $\begin{array}{l}\text { Results: we cannot reject the null } \\
\text { hypothesis that champions do not motivate } \\
\text { others. }\end{array}$ \\
\hline $\begin{array}{l}\text { Hypothesis 4: There are clear differences in } \\
\text { the characteristics of champions and non- } \\
\text { champions, champions have higher levels of } \\
\text { motivating others than non-champions. }\end{array}$ & $\begin{array}{l}\text { Results: we can reject the null hypothesis } \\
\text { that there are no differences in the } \\
\text { characteristics of champions and non- } \\
\text { champions. Champions have higher levels } \\
\text { of motivating others than non-champions. }\end{array}$ \\
\hline
\end{tabular}

We have completed our examination of our first theme, the characteristics of innovators and champions. We have proposed that innovators possess three characteristics including: competence; cosmopolitanism; and risk taking. We have found that innovators in our study possess the characteristics of competence and cosmopolitanism, but are not risk takers. We have also hypothesized that there are clear differences in the characteristics of innovators and non-innovators. We have found that

\footnotetext{
${ }^{386}$ Energy Technology Centre focus group participants

${ }^{387}$ Canada Centre for Remote Sensing focus group participants
} 
there are differences in the characteristics of competence and risk taking, but for cosmopolitanism, while the results are directionally as we expected, they are not statistically significant.

We expected that champions possess three characteristics including: taking ownership of innovation; motivating others; and taking risks. We have found that contrary to our expectations, the majority of champions do not take ownership of innovations, they are not risk takers, nor do they motivate others. We also tested the hypothesis that there are clear differences in the characteristics of champions and nonchampions, and we have found that on all three factors our results are as we expected. While the majority of champions do not possess these characteristics, champions take risks, ownership and motivate others more than non-champions. In the next section, we examine the results related to our second analytical theme of hierarchy and its relationship to innovation and championing.

\section{Theme 2 Results: Hierarchy and Innovation and Championing}

To examine hierarchy and its relationship to innovation and championing, we divided respondents into a subgroup of employees and managers who could: assign subordinates to work on an innovation; allocate funds greater than $\$ 10000$ towards an innovation; and allocate equipment to be used to work on an innovation. We call this subgroup the "elite". We found that $18 \%$ of respondents are the elite, including a few staff respondents. In the three labs, MTL had the highest percentage (29\%) of elites, compared to $17 \%$ in CCRS and $14 \%$ in CETC, although

\begin{tabular}{|l|c|c|}
\hline \multicolumn{3}{|c|}{ Elites } \\
\hline N=88 & Non-elites & Elites \\
\hline CETC & $\mathbf{8 6 \%}$ & $14 \%$ \\
\hline MTL & $71 \%$ & $29 \%$ \\
\hline CCRS & $83 \%$ & $17 \%$ \\
\hline Overall & $82 \%$ & $18 \%$ \\
\hline Chi Square 2.078 & Sig 0.354 & \\
\hline
\end{tabular}


our chi square $2.078 p<0.354$ is not significant. In total, only 16 respondents are elites, so the following analysis is based upon all elites and will not be broken out by lab.

We can test hypothesis 5: there is a positive relationship between hierarchy, innovation, and championing, a higher proportion of elites are innovators, and champions compared to non-elites. We can test the null hypothesis (Ho) that there are no differences in the characteristics of innovators and champions. We found a slightly higher percentage $(69 \%)$ of elites are innovating than non-elites $(60 \%)$. Our T test $(\mathrm{T}=0.665 \mathrm{p}$ $<0.504)$ is not statistically significant, so we cannot reject the null hypothesis.

When we look at elites and championing, we find that almost all of the elite

\begin{tabular}{|l|c|c|}
\hline \multicolumn{3}{|c|}{ Elites and Championing } \\
\hline $\mathbf{N}=\mathbf{8 8}$ & Non-champions & Champions \\
\hline Non-elite & $\mathbf{5 1 \%}$ of non-elite & $\mathbf{4 9 \%}$ of non-elite \\
\hline Elite & $\mathbf{1 2 \%}$ of elite & $\mathbf{8 8 \%}$ of elite \\
\hline Chi Square 8.023 & Sig 0.005 & $\mathbf{T}=3.740$ Sig $=\mathbf{0 . 0 0 1}$ \\
\hline
\end{tabular}

(88\%) are champions, compared with $49 \%$ of non-elites who are championing. Our null hypothesis is that there are not differences in the characteristics of elites and non-elites. Our chi square of $8.023 p<0.005$ is statistically significant, so we can reject the null hypothesis. A higher proportion of the elite are champions, compared to non-elites.

\begin{tabular}{|l|c|c|c|c|}
\hline & \multicolumn{4}{|c|}{ Possession of Characteristics } \\
\hline & \multicolumn{2}{|c|}{ Expectations } & \multicolumn{2}{c|}{ Results } \\
\hline \multicolumn{1}{|c|}{ Characteristics } & Elite & Non-elite & Elite & Non-elite \\
\hline $\begin{array}{l}\text { Innovators and } \\
\text { champions }\end{array}$ & More & \multicolumn{1}{|c|}{ Less } & More* & Less* \\
\hline $\begin{array}{l}\text { Hypothesis 5: there is a positive } \\
\text { relationship between hierarchy, innovation, } \\
\text { and championing, a higher proportion of } \\
\text { elites are innovators, and champions } \\
\text { compared to non-elites. }\end{array}$ & $\begin{array}{l}\text { Results: *we cannot reject the null hypothesis } \\
\text { that elites are not innovators, although our } \\
\text { results are directionally consistent with our } \\
\text { research hypothesis. However, we can reject } \\
\text { the null hypothesis that elites are not } \\
\text { champions. }\end{array}$ \\
\hline
\end{tabular}




\section{Success Advocating}

While most elites are innovating or championing, we are also interested in finding out if elites are successful champions. We want to test hypothesis 6: there is a positive relationship between hierarchy and success championing where elites are more successful champions than non-elites. Our results indicate that elites are somewhat more

successful $^{388}$ at advocating than non- elites, with $36 \%$ saying they were successful or very

\section{How successful were you advocating?}

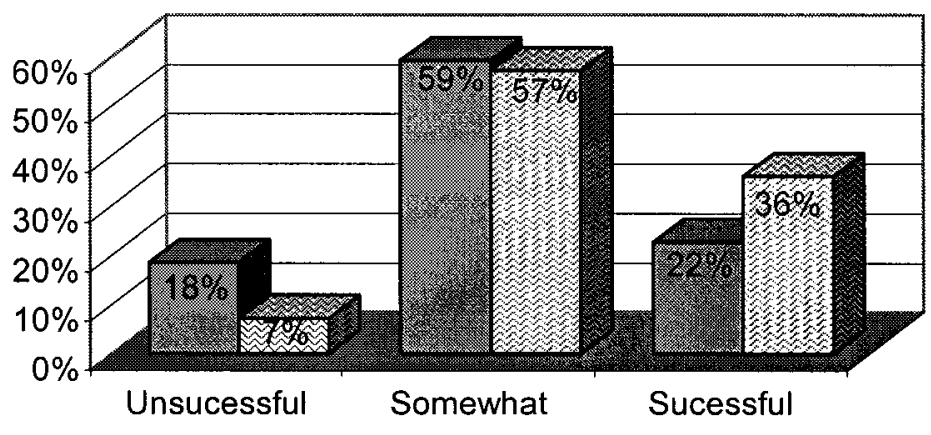

圆Non-elite $\mathrm{O}$ Elite

successful,

compared to $22 \%$ of non-elites. A lower percentage ( $7 \%$ ) of elites were unsuccessful than non-elites $(18 \%)$. We can test the null hypothesis $(\mathrm{Ho})$ that there are no differences between elites and non-elites. Our chi square $1.626(\mathrm{p}<0.443)$ is not statistically significant, so we cannot reject the null hypothesis, although the differences in the success of elites and non-elites championing are directionally as expected.

\footnotetext{
${ }^{388}$ Success was identified by respondents who responded "successful" or "very successful" when asked how successful they thought they were at promoting the technical or other merits of an innovation.
} 


\begin{tabular}{|c|c|c|c|c|}
\hline & \multicolumn{4}{|c|}{ Possession of Characteristics } \\
\hline & \multicolumn{2}{|c|}{ Expectations } & \multicolumn{2}{|c|}{$\begin{array}{r}\text { Results } \\
\end{array}$} \\
\hline Characteristics & Elite & Non-elite & Elite & Non-elite \\
\hline Success innovating & More & Less & More* & Less* \\
\hline \multicolumn{2}{|c|}{$\begin{array}{l}\text { Hypothesis 6: there is a positive } \\
\text { relationship between hierarchy and success } \\
\text { championing where elites are more } \\
\text { successful champions than non-elites. }\end{array}$} & \multicolumn{3}{|c|}{$\begin{array}{l}\text { Results: we cannot reject the null hypothesis } \\
\text { that there are no differences in the success } \\
\text { innovating of elites and non-elites. The } \\
\text { results are directionally consistent with our } \\
\text { research hypothesis. }\end{array}$} \\
\hline
\end{tabular}

\section{Other Characteristics of Elites}

While not a specific research question in our study, we found a few characteristics of elites that we will now share as areas for potential future research. One characteristic of elites is that they appear to be cosmopolitans. Eighty-one percent of elites possess high cosmopolitan characteristics, although our Chi Square $7.232 \mathrm{p}<0.27$ is not statistically significant.

\begin{tabular}{|l|c|c|c|}
\hline \multicolumn{4}{|c|}{ Elites and Cosmopolitanism } \\
\hline $\mathrm{N}=88$ & Low cosmopolitan & $\begin{array}{c}\text { Medium } \\
\text { cosmopolitan }\end{array}$ & High cosmopolitan \\
\hline Non-elite & $\mathbf{2 8 \%}$ & $\mathbf{2 8 \%}$ & $\mathbf{4 4 \%}$ \\
\hline Elite & $\mathbf{6 \%}$ & $13 \%$ & $\mathbf{8 1 \%}$ \\
\hline Chi Square 7.232 & Sig 0.27 & & \\
\hline
\end{tabular}

Given the relative success and ownership rates, one might have expected that elites might be risk takers. However, $85 \%$ of elites are not risk takers. This indicates that the elites go where there is less risk and they are likely to succeed. Comparatively, $24 \%$ of non-elites are risk takers, although our chi square $(0.394 \mathrm{p}<0.530)$ is not statistically significant. As elites appeared to be successful in promoting innovations, did they take ownership? We found that $63 \%$ of elites took ownership of an innovation, compared to $39 \%$ of non-elites, suggesting a difference, which our chi square $(2.975 \mathrm{p}<$ 0.085 ) indicates is statistically significant. We were curious to see if elites were 
motivating others to work on an innovation. Our results suggest that $56 \%$ of elites tried to motivate others, compared to $21 \%$ of non-elites, which we also found to be statistically significant (chi square $8.279 \mathrm{p}<0.004$ ). These characteristics are meant to provide potential areas for future research on the characteristics of elites. In the next section, we examine the hierarchical level of the technical specialists, which is believed to be related to innovation.

\section{The Technical Specialist}

Along with elites, the technical specialist is thought to be a main source of innovation. We identified staff respondents as technical specialists who were approached often or very often to solve difficult technical problems in (or near) their field and whose technical expertise allows them to influence the acceptance/rejection of innovations in the lab. We identified $22 \%$ of all staff respondents as technical specialists, $(\mathrm{N}=13)$, so we will not break down the analysis by lab.

Our comparison group of non-specialists is made up of only staff members $(\mathrm{N}=59)$. We want to compare staff members with technical expertise to other staff, not management. We can now test hypothesis $7:$ there is a positive relationship between hierarchy, innovation, and championing, a higher proportion of technical specialists are innovators, and champions compared to non-technical specialists. We can test the null hypothesis (Ho) that there are no differences in the characteristics of technical specialists and non-specialists. Our results indicate that almost all technical specialists (92\%) worked on an implemented innovation. This compares to $46 \%$ of technical nonspecialists who worked on an implemented innovation. Chi Square $8.951 \mathrm{p}<0.003$ is 
statistically significant, so we can reject the null hypothesis. Our findings agree with the literature that technical specialists are innovators.

For the relationship between championing and technical specialists, we found that $62 \%$ of technical specialists are champions, compared to $46 \%$ of staff non-specialists.

We want to test the null hypothesis that there are no differences in the characteristics of technical specialists and non-specialists. Our chi square $1.023 \mathrm{p}<0.312$ is not statistically significant, so we cannot reject the null hypothesis, although the results are directionally consistent with our expectations.

\begin{tabular}{|c|c|c|c|c|c|}
\hline & \multicolumn{5}{|c|}{ Possession of Characteristics } \\
\hline & \multicolumn{3}{|c|}{ Expectations } & \multicolumn{2}{|c|}{ Results } \\
\hline Characteristics & $\begin{array}{l}\text { Technical } \\
\text { Specialist }\end{array}$ & $\begin{array}{r}\text { Non- } \\
\text { Sp }\end{array}$ & & & $\begin{array}{l}\text { Non-Technical } \\
\text { Specialist }\end{array}$ \\
\hline & More & & & More* & \\
\hline \multicolumn{3}{|c|}{$\begin{array}{l}\text { Hypothesis 7: there is a positive } \\
\text { relationship between hierarchy, innovation, } \\
\text { and championing, a higher proportion of } \\
\text { technical specialists are innovators, and } \\
\text { champions compared to non-technical } \\
\text { specialists. }\end{array}$} & \multicolumn{3}{|c|}{$\begin{array}{l}\text { Results: we can reject the null hypothesis that } \\
\text { there are no differences in innovation between } \\
\text { technical specialists and non-specialists. } \\
\text { We cannot reject the null hypothesis that ther } \\
\text { are no differences in championing of } \\
\text { technical specialists and non-specialists. }\end{array}$} \\
\hline
\end{tabular}

\section{Success Advocating and Other Characteristics of Technical Specialists}

Because technical

specialists have

expertise, we expected

they would be

successful in

promoting innovations

on their technical

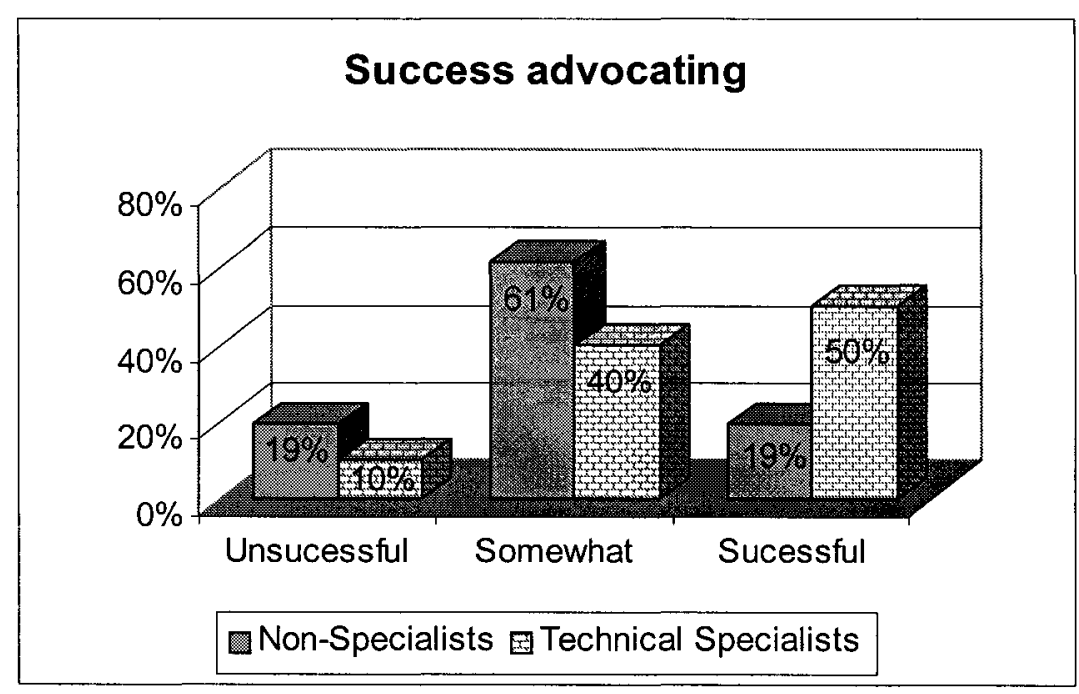


merits. Hypothesis 8: There is a positive relationship between hierarchy and success championing where technical specialists are more successful championing than nontechnical specialists. We found half of technical specialists were successful or very successful advancing an innovation, $40 \%$ were somewhat successful and $10 \%$ were unsuccessful. This compares with $19 \%$ of non-specialists who were successful, $61 \%$ somewhat successful and 19\% unsuccessful. Our null hypothesis (Ho) is that there are no differences in the success of technical specialists and non-specialists. Our chi square $(3.645 \mathrm{p}<0.162)$ is not statistically significant, so we cannot reject the null hypothesis, although our results are directionally consistent with our research hypothesis.

\begin{tabular}{|c|c|c|c|c|c|}
\hline & \multicolumn{5}{|c|}{ Possession of Characteristics } \\
\hline & \multicolumn{3}{|c|}{ Expectations } & \multicolumn{2}{|c|}{ Results } \\
\hline Characteristics & $\begin{array}{l}\text { Technical } \\
\text { Specialist }\end{array}$ & $\begin{array}{r}\text { Non- } \\
\text { Sp }\end{array}$ & $\begin{array}{l}\text { Technical } \\
\text { ecialist }\end{array}$ & $\begin{array}{l}\text { Technical } \\
\text { Specialist }\end{array}$ & $\begin{array}{l}\text { Non-Technical } \\
\text { Specialist }\end{array}$ \\
\hline $\begin{array}{l}\text { Innovators and } \\
\text { champions }\end{array}$ & More & & Less & More* & Less* \\
\hline \multicolumn{3}{|c|}{$\begin{array}{l}\text { Hypothesis 8: There is a positive } \\
\text { relationship between hierarchy and success } \\
\text { championing where technical specialists } \\
\text { are more successful championing than non- } \\
\text { technical specialists. }\end{array}$} & \multicolumn{3}{|c|}{$\begin{array}{l}\text { Results: we cannot reject the null hypothesis, } \\
\text { although our findings are directionally } \\
\text { consistent with our research hypothesis. }\end{array}$} \\
\hline
\end{tabular}

While there are only a small number of technical specialists in our survey, we checked to see if they matched any of our other characteristics. We now present a few of our findings as areas for future research. Our results indicate that technical specialists were evenly split between risk takers (50\%) and non-risk takers. This compares to $85 \%$ of non-specialists who are not risk takers, although our results (chi square $4.176 \mathrm{p}<0.41$ ) are not statistically significant. We also found that more specialists took ownership of an innovation (46\%) compared to non-specialists (30\%), although our results (Chi square $1.18 \mathrm{p}<0.290$ ) are not statistically significant. 
This concludes our examination of our second theme of the relationship between hierarchy, innovation and championing. Unfortunately, we were unable to produce statistically significant results for many of the hypotheses, although our results were directionally consistent with the literature. Our main findings related to the elites were that a higher percentage of elites are champions than non-elites, and the relationship between elites and innovation is directionally consistent with the hypothesis, but not statistically significant. Elites are more successful champions, although our results are not statistically significant.

For technical specialists, we found a statistically significant higher percentage of technical specialists were innovators compared to non-technical specialists. Technical specialists and non-specialists did not differ on the characteristics of championing. Technical specialists were more successful championing, although the results were not statistically significant. In the next section, we will look at the method of championing used and the barriers faced.

\section{Theme 3 Results: Overcoming Barriers; the Rational, Participative and Renegade Championing Processes}

Our third theme looks at the methods champions use to advance innovations and what barriers they face. Do champions advance innovations using any of the three methods suggested in the literature: the rational; participative; and renegade process? The rational process involves discussing and promoting an innovation to a supervisor/ boss, and seeking approval to go forward. After receiving approval, the innovation is advanced. In the participative process, the innovator tries to enlist colleague's support to advance the innovation. In the renegade process, an innovator works on the innovation alone, often without the approval of management. 
We can test hypothesis 9: The rational and participative processes are used more often by champions than the renegade process. We found that almost half $(47 \%)$ of champions were using the rational process of consulting with their boss to advance an innovation. ${ }^{389}$ We found $35 \%$ of champions were using the participative process. ${ }^{390}$ It is somewhat surprising that the use of the participative process is less than half, given the teamwork environment. It is possible to use both the rational and the participative processes in advancing an innovation. Of those using the rational process, only $27 \%$ also used the participative process. In the focus groups the use of multiple methods was identified. "Usually, you would go to both your boss and colleagues.",391

In the labs, we found that the largest percentage of champions using the rational process

was in CCRS (46\%)

and the smallest

percentage is in

$\operatorname{MTL}(29 \%)$,

although our chi

square $2.042 \mathrm{p}<$

0.360 is not

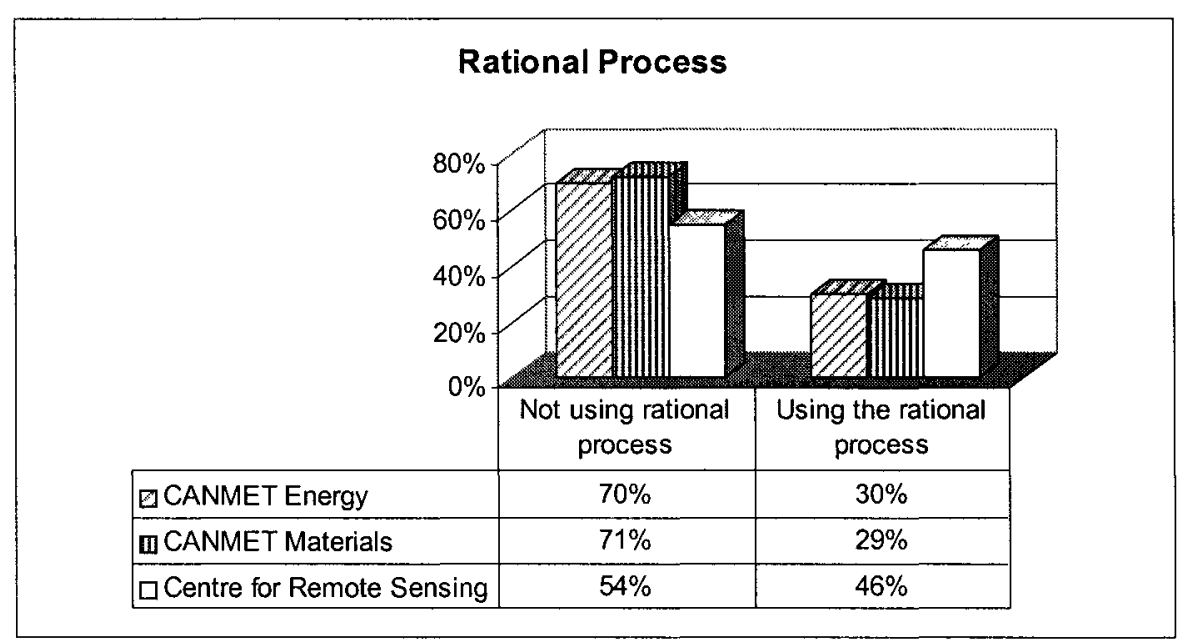

significant.

The participative process was used by $38 \%$ of MTL champions. As one participant stated: "Not very many innovators work in isolation around here, you can't do

\footnotetext{
${ }^{389} \mathrm{~N}=23$ champions using rational process.

${ }^{390} \mathrm{~N}=17$ champions using the participative process

${ }^{391}$ Materials Technology Laboratory focus group participants
} 
it alone." ${ }^{392}$ In CCRS, we found the highest percentage (46\%) of champions using the participative innovative process, although percentages were smaller than we expected to find, and our chi square $0.588 \mathrm{p}<0.745$ is not significant.

However, participants
pointed out sometimes
there is no value to
colleagues' support.

\begin{tabular}{|l|c|c|}
\hline \multicolumn{3}{|c|}{ Participative Innovation Process } \\
\hline N=88 & $\begin{array}{c}\text { Non- } \\
\text { Participative }\end{array}$ & $\begin{array}{c}\text { Using } \\
\text { Participative } \\
\text { Process }\end{array}$ \\
\hline CETC & $67 \%$ & $33 \%$ \\
\hline MTL & $62 \%$ & $38 \%$ \\
\hline CCRS & $58 \%$ & $33 \%$ \\
\hline Overall & $64 \%$ & $36 \%$ \\
\hline Chi Square 0.588 & Sig $=0.745$ & \\
\hline
\end{tabular}

We found that only $2.0 \%$ of champions were likely to use the renegade process.

It could be so few people use this because so much of the work is done in teams. "It's the odd individual who wants to do it alone, but they are not very successful."393 Other reasons may relate to control over resources and activities. ${ }^{394}$ Another reason why champions may not want to use the renegade innovative process identified by focus group participants was to go over your supervisor's head was an indication of disrespect. ${ }^{395}$ Also, it's not just that they are the boss, but they have technical expertise. Even if this was not true, "there was a residual collegiality involved.",396

\section{Championing Process Used}

Hypothesis 9: the rational and participative Results: we can confirm the hypothesis that processes are used more often by champions than the renegade process. the rational and participative processes are used more often than the renegade process.

In spite of all of the reasons against the use of the renegade process, in the focus groups, it was clear that if a renegade's innovation were useful, it definitely would be put

\footnotetext{
392 Materials Technology Laboratory focus group participants

${ }^{393}$ Materials Technology Laboratory focus group participants

${ }^{394}$ Canada Centre for Remote Sensing focus group participants

395 Materials Technology Laboratory focus group participants

${ }^{396}$ Canada Centre for Remote Sensing focus group participants
} 
into use. Overall, we found the rational process was slightly more successful $(36 \%)$ than the participative process (28\%). When both processes were used, the chances for success are about the same (35\%). None of the chi square values were significant. While the renegade process was successful in all attempts, this was based on a very small number of cases (3).

\section{What Problems Did You Encounter?}

We found that the largest problem encountered in advancing an innovation in government labs, identified by $41 \%$ of respondents was resources. Another $12 \%$ of respondents identified lack of time as a major problem. "Both preference for other projects and lack of time indicate a generally competitive environment to get an idea through. More projects than there are resources for, so it's like an internally dependent process allocating those resources." 397

Since respondents were only allowed to identify one major problem, it is possible that those who identified a lack of resources as a major problem also faced technological problems, or skepticism and indifference. As one focus group participant noted: "It's interesting how people gloss over the technological problems, but that's to be expected from innovators. It all is resources. Give me enough money and I'll solve your problem." 398 Other problems may be underestimated.

Another interesting observation was that problems are partially sequential. "If you don't have any lack of resources, then you don't get to the technical problems, then once you get to the technical problems and solve those, then you can get to the lack of market. These things are sequential. The fact that the lack of market is so low suggests

\footnotetext{
${ }^{397}$ Materials Technology Laboratory focus group participants

${ }^{398}$ Energy Technology Centre focus group participants
} 
that lots of innovations are stopped because they don't get the resources." 399 Resources may be the first in a series of hurdles. Part of the perceived problem of resources may also be one of timing: "There are notions that things need to be done at a certain pace."400 Resources may be a problem to get completion quickly.

\section{Chapter Summary}

In this chapter, we have examined the results of our survey and focus groups related to three themes of individual innovation. The first theme was the characteristics of innovators and champions. We expected that innovators would possess three characteristics: competence; cosmopolitanism; and risk taking, and there would be differences between innovators and non-innovators. We found that innovators possessed the characteristics of competence and cosmopolitanism, but were not risk-takers. We found clear differences between innovators and non-innovators on these characteristics, although in the case of cosmopolitanism, the differences were not statistically significant.

We expected that champions would possess three characteristics: taking ownership of innovators, motivating others; and taking risks, and there would be differences between champions and non-champions. Our findings indicated that champions in our study did not possess the characteristics of taking ownership; motivating others or take-risks, statistically different from non-champions. Comparing champions and non-champions, there were clear differences in all three characteristics, so while as large a percentage of champions did not possess the characteristics we expected, a higher percentage of champions had these characteristics than non-champions.

\footnotetext{
${ }^{399}$ Energy Technology Centre focus group participants

${ }^{400}$ Materials Technology Laboratory focus group participants
} 
Our second theme examined the relationship between hierarchy, innovation and championing by looking at elites and technical specialists, expecting that both would be innovators and champions, and they would be more successful than non-elites and nontechnical specialists. We found that there was a positive relationship between hierarchy and innovation, where elites were champions more than non-elites, although related to innovation, differences between elites and non-elites were not statistically significant. Elites were also found to be more successful championing than non-elites, although the results were not statistically significant. Similarly, a larger percentage of technical specialists were also found to be innovating than non-technical specialists. Technical specialists were also found to be championing and also had more success championing than technical non-specialists, although the results were not statistically significant.

Our third theme examined the processes that champions used to advance innovations: the rational; participative; and renegade process, as well as the barriers faced by champions. Our findings indicate that almost half of respondents used the rational process, and a little over a third used the participative process, and only a very small percentage used the renegade process. The rational and participative processes were used more often. Resources were the major problem advancing innovation. Please see the table below for results related to each hypothesis. In the next chapter, we change our lens from the individual to the institutional. 


\begin{tabular}{|c|c|c|c|c|}
\hline $\begin{array}{l}\text { Hypothesis } \\
\#\end{array}$ & Hypothesis & \multicolumn{3}{|c|}{$\begin{array}{c}\text { Accept/Reject Null } \\
\text { Hypothesis? } \\
\end{array}$} \\
\hline $\begin{array}{l}\text { Hypothesis } \\
\text { 1: }\end{array}$ & $\begin{array}{l}\text { Innovators possess three characteristics we have } \\
\text { chosen from the literature: competence; } \\
\text { cosmopolitanism; and risk taking. }\end{array}$ & $\begin{array}{l}\text { Competence } \\
\text { Cosmopol } \\
\text { Risk taking }\end{array}$ & $\begin{array}{l}\mathrm{R} \\
\mathrm{R}\end{array}$ & A \\
\hline $\begin{array}{c}\text { Hypothesis } \\
\text { 2: }\end{array}$ & $\begin{array}{l}\text { There are clear differences in the characteristics of } \\
\text { innovators and non-innovators, innovators have } \\
\text { higher levels of competence, participate more in } \\
\text { cosmopolitan activities, and are more risk-loving } \\
\text { than non-innovators. }\end{array}$ & $\begin{array}{l}\text { Competence } \\
\text { Cosmopol } \\
\text { Risk taking }\end{array}$ & $\mathrm{R}$ & A \\
\hline $\begin{array}{c}\text { Hypothesis } \\
\text { 3: }\end{array}$ & $\begin{array}{l}\text { Champions possess three characteristics we have } \\
\text { chosen from the literature: taking ownership of } \\
\text { innovations; motivating others; and taking risks. }\end{array}$ & $\begin{array}{l}\text { Ownership } \\
\text { Motivating } \\
\text { Risk taking }\end{array}$ & & $\begin{array}{l}\mathrm{A} \\
\mathrm{A} \\
\mathrm{A}\end{array}$ \\
\hline $\begin{array}{c}\text { Hypothesis } \\
\text { 4: }\end{array}$ & $\begin{array}{l}\text { There are clear differences in the characteristics of } \\
\text { champions and non-champions, champions have } \\
\text { higher levels of taking ownership of innovations, } \\
\text { motivating others and taking risks than non- } \\
\text { champions. }\end{array}$ & $\begin{array}{l}\text { Ownership } \\
\text { Motivating } \\
\text { Risk taking }\end{array}$ & $\begin{array}{l}\mathrm{R} \\
\mathrm{R} \\
\mathrm{R}\end{array}$ & \\
\hline $\begin{array}{l}\text { Hypothesis } \\
\text { 5: }\end{array}$ & $\begin{array}{l}\text { There is a positive relationship between hierarchy, } \\
\text { innovation, and championing, a higher proportion } \\
\text { of elites are innovators, and champions compared } \\
\text { to non-elites. }\end{array}$ & $\begin{array}{l}\text { Innovators } \\
\text { Champions }\end{array}$ & $\mathrm{R}$ & $\mathrm{A}^{*}$ \\
\hline $\begin{array}{c}\text { Hypothesis } \\
\text { 6: }\end{array}$ & $\begin{array}{l}\text { There is a positive relationship between hierarchy } \\
\text { and success championing where elites are more } \\
\text { successful champions than non-elites. }\end{array}$ & Success & & $\mathrm{A}^{*}$ \\
\hline $\begin{array}{c}\text { Hypothesis } \\
7:\end{array}$ & $\begin{array}{l}\text { There is a positive relationship between hierarchy, } \\
\text { innovation, and championing, a higher proportion } \\
\text { of technical specialists are innovators, and } \\
\text { champions compared to non-technical specialists. }\end{array}$ & $\begin{array}{l}\text { Innovators } \\
\text { Champions }\end{array}$ & $\mathrm{R}$ & $\mathrm{A}^{*}$ \\
\hline $\begin{array}{c}\text { Hypothesis } \\
\text { 8: }\end{array}$ & $\begin{array}{l}\text { There is a positive relationship between hierarchy } \\
\text { and success championing where technical } \\
\text { specialists are more successful championing than } \\
\text { non-technical specialists. }\end{array}$ & Success & & $\mathrm{A}^{*}$ \\
\hline $\begin{array}{c}\text { Hypothesis } \\
\text { 9: }\end{array}$ & $\begin{array}{l}\text { The rational and participative processes are used } \\
\text { more often by champions than the renegade } \\
\text { process. }\end{array}$ & Process & $\mathrm{R}$ & \\
\hline
\end{tabular}

* = Findings directionally consistent with hypothesis but not statistically significant 


\section{CHAPTER 4: RESULTS: INSTITUTIONAL FACTORS}

In this chapter we switch to the institutional lens to provide results related to our four main analytical themes: publicness; political direction and interest; recognition and rewards preference; and work environment. To help the reader understand the broader context we begin with a brief description and analysis of Natural Resources Canada (NRCan) and each of the three labs in our study: CANMET Materials Technology Laboratory (MTL); CANMET Energy Technology Centre (CETC); and Canada Centre for Remote Sensing (CCRS).

\section{Natural Resources Canada (NRCan) and the Labs}

Natural Resources Canada (NRCan), and its previous namesake Energy, Mines and Resources Canada trace their roots to the earliest days of federal government science, well before the turn of the century. Initial emphasis was heavily towards natural resource utilization. ${ }^{401}$ The role of the department was to provide support and assistance to its constituent industries: mining and metals; energy; and forestry. "This central image is still fundamental to understanding NRCan as an institution, because its support of resources industries is still at the heart of its mandate and its internal culture. ${ }^{, 402}$ Recent NRCan documents support this opinion, indicating NRCan has a role to help position Canada's natural resources sector as a world leader in innovation, sustaining our comparative global advantage in natural resources products and services. ${ }^{403}$

\footnotetext{
${ }^{401}$ M.E. Smith, "The Role of Federal Laboratories in the Technological Development of Canadian Industry," in Journal of Canadian Studies Vol 17, no. 4 (Winter 1982-83), 10.

${ }_{402}$ Bruce Doern and Monica Gattinger, "New Economy/Old Economy? Transforming Natural Resources Canada," in How Ottawa Spends 2001-02: Power in Transition, 2002, (Toronto: Oxford University Press, 2002),225.

${ }^{403}$ Natural Resources Canada, Report on Plans and Priorities 2002-2003 (Ottawa: Public Works and Government Services Canada, 2002), 10.
} 


\section{CANMET Materials Technology Laboratory (MTL)}

The Materials Technology Laboratory (MTL) is one of the five major laboratories that form CANMET; the Canada Centre for Mineral and Energy Technology - the main research and technology arm of Natural Resources Canada. ${ }^{404}$ MTL began with CANMET's creation in 1907 under the mandate to undertake R\&D on the extraction of Canadian mineral resources. ${ }^{405}$ MTL is the largest research facility in Canada dedicated to metals, ceramics and concrete technology, with nearly 100 scientists and more than $6000 \mathrm{~m}^{2}$ of laboratory space. ${ }^{406}$ While there have been some changes in the last hundred years, its current mandate: "to develop and deploy technologies to improve all aspects of producing and using value added products from metals and minerals, with particular emphasis on solving technological problems of relevance to NRCan's mandate in sustainable development, and on transferring materials technology to Canadian industry ${ }^{907}$ remains similar.

MTL appears to have two overarching goals: first; to encourage sustainable development and protect/ increase the public good and second; to transfer technology to Canadian industry to enhance efficiency and effectiveness. To encourage sustainable development and the public good, through its research facilities and its funding programs, MTL works with the minerals, metals and energy industries to find safer, cleaner and

\footnotetext{
${ }^{404}$ Natural Resources Canada, CANMET Building the future (Ottawa: Public Works and Government Services Canada, 2001), 3.

${ }^{405}$ Frances Anderson and Charles Davis, "The government research infrastructure," in Science And Technology in Canada, Paul dufour and John de la Mothe editors, (Essex: Longman,1993).

${ }^{406}$ Natural Resources Canada, CANMET Building the future (Ottawa: Public Works and Government Services Canada, 2001), 10.

${ }^{407}$ CANMET MTL, MTL Business Plan 2003-2006 Not Published, (2003), 5.
} 
more efficient methods to develop and use Canada's mineral and energy resources. ${ }^{408}$ MTL develops technology: that can be used to reduce greenhouse gas emissions; results in innovative products within a sustainable development framework; reduces environmental impacts; and enhances health, security and safety. ${ }^{409}$

MTL does not administer any acts or regulations, and although MTL staff are often called upon to provide input into technical standards on technology and processes, they are not responsible for writing acts or regulations. "CANMET-MTL is at the forefront of the application and support of corrosion data management systems and contributes substantially to the writing of international standards." ${ }^{410}$ Approximately 5\% of the lab's total employees work on input for technical standards. This work can be innovative as it involves the creation of new test methodologies and processes, which are used to test a new or improved standard.

Through the transfer of materials technology to industry, MTL hopes to ensure the competitiveness of Canadian industry. "MTL, recognizing that job creation and economic growth will occur through the growth of small and medium-sized enterprises, strives to ensure the competitiveness of these industries by advising them on how to improve their products and processes. ${ }^{, 411}$ As many projects are directed towards industry, MTL works closely with partners to address their needs. The closeness of the relationship with industry and the type of research undertaken (core vs. industry focused) are important considerations for this lab.

\footnotetext{
${ }^{408}$ CANMET, CANMET Annual Report 1993-94 (Ottawa: Supply and Services Canada, 1994), "Mission and mandate" and CANMET, CANMET'95 New Directions (Ottawa: Supply and Services Canada, 1995), foreword.

${ }^{409}$ CANMET, CANMET Annual Report 1993-94 (Ottawa: Supply and Services Canada, 1994), 8.

${ }^{410}$ CANMET MTL, "Corrosion and Protection," accessed January 2004, CANMET MTL Website [http://www.nrcan.gc.ca/mms/canmet-mtb/mtl/scientific/corrostion_e.htm]

411 CANMET MTL, "What we do," accessed January 2004, CANMET MTL Website [http:/www.nrcan.gc.ca/mms/canmet-mtb/mtl/default_e.htm]
} 
MTL is organized into Engineering and Technical Services and Functional Groups. MTL also operates a test center for the Non-Destructive Testing Certifying Agency, ${ }^{412}$ administering the testing process that leads to certificates in non-destructive testing. MTL conducts research programs, which focus on five areas: advanced concrete; advanced materials; efficient metal production; infrastructure reliability; and sustainable casting.

Engineering and Technical Services is organized into Electrical and Electronics Services, Fabrication and Manufacturing Services and Technical Services-stores. MTL's Engineering and Technical Services provides mechanical, electrical, electronics and pattern-making services. Understanding the business and complex requirements of their clients is very important, and they strive to provide high-quality products and services that meet the needs of clients. ${ }^{413}$

MTL's functional groups are composed of: Advanced Materials; Casting; Concrete; Corrosion and Protection; Joining and Structural Integrity; Materials Characterization; and Metal Forming. These functional groups offer "the capability to cover the complete materials cycle, from materials selection, fabrication, in-service performance and characterization to prototype product development." ${ }^{\text {414 }}$ They offer unique facilities such as an experimental casting laboratory, a pilot-scale rolling mill, formability testing equipment, corrosion testing, mechanical testing, and an extensive array of characterization facilities, which allows them to investigate a wide variety of

\footnotetext{
${ }^{412}$ CANMET MTL, "How we're organized," accessed February 2004, CANMET MTL Website [http://www.nrcan.gc.ca/mms/canmet-mtb/mtl/organized_e.htm]

${ }_{413}$ CANMET MTL, "Technical Services," accessed February 2004, CANMET MTL Website [http://www.nrcan.gc.ca/mms/canmet-mtb/mtl/technical_e.htm]

${ }^{414}$ CANMET MTL, "Scientific Services," accessed February 2004, CANMET MTL Website

[http://www.nrcan.gc.ca/mms/canmet-mtb/mtl/scientific_e.htm]
} 
materials such as metals and alloys, ceramics, concrete, etc. MTL can also simulate manufacturing processes like casting, rolling, stamping, forging, drawing and welding, and metal powder injection moulding. ${ }^{415}$

Current MTL research focuses on the development and deployment of technologies to improve all aspects of producing and using value-added products from metals and other materials. Examples include working to improve the integrity of metal structures from gas pipelines to offshore drilling platforms. ${ }^{416}$ These projects are unique as they are designed for a private sector end-user, but also serve the public good. The balance of creating products, processes and services for industry and serving the public good are important to this lab.

Many of the projects undertaken by MTL are tailored to solve a specific problem, and the solutions are directed towards industrial clients. While it is possible that the lab and its innovations may receive attention, particularly in light of a major disaster related to the areas the lab is working in (an oil platform or pipeline disaster, for example), this lab would not seem to conduct research in an area that would receive widespread political or media attention outside constituent industries.

\section{CANMET Energy Technology Centre (CETC)}

The second lab in our study is the CANMET Energy Technology Centre (CETC). "The CETC emerged from a 1996 amalgamation of three earlier CANMET divisions dealing with energy research, alternative energy and energy efficiency. But ultimately, it

\footnotetext{
${ }^{415}$ CANMET MTL, "Scientific Services," CANMET MTL Website [http://www.nrcan.gc.ca/mms/canmet$\mathrm{mtb} / \mathrm{mtl} / \mathrm{scientific \_ e.htm]}$

${ }^{416}$ CANMET Mineral Technology Branch, "Who we are," accessed November 2003, [http://www.nrcan.gc.ca/mms/canmet-mtb/homeeng.htm]
} 
can trace some of its history back to the earliest years of the $20^{\text {th }}$ century. ${ }^{4417}$ CETC has been in the R\&D business for over 80 years, and offers a broad range of knowledge and experience, supported by world-class research facilities. ${ }^{418}$ CETC's mission is to provide energy science and technology for the economic, environmental and social well being of Canadians, ${ }^{419}$ such as health and safety improvements. ${ }^{420}$ The CANMET Energy Technology Centre has two locations in the National Capital Region: the Bells Corners complex primarily conducts S\&T; and policy and administration offices on Booth Street. Both locations participated in our study.

To support their mandate of developing energy science technology, "CETC works in a variety of partnership arrangements on the research, development, demonstration, export and outreach of innovative energy-efficient and climate-change mitigating technologies associated with alternative, renewable and conventional energy., ${ }^{, 421}$ Some current areas of research include:

- renewable energy, including solar, wind, small hydro and bioenergy;

- energy-efficient technologies for industry, communities and buildings;

- alternative transportation fuels, including natural gas, propane, ethanol, methanol, hydrogen and electric and hybrid vehicles;

- district heating and cooling and integrated energy systems;

- advanced low-emission combustion technologies;

- processing and environmental catalysis for fuels production and hydrocarbon conversion; and

- energy-efficient metallurgical fuel products and technologies. ${ }^{422}$

\footnotetext{
${ }^{417}$ Bruce Doern, The CANMET Energy Technology Centre: Key Features of Institutional Change, (CRUISE, 2002), 5.

${ }^{418}$ Natural Resources Canada, CANMET Energy Technology Centre Brochure, (2003).

${ }^{419}$ CANMET Energy Technology Centre, CETC /ETB Business Plan 2002/03-2004/05, (2003), i.

${ }^{420}$ Natural Resources Canada, CANMET making an impact on Canada (Ottawa: Public Works and Government Services Canada, 1997), 13.

${ }^{421}$ CETC, Frequently asked Questions, "What is CETC?" accessed January 2004, CETC Website [http://www.nrcan.gc.ca/es/etb/cetc/cetc01/htmldocs/faq e.html]

${ }^{422}$ CETC, "About us," accessed February 2004, CETC Website [http://www.nrcan.gc.ca/es/etb/cetc/cetc01/htmldocs/about_us_e.html]
} 
Given the Canadian government's ratification of the Kyoto Protocol, and the importance of renewable energy, energy efficient technologies, and hybrid vehicles, one might expect that this lab may attract a lot of attention from government officials and the media.

In order to advance this research agenda, the CETC also administers various energyrelated repayable and cost-shared contract funding programs, such as:

- Canadian Initiative for International Technology Transfer

- Canadian Transportation Fuel Cell Alliance

- Emerging Technologies Program

- Industry Energy Research and Development

- Renewable Energy Technologies Program, and

- Transportation Energy Technologies Program

In total these funding programs were valued at approximately eleven million dollars in 2002/03, provided in part by Natural Resource Canada's Program on Energy Research and Development (PERD). ${ }^{423}$

CETC also has five "fee-for-service" research programs including: Advanced Combustion Technologies Program; Community Energy Systems Program; Energy Technologies for High Temperature Processes Program; Federal Industrial Boiler Program; and Processing and Environmental Catalysis Program. An analytical testing laboratory supports these programs. ${ }^{424}$ To make these programs effective, "CETCOttawa largely targets and partners with domestic manufacturers, utilities, construction, SME's, and to some degree other government departments, non-governmental organizations and universities. ${ }^{.425}$

\footnotetext{
${ }^{423}$ CETC, "Doing Business with us: funding Programs," accessed February 2004, CETC Website [http://www.nrcan.gc.ca/es/etb/cetc/cetc01/htmldocs/funding_programs_e.html] ${ }^{424}$ CETC, "Doing business with us research programs," accessed February 2004, CETC Website [http://www.nrcan.gc.ca/es/etb/cetc/cetc01/htmldocs/research_programs_e.html]

${ }_{425}$ CETC, Frequently asked Questions, "Who are CETC's clients?" accessed January 2004, CETC Website [http://www.nrcan.gc.ca/es/etb/cetc/cetc01/htmldocs/faq_e.html]
} 
Given that these granting programs include a public good purpose (improve energy efficiency, etc) and are completed in partnership, we can look for the tension between research for the public good and commercial products. As potential recipients of these funds must apply for them, it seems reasonable that this lab may be in a better position to ensure a public good component to the research over another lab that has to make products for industry to recover costs. At the same time, this lab still needs to produce innovations that industry is interested in.

\section{Canada Centre for Remote Sensing (CCRS)}

The third lab in our study is the Canada Centre for Remote Sensing (CCRS), which is responsible for the reception, processing, archiving and dissemination of remotely sensed data for Canada. Remote Sensing ${ }^{426}$ in Canada has a long history “....in the early development and application of aerial photography, photogrammetry and airborne geophysics to the mapping, resource development and environmental monitoring to its very large and remote territory., ${ }^{, 27}$

In addition to the challenges of the Canadian landmass, remote sensing fulfilled other important requirements, such as maintaining crop and forest inventories, monitoring forest fire hazards and ice floe movements as well as searching for minerals and fossil fuels. ${ }^{428}$ To meet these challenges in a country as vast and diverse as Canada, the

\footnotetext{
${ }^{426}$ The term 'Remote Sensing', was first used by the U.S. Military to describe a type of aerial surveillance that went beyond the use of photography into the use of parts of the electromagnetic spectrum other than the visible such as the infrared and the microwave parts. From "History," Accessed October 2003, CCRS Website [http://www.ccrs.nrcan.gc.ca/ccrs/org/history/history1_e.html]

${ }^{427}$ Canada Centre for Remote Sensing, "History" Accessed October 2003, CCRS Website [http://www.ccrs.nrcan.gc.ca/ccrs/org/history/history1_e.html]

${ }^{428}$ Industry, Science and Technology Canada, Geomatics Industry Profile (Ottawa: Queen's Printer, 1991), 6.
} 
geomatics industry developed world-class expertise, and Canadian technology and innovation are used throughout the world. ${ }^{429}$

When the Canada Centre for Remote Sensing was created in the early 1970's its mandate was: " $[t]$ o produce in a timely and effective manner, remotely sensed data and derived information needed for the management of Canada's natural resources and environment, and to perform and support research and development on the collection, processing and interpretation of such data" ${ }^{430}$ Today, the CCRS is responsible for: "receiving, processing, and archiving Earth observation data; coordinating a national research programme, which develops and applies remote sensing technology to sustainable development and environmental protection; developing geospatial information applications; and providing electronic access to spatial databases." ${ }^{431}$

CCRS is not responsible for input, administration, or monitoring of an act or regulations, although some of the work of the lab is directed towards allowing other federal bodies to complete their monitoring roles. The use of CCRS satellite stations to provide information for the ice service is an example. Similarly, in support of the Canadian industry, the CCRS also provides technical information and data.

The CCRS has 5 divisions, including: The Applications Division; The Data Acquisition Division; GeoAccess division; Technology Assessment Division; and

\footnotetext{
${ }^{429}$ Natural Resources Canada, Earth Sciences Sector Business Plan 2002-2005 (Ottawa: Public Works and Government Services Canada, 2002), 1.

${ }^{430}$ Canada Centre for Remote Sensing, "Remote Sensing Then and Now," accessed November 2003, CCRS Website [http://www.ccrs.nrcan.gc.ca/ccrs/org/history/history9_e.html]

${ }_{431}$ Canada Centre for Remote Sensing, "About Us," accessed October 2003, CCRS Website [http://www.ccrs.nrcan.gc.ca/ccrs/org/org_e.html]
} 
Geodetic Survey Division. ${ }^{432}$ The Applications Division is responsible for the research, development and demonstration of the use of remote sensing for resource management and environmental monitoring. The Data Acquisition Division is responsible for the acquisition, archiving and distribution of earth observation data in Canada; and development of advanced ground systems for efficient reception.

The GeoAccess division offers linkages, through the Canadian Geospatial Data Infrastructure (CGDI), to government and the private sector geospatial data holdings and services. The GeoAccess Division assists the Canadian private sector in developing specialized tools and services that permit the exploitation of the CGDI. It provides geographic modeling and custom thematic cartographic services in support of policy development by other federal agencies. The Technology Assessment Division is responsible for developing and implementing strategies that derive maximum industrial benefits from new geomatics and related technologies. The Geodetic Survey Division is responsible for providing and maintaining spatial reference systems, standards, and national networks of control points for Canada in support of geomatics applications.

An important part of CCRS's business is to work with other agencies to provide support programs that encourage the use and development of Earth observation data. "These funding programmes demonstrate Canada's commitment to supporting sustainable resource development as well as confirm the ongoing co-operation between the public sector and private industry in the development and commercial exploitation of remote

\footnotetext{
${ }^{432}$ Each Division has its own website with the name of the division as its title, ie: Applications division webpage. Please see:

[http://dweb.ccrs.nrcan.gc.ca/ccrs/db/staffdir/orgchart/divchrt_e.cfm?DivSelection=3]
} 
sensing and geomatics technology." 433 Examples of current support programs at CCRS include the Innovation Acceleration Centre and GlobeSAR2, which is designed to build capacity in radar remote sensing, with 11 participating countries in Latin America. These indicate private and public sector linkages, and potential for cost sharing and recovery.

Other important activities include improving our understanding about climate change by developing remote sensing techniques to monitor and model environmental and climate change (including: forestry; hydrology; landcover and marine) processes. ${ }^{434}$ CCRS also conducts research in Canadian Arctic and sub-Arctic regions to develop efficient remote sensing monitoring and mapping methods for land, water and man-made features of our north. ${ }^{435}$

Researchers at CCRS have developed new techniques in the processing, visualization, and analysis of hyperspectral data that can be used in such fields as agriculture, environmental monitoring and exploration geology. ${ }^{436} \mathrm{CCRS}$ scientists are developing remote sensing methods that monitor, model, and map natural hazards such as floods, forest fires, hurricanes, and oil spills quickly and reliably, so as to diminish possible threats to human safety and infrastructure. ${ }^{437}$ From these activities, the public good role of the lab is clear.

As with the MTL, it is easy to see how attention could be directed towards this lab and its innovations if a natural disaster such as a flood or forest fire struck a populated

\footnotetext{
${ }^{433}$ CCRS, "R\&\&D support programs," accessed February 2004, CCRS Website [http://www.ccrs.nrcan.gc.ca/ccrs/rd/programs/programs_e.html]

${ }^{434}$ CCRS, "Climate Change," accessed February 2004, CCRS Website [http://www.ccrs.nrcan.gc.ca/ccrs/misc/issues/cchange_e.html]

${ }^{435}$ CCRS, "Northern development," accessed February 2004, CCRS Website [http://www.ccrs.nrcan.gc.ca/ccrs/misc/issues/nst_e.html]

${ }^{436}$ CCRS, "Hyperspectral Techniques," accessed February 2004, CCRS Website [http://www.ccrs.nrcan.gc.ca/ccrs/misc/issues/hypersp_e.html]

${ }^{437}$ CCRS, "Natural Hazards," accessed February 2004, CCRS Website [http://www.ccrs.nrcan.gc.ca/ccrs/misc/issues/hazards_e.html]
} 
area. However, since these are rare occurrences, it is un-likely that this lab receives a lot of attention from the political level, except in these extreme circumstances.

\section{Program Review \& S\&T Management}

All labs conduct research to support departmental mandates, research frontier technologies, commercialize innovations, administer funding programs, and participate in international science. ${ }^{438}$ However, in the late 1980 's, the role of government labs was uncertain. "Cuts were being made regularly, highly trained personnel were being lost, policy expectations for performance rose, while ancient mandates for most labs were being left un-modernized and un-clarified." ${ }^{439}$ In the early 1990s' the new Liberal government had taken power and had conducted a reorganization of the federal government. In the reorganization plan, Energy, Mines and Resources changed into Natural Resources Canada (NRCan), bringing together three economic sectors: mining; energy; and forestry into one organization. ${ }^{440}$ This set the stage for the mid 1990's Program Review of the federal government, which had a major impact on the mandate, structure and operations of Energy, Mines and Resources Canada.

Almost ten years have passed since Program Review, and NRCan has "settled" into its organizational structure. Before the reorganization, Energy, Mines and Resources Canada's mission was to "lead Canadians in the understanding of our vast landmass, and in the responsible development and use of our mineral and energy resources." ${ }^{441}$ This

\footnotetext{
${ }^{438}$ Industry Canada, Science and Technology Advice: A Framework to Build On (Ottawa: Public Works and Government Services Canada, 2002), 26.

439 John de la Mothe, "One small step in an uncertain direction: the Science and Technology Review and public administration in Canada," in Canadian Public Administration Vol 39, no. 3 (Fall 1996), 409.

${ }^{440}$ Bruce Doern and Monica Gattinger, 2002, 235.

${ }^{441}$ Energy Mines and Resources Canada, Profile of EMR June 1993, 3.
} 
mandate appears to be similar from the late 1980's and early 90 's. ${ }^{442}$ NRCan as a Department came through Program Review re-orientated towards its core federal responsibilities and activities, although it also acquired an increased international and sustainable development focus. ${ }^{443}$ The department "has re-orientated its policies and S\&T programs to promote the sustainable development and use of natural resources: the integration of economic, social and environmental objectives in decisions to develop and use energy, minerals and metals, and forests." ${ }^{\text {,44 }}$ While there remains a diversity of activities and cultures among the sectors, the department has developed a comprehensive set of principles and practices as a unifying force for the conduct of its operations. ${ }^{445}$

Program Review had an impact on both CANMET labs in our study, as two new CANMET branches were formed in NRCan's reorganization. CANMET's Energy Technology Branch was integrated into the Department's Energy Sector, while the Mineral Technology Branch now forms part of the Minerals and Metals Sector. CANMET documentation indicates that "[w]hile Program Review has forced some tough budgetary and resource decisions, it has also helped program focus. For example, while some activity areas are being reduced or eliminated, other critical or emerging issues, such as sustainable development and climate change are receiving higher priority. ${ }^{, 446}$ For the CETC, the changes were substantial, such as significant cuts in areas of S\&T

\footnotetext{
${ }^{442}$ Energy Mines and Resources Canada, Annual Reports 1988,89, 1989-90, 1990-91 etc.

${ }^{443}$ Natural Resources Canada, Business Plan 1997-2000 (Ottawa: Public Works and Government Services Canada, 1997), introduction.

${ }^{444}$ Industry Canada, Science and Technology Advice: A Framework to Build On (Ottawa: Public Works and Government Services Canada, 2002), 64.

${ }^{445}$ JEH Associates, "Scientific Advice in Government Decision Making The Canadian Experience,"(March 1999), Appendix 1, 50.

${ }^{446}$ CANMET, CANMET '95 New Directions (Ottawa: Supply and Services Canada, 1995), foreword.
} 
including fossil fuels (especially coal), natural gas and combustion, the areas that had been focal points in the expansive days of the National Energy Program. ${ }^{447}$

Another impact of Program Review is that Sustainable Development is clearly reflected in the mandates of the sectors that our labs are part of. MTL is part of the Minerals and Metals Sector, and sustainable development is of key importance in promoting the integration of economic, social and environmental objectives such as health and safety towards globally safe use of minerals and metals. ${ }^{448}$ CETC is part of the Energy Sector, which fosters the responsible use of Canada's energy resources to meet the needs of Canadians, focusing on the areas of energy efficiency, renewable energy, alternative transportation fuels, to further sustainable development. ${ }^{449}$ CCRS is part of Geomatics Canada, which together with the Geological Survey of Canada and the Polar Continental Shelf Project makes up the Earth Sciences Sector. The Earth Sciences Sector "...provides essential information to make scientifically sound decisions regarding the sustainable development of Canada's natural resources." 450

One result of Program Review was that NRCan faced downsizing and budget cuts, and had to deliver programs with fewer S\&T resources. "The need to simplify its operations and increase the cost-effectiveness of its S\&T programs has led to new approaches to S\&T management and coordination." "451 This led to the creation of a S\&T management framework in 1996 , with a core objective of adopting a strong client focus

\footnotetext{
${ }^{447}$ Bruce Doern, 2002, 9.

${ }^{448}$ Natural Resources Canada, CANMET an Investment in Canada Achieving Sustainable Economic Growth and Sustainable Development (Ottawa: Supply and Services Canada, 1995), 5.

${ }^{449}$ Natural Resources Canada, Report on Plans and Priorities 2002-2003 (Ottawa: Public Works and Government Services Canada, 2002), 40.

${ }^{450}$ Natural Resources Canada, Earth Sciences Sector Business Plan 2002-2005 (Ottawa: Public Works and Government Services Canada, 2002), 5.

${ }^{451}$ Industry Canada, Investing in Excellence, 1996-2001 A Report on Federal Science and Technology $\underline{2001}$

(Ottawa: Public Works and Government Services Canada, 2001), 98.
} 
and ensuring relevance and usefulness. Related to innovation, its guiding principles are: encourage creativity, innovation and risk taking; be responsive to clients; effective management of resources and; continuous improvement. ${ }^{452}$

To improve the management of S\&T, a broader government priority was to generate revenue and recover and share costs. ${ }^{453}$ NRCan explains that even though most of its work is for the public good, its rationale for cost recovery is when other organizations share one or more of NRCan's objectives, both benefit from sharing some of the costs of delivering the programs. In other cases, it is the user who is the primary beneficiary, so NRCan can recover the costs from the user, or charge royalties or license fees. Cost-sharing arrangements involve sharing specified costs, such as product development. ${ }^{454}$

To create products and services that are wanted by industry, government labs seek to create partnerships, to share costs and risks. The commercialization of products, along with revenue targets were added under Program Review “... as surrogate ways of showing the extent to which private firms thought that the work of the labs was commercially relevant and useful to them and in expediting subsequent implementation of the results. ${ }^{255}$ If products produced by government labs were useful, industry would pay for them, or partner with labs to develop them.

Partnerships are important, as they form the backbone of NRCan's ability to further the public good. "An increasing proportion of NRCan S\&T is delivered through

\footnotetext{
${ }^{452}$ Natural Resources Canada, NRCan's S\&T Management Framework, (March 1996), accessed December 2001, [http://www.nrcan.gc.ca/dmo/scitech/documents/stmf/stfm_e.html], page 4.

${ }^{453}$ Natural Resources Canada, Compendium of science and Technology Mañagement Practices, accessed January 2002, [http:/www.nrcan.gc.ca/dom/scitech/documents/compendium/ compen_e.html], page 37.

${ }^{454}$ Natural Resources Canada, Framework for revenue Generation, external funding and collaborative activities, accessed March 2003, [http://www.nrcan.gc.ca/dmo/scitech/revgen/ revgen_e.htm], page 5 .

${ }^{455}$ Bruce Doern, 2002, 8 .
} 
collaborative research agreements with universities, industry and other government partners. This remains a high priority for NRCan management to maximize both the use of scarce research dollars and the relevance of transfer of new knowledge and technologies." ${ }^{\text {456 }}$ Partnerships can maximize the potential for both the government and the partner, because the resources and ideas of our partners complement the government's capacities in $\mathrm{S} \& \mathrm{~T}{ }^{457}$

Industry benefits from partnerships because "[g]overnment Research labs can offer confidentiality, intellectual independence, continuity, in-house expertise to oversee procurement of scientifically or technically complex inputs, and close contact with the user of research - the government itself."458 This implies a closer link between government labs and industry. If government labs are aware of the problems and opportunities of industry, they can try to help. Similarly, the more aware that industry is of what government laboratories can contribute towards developing new technologies or reducing $R \& D$ risks, the more likely industry will be to attempt to utilize federal scientific facilities and expertise. ${ }^{459}$

In sum, NRCan began with the federal government's attempts to assist Canada's natural resource sectors at the beginning of the $20^{\text {th }}$ century. The current organizational structure evolved as a result of the government's reorganization in the early 1990's. Sustainable development, and cost recovery/sharing through partnerships became more

\footnotetext{
${ }^{456}$ Industry Canada, Investing in Excellence, 1996-2001 A Report on Federal Science and Technology 2001 (Ottawa: Public Works and Government Services Canada, 2001), 99.

${ }_{457}$ Natural Resources Canada, Departmental Performance Report 2002 (Ottawa: Public Works and Government Services Canada, 2002), 6.

${ }^{458}$ Frances Anderson and Charles Davis, 1993.

${ }^{459}$ M.E. Smith, Winter 1982-83, 17.
} 
important to NRCan post Program Review. This section has set the stage to begin our look at the institutional factors that relate to innovation in our labs.

\section{Institutional Theme 1 Results: Publicness; Cost Recovery}

The first of our four themes related to institutional factors is publicness, which is defined as "the degree of external control or influence exerted by governmental actors. ${ }^{\not 460}$ The literature suggests that the motivation to innovate in the private sector is driven by profit, and this is absent in the public sector. We suggest that cost recovery might motivate innovation. One of our overall research questions related to publicness is: does cost recovery/sharing have an impact on innovation in the lab? To answer this question, we first need to find out how important cost recovery/sharing is to the lab, and second if there are any impacts on innovation. We need to know the importance of cost recovery/sharing before we can measure its effects.

As partnerships and cost recovery/sharing have become an NRCan goal as a result of Program Review, it is likely all three labs in our study will have some levels of cost recovery/sharing, however, there are likely differences in degree. We will use two measures to determine if cost recovery/sharing is important in the lab. First, we will see if cost recovery/sharing and partnerships are identified in the lab's mandate or documentation. If it appears, this is one measure that cost recovery/sharing is important, if not, it is an indication it is less important.

Looking at the documentation of the CANMET Energy Technology Centre (CETC), we find that "CETC's mission is to provide energy science and technology for

\footnotetext{
${ }^{460}$ Michael Crow and Barry Bozeman, 1998, 109.
} 
the economic, environmental and social well being of Canadians." ${ }^{.461}$ While this mission does not indicate partnerships or cost recovery, other documentation makes the importance of partnerships and cost recovery clear. Other research has found the main impact of Program Review on the CETC is that it functions in a more collaborative and horizontal manner. ${ }^{462}$ CETC works closely with all major stakeholders in the Canadian energy and R\&D sectors, such as other departments through the interdepartmental Program for Energy R\&D (PERD), academia, firms in the energy sector, utilities, municipal/provincial organizations, and representative policy and advisory groups. ${ }^{463}$

CETC forges strategic partnerships among developers, suppliers and users, and forms research consortia. With these clients and partners CETC may cost share joint projects, provide research capability using its extensive and unique expertise and facilities, provide access to national and international networks of information and knowledge and broker relationships with additional partners. ${ }^{464}$ Many programs are undertaken in partnership, and a combination of in house and contracting out delivery mechanisms allows flexibility. ${ }^{465}$ The goal is to help find "partners and secure funding for further technology development and subsequent commercialization.”,466

The CANMET Material Technology Laboratory's (MTL) mandate is “to develop and deploy technologies to improve all aspects of producing and using value-added products from metals and minerals, with particular emphasis on solving technological

\footnotetext{
${ }^{461}$ CETC, CANMET Energy Technology Centre Business Plan 2002/03 2004/05 (Not published, 2003), i.

${ }^{462}$ Bruce Doern, 2002,11.

${ }^{463}$ KPMG Consulting, "Measuring and Ensuring Excellence in Government Science and Technology: Canadian Practices," (Ottawa, March 2001), 24.

${ }^{464}$ CANMET Energy Technology Centre, CETC/ETB Business Plan 2002/03-2004/05 (Not published 2003), i.

${ }^{465}$ KPMG Consulting, 2001, 23.

${ }^{466}$ CANMET Energy Technology Centre, CETC /ETB Business Plan 2002/03-2004/05 (Not published 2003), iii.
} 
problems of relevance to NRCan's mandate in sustainable development, and on transferring materials technology to Canadian industry." ${ }^{, 467}$ MTL wants to achieve longterm impacts of: improved performance in Canadian infrastructure; a more competitive Canadian industry; and reduced pollution. ${ }^{468}$ The impacts balance both the private (infrastructure, competitiveness) and the public (greenhouse gas emissions and pollution) good. Cost recovery does not appear in its mandate, although the importance of partnerships is implied through the transfer of technology to industry.

The Materials Technology Lab and the Energy Technology Centre are both part of CANMET, so we can also use CANMET documentation as evidence of the importance of partnerships, cost sharing and recovery. The two CANMET labs in our study are on the forefront of partnerships and cost sharing and recovery. "CANMET has formed many alliances and partnerships with industry, other federal departments, provincial governments, universities and international agencies to share the costs and risks of R\&D. Such alliances ensure that Canada achieves the maximum return on its R\&D investment and facilitate the implementation and commercialization of CANMET sponsored technologies by industry to generate wealth, create jobs..."469

In partnership with clients, CANMET performs and sponsors predominantly costshared research and development, and technology transfer, with the following mandate: to enhance the competitiveness, improve and develop energy efficiency and alternative energy, improve health and safety and support government policy initiatives. ${ }^{470} \mathrm{~A}$

\footnotetext{
${ }^{467}$ CANMET MTL, MTL Business Plan 2003-2006 (Not published 2003), 5.

${ }^{468}$ CANMET MTL, MTL Business Plan 1999-2002 (Not published 1999), 1.

${ }^{469}$ Natural Resources Canada, CANMET An Investment in Canada Achieving Sustainable Economic Growth and Sustainable Development (Ottawa: Supply and Services Canada, 1995), 1.

${ }^{470}$ CANMET, CANMET Annual Report 1993-94 (Ottawa: Supply and Services Canada, 1994), "Mission and mandate" and CANMET, CANMET '95 New Directions (Ottawa: Supply and Services Canada, 1995), foreword.
} 
consultant's report indicates that the integration process has led to a strengthening of the client supplier relationship, which developed more rapidly in sectors with a private sector client, and slower in ones with a government client. ${ }^{471}$ While cost recovery/sharing do not appear in the mandates of the CETC or MTL, other documentation suggests that both are very important.

The third lab in our study is the Canada Centre for Remote Sensing (CCRS). CCRS documentation indicates, "CCRS is responsible for the reception, processing, archiving and dissemination of remotely sensed data for Canada. In conjunction with the private sector, it develops remote sensing technology and applications." ${ }^{\text {" }} 72$ While cost recovery does not appear in this mandate, partnerships with the private sector appear to be important to develop remote sensing technology and applications.

CCRS is part of Earth Sciences Sector of Natural Resources Canada. Partnerships are also important to the Earth Sciences Sector, which makes its expertise available on both a collaborative and cost-shared basis to a variety of partners - governments, business, educational institutions and individual Canadians - to help them meet the challenges of competing in a faster-paced, technology driven economy. ${ }^{473}$ Sector documentation indicates cost recovery exists.

On our first measure of the importance of cost recovery/sharing, we can conclude that for MTL and CETC, while not indicated in their mandates, other documentation points to the clear importance of cost sharing/recovery and partnerships. For the CCRS,

\footnotetext{
${ }^{471}$ JEH Associates, 1999, Appendix 1, 50.

${ }^{472}$ Canada Centre for Remote Sensing, "Mandate," accessed January, 2004, CCRS Website [http://www.ccrs.nrcan.gc.ca/ccrs/org/chart/mandate_e.html]

${ }^{473}$ Natural Resources Canada, Earth Sciences Sector Business Plan 2002-2005 (Ottawa: Public Works and Government Services Canada, 2002), 1.
} 
we are uncertain as to the importance of cost recovery, although partnerships appear to be important.

Our second measure of the importance of cost recovery/sharing is the percentage of the lab's total budget that comes from cost recovery. Unfortunately, cost recovery information is proprietary and difficult to determine. However, as a proxy, we can use the amount of money that comes from non-government sources, ${ }^{474}$ which we will determine using financial information. Lab financial information identifies that MTL has an "A-base", and program funding amounting to $\$ 9,646,000$. It has revenues from nongovernment sources (a Vote Net float) of $\$ 2,840,000$. The total lab budget is $\$ 12,486,000(2,840,000+9,646,000)$. Therefore, $\$ 2,840,000$ out of the total budget of $\$ 12,486,000$ comes from non-government sources which works out to a ratio of $(\$ 2,840,000 / \$ 12,486,000)=23 \%$ non-government funding. ${ }^{475}$

Other documentation highlights that MTL faces challenges of fiscal constraints. "This makes MTL particularly vulnerable to poor economic times, because of the high proportion of funds derived from cost recovery revenues (in 1998/99, about 33\%). The funding of MTL's activities also faces uncertainties as NRCan's budget is held relatively constant while priorities shift within the organization."

In CCRS, "A-base" is $\$ 14$ million and $\$ 6.23$ million in external funding. Of the external funding about $\$ 1$ million is cost recovered. The rest comes from other government departments, for activities such as contract $\mathrm{r} \& \mathrm{~d}$, satellite operations, and some support of other organization's equipment on our sites. Added together the lab's

\footnotetext{
474 This amount may differ from cost recovery as it may also include cost-sharing, partnerships, etc. ${ }^{475}$ CANMET MTL, MTL Business Plan 2003-2006 (Not published 2003), 24.

${ }^{476}$ CANMET MTL, MTL Business Plan 1999-2002 (Not published 1999), 4.
} 
total budget is $\$ 20.23$ million. Dividing $\$ 1$ million/20.23 million, about 5\% of the total budget comes from non-government sources. ${ }^{477}$

CETC's total budget is in 2002-03 is about 48.2 million, ${ }^{478}$ "A-base" makes up about \$8.2 million, Program on Energy Research and Development (PERD) \$19.9 million, external revenue, including other government departments, is $\$ 4.9$ million, internal NRCan revenue is $\$ 1.6$ million and Climate Change Action Fund (CCAF) is $\$ 13.4$ million. Revenue generation targets for 2002-03 are $\$ 6.54$ million, ${ }^{479}$ of which 4.9 million is targeted to come from external sources, while $\$ 1.6$ million is expected to come internally from NRCan. Of the total budget of 48.2 million, 4.9 million or $(\$ 4.9 / \$ 48.2)$ just over $10 \%$ comes from non-government sources, and the remaining $89 \%$ comes from public sources.

Crow and Bozeman divide the results of the percentage of research funded by the government into three categories of publicness: high (76-100\%), moderate (26-75\%) and low $(0-25 \%)$. Based on our calculations, all three labs fit into the high category of publicness, although MTL (77\%) is on the cusp of moderate publicness. MTL has the highest percentage of non-government funding and CCRS the least. One shortcoming of Crow and Bozeman's categories of publicness is that if we place all three labs into the high publicness category, it masks that there is a $20 \%$ difference in the levels of publicness between the labs in our study.

There are important differences between cost recovery, cost sharing, partnerships and leveraging. While many activities are conducted with a private sector partner, they do not necessarily recover all the costs. Similarly, government financial statements do

\footnotetext{
${ }^{477}$ Communication from Director to Researcher

${ }^{478}$ All budget numbers appear in the CETC/ETB Business Plan 2002/03, (Not published 2003), 85.

${ }^{479}$ CETC, CETC Business Plan, 2002/03-2004/05, (Not published 2003), 81.
} 
not include the total amount of private sector money, equipment, personnel and resources that the private sector partner provides in support of the projects. "CANMET investment leveraged substantial private sector funds in support of quality of life activities. With respect to these efforts (e.g., knowledge formation for codes and standards, improved health and safety, and sustainable energy development) partners invested $\$ 2.30$ for every $\$ 1$ of CANMET investment." ${ }^{480}$ The labs may be more towards moderate/low publicness than they appear.

In order to make a comparison of the importance of cost recovery between the labs, we accept that all three are in the high publicness category as defined by Crow and Bozeman, but to accentuate differences in levels of cost recovery/sharing, we need to modify the high publicness scale. For our purposes, if the percentage of financing from non-government sources is above fifteen percent, cost recovery/sharing is very important, if it is above ten percent and below fifteen percent, it is important, and if it is below ten percent, it is less important. In this revised scale, we can conclude that based on financial documentation, cost recovery/sharing is very important for the MTL, important for the CETC and less important for the CCRS.

Using both measures of the importance of cost recovery, we can now make an overall judgment on the importance of cost recovery in the lab. For the CETC, we have seen that cost recovery/sharing and partnerships are identified as important in their documentation, and our financial results indicate that over ten percent, but less than fifteen percent of their budget comes from private sources. We will classify the importance of cost recovery/sharing as important. For the MTL, as cost recovery/sharing and partnerships are identified as important in their documentation and as over fifteen

${ }^{480}$ Natural Resources Canada, CANMET, 1995, 99. 
percent of their total budget comes from private sources, we conclude that cost recovery/sharing is very important. Looking at CCRS documentation, we are uncertain as to the importance of cost recovery, although partnerships are clearly important, and because less than ten percent of their budget comes from private sources, our judgment is that cost recovery is relatively less important.

\begin{tabular}{|c|c|c|}
\hline \multicolumn{3}{|c|}{ Importance of Cost Recovery } \\
\hline Less Important & Important & Very Important \\
\hline$\bullet$ & - = & $\boldsymbol{\Delta}$ \\
\hline
\end{tabular}

We wanted to get a perception from focus groups of how cost recovery impacts their lab. Some believed that cost recovery was very important. "It's either getting money or laying those people off." ${ }^{, 481}$ Similarly, "CANMET is the only government lab that it totally dependant on cost recovery. The other ones are more " $A$ " based labs. They can pick and choose what they do where we have a little less choice of what we do. I don't think it's damaged too much what we've managed to accomplish." ${ }^{482}$

However, others are of the opinion that the emphasis towards cost recovery is declining. This could be because historically the emphasis on cost recovery was how the lab justified its existence. If other people pay for something you make, you must be doing something really well. Now, if you can get money from another organization that is also a really good indication that you're doing things that are worthwhile. ${ }^{483}$ As long as money comes from outside sources, it does not have to be cost recovery based to be worthwhile.

\footnotetext{
${ }^{481}$ Energy Technology Centre focus group participant

${ }^{482}$ Materials Technology Laboratory focus group participants

${ }^{483}$ Energy Technology Centre focus group participant
} 
For the Canada Centre for Remote Sensing, the perception of focus group participants is that cost recovery was much less predominant, and "there are hardly any imperatives towards cost recovery." ${ }^{\prime 484}$ This is a clear difference in perception where MTL participants saw cost recovery imperatives as strong, CETC had strong but declining cost recovery imperatives and the CCRS, had weaker cost recovery imperatives. This seems consistent with financial and non-financial documentation.

In the focus groups, we asked if the source of funding (public or private) made any difference in the development and advancement of innovation? Were there complications or difficulties, which arise depending on the type of funding. Participants identified difficulties related to the source of funding involved the bureaucracy and complexity of publicly funded projects. ${ }^{485}$ The funding source made a difference in the timeliness and the delivery of results. Typically industry projects are focused on immediate results. "No one wants to wait ten years to see the impact of their investment." ${ }^{486}$ Compared to publicly funded research, industry research is more focused and disciplined. There appears to be more pressure to deliver on time because it is an outside agency. ${ }^{487}$

Another difference in the type of funding is that "once results are established, the (private) funding does not normally permit you to do an in depth investigation, whereas a core project is more flexible." 488 The source of the funding can also be a demonstration of perceived relevance, where some believe that if they receive private funding for an innovation, this indicates that it has more relevance. Others thought that new products

\footnotetext{
${ }^{484}$ Canada Centre for Remote Sensing focus group participant

${ }^{485}$ Materials Technology Laboratory focus group participant

${ }^{486}$ Energy Technology Centre focus group participant

${ }_{487}$ Materials Technology Laboratory focus group participant

${ }^{488}$ Materials Technology Laboratory focus group participant
} 
and services needed to be more sellable. ${ }^{489}$ However, it was clear that even with public funding, there must be results. "No one is going to give you money to do pie in the sky research." 490

\section{Publicness: Market Influence and Product Mix}

We have not yet answered the question: is cost recovery/sharing having an impact on innovation in the lab? To identify the impact cost recovery is having on innovation, we will examine if the products that the lab produces are orientated towards the public or private sector. Crow and Bozeman identify the level of "market influence", measured by the extent to which the product is appropriable. There are three levels of market influence on a lab: little market influence; where the principal output is for the public good; balanced: (market and non market products); and proprietary (heavy market influence). ${ }^{491}$ We will use focus groups to determine the mix of goods, and ask what effects market influences have on the balance between the public and private goods.

Hypothesis 10: in a lab where cost recovery/sharing is very important, it will produce more balanced/ proprietary innovations, to serve cost recovery imperatives. If cost recovery/sharing is less important, we expect to see more public good innovations. The logic is that if cost recovery is very important, the lab's output of innovations will be balanced towards proprietary products to be sold (shared) with the private sector, and less innovations for the public good. In a lab where cost recovery is less important we expect more innovations produced for the public good. It is important to note that all labs produce some proprietary, balanced and public goods.

\footnotetext{
${ }^{489}$ Energy Technology Centre focus group participant

${ }^{490}$ Energy Technology Centre focus group participant

${ }^{491}$ Michael Crow and Barry Bozeman, 1987, 336.
} 
Our results indicate that all labs produce some proprietary products and some pure public goods, and participants indicated they had innovations that could fall into the generic, balanced and proprietary categories. Participants indicated that MTL produced balanced and proprietary products, noting they are moving more towards proprietary. Of the three labs, they were the furthest towards proprietary products. As they appeared to have the strongest cost recovery imperatives shown through documentation and focus group participants, this is consistent. CETC and CCRS had more balanced products, with some private and public goods, with CCRS being placed the furthest towards balanced products, also consistent with our expectations. Combined with the lab financial documentation, we can plot the labs using the Crow-Bozeman grid.

\begin{tabular}{|c|c|c|c|}
\hline \multicolumn{4}{|c|}{ Crow and Bozeman Publicness Grid } \\
\hline & & Product & \\
\hline Publicness & Generic & Balanced & Proprietary \\
\hline High (76-100\%) & & - & $\Delta$ \\
\hline Moderate (26-75\%) & & & \\
\hline Low $(0-25 \%)$ & & & \\
\hline
\end{tabular}

$$
=\mathrm{CETC} \boldsymbol{\Delta}=\mathrm{MTL} \bullet=\mathrm{CCRS}
$$

Overall, the labs are characterized by a balanced to proprietary product and all were in the high publicness category, with most funding coming from public sources. MTL had the lowest percentage of public funding and CCRS the highest. There was some variation between labs, as the MTL produced the most proprietary products, and the CETC and CCRS produced balanced products. 


\begin{tabular}{|l|l|}
\hline \multicolumn{2}{|c|}{ Products Produced } \\
\hline $\begin{array}{l}\text { Hypothesis 10: in a lab where } \\
\text { cost recovery/sharing is very } \\
\text { important, it will produce more } \\
\text { balanced/ proprietary innovations, } \\
\text { to serve cost recovery }\end{array}$ & $\begin{array}{l}\text { Results: we can reject the null hypothesis that there } \\
\text { are no differences between the labs. The lab with the } \\
\text { imperatives. If cost }\end{array}$ \\
$\begin{array}{l}\text { highest cost recovery imperatives, (MTL) produced } \\
\text { recovery/sharing is less important } \\
\text { re expect to see more public } \\
\text { good innovations. }\end{array}$ & $\begin{array}{l}\text { moderate level of cost recovery importance, produced } \\
\text { more proprietary/ balanced products. The lab with } \\
\text { the least cost recovery imperatives (CCRS) produced } \\
\text { more public goods, although they were in the } \\
\text { balanced category rather than in the pure public } \\
\text { category, indicating some market influence. }\end{array}$ \\
\hline
\end{tabular}

Other documentation suggests the challenges faced by the labs trying to balance basic research for the public good, and creating proprietary products. "Most of CANMET's programs simultaneously address multiple goals: environmental protection and remediation, health and safety, and competitiveness in global markets. ${ }^{, 492}$ As Bruce Doern noted: "these capacities and processes involve a very difficult tradeoff between the program demands and wishes in particular of 'the government' and the 'private sector customer' with the CETC interacting with both.",493

We asked participants if any difficulties or opportunities arose trying to balance the product mix; i.e.: production of marketable goods, processes or service and conducting basic research, or research for the public good? Participants told us that there's no magic formulae in balancing the private and public good, and trying to achieve a balance is a struggle, because it underlies a tension between recovering costs and making marketable goods and serving the public good. You have to get funding and still conform with Departmental strategies. ${ }^{494}$ The two goals are not mutually exclusive, as

\footnotetext{
${ }^{492}$ Natural Resources Canada, CANMET 1995, 97.

${ }^{493}$ Bruce Doern, 2002, 6.

${ }^{494}$ Materials Technology Laboratory focus group participant
} 
several participants noted: "we can still manage to conform to government objectives and still satisfy the private sector." 495

The labs are still research-based entities looking to solve scientific and engineering problems. Labs have attempted to combine cost-recovery and private partnerships with public good research, with some success. "Some of our projects have been able to marry public good research with industry needs. I'm thinking of the pipeline corrosion research."496 Most of what the labs fund has a public good component, and sometimes it is difficult to distinguish between R\&D support for the public and private good as many of the cost shared/recovered private sector orientated projects have public good properties, such as environmental and employment benefits. ${ }^{497}$ Many projects have a public and private good overlap.

\section{Impact of Cost Recovery; Short-Term Innovation}

Cost recovery affects the products and services offered. "As we've had to deal more and more with cost recovery, our portfolio has suffered, because we have to deal with short term needs of the private sector, we can't look at long term research. We have to focus on very realistic problems. This is not necessarily bad because you can still be very innovative solving short term problems." ${ }^{498}$ As innovation is uncertain, short-term activities make it difficult to stay on schedule. Another focus group participant noted: "we need to come to grips with the paradox of having world class scientists working on short term activities." 499

\footnotetext{
${ }^{495}$ Materials Technology Laboratory focus group participant

${ }^{496}$ Materials Technology Laboratory focus group participant

${ }^{497}$ Natural Resources Canada, CANMET 1995, 100.

${ }^{498}$ Energy Technology lab focus group participant

${ }^{499}$ Canada Centre for Remote Sensing focus Group Participant
} 
The difficulty in dealing with short-term problems is that it contradicts a role of government, which was seen to be visionary, plan for the future and go where industry can't. All of the participants indicated that long term planning for innovation was problematic. Industries tend to have a one-year planning cycle, so to plan for long-term innovation; labs can try to work with consortiums, which have a longer-term view. ${ }^{500}$ One participant summed up the difficulty with short-term research:

If I was in an industry advisory group 30 years ago and someone said let's explore CFC's and its effects on the ozone layer, I would almost guarantee that industry would say: what are you talking about? It would have never gotten funding, ever. There is this double-edged sword with industry one, where relevance is important, but on the other hand, if you're totally structured around industry, and driven for it, which we actually are now, I think it does actually hurt long-term innovation. ${ }^{501}$

The other impact of the industry focus is that the products that are produced are generally ones that are sellable. "There is little public good research because of that. There is some, but it is often done on a cost recovery basis." ${ }^{, 502}$ Concern was expressed that not enough attention is paid to the future public good. Unlike the two CANMET labs, CCRS appears to be less directed towards private industry, and cost recovery imperatives are not paramount. However, there is still a market influence as some of their goods are directed towards the market and there is a movement towards more proprietary products. The result of this movement was that it could impact on the product balance where "we don't have the freedom to conduct basic research."

Another indication of the effect of cost recovery/sharing on innovation is the main impact of an implemented innovation, and the amount of advocacy towards the private

\footnotetext{
${ }^{500}$ Energy Technology Centre focus group participant

${ }^{501}$ Energy Technology Centre focus group participant

${ }^{502}$ Energy Technology Centre focus group participant

${ }^{503}$ Canada Centre for Remote Sensing Focus Group Participant
} 
sector. Hypothesis 11: In labs where cost recovery is important, the main impact of an implemented innovation would be financial, and there is more advocacy to the private sector than in labs where cost recovery/sharing is less important.

Related to hypothesis 11 , we want to see if financial impacts of innovations are identified by a larger percentage of respondents in a lab that had stronger cost recovery imperatives. Similarly, in labs where cost recovery/sharing is very important, we expect advocacy would be directed towards industry clients. When we asked respondents to identify the impacts of an innovation, they could choose more than one impact. Our findings indicate that a higher percentage of respondents identified potential financial impacts $^{504}$ in MTL (38\%) compared to the other labs. Our null hypothesis (Ho) is that there are no differences between the labs. As our Chi Square 2.933 is not significant $\mathrm{p}<0.231$, we cannot reject the null hypothesis.

\begin{tabular}{|l|c|c|}
\hline \multicolumn{3}{|c|}{ Financial Return the Main Impact of Innovation } \\
\hline N=88 & Financial Impact & Other Impacts \\
\hline CETC & $19 \%$ & $81 \%$ \\
\hline MTL & $38 \%$ & $62 \%$ \\
\hline CCRS & $29 \%$ & $71 \%$ \\
\hline Chi Square 2.933 & Sig 0.231 & \\
\hline
\end{tabular}

We expected MTL to have the highest percentage of respondents identifying financial impacts, but it was surprising that CCRS had a larger percentage (29\%) of respondents identifying financial impacts than CETC (19\%), since CCRS had less strong cost recovery imperatives.

In all three labs, the largest percentage of respondents identified customer satisfaction and solving process and product problems as the main impact of an implemented innovation (MTL 47\%, CETC 46\%, and CCRS 50\%). Differences between

\footnotetext{
${ }^{504}$ We grouped together modest and significant financial impacts into one variable.
} 
the labs were not significant (chi square $0.075 \mathrm{p}<0.963$ ). Customer satisfaction is important to all three labs, whether to serve their mandates, sustain relationships and create opportunities for future business. The importance of customer satisfaction is also congruent with our findings that partnerships are important for all three labs.

For the second part of hypothesis 11 , we wanted to find out if there was a focus on championing to the private sector. We found some differences between the labs in the direction of advocacy to current and potential clients. MTL had the most advocacy (93\%) towards current clients in the private sector, 20 percentage points above the CETC $(73 \%)$ and more than 40 percentage points above the CCRS. Our null hypothesis (Ho) was that there are no differences between the labs. Our results (chi square $5.023 \mathrm{p}<0.081$ ) are statistically significant, so we can reject the null hypothesis. One focus group participant explained: "The type of research we do - industrial R\&D,

the main user is

industry. ${ }^{, 505}$

Of the three labs,

CCRS had the most

balanced $(69 \%$

government, $50 \%$

private, $50 \%$

University) advocacy. The two CANMET labs were much more focused on the private sector.

$\overline{505}$ Materials Technology Laboratory focus group participants
Advocate to Current clients

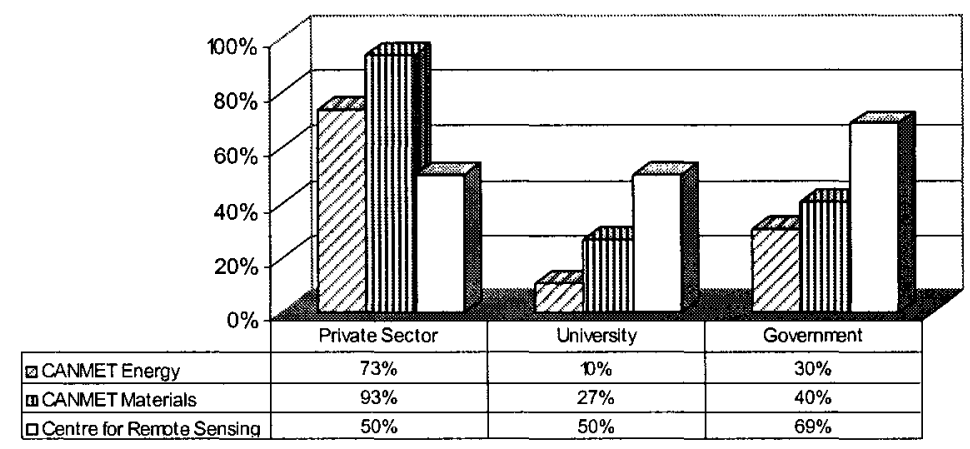




\section{Effect Of Cost Recovery On Innovation}

Hypothesis 11: In labs where cost recovery is important, the main impact of an implemented innovation would be financial, and there is more advocacy to the private sector than in labs where cost recovery/sharing is less important.
Results: we cannot reject the null hypothesis that financial implications were not the major result in any of the three labs.

We can reject the null hypothesis that there are no differences in the labs in the advocacy. In the lab where cost recovery was the most important, the most advocacy was to the private sector, and in the lab with the least cost recovery imperatives, advocacy was more balanced.

In this section, from mandates, financial and other documentation and focus groups, we described that MTL has strong cost recovery imperatives, CETC has medium and CCRS the least strong cost recovery imperatives. Cost recovery is having an impact on all three labs to different degrees. In MTL where cost recovery imperatives were strongest, the result was a focus on proprietary goods, and on short-term innovation. In CETC, which had medium cost recovery impacts, there was movement towards more proprietary products, although at this time, they produced mainly balanced products. There was some concern that cost recovery results in the focus being shifted away from government's role of being visionary. CCRS had the least cost recovery imperatives, and produced more public good products. CCRS focus group participants expressed concerns similar to the other labs related to cost recovery impacts. In the next section, we examine political interest and direction.

\section{Institutional Theme 2 Results: Political Interest and Direction}

Our second theme related to institutional factors involves political interest and direction. We wanted to examine the link between the political realm and the lab.

Political interest is defined as: interest in the activities and outputs of the lab by a political figure (Minister, Member of Parliament, Deputy Minister) or a political body (Standing, 
Senate or international committees). Interest could be shown though requests for site visits, briefings, briefing notes and materials, questions in the House of Commons/Senate, Standing or Senate committee, etc. We asked focus group participants to discuss their perceptions of political interest in their lab and its innovations.

Participants from all three labs expressed that there was little interest in the lab as an institution, but some projects/innovations have high interest. "Most people don't know that we as a research facility exists, but they know a lot of our work." ${ }^{, 506}$ Senior and international officials visit the facilities occasionally. Most of the political interest is shown on initiatives, such as climate change, or projects that may impact on an individual political riding, for example, proposals to physically move government labs. The consensus was that while there is some political contact on specific projects, most political interest is directed towards policy, rather than technical issues. ${ }^{507}$ This did not translate into political interference or intervention. Put simply: "there is no political effect on the day to day work." ${ }^{508}$

The lab's relationship with the political level is considered to be distant, although some participants considered that NRCan had a much higher profile. "The problem for us is that NRCan as an organization has high a visibility and profile as an organization. For us, it is very low, as an organization, partly because we're buried within a branch, within a sector, within a Department..."509 While it may appear that NRCan has high political visibility from within the organization, others outside are not as sure: “...for

\footnotetext{
${ }^{506}$ Energy Technology Centre focus group participant

${ }_{507}^{507}$ Energy Technology Centre focus group participant

${ }_{508}^{508}$ Materials Technology Laboratory focus group participant

${ }^{509}$ CANMET Energy Technology Centre focus group participant
} 
much of the Chretien Liberal Government era, has remained several steps removed from the political limelight."

The main rub between the labs and the political level seems to relate to funding, particularly for facilities and equipment. "The main problem in most of the government labs in Ottawa is that the government is using obsolete facilities, which cost twice as much to maintain as to build a new one." ${ }^{511}$ Others pointed out that the labs have unique facilities and equipment that need upkeep, and replacement. This produces a substantial challenge to long term planning “...to ensure the quality and efficiency of research and to attract and retain highly skilled researchers within a constrained budget." $" 512$

\section{Political Direction}

Political direction was defined as: innovations or projects are scrutinized, delayed, or stopped (promoted) by political figures or lower level officials acting on the belief that an innovation/project may be politically sensitive. As a major performer of federal S\&T, Natural Resources Canada, and its labs have to respond to broader government initiatives, including Canada's innovation strategy. ${ }^{513}$ All of the labs still operate within their Department and Sector and must provide timely scientific and technological advice for informed decision-making and be responsive to the Minister, and broader government priorities. $^{514}$

Focus group participants were shown a matrix with political interest on one axis and political direction on the other. They were asked to describe the impact of these two

\footnotetext{
${ }^{510}$ Bruce Doern and Monica Gattinger, 2002, 223.

511 Materials Technology Laboratory focus group participant

512 The Conference Board of Canada, Investing in Innovation, $3^{\text {rd }}$ Annual Innovation Report (Ottawa: Conference Board of Canada, 2001), 27.

${ }^{513}$ CANMET MTL, MTL Business Plan 2003-2006, (Not published 2003), 6.

${ }^{514}$ CANMET Energy Technology Centre, CETC/ETB Business Plan 2002/03-2004/05, (Not published 2003), 2.
} 
factors, and place their lab on the grid. CCRS focus group participants noted that there was not much political interference in day to day operations, although some political decisions impact the lab, for example the decision that space based sensing is the domain of the Canada Space Agency. This prevents CCRS from adopting space based remote sensing, which leads to a concentration on radar, as opposed to other sources. ${ }^{515}$ There have been some innovations stopped historically, but this is rare, more often it involves political direction to produce something, which takes time away from primary research and innovation. ${ }^{516}$

On the political interest/ direction grid, focus group participants plotted the CCRS as low interest, and low direction. As this lab operates in a technical field that is not likely top of mind to most politicians or the public, and would likely only attract attention when their technology could assist in preventing or monitoring natural disasters, focus group participant's placement of the level of political interest and direction is consistent with our expectations.

The two CANMET labs positioned themselves in the medium category, as some of their work attracts political interest, particularly on new energy technologies and pipeline research. The labs also had international interest and visits from time to time. While there is a connection to the department, there are challenges reconciling cost sharing/recovery with political initiatives. "We connect with the goals, but we are at a crossover point where our work takes us to non-traditional work in Natural Resources,

\footnotetext{
${ }^{515}$ Canada Centre for Remote Sensing focus group participant

${ }^{516}$ Canada Centre for Remote Sensing focus group participant
} 
where you have to get funding and still conform with Departmental Strategies." ${ }^{2517}$ Both plotted their lab as low direction and medium interest.

For the CETC, due to the recent interest in energy technology, particularly in fuel cells, the focus groups placement in the medium category would seem to be consistent with our expectations. For MTL, their rating of political interest would seem to be a little higher than we may have expected, although this may be a function of the activities of the lab at this time.

\section{Political Interest}

\begin{tabular}{|l|l|l|l|}
\hline $\begin{array}{l}\text { Political } \\
\text { Direction }\end{array}$ & $\begin{array}{l}\text { Low } \\
\text { Little interest in lab's } \\
\text { activities and outputs }\end{array}$ & $\begin{array}{l}\text { Medium } \\
\text { Some interest in lab's } \\
\text { activities and outputs }\end{array}$ & $\begin{array}{l}\text { High } \\
\text { High interest in lab's } \\
\text { activities and outputs }\end{array}$ \\
\hline $\begin{array}{l}\text { Low } \\
\text { Little direction in } \\
\text { lab's activities. }\end{array}$ & & & \\
\hline $\begin{array}{l}\text { Medium } \\
\text { Some direction in } \\
\text { lab's activities. }\end{array}$ & & & \\
\hline $\begin{array}{l}\text { High } \\
\text { Lots of direction in } \\
\text { lab's activities. }\end{array}$ & & & \\
\hline
\end{tabular}

$$
=\mathrm{CETC} \boldsymbol{\Delta}=\mathrm{MTL} \bullet=\mathrm{CCRS}
$$

All three labs rated their political direction as low, however there were differences in the level of political interest. MTL participants placed their lab in the medium interest category, while CETC and CCRS focus group participants placed their labs in the low

\footnotetext{
${ }^{517}$ Materials Technology Laboratory focus group participant
} 
interest category. ${ }^{518}$ Overall, the consensus is that there is low political direction and some interest.

We wanted to find if any of the lab's successful (or unsuccessful) innovations attracted media attention (including industry publications)? All three of the labs indicated that they had some mainstream media exposure in the last two years, on scientific programs on the CBC, Discovery Channel and NOVA. All of the labs also had media exposure in trade publications and with scholarly journals. In most cases it is the innovations that attract attention, not the lab. In our next institutional theme, we consider the relationship between rewards preference and feedback related to innovation.

\section{Institutional Theme 3 Results: Recognition and Rewards Preference}

In our third theme, we will look at recognition and rewards preference as it relates to innovation. Innovation and achievement awards are widely used as tool to recognize those who have made a contribution to the advancement of an innovation. We found that $35 \%$ of respondents had won an innovation award in the last two years. When asked if those who had not won would like to win an award, $66 \%$ responded they would, $34 \%$ would not or didn't know. If respondents were unaware of innovation awards, they were asked if one should be created. Sixty three percent said one should be created, $18 \%$ said no and $18 \%$ didn't know.

Interestingly, $70 \%$ of innovators would like to win an award, $15 \%$ would not, and another $15 \%$ didn't know. Even among non-innovators, $60 \%$ wanted to win an award, $20 \%$ did not, and $20 \%$ didn't know, although our chi square $(0.522 \mathrm{p}<0.770)$ is not statistically significant. Whether the awards are a motivator or not, most people would

\footnotetext{
${ }^{518}$ Participants were just asked to rate their lab, not compare themselves to the other labs. While MTL gave themselves a medium interest rating, the other labs may not agree.
} 
like to win them. What was most interesting was the overall view from all focus groups and almost all participants that the awards are not motivators, nor are they administered well! There are many awards given out and people receive these awards often; "when you look at my boss's office, it is covered by awards, so it's hard not to notice."519 It's possible that too many awards dilute their impact. ${ }^{520}$

There were also clear differences in opinions of the awards, depending on whom the awards came from. If the recognition was internal (branch/department), the award seemed to have less impact. This could be partly because internal awards are perceived as "a photograph and a free lunch." ${ }^{521}$ Also, once you've seen it year after year, it loses its effect. This might explain why the awards used to be valued for achievement, but recently they have been devalued. ${ }^{522}$ External awards seemed to hold more meaning, as recognition that your work was important. ${ }^{523}$ Recognition from the peer community appears to be important, as "some people use the awards as a benchmark of their work" 524

The awards are still a motivator for some. "Our group works pretty hard to win the awards, and we do pretty well at winning them. I'm surprised to hear that there are those who don't want to win awards." ${ }^{525}$ It can also have an impact on one's career. If you win an award, it makes it a lot easier to defend when you ask for a promotion. There is also a temporal order to innovation that might not mesh with awards. You don't usually start a piece of work thinking that you will win an award. The award comes after

\footnotetext{
${ }^{519}$ Materials Technology Laboratory focus group participants

${ }^{520}$ Energy Technology Centre focus group participants

${ }^{521}$ Materials Technology Laboratory focus group participants

${ }^{522}$ Canada Centre for Remote Sensing focus group participants

${ }^{523}$ Materials Technology Laboratory focus group participants

${ }^{524}$ Energy Technology Centre focus group participants

${ }^{525}$ Materials Technology Laboratory focus group participants
} 
the fact, once it's completed and successful. ${ }^{526}$ The awards may be less important than other means of recognition.

Focus groups in all three labs made it clear that the awards process was part of the problem. Unprompted, participants described how awards aren't worth it. "Awards take work, someone has to write up the proposal. Fewer awards are given because people really don't have the time to do the work to write up the submissions." ${ }^{, 527}$ Other participants had "not actually gone out and applied for some of these awards, because we've decided it's not worth the paperwork." 528 Another: "I've given up trying to put people up for awards." ${ }^{.529}$

Other problems are similar to ones we noted in chapter 2, where awards create winners and losers. "There is quite a strong feeling of team spirit. There is a real problem in picking somebody out of a team, and giving them an award. ${ }^{, 530}$ Or as another put it: "if you give an award to someone, there's always someone else who thinks that they should have got it too. You'd have been better off not to give it to anyone., 531 Recognition can also come in less formal ways. A supervisor can give a "pat on the back" or individuals can be singled out for good work in meetings, etc. In the 2002 Public Service Survey, respondents were asked ${ }^{532}$ if they received adequate recognition from their immediate supervisor when they did a good job? Of the entire public service, $72 \%$ of respondents replied that they received adequate recognition.

\footnotetext{
${ }^{526}$ Materials Technology Laboratory focus group participants

${ }^{527}$ Materials Technology Laboratory focus group participants

${ }^{528}$ Energy Technology Centre focus group participants

${ }^{529}$ Canada Centre for Remote Sensing focus group participants

${ }^{530}$ Canada Centre for Remote Sensing focus group participants

${ }^{531}$ Energy Technology Centre focus group participants

${ }^{532}$ Public Service Survey 2002, question 21.
} 


\section{Rewards Preferences of Innovators and Champions}

While we cannot identify motivation, we can determine the rewards preferences of respondents to see if there are differences between the rewards preferences of innovators and non-innovators. Through our survey instrument, we asked respondents if they played a major role in the development of an innovation that turned out to be successful, how they would prefer to be rewarded. Respondents who identify rewards such as: "formal recognition; name on the patent; monetary incentive; or an innovation award" are identifying an extrinsic rewards preference. Those who identify: "no reward necessary; given time to work on their own research projects; informal recognition; or new machinery or equipment" are identifying an intrinsic rewards preference. ${ }^{533}$

We identified $35 \%$ of respondents as having an intrinsic rewards preference. It is important to remember that most people are mixes of intrinsic and extrinsic motivations. We identified $53 \%$ of all respondents as extrinsically motivated. A smaller percentage of respondents did not identify intrinsic or extrinsic rewards in the question. The differences between the labs (chi square $0.881 \mathrm{p}<0.927$ ) were not statistically significant.

\begin{tabular}{|l|c|c|c|}
\hline \multicolumn{4}{|c|}{ Reward Preference } \\
\hline N=88 & Extrinsic & Intrinsic & Unknown \\
\hline CETC & $\mathbf{9 \%}$ & $\mathbf{3 3 \%}$ & $\mathbf{5 8 \%}$ \\
\hline MTL & $\mathbf{1 4 \%}$ & $\mathbf{3 8 \%}$ & $\mathbf{4 8 \%}$ \\
\hline CCRS & $12 \%$ & $\mathbf{3 7 \%}$ & $\mathbf{5 0 \%}$ \\
\hline Overall & $11 \%$ & $\mathbf{3 5 \%}$ & $\mathbf{5 3 \%}$ \\
\hline Chi Square $\mathbf{0 . 8 8 1}$ & Sig 0.927 & & \\
\hline
\end{tabular}

Is there a relationship between rewards preference and innovation? We will test hypothesis 12: innovators will identify a preference for intrinsic rewards. Our findings

\footnotetext{
${ }^{533}$ Originally, we also included respondents who were very interested in a project that involved the solving of a challenging problem, but fortunately for the labs, the vast majority of respondents (87.5\%) were interested in a project that involved the solving of a challenging problem.
} 
indicate that of innovators, $39 \%$ identified a preference for intrinsic rewards. Of noninnovators, $30 \%$ identified a preference for intrinsic rewards. Our null hypothesis is that less than half of innovators do not prefer intrinsic rewards. As the percentage of innovators who do prefer intrinsic rewards is less than $50 \%$, we cannot reject the null hypothesis.

\begin{tabular}{|l|c|c|}
\hline \multicolumn{3}{|c|}{ Innovators and Reward Preference } \\
\hline $\mathrm{N}=\mathbf{8 8}$ & Innovator & Non- innovator \\
\hline Intrinsic preference & $39 \%$ of innovators & $\mathbf{3 0 \%}$ of non-innovator \\
\hline Extrinsic preference & $\mathbf{4 8 \%}$ of innovators & $\mathbf{6 2 \%}$ of non-innovator \\
\hline Chi Square 1.555 & Sig 0.212 & \\
\hline
\end{tabular}

Counter to our expectations, a larger percentage (45\%) of innovators identified a preference for extrinsic rewards. Of non-innovators, a greater percentage $(62 \%)$ was extrinsically motivated, although our results (chi square $1.555 \mathrm{p}<0.212$ ) are not statistically significant.

\section{Innovation and Rewards Preference}

Hypothesis 12: innovators will identify a $\quad$ Results: we cannot reject the null hypothesis preference for intrinsic rewards that innovators do not show a preference for intrinsic rewards.

While the rewards preferences of technical specialists was not a specific hypothesis of our thesis, our findings indicate that $77 \%$ of technical specialists showed an intrinsic rewards preference, compared to $28 \%$ of non-specialists. Overall, technical specialists tend to be much more likely to choose intrinsic rewards, this difference is statistically significant (chi square $10.090 \mathrm{p}<0.001$ ). This is a potential area of future research. In the next section, we consider feedback and its link to innovation.

\section{Feedback}

Positive feedback is believed to be crucial to innovation. We asked how often respondents received feedback (either oral or written) from their supervisor about their 
work. Of respondents, $26 \%$ replied they only received feedback rarely, $36 \%$ received feedback sometimes and $38 \%$ received feedback often.

Officially, managers are required to give feedback annually, although they are encouraged to give more frequent feedback. In all three labs, participants mentioned most feedback was informal, rather than the "official" reviews. Feedback was fairly frequently given with $44 \%$ of MTL and $48 \%$ of CETC respondents receiving feedback often. This could be because there is an annual requirement to receive feedback on your work. MTL had the smallest

percentage of responses

in the rare category, and

the most in the often

category. Most CCRS

respondents received

feedback sometimes

$(48 \%)$, and had the

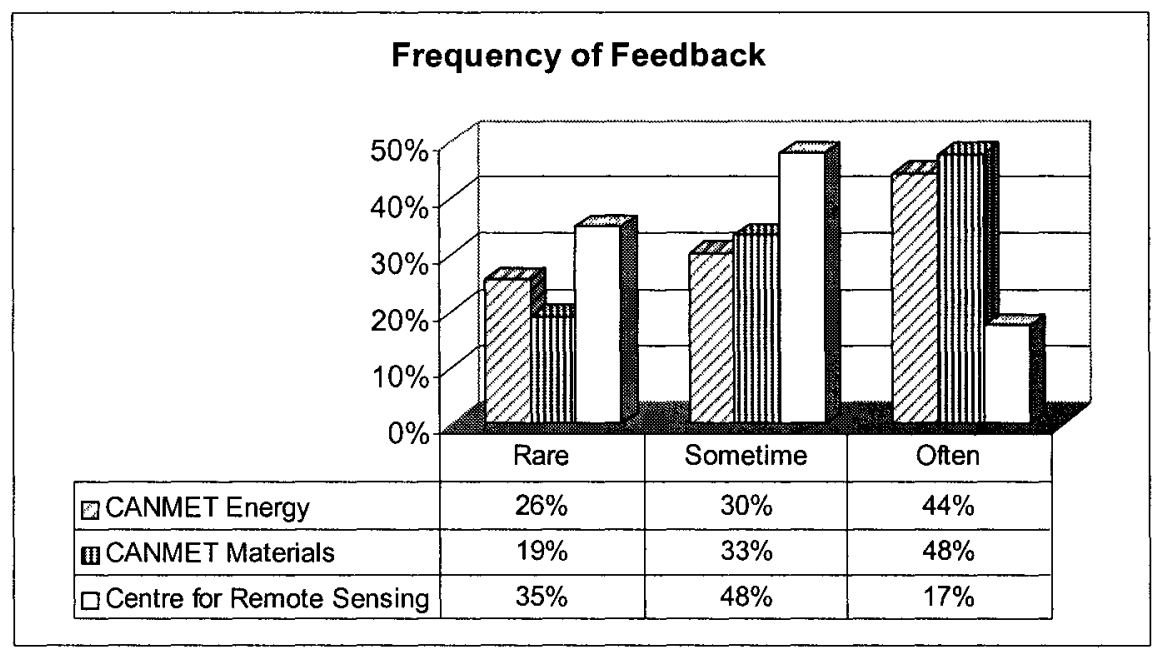

smallest percentage

of respondents in the often category $(17 \%)$, almost $30 \%$ below the other two labs and the largest percentage (35\%) in the rare category, although our results (chi square 5.916 $\mathrm{p}<0.206$ ) are not statistically significant. Focus group participants were surprised, and noted that perhaps because the feedback is often casual and informal, there may be more feedback going on than people recognize. ${ }^{534}$ When we looked at relationship between the frequency of feedback and innovation, we did not find any clear patterns, and the results were not statistically significant (chi square $1.346 \mathrm{p}<0.510$ ).

${ }^{534}$ Canada Centre for Remote Sensing focus group participants 
We want to examine whether feedback was perceived by respondents to be positive or negative. Our results suggest that the majority of feedback is positive. Fully $76 \%$ reported having positive feedback, $17 \%$ received neutral and only $7 \%$ received negative feedback.

Remembering that many respondents are scientists or researchers, neutral or negative feedback might not be unexpected. One participant noted that they "attempt to give fair feedback, rather than positive feedback. ${ }^{, 535}$ Of course, since the people giving and receiving the feedback have to work together, "people try to establish positive relationships, so there would be a tendency towards positive feedback. Overall, it's all in the spirit of improving everybody's performance."

The majority of respondents in all labs perceived the feedback to be positive, however, MTL had a higher percentage of respondents (14\%) who perceived feedback as negative, compared to other labs. Some noticed, "certainly technicians get criticized fairly often, and some groups work pretty close, so it's hard

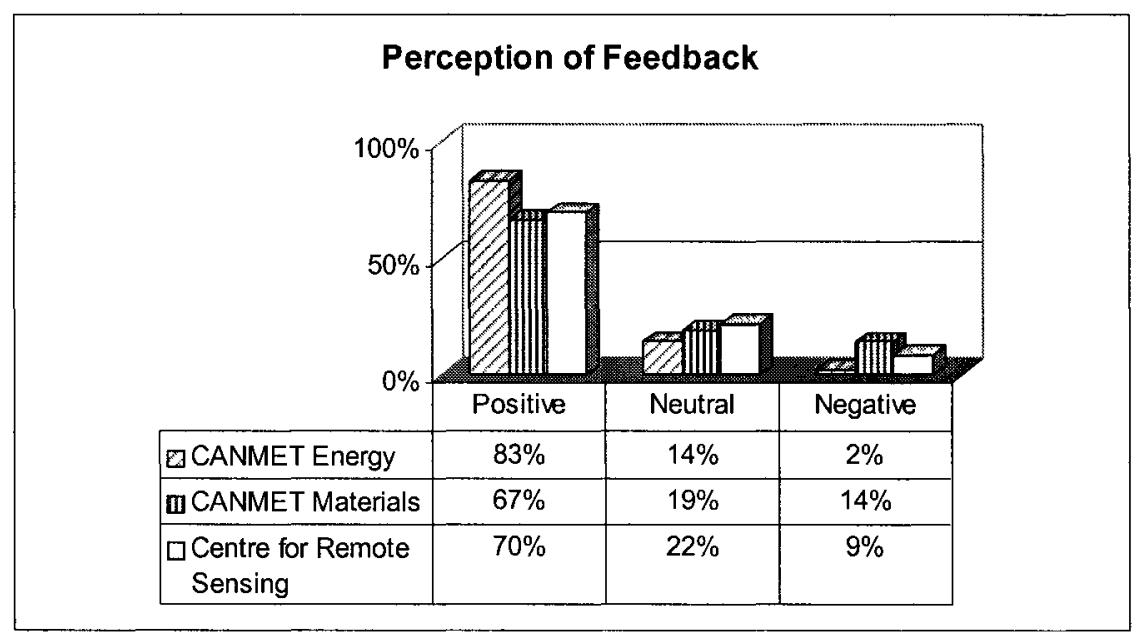
not to tell somebody how he's doing., ${ }^{, 537}$ While they may not get feedback as often as others, CCRS respondents had a relatively positive view of their feedback. There was a

\footnotetext{
${ }^{535}$ Materials Technology Laboratory focus group participants

${ }^{536}$ Materials Technology Laboratory focus group participants

${ }^{537}$ Materials Technology Laboratory focus group participants
} 
sense in the focus groups the culture of the public service encourages positive feedback.

"The only tool you have to encourage people is positive feedback." ${ }^{\text {"T38 }}$ CETC respondents had a much more positive view of their feedback than respondents in the other labs, where $83 \%$ received positive feedback, and only $2 \%$ received negative feedback! The differences between the labs were not statistically significant, chi square $4.156 \mathrm{p}<0.385$.

We can now test hypothesis 13: positive feedback is positively related to innovation. If this is not true, the null hypothesis $(\mathrm{Ho})$ is that the characteristics of innovators and non-innovators are not different. Our results indicate that of innovators, $81 \%$ had received positive feedback, and a smaller percentage (67\%) of non-innovators received positive feedback, although our results (chi square $2.326 \mathrm{p}<0.313$ ) are not statistically significant. Therefore we cannot reject the null hypothesis.

\section{Feedback and Innovation}

\begin{tabular}{l|l} 
Hypothesis 13: positive feedback is & Results: we cannot reject the null hypothesis
\end{tabular} positively related to innovation that the characteristics of innovators and noninnovators are different. Our results are directionally consistent with the hypothesis that positive feedback is related to innovation.

While feedback may be regular and positive, it may not be appropriate. It is possible to have inappropriate positive and appropriate negative feedback. Slightly over half $(54 \%)$ reported that the feedback was appropriate, $18 \%$ thought it was somewhat appropriate and $28 \%$ thought it was inappropriate. This lends credence to the focus group findings, that there may be a reliance on positive feedback whether it is appropriate or not. "Looking at the feedback on an innovation, maybe the feedback from a supervisor might not be that important, if the supervisor is not that familiar with the

\footnotetext{
${ }^{538}$ Canada Centre for Remote Sensing Focus Group Participants
} 
innovation. ${ } 539$ We combined positive and appropriate feedback to find its relationship to innovation, and $56 \%$ of innovators received positive appropriate feedback, compared to non-innovators, $38 \%$ received positive appropriate feedback, while $62 \%$ did not. Our chi square $2.505 \mathrm{p}<0.113$ is not statistically significant.

\section{Institutional Theme 4: Work Environment; Job Satisfaction and Involvement}

Our fourth and final institutional theme is work environment. The literature suggested that work environment might be an important institutional factor related to innovation. We will look at job satisfaction and job involvement as measures of the work environment. Job satisfaction is how much the respondent likes their job. If one is very satisfied with one's job, one may be willing to innovate and create new products, processes and services. We asked respondents overall if they like their job." ${ }^{540} \mathrm{We}$ found that $74 \%$ liked their job, $16 \%$ were neutral, while about $10 \%$ percent did not like their job.

Comparing the three labs, almost all MTL respondents (86\%) like their jobs. MTL respondents are more satisfied than the other labs, by about fifteen percentage points. MTL also had the least percentage (5\%) who did not like their job. CCRS respondents are about as satisfied as the other labs, although they tend to be more neutral than the other labs, possibly because at the time of the survey the CCRS was in the midst of a reorganization, and people were uncertain about the future. CETC respondents are between the MTL and the CCRS in job satisfaction, although the differences between the labs are not statistically significant, chi square $2.535 \mathrm{p}<0.638$. Our results are similar to the

\footnotetext{
${ }^{539}$ Canada Centre for Remote Sensing focus group participants

540 We coded those that "agreed or strongly agreed" into the "agree" category, those who "disagree" or "strongly disagree" into a disagree category, and the rest into a "neutral" category.
} 
Public Service

Survey 2002,

where $84 \%$ of

respondents ${ }^{541}$

thought their

organization is

a good place to

work, while

$15 \%$ did not.

\section{Overall I like my job}

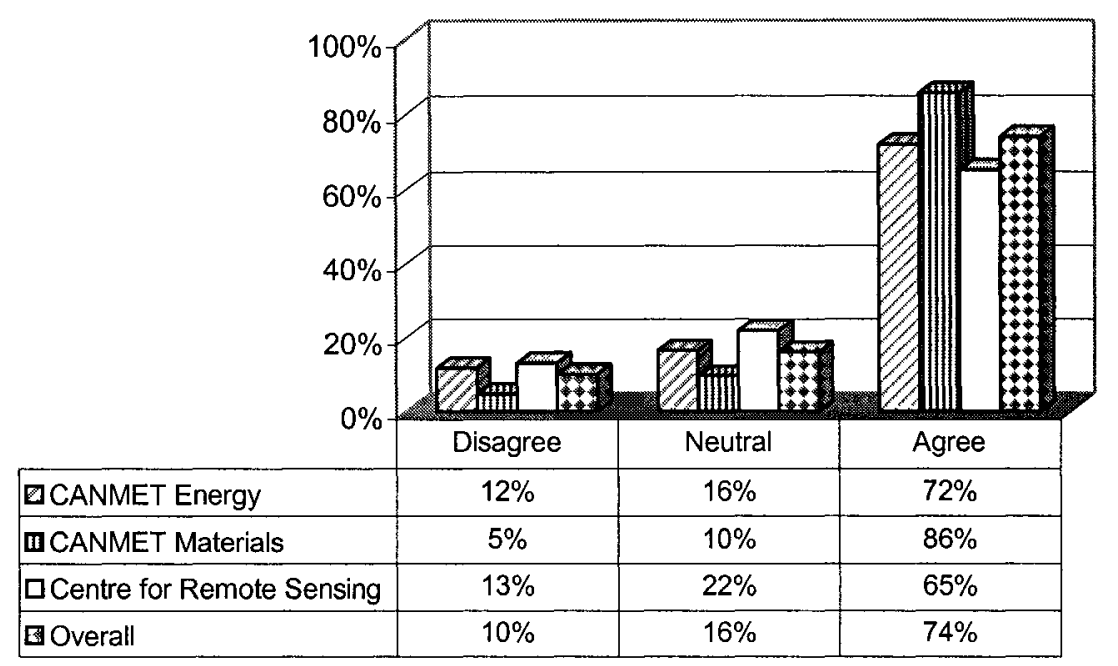

Another measure of job satisfaction is how much the respondent feels that their own satisfaction is related to how well they do their job. In our survey, we found $85 \%$

believe that

their personal

satisfaction is

related to how

well they do

their job, only

$5 \%$ believe it is

unrelated.

\section{Personal Satisfaction related to job}

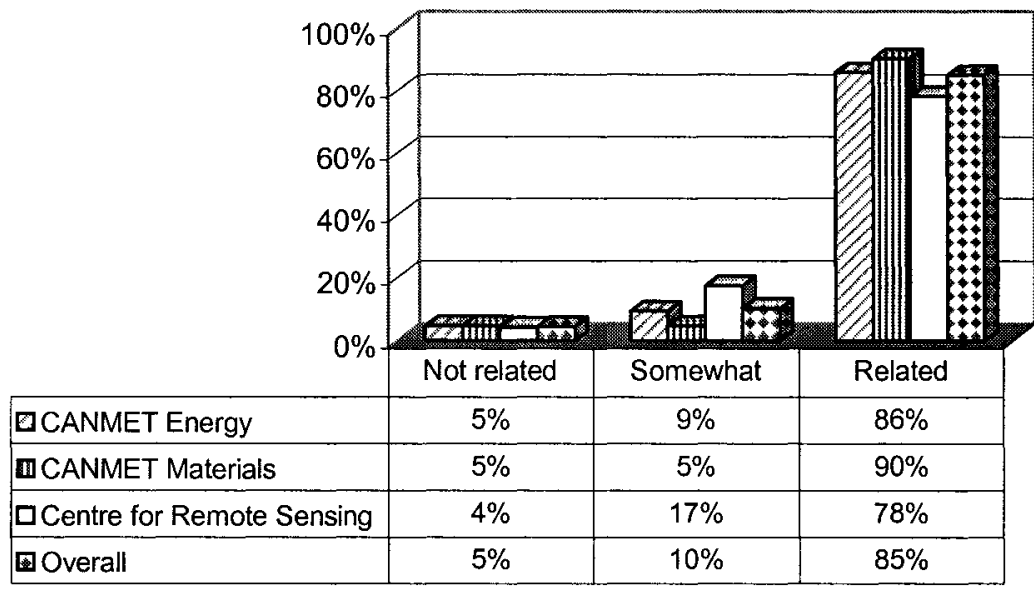

Across the labs, almost all MTL (90\%) and CETC (86\%) respondents believed that their personal satisfactions were related to their job satisfaction. The CCRS had a smaller

${ }^{541}$ Public Service Survey 2002, question 88. 
percentage of respondents in the related category, but more in the somewhat related category, although the differences between the labs are not statistically significant, chi square $1.989 \mathrm{p}<0.738$.

In order to test hypothesis 14: innovators are more satisfied with their jobs than non-innovators, we need to combine both of our measures of job satisfaction: how much a respondent likes their job, and how closely their personal satisfaction relates to how well they do their job into one equally weighted overall measure of job satisfaction. We considered that respondents who answered that they liked their job (agree) and believed that their own personal satisfaction was related to their job, (related) as "satisfied" with their job. Respondents who were "neutral" about liking their job, and somewhat agreed that their personal satisfactions were related to their job were coded as "neutral". Remaining respondents were coded as "not satisfied". The results are $64 \%$ of respondents are satisfied with their jobs, $31 \%$ are neutral and $5 \%$ are not satisfied.

When we test the null hypothesis (Ho) that there is no relationship between job satisfaction and innovation, our findings indicate

\begin{tabular}{|l|c|c|c|}
\hline $\mathrm{N}=\mathbf{8 7}$ & \multicolumn{3}{|c|}{ Innovation and Overall Job Satisfaction } \\
\hline & Satisfied & Neutral & Not satisfied \\
\hline Innovators & $\mathbf{6 6 \%}$ & $\mathbf{3 0 \%}$ & $\mathbf{4 \%}$ \\
\hline Non-innovators & $\mathbf{6 2 \%}$ & $\mathbf{3 2 \%}$ & $\mathbf{6 \%}$ \\
\hline Chi Square 0.290 & Sig $=\mathbf{0 . 8 6 5}$ & & \\
\hline
\end{tabular}

that because such a large proportion of the respondents liked their jobs and believed their personal satisfaction was related to their work, only a slightly higher percentage of innovators are satisfied with their jobs than non-innovators. Our chi square $0.290 \mathrm{p}$ $<0.865$ is not statistically significant, so we cannot reject the null hypothesis. 


\section{Job Satisfaction and Innovation}

Hypothesis 14: innovators are more satisfied with their jobs than noninnovators.
Results: we cannot reject the null hypothesis, as the results for innovators and non-innovators are not statistically significant.

We now turn to look at the second factor in our theme of work environment: job involvement.

\section{Job Involvement}

Our second measurement of the work environment is job involvement. Job involvement is the extent to which work is important to an individual. We included two measures of job involvement in our survey. The first asked whether you agree that you are a perfectionist about your work? Those who care about the quality of their work and want it to be perfect are likely job involved. We found that $67 \%$ of respondents agreed that they were a perfectionist about their work, $29 \%$ somewhat agreed, and only $5 \%$ disagreed. No respondents strongly disagreed. This suggests that there is a culture of job involvement. We can pose hypothesis 15: innovators are more job involved that noninnovators. Our findings indicate that similar percentages of innovators (68\%) and noninnovators $(65 \%)$ believe they are perfectionists, although our results are not statistically significant (chi square $0.097 \mathrm{p}<0.756$ ), so this is not a characteristic unique to innovators in our survey.

Our second question related to job involvement is if a problem arises at work that isn't solved before the time one goes home, how likely is it that one thinks about it at home? In our survey, it turns out that $79 \%$ responded that they would likely think about a work related problem at home. Almost $60 \%$ thought that it was very likely that they would think about it at home, and only $6 \%$ said it would be unlikely they would think about it. This also indicates a relatively strong level of job involvement. Related to 
innovation, most innovators $(74 \%)$ would likely think about a problem at home, while even more non-innovators ( $88 \%$ ) would think about an unsolved problem at home! Our results are unexpected, but statistically significant (chi square $2.709 \mathrm{p}<0.100$ ).

\begin{tabular}{|r|} 
Job Involvem \\
\hline Hypothesis 15: innovators are more job
\end{tabular} involved that non-innovators.

\section{ind and Inovation}

Results: we cannot reject the null hypothesis as innovators in our study are not more job involved than non-innovators.

In this section, job satisfaction and involvement were examined and we found that most respondents liked and were involved with their jobs. We did not find the differences we expected between innovators and non-innovators in these factors.

\section{Chapter Summary}

In this chapter, we have examined four themes related to the institutional factors of: publicness; political direction and interest; recognition and rewards preference; and work environment. Our findings indicated that cost recovery imperatives exist in our three labs, although there are differences among labs even in the same department. All three labs had most of their budget financed by government sources, although there was a twenty percent difference between the lab with the greatest cost recovery and the lab with the least cost recovery. We concluded that cost recovery was very important in MTL, important in CETC and less important in CCRS.

We found that where cost recovery was important, the lab tended to produce more proprietary products, and had more advocacy towards the private sector. In the labs with less strong cost recovery imperatives, there was a more balanced advocacy and a more balanced product produced. All three labs felt the impact of cost recovery, indicating that they felt pressure to produce more innovations that could be sold, and that they were moving towards proprietary products. Interestingly, this movement did not translate into 
the main impact of implemented innovations being financial, as most respondents in all three labs indicated that customer satisfaction was the main outcome of a successful innovation.

In some labs, respondents were concerned that the movement towards cost recovery may take away from the government's ability to create future innovations for the public good. All were also concerned that cost recovery imperatives produced a focus on short-term innovation, and it is possible that their products may have suffered because of this. In the MTL, which had the strongest cost recovery imperatives, there was an effort to couple research for industry with research for the public good. These efforts had met with some success.

In our second theme of political interest and direction, we found that none of the three labs saw political interference in their day-to-day operations. There was some political interest, although it was orientated towards the innovations rather than the lab. All three labs rated their political direction as low, while CETC and MTL rated their political interest as medium.

For our third theme of recognition and rewards preference, we were surprised to find that in all three labs, innovation awards were not seen as motivators of innovation, and the process of applying and receiving the awards was regarded negatively. We did not find evidence to substantiate our hypothesis that innovators would show a preference for intrinsic rewards for successful innovations. We did however find that feedback was generally positive in all three labs, and as we hypothesized, there appears to be a positive relationship between innovation and feedback received although the differences between innovators and non-innovators were not statistically significant. 
In our final theme of work environment, we found that overall most respondents were satisfied with and involved in their jobs. We did not uncover a relationship between these two factors and innovation. We have included a summary table of the results of the hypotheses in this chapter to assist the reader.

\begin{tabular}{|c|c|c|c|c|}
\hline $\begin{array}{c}\text { Hypothesis } \\
\#\end{array}$ & Hypothesis & \multicolumn{3}{|c|}{$\begin{array}{c}\text { Accept/Reject Null } \\
\text { Hypothesis? }\end{array}$} \\
\hline $\begin{array}{c}\text { Hypothesis } \\
10:\end{array}$ & $\begin{array}{l}\text { In a lab where cost recovery/sharing is very } \\
\text { important, it will produce more balanced/ } \\
\text { proprietary innovations, to serve cost } \\
\text { recovery imperatives. If cost } \\
\text { recovery/sharing is less important, we } \\
\text { expect to see more public good } \\
\text { innovations. }\end{array}$ & Important & $\mathrm{R}$ & \\
\hline $\begin{array}{c}\text { Hypothesis } \\
11:\end{array}$ & $\begin{array}{l}\text { In labs where cost recovery is important, } \\
\text { the main impact of an implemented } \\
\text { innovation would be financial, and there is } \\
\text { more advocacy to the private sector than in } \\
\text { labs where cost recovery/sharing is less } \\
\text { important. }\end{array}$ & $\begin{array}{l}\text { Financial } \\
\text { Advocate }\end{array}$ & $\mathrm{R}$ & $\mathrm{A}$ \\
\hline $\begin{array}{c}\text { Hypothesis } \\
\text { 12: } \\
\end{array}$ & $\begin{array}{l}\text { Innovators will identify a preference for } \\
\text { intrinsic rewards. }\end{array}$ & Intrinsic & & A \\
\hline $\begin{array}{l}\text { Hypothesis } \\
\text { 13: }\end{array}$ & $\begin{array}{l}\text { Positive feedback is positively related to } \\
\text { innovation. }\end{array}$ & Feedback & & $\mathrm{A}$ \\
\hline $\begin{array}{l}\text { Hypothesis } \\
\text { 14: }\end{array}$ & $\begin{array}{l}\text { Innovators are more satisfied with their job } \\
\text { than non-innovators. }\end{array}$ & Satisfied & & $\mathrm{A}$ \\
\hline $\begin{array}{c}\text { Hypothesis } \\
\text { 15: }\end{array}$ & $\begin{array}{l}\text { Innovators are more job involved than non- } \\
\text { innovators. }\end{array}$ & Involved & & A \\
\hline
\end{tabular}

In the next chapter, we will make our conclusions related to both individual and institutional factors. 


\section{CHAPTER 5: CONCLUSIONS}

The purpose of this thesis was to examine innovation at the individual and institutional level in three Canadian federal government labs: Canada Centre for Remote Sensing; CANMET Materials Technology Laboratory; and CANMET Energy Technology Centre. We defined innovation as the creation of a new product, process or service that has been implemented within the last two years. The ideas for the innovations may come from other organizations or existing products. We considered government labs in the broadest sense, including all of its functions (research, administration, policy, etc) and all participants in our primary research could come from any part of the lab.

Our main contribution was to extend existing understandings of innovation, which tends to be derived from the private sector, to government labs. The use of both an individual, and an institutional lens has not, to the best of our knowledge, been used to study government labs before. We will begin with our conclusions related to individual factors and end with our conclusions related to institutional factors.

\section{Conclusions for Individual Factors}

To study individual factors related to innovation we examined the literature from many disciplines, and our goal is to build upon it by adding evidence related to individuals in government labs. Our scope included individual and institutional factors related to innovation, rather than the innovation process, the innovations themselves, or broader science and technology or economic policy. 
Through the individual lens, we looked at three analytical themes: characteristics of innovators and champions; hierarchy; and; barriers faced and promotion methods used to advance innovation. Where necessary, we re-postulated the factors to apply to innovators and champions in government labs. In the process, we provided new groupings of these characteristics into manageable categories, as well as a new survey instrument to test our theories. We administered a survey and focus groups, which gave us new primary quantitative and qualitative evidence.

The first individual theme related to the characteristics of innovators and champions. We expected that innovators would possess three characteristics: competence; cosmopolitanism; and risk taking, and there would be differences between innovators and non-innovators. We found that innovators possessed the characteristics of competence and cosmopolitanism, but were not risk-takers. We found clear differences between innovators and non-innovators on these characteristics, although in the case of cosmopolitanism, the differences were not statistically significant.

The implications of these findings are that we can confirm that innovators in government labs possess two of the characteristics identified as important in the literature, which is primarily focused on the private sector. However, it is clear that some non-innovators in government labs also possess these characteristics. For the characteristic of competence, we found that innovators were more competent than noninnovators, and our results were statistically significant. Similarly, we found that all three components of competence: experience; technical expertise; and education were also positively related to innovation and statistically significant. The implication for the 
labs is that if they can increase the levels of these components in their employees, for example by encouraging educational opportunities it may increase innovation in the lab.

Of interest is that overall many respondents in all three labs participate in cosmopolitan activities. This is due in part to the importance placed on these activities by management, and because they are used as part of the evaluation process for promotion in some groups. As we found cosmopolitanism to be a characteristic of innovators, and as the activities are ones that could be accessible to many employees, the continued encouragement of activities such as: conference attendance; journal readership; holding office in professional associations; etc, are important connections outside the lab. Labs should encourage these activities to improve one's repertoire of knowledge and skills to become more innovative.

In a country with a relatively small research community like Canada, where most labs do not have the expertise, equipment or resources to do all the work by themselves, these cosmopolitan linkages may be even more important. One possibility to improve innovation in government labs is to encourage linkages between government labs, and as well support cosmopolitan activities such as exchanges, conference attendance, articles in scientific journals, etc.

Innovators in our study did not appear to take risks, as suggested in the literature. Empirical evidence from our survey suggests that given the relatively low levels of risk potential and risk taking behavior, risk-taking is not widespread, even among innovators. These results coupled with focus group information led us to pose a tentative conclusion: many innovators are working with their clients in industry or the government closely, so they already know what their client wants. As such, their innovations seem more like 
"sure bets" rather than "long shots", since they already have a market for their product or service. This may be why many of our respondents do not appear to take risks.

While collaboration with industry may lead to successful innovation and implementation, it may not result in thinking outside the box, or the creation of breakthrough technologies. Changes in policies, working environment or management techniques may potentially be required to change behavior. To encourage risk taking, methods must be found to encourage innovators in government labs to take risks to advance innovations. Management should be open to new ideas and employees need to bring them forward.

Alternatively, this may be a difference between the characteristics of innovators described in the private sector literature, and innovators in government labs. However, since we did find differences in characteristics between innovators and non-innovators in our study, we are less convinced that this is the case. More research is needed to determine if our results are anomalies, or if this represents a difference in characteristics.

We also identified three characteristics that champions are theorized to possess: taking ownership of innovators, motivating others; and taking risks. We expected there would be differences between champions and non-champions. Our findings indicated that a statistically significant percentage of champions do not possess any of the characteristics we identified (taking ownership; motivate others; take risks). Much smaller percentages of champions possessed these characteristics than we expected. These findings are even more puzzling when we found out that almost all of the champions had some success advocating innovations. 
In all three characteristics, champions possessed more of the characteristic than non-champions, but the percentages of champions with the characteristic was not nearly as large as we expected. Some of the results are easier to explain than others. It is possible that champions did not feel that the innovations "belonged to them" because they were part of a team that worked on it. In this case, our results related to ownership are not alarming. Buy-in could be at a group, rather than individual level. However, because we believe that taking ownership is an important characteristic, the lab should encourage ownership at a group or individual level to encourage champions to vigorously promote innovations to fruition.

Looking at motivating others, focus groups were surprised at our results, and they indicated that there was more motivation of others taking place in the lab than the survey results indicated. Future research is needed to see if these findings are unique to our survey or to government labs. It is also possible that the relatively small size of our survey prevented clear results from emerging, and it is possible that a larger survey may be able to uncover clearer results and remove these inconsistencies between the literature and our findings on these characteristics.

The most interesting results were related to the characteristic of risk-taking, and our finding that champions did not take risks at levels we expected. The implication is that in the government labs in our study, focus group evidence suggests that working closely with industry to produce products they want reduces some of the risk, thereby explaining why champions do not think they are taking risks, and why they think they are mostly successful - industry has already expressed a need (market) for, and bought into (purchased) the product, process or service they are creating. 
Comparing champions and non-champions, there were clear differences in all three characteristics, so while as large a percentage of champions did not possess the characteristics as we expected, champions had more of this characteristic than nonchampions. From this evidence, one possibility is that the characteristics of champions in the government labs we studied differ slightly from those identified in the literature, which mostly focuses on the private sector. The difference seems to lie in the level of risk-taking behavior, but unfortunately, we have no empirical benchmark to compare private and public sector risk-taking levels. We can say however that the champions in our survey were less risk-loving than the literature suggests champions would be.

Our second individual theme examined the relationship between hierarchy, innovation and championing. Hierarchy is sometimes considered an institutional factor because it can examine how the lab operates in relationship to its "parent" Department, Agency or Council. Our examination of hierarchy is different, focusing on the hierarchical levels of champions and innovators in the lab, rather than each lab's relationship to NRCan. To the best of our knowledge, the application of hierarchy, as we have defined it, has not been applied to the study of innovation in government labs before, so part of our contribution is a test of this factor.

We looked at elites and technical specialists, expecting that both would be innovators and champions, and more successful champions than non-elites and nontechnical specialists. Our results are directionally consistent with the literature that suggests a relationship between hierarchy and innovation, and we found a statistically significant positive relationship between elites and championing. We also found that elites were more successful promoting innovation than non-elites, although the difference 
was not statistically significant. Our examination of technical specialists also found them to be championing and innovating more than non-technical specialists, and more successful championing, although the results were not statistically significant. Overall, our results were directionally similar to the literature, but we did not uncover a statistically significant relationship between innovation and hierarchy.

The implication of these findings is that in accordance with the private sector literature, we can state that elites and technical specialists appear to be important in the study of innovation and championing. Unfortunately, we can only confirm that our results are directionally consistent with the literature, and statistically significant for elites and championing, but not statistically significant for the other results. Therefore, if the lab is not already doing so, it can look to technical specialists as potential sources of innovation. Also, we found technical specialists identified an intrinsic rewards preference, so the labs may find that they can increase the job satisfaction and possibly innovative output from technical specialists by utilizing intrinsic rewards by giving them challenging tasks, allowing them to define part of their work, etc.

Our third theme examined the processes that champions used to advance innovations: the rational; participative; and renegade process, as well as the barriers faced. Our findings indicate that almost half of respondents used the rational process, and a little over a third used the participative process, and only a very small percentage used the renegade process. Given the nature of hierarchy in the public service, the use of the rational and participative process, and the relative absence of the renegade process confirmed our hypothesis; and this is likely a difference between the public and private sectors. In all three labs, resources were the major problem advancing innovation, 
although focus group participants also indicated that resources are but one of many problems faced.

Taking these three individual themes together, we found relatively large percentages of respondents are innovating and championing. Most believe they are successful, but on the whole they are not taking ownership, or promoting what they consider to be risky innovations and most are not motivating others. Our findings can add to the literature related to individual innovation. We found that innovators in the three government labs in our study possessed the characteristics of competence and cosmopolitanism as identified in the literature. We did not find that the innovators were risk takers. We can confirm that there were clear differences in the characteristics of innovators and non-innovators. The champions in our study did not possess the characteristics that the literature expected, including taking ownership, motivating others and taking risks. There were however differences in the characteristics of champions and non-champions. In the next section, we move to the institutional level.

\section{Conclusions for Institutional Factors}

To look at institutional factors related to innovation in the three labs in our study, we examined the literature on government laboratories in Canada and the United States. We examined four themes of institutional factors: publicness; political direction and interest; recognition and rewards preference; and work environment. In publicness, we wanted to find out the extent of cost recovery imperatives in the labs. Our findings indicated that cost recovery imperatives exist in our three labs, although there are differences among labs, even in the same department. We provided new quantitative 
evidence on the extent and importance of cost recovery in the labs by looking at their budgets.

Our findings indicate that all three labs had most of their budget financed by government sources, although there were differences between labs, as MTL had the lowest percentage of public financing and CCRS the highest, and there was a twenty percentage point difference between them. Using the scale developed by Crow and Bozeman, all three labs are in the "high" category of publicness, with over $75 \%$ of their budget coming from public sources.

Other evidence on the extent of cost recovery identified that while it did not appear in the mandates of the labs, cost recovery was clearly identified as important in other documentation for two of the three labs. Our focus groups corroborated these findings. Partnerships were important in all three labs. Combining these two measures, we concluded that cost recovery was very important in MTL, important in CETC and less important in CCRS. The ranking of the importance of cost recovery imperatives in the three labs allows us to see the relative impacts of cost recovery/sharing.

We looked at the effects of cost recovery on innovation in the labs through two factors: product mix and the main impact of implemented innovations and advocacy towards the private sector. Related to the product mix, our findings indicated that overall, the labs were characterized by a balanced to proprietary product. There was some variation between labs, as the MTL produced the most proprietary products, and the CETC and CCRS produced balanced products. Focus groups indicated cost recovery imperatives had increased the percentage of proprietary products all labs were producing. 
In MTL, where cost recovery was important, the lab tended to produce more proprietary products, and had a higher percentage of advocacy towards the private sector. In the other two labs, even with lower private funding, there was a clear sense from focus groups that there is a necessity to produce a marketable product or service. However, focus group participants identified they were experiencing the effects of the movement towards cost recovery, including pressure to focus on short-term innovation, as well as creating more marketable products and services. Many participants expressed concern that this took away from the ability of the labs to conduct basic research.

The implication of the emphasis on cost recovery is that government labs may not be able to innovate for the future public good. This underlines once again the public policy difficulty where government labs are expected to innovate for the public good, while at the same time recover costs. On the whole, the labs are balancing both, by having some cost recovered projects and others that are completely government funded. Similarly, they are making a concerted effort to try to marry public good research with the needs of industry. The strengthening of cost recovery imperatives would tip this balance. All focus groups agreed that cost recovery has impacted the product mix and the research that's being conducted.

For our second measure of the impacts of cost recovery we wanted to see if the impact of an implemented innovation would be financial as labs tried to implement innovations in order to receive money. Interestingly, the largest impact of implemented innovations is customer satisfaction. However, of the three labs, the lab with the strongest cost recovery imperatives (MTL) had the largest percentage of respondents who identified financial impacts, compared to the other two labs. We were also interested to 
see if cost recovery imperatives related to where the lab would direct its advocacy activities. Overall in the three labs, we found that a lot of current and potential advocacy went to the private sector, and some to the government sector, with very little to the university sector. The reason for the advocacy to the private sector was purely financial: they were seen as having the resources that the labs need.

Our findings indicate that there is advocacy towards all three sectors in all three labs. MTL had the strongest cost recovery imperatives, and the most advocacy to the private sector. CCRS had the least cost recovery and the least advocacy to the private sector. CETC had advocacy balanced between the sectors. In sum, where cost recovery is more important, there is more advocacy to the private sector, and where it is less important, there is more balanced advocacy.

The implications of this finding are that if the Department forces the labs to increase the amount of their budget that comes from cost recovery, the labs may have to advocate towards the private sector. This is not necessarily negative, although due to the nature of private sector projects, it may force a reliance on short-term innovation, and the creation of mainly proprietary products. This can reduce the amount of public good research conducted by the labs, and hinder their role in making innovations to improve the lives of Canadians.

To sum our first institutional theme, and to add to the government lab literature, we have found evidence that cost recovery activities exist in all three of our labs, and that there is a range of cost recovery going on, from a low of $5 \%$ of the lab's total budget to a high of $24 \%$. While none of the labs had cost recovery in their mandate, other documentation indicated its importance. Surprisingly, even where cost recovery 
imperatives were strongest, financial impacts were not the main result of implemented innovations. Customer satisfaction topped the list in all three labs. Cost recovery has an impact on innovation, as the products that the labs produce become more orientated towards the private sector as cost recovery/sharing increases. Similarly, increases in cost recovery appear to increase advocacy to the private sector. Focus groups indicated that this led to a short-term industry focus, which can hurt the role of government performing research for the public good.

In our second institutional theme of political interest and direction, we created a new matrix to capture high-level differences between the labs on the two dimensions. We asked focus groups to place their lab on this matrix, and all three labs rated their political direction as low, meaning that the labs did not see political interference in their day-to-day operations. There was some political interest, although it was orientated towards the innovations rather than the lab. We did not see huge differences between the labs. Overall, the consensus is that there is low political direction and interest.

The implication of this finding is that for the labs the issue of political interest and direction is a double-edged sword. On one hand, if the labs continue to toil in obscurity, this allows a freedom to conduct research away from political constraints and interference. On the other hand, it makes it very difficult to attract attention in order to increase their budget for upgrades to the labs. A lack of resources was identified as a problem by all three labs, they may need to adopt a higher profile to attract more political attention in order to get increased funding. Of course, with increased funding can come increased attention, which may hinder innovation. 
For our third theme of recognition and rewards preference, we were surprised to find that in all three labs, innovation awards were not seen as motivators of innovation. While many survey respondents wouldn't mind winning an award, in the focus groups, participants had negative opinions of the administration and utility of these awards. The awards were clearly not seen as a motivator. Focus groups in all three labs made it clear that the process of applying for and receiving the awards was part of the problem. As the public sector faces challenges in using extrinsic motivations such as money to reward successful innovators, this negative perception of the awards produces another frustration for public sector innovators.

In order to encourage innovation, if government labs want to continue to use innovation awards, steps are required to make the process of applying for the awards easier, and make the criteria for selection clear to all. It may be beneficial to reduce the number of awards given out, to increase their importance. Alternatively, government labs may have to find other ways to reward and motivate employees.

We did not find evidence to substantiate our hypothesis that innovators would show a preference for intrinsic rewards for successful innovations. We were surprised to find that of innovators; fewer than expected showed a preference for intrinsic rewards. Even more surprising was that more innovators identified an extrinsic rewards preference. This is not what was expected by the literature. One possibility is that the innovators in our study have rewards preferences that differ from those in the literature. Another possibility is that the size of our sample failed to be large enough to produce differences, or because we had only a single measure for rewards preference, it may not clearly identify intrinsic and extrinsic rewards preferences. 
When we looked at feedback, we found that most respondents in all three labs received fairly frequent feedback, and most of it was positive. As we hypothesized, there appears to be a positive relationship between innovation and feedback received although it was not statistically significant. As positive feedback seems to be related to innovation, and labs are for the most part giving positive feedback, their challenge will be to continue providing lots of positive feedback to encourage innovation. The only area for improvement related to feedback would be to make it as appropriate as possible, not only positive.

In our final institutional theme of work environment, we examined job satisfaction and involvement. Our empirical findings indicate that the majority of respondents were satisfied with their jobs and most were job involved. Due to the relatively high levels of satisfaction and involvement of all respondents, we did not see differences between innovators and non-innovators, as both appeared to be satisfied and involved. The challenge for labs will be to attract and keep world-class researchers in a positive work environment, while facilities and equipment age, and labs continually face financial constraints.

In sum, we have applied individual and institutional factors related to innovation to study three government labs. Since we only studied three government labs, and due to the small size of our sample, we are prevented from extrapolating our results to all government labs. It is hoped that future research could yield a large enough sample to make some of the emerging patterns clearer, and confirm with more certainty some of our tentative conclusions. We have extended theories of innovation to the public sector, including the creation of new groupings of concepts, a new matrix for political interest 
and direction, and most important, we have performed empirical tests of our hypotheses through our survey and qualitative tests through our focus groups. We have uncovered many similarities and differences between what the literature expected and our findings, and have advanced our knowledge of innovation in government labs. 


\section{BIBLIOGRAPHY}

$\boldsymbol{A}$

Abbey, Augustus and John Dickson. "R\&D work climate and innovation in semiconductors." Academy of Management Journal Vol 26, no. 2 (1983), 362-368.

Abrahamson, E. "Managerial Fads and fashions: the diffusion and rejection of innovations." Academy of Management Review 16, (1991), 586-612.

Acs, Zoltan and David Audretch. "Innovation in Large and Small Firms." American Economic Review Vol 78, no. 4 (1988), 678-690.

Acs, Zoltan and David Audretsch. "Innovation, Market structure and firm size." Review of Economics and Statistics 69, (November 1987), 567-75.

Aiken, Michael, S.B Bacharach, and J.L. French. "Organizational structure, work processes and proposal making in administrative bureaucracies." Academy of Management Journal 23, (1980), 631-652.

Allen, Thomas J., and Stephen D. Cohen. "Information flows in R\&D labs." Administrative Science Quarterly 20, (1969), 12-19.

Altshuler, Alan. Public Innovation and Political Incentives. Boston: Harvard University, 1997.

Amabile, Teresa. "Motivating creativity in organizations: on doing what you love and loving what you do." California Management Review Vol 40, no. 1 (Fall 1997), 39-58.

Amabile, Teresa, Regina Conti, Heather Coon, Jeffrey Lazenby and Michael Herron. "Assessing the work environment for creativity." Academy of Management Journal Vol 39, no. 5 (1996), 1154-1184.

Amabile, Teresa, Karl G. Hill, Beth A. Hennessey and Elizabeth M. Tighe. "The Work Preference Inventory: Assessing Intrinsic, Extrinsic Motivational Orientations." Journal of Personality and Social Psychology Vol 66, no. 5 (1994), 950-967.

Amabile, Teresa, William DeJong and Mark Lepper. "Effects of Externally Imposed Deadlines on Subsequent Intrinsic Motivation." Journal of Personality and Social Psychology Vol 34, no. 1 (1976), 92-98.

Anderson, Frances and Charles Davis. "The government research infrastructure." In Science And Technology in Canada, Paul dufour and John de la Mothe editors, Essex: Longman: 1993.

\section{$\boldsymbol{B}$}

Badawy, Michael K. "The role of the technical manager why managers fail." In The Human Side of Managing Technical Innovation Edited by Ralph Katz, New York: Oxford University Press, 1997.

Bailyn, L. "Autonomy in the industrial R\&D laboratory." Human Resource Management 24, (1985), 129-146.

Baldridge, J. Victor and Robert A. Burnham. "Organizational Innovation: Individual, Organizational and Environmental Impacts." Administrative Science Quarterly 20, (1975), 165-176.

Barron, Frank and David Harrington. "Creativity, intelligence and personality." Annual Review of Psychology 32, (1981), 439-476. 
Baumgartel, H. "Leadership, motivations and attitudes in research laboratories." Journal of Social Issues $12,(1956), 24-31$.

Beath, Cynthia Mathis. "Supporting the Information Technology Champion." MIS Quarterly (September 1991), 355-372.

Behn, Robert. "The Big Questions of Public Management." Public Administration Review Vol 55, no. 4 (July/August 1995), 313-324.

Belcourt, Monica and Simon Taggar. Making Government the Best Place to Work: Building Commitment. Toronto: IPAC, 2002.

Benson, Kenneth. "Organizations: A dialectical view." Administrative Science Quarterly 22, (1977),1-21.

Bigoness, William J. and Perreault, W.D. Jr. "A conceptual paradigm and approach for the study of innovators." Academy of Management Journal 24, (1981), 68-82.

Blau, Judith R. and William McKinley. "Ideas, complexity and innovation." Administrative Science Quarterly 24, (June 1979), 200-219.

Blau, Peter. "Small Bureaucracies." American Sociological Review 31, (1966),179-191.

Borins, Sandford. "Public-service awards programs: an exploratory analysis." Canadian Public Administration Vol 43, no. 3 (2000), 321-342.

Bower, Joseph. "Effective public management." Harvard Business Review (March-April 1977), 131-140.

Bozeman, Barry and Stuart Bretschneider. "The Publicness Puzzle in Organization Theory: A Test of Alternative Explanations of Differences Between Public and Private Organizations." Journal of Public Administration Research and Theory Vol 4, no. 2 (April 1994), 197-224.

Brass, Daniel. "Being in the Right Place: A Structural Analysis of Individual Influence in an Organization." Administrative Science Quarterly 29, (1984), 518-539.

Brewer, Gene, Sally Coleman Selden and Rex Facer. "Individual Conceptions of Public Service Motivation." Public Administration Review Vol 60, no. 3 (May/June 2000), 254-264.

Brooke, Paul, Daniel Russell and James Price. "Discriminant Validation of Measures of Job Satisfaction, Job Involvement, and Organizational Commitment." Journal of Applied Psychology Vol 73, no. 2 (1998), 139-145.

Brunner, Gordon. "The tao of innovation." Research Technology Management (January-February 2001), 45-51.

Buchanan, Bruce. "Red tape and service ethic: some unexpected differences between public and private managers." Administration and Society (February 1975), 423-438.

Buchanan, Bruce. "Government Managers, Business Executives and Organizational Commitment." Public Administration Review (July-August, 1974), 339-347.

Buker, Peter. Always Better Continuously Innovative Public Sector Organizations in Canada. Toronto: Institute of Public Administration of Canada, 2003.

Burns, Tom and G.M. Stalker. The Management of Innovation. London: Tavistock, 1961. 
Butler, John E. "Theories of technical innovation as useful tools for corporate strategy." Strategic Management Journal Vol 9, (1988), 15-29.

$C$

Calsyn, Robert J., Louis G. Tornatsky and Susan Dittmar. "Incomplete adoption of an innovation: the case of goal attainment scaling." Evaluation 4, (1977), 127-130.

CANMET. CANMET '95 New Directions. Ottawa: Supply and Services Canada, 1995.

CANMET. CANMET Annual Report 1993-94. Ottawa: Supply and Services Canada, 1994.

CANMET Energy Technology Centre. CETC Business Plan, 2002/03-2004/05. Not Published, 2002.

CANMET Energy Technology Centre. CETC/ETB Business Plan 2002/03-2004/05. Not Published, 2003.

CANMET Materials Technology Lab. MTL Business Plan 2003-2006. Not Published, 2003.

CANMET Materials Technology Lab. MTL Business Plan 1999-2002. Not Published, 1999.

Carr, Houston H. and Jack T. Hogue. "It Takes A Champion." Journal of Systems Management (August 1989), 15-17.

Chakrabarti, Alok K. "The Role of Champion in Product Innovation." California Management Review Vol XVII, (Winter 1974), 58-62.

Chen, Chao, Cameron Ford and George Farris. "Do Rewards Benefit the Organization? The Effects of Reward Types and the Perceptions of Diverse R\&D Professionals." IEEE Transactions on Engineering Management Vol 46, no. 1 (February 1999), 47-55.

Cheng,Yu-Ting and Andrew Van de Ven. "Learning the Innovation Journey: Order Out of Chaos?" Organization Science Vol 7, no. 6 (November-December 1996), 593-614.

Child, John. "Organizational structure, environment and performance." Sociology 6, (1972), 1-22.

Churchman, C.W. and A.H. Scheinblatt. "The researcher and the manager: a dialectic of implementation." Management Science (1965), 69-87.

Clegg, Brian. Creativity and Innovation for Managers. Boston: The Institute of Management, 1999.

Colarelli, Gina O'Connor and Mark P. Rice. "Opportunity Recognition and breakthrough innovation in large established firms." California Management Review Vol 43, no. 2 (Winter 2001), 95- 116.

Conference Board of Canada. Investing in innovation, $3^{\text {rd }}$ Annual Innovation Report. Ottawa: Conference Board of Canada, 2001.

Conference Board of Canada. Members Briefing Measuring Innovation: is it doable? Ottawa: Conference Board of Canada, January 1997.

Cooper, Robert. "Strategic Planning for Successful Technological Innovation." Business Quarterly 43, (1978), 46-54.

Coopey, John, Orla Keegan and Nick Emler. "Managers' innovations and the structuration of organizations." Journal of Management Studies Vol 35, no. 3 (May 1998), 263-284.

Corwin, Ronald G. "Strategies for organizational innovation: an empirical comparison." American Sociological Review 37, (1972),441-452. 
Cotton, John, David Vollrath, Kirk Froggatt, Mark Lengnick-Hall and Kenneth Jennings.

"Employee Participation: Diverse forms and Different Outcomes."

Academy of Management Review Vol 13, no. 1 (1988), 8-22.

Crewson, Philip. "Public-Service motivation: building empirical evidence of incidence and effect."

Journal of Public Administration and Research Vol 7, no. 4 (October 1997), 499-519.

Crow, Michael and Barry Bozeman. Limited by Design: R\&D Laboratories in the U.S. National Innovation System.

New York: Columbia University Press, 1998.

Crow, Michael and Barry Bozeman. "A new typology for R\&D Laboratories: implications for policy analysis." Journal of Policy Analysis and Management Vol 6, no. 3 (1987), 328-341.

Crow, Michael and Barry Bozeman. "R\&D Laboratories Environmental Contexts: are the government labindustrial lab stereotypes still valid?" Research Policy (December 1987), 329-355.

Czepiel, John. "Patterns of Interorganizational Communications and the Diffusion of a Major Technological Innovation in a Competitive Industrial Community." Academy of Management Journal Vol 18, no. 1 (1975), 6-24.

$D$

Dachler, H.P. and Bernhard Wilbert. "Conceptual dimensions and boundaries of participation in organizations: a critical evaluation." Administrative Science Quarterly 23, (1978), 1-39.

Daft, Richard L. "A dual-core model of organizational innovation." Academy of Management Journal 21, (1978), 193-210.

Damanpour, Fariborz. "Organizational Innovation: A Meta Analysis of Effects of Determinants and Moderators." Academy of Management Journal Vol 34, no. 3 (1991), 555-590.

Damanpour, Fariborz, Kathryn Szabat and William Evan. "The Relationship Between Types of Innovation and Organizational Performance." Journal of Management Studies Vol 26, no. 3

(November 1989), 587-601.

Damanpour, Fariborz and William Evan. "Organizational Innovation and Performance: The Problem of Organizational Lag." Administrative Science Quarterly 29, (1984), 392-409.

Davenport, Thomas, Laurence Prusak and James Wilson. "Who's bringing you hot ideas and how are you responding?" Harvard Business Review (February 2003),59-64.

Day, Diana L. "Raising radicals: different processes for championing innovative corporate ventures." Organization Science Vol 5, no. 3 (May 1994), 148-172.

de la Mothe, John. "One small step in an uncertain direction: the Science and Technology Review and public administration in Canada." Canadian Public Administration, Vol 39, no. 3 (Fall 1996), 403-417.

Deci, Edward. "The Effects of Contingent and Noncontingent Rewards and Controls on Intrinsic Motivation." Organizational Behavior and Human Performance 8, (1972), 217-229.

Deci, Edward. "Effects of externally motivated rewards on intrinsic motivation." Journal of Personality and Social Psychology 18, (1971), 105-115. 
Decima Research. Canadian's Attitudes Towards Natural Resource Issues 2002. Not published, May 2002, $1-47$.

Delbecq, Andre L. and Peter Mills. "Managerial practices that enhance innovation." Organizational Dynamics Vol 14, no 3. (1985), 24-34.

Dewar, Robert and Jane Dutton. "The adoption of or radical and incremental innovations: an empirical analysis." Management Science 32, (1986), 1422-1433.

Doern, Bruce. The CANMET Energy Technology Centre: Key Features of Institutional Change. Not Published, CRUISE, 2002.

Doern, Bruce and Monica Gattinger. "New Economy/Old Economy? Transforming Natural Resources Canada." In How Ottawa Spends 2001-02: Power in Transition, Toronto: Oxford University Press, 2002.

Doern, Bruce and Richard Levesque. The National Research Council in the Innovation Policy Era, Changing Hierarchies, Networks, and Markets. Toronto: University of Toronto Press, 2002.

Doern, Bruce and Jeff Kinder. "One Size Does Not Fit All: Canadian Government Laboratories as Diverse and Complex Institutions." Journal of Canadian Studies. (in press).

Doern, Bruce and Jeff Kinder. "Federal government laboratories as complex institutions: the changing mix of hierarchies, networks and markets." Unpublished Paper for Industry Canada, March 2001.

Doern, Bruce and Ted Reed Editors. Risky Business: Canada's Changing Science-Based Policy and Regulatory Regime. Toronto: University of Toronto Press, 2000

Dougherty, Deborah and Cynthia Hardy. "Sustained product innovation in large, mature organizations: overcoming innovation to organization problems." Academy of Management Journal Vol 39, no.5 (1996), 1120-1153.

Dougherty, Deborah. "Interpretive barriers to successful product innovation in large firms." Organization Science Vol 3, no. 2 (May 1992), 179-202.

Downs, George Jr. and Lawrence B. Mohr. "Conceptual Issues in the Study of Innovation." Administrative Sciences Quarterly Vol 21, (December 1976), 700-714.

Driscoll, James, Gary Cowger and Robert Egan. "Private Managers \& Public Myths - Public Managers \& Private Myths." Sloan Management Review (Fall 1979), 53-57.

Drucker, Peter F. "The discipline of Innovation." Harvard Business Review

(November-December 1998), 149-157.

$\boldsymbol{E}$

Ellickson, Mark. "Determinants of Job Satisfaction of Municipal Government Employees." Public Personnel Management Vol 31, no. 3 (fall 2002), 343-358.

Energy, Mines and Resources Canada. Profile of EMR. Ottawa: Queen's Printer, 1993.

Energy, Mines and Resources Canada. Annual Reports. Ottawa: Queen's Printer, 1988,89, 1989-90, 1990-91.

Ettlie, John, W.P. Bridges and O'Keede R.D. "Organizational strategy and structural differences for radical vs incremental innovation." Management Science 30, (1984), 682-695. 
Evan, William M. and Guy Black. "Innovation in business organizations: some factors associated with success or failure of staff proposals." The Journal of Business 40, (1967), 519-530.

$\boldsymbol{F}$

Farris, George. "The effect of individual roles on performance in innovative groups." R\&D Management 3, (1972), 23-28.

Federal Partners in Technology Transfer. Report on Activities Spring 1999 to Spring 2000. Ottawa: Public Works and Government Services Canada, 2000.

Federal Partners in Technology Transfer. Annual Report 2001-02 Building Technology Transfer Capacity in Federal Laboratories. Ottawa: Public Works and Government Services Canada, 2002.

Feller, Irwin and Donald C. Menzel. "Adoption of technological innovation by municipal governments." Urban Affairs Quarterly 13, (June 1978), 469-478.

Fennell, Mary L. "Synergy, influence and information in the adoption of administrative innovation." Academy of Management Journal 27, (1984), 113-129.

Fischer, William A. Willard Hamilton, Curtis P. McLaughlin and Robert W. Zmud. "The elusive product champion." Research Management (May-June 1986), 13-16.

Fliegel, Frederick C and Joseph E, Kivlin. "Attributes of innovations as factors in diffusion." American Journal of Sociology Vol 72, (1966), 235-248.

Fottler, Myron. "Is Management Really Generic." Academy of Management Review Vol 6, no. 1 (1981), 1-12.

Freeman, Christopher and Luc Sote. The Economics of Industrial Innovation. Cambridge: MIT Press, 1997.

Frey, Don. "Learning the Ropes, My Life as a Product Champion." Harvard Business Review (SeptemberOctober 1991), 46-56.

Frohman, Alan. "Personal Initiative Sparks Innovation." Research Technology Management (May-June 1999), 32-38.

Frohman, Alan L. "The Performance of Innovation: Managerial Roles." California Management Review Vol, XX, no. 3 (Spring 1978),5-12.

Frost, Peter and Carolyn Egri. "The Political Process of Innovation." Research in Organizational Behavior 13, (1991), 229-295.

$G$

Gabarro, John. "Socialization At The Top - How CEOs and Subordinates Evolve Interpersonal Contracts." Organizational Dynamics (Winter 1979), 3-23.

Galbraith, Jay. "Designing the Innovating Organization." Organizational Dynamics Vol 11, no. 1 (Winter 1982), 5-25.

Gibson, Judith and Musawir Karim. Laying the foundation for successful innovation. Ottawa: Conference Board of Canada, 1999. 
Ginsberg, A and Abrahamson, E. "Champions of change and strategic shifts the role of internal and external change advocates." Journal of Management Studies Vol 28, no. 2 (1991), 173-191.

Glor, Eleanor. "Key factors influencing innovation in government." The Innovation Journal (March 2001),1- 24.

Glynn, Mary Ann. "Innovative genius: a framework for relating individual and organizational intelligences to innovation." Academy of Management Review Vol 21, no. 4 (1996),1081-1111.

Golden, O. "Innovation in the public sector Human Services Programs: The implications of innovation by groping along." Journal of Policy Analysis and Management Vol 9, no. 2 (1990), 219-248.

Golembiewski, Robert T. "Organization development in public agencies: perspectives on theory and practice." Public Administration Review Vol 29, (1969), 367-368.

Golembiewski, Robert T. "Innovation and Organizational Structure." Personnel Administration Vol 27, no. (Sept-Oct 1964), 3-4.

Gooding, R. and Wagner, J., III. "A Meta-Analytic Review of the Relationship Between Size and Performance: The Productivity and Efficiency of Organizations and Their Subunits." Administrative Science Quarterly 30, (1985), 462-481.

Goodman, Paul.S. and Jerry Rose and John Furcon. "Comparison of motivational antecedents and work performance of scientists and engineers." Journal of Applied Psychology Vol 54, no.6 (1970), 491-495.

Gow, James Iain. Innovation in the Public Service. Ottawa: CCMD, 1992.

Greve, Henrich and Alva Taylor. "Innovations as catalysts for organizational change: shifts in organizational cognition and search." Administrative Science Quarterly 45, (2000), 54-80.

Gualtieri, Roberto. "Science Policy and Basic Research in Canada." In How Ottawa Spends, 1994-95: making change, Ottawa: Carleton University Press, 1994.

Guthrie, Brian and Jacek Warda. The Road to Global Best: Leadership, Innovation and Corporate Culture. Ottawa: The Conference Board of Canada, May 2002.

Guyot, James. "Government Bureaucrats are Different." Public Administration Review, Vol 22, (1962), 195-202.

\section{$\boldsymbol{H}$}

Hage, Jerald and Robert Dewar. "Elite Values Versus Organizational Structure in Predicting Innovation." Administrative Science Quarterly Vol 18, (1973), 279-290.

Hage, Jerald. "An axiomatic theory of organizations." Administrative Science Quarterly 10, (1965), 289-320.

Hager, Mark. Joseph Galaskiewicz, Wolfgang Bielefeld and Joel Pins. "Tales from the grave: Organizations Accounts of their own demise." American Behavioral Scientist Vol 39, no. 8 (1996), 975-994.

Hall, Donald. "You've got to conform to create: the implications of corporate culture on innovation in the Canadian Federal Public Service." The Innovation Journal (Feb 2002), 1-7.

Hamberg, Daniel. "Invention in the industrial research laboratory." Journal of Political Economy 71, (April 1963), 95-115. 
Hannan, Michael and Freeman, J. "Structural inertia and organizational change." American sociological review 49, (1984), 149-164.

Hardy, Cynthia. "Sustained product innovation in large, mature organizations: overcoming innovation to organization problems." Academy of Management Journal Vol 39, no. 5 (1996), 1120-1153.

Hargadon, Andrew and Robert I. Sutton. "Building an innovation factory." Harvard Business Review (May June 2000), 157-166.

Harter, Susan. "A new self report scale of intrinsic versus extrinsic orientation in the classroom: motivational and informational components." Developmental Psychology Vol 17, no. 3 (1981), 300-312.

Hauschildt, Jurgen and Edgar Kirchmann. "Teamwork for innovation - the 'troika' of promoters." R\&D Management Vol 31, no. 1 (2000),41-49.

Haveman, H. "Between a rock and a hard place: Organizational change and performance under conditions of fundamental environmental transformation." Administrative Science Quarterly Vol 37, no. 1 (1992), 48-75.

Herzberg, F. "One more time: how do you motivate employees?" Harvard Business Review Vol 65, no. 5 (1987), 109-120.

Houston, David. "Public Service Motivation: A Multivariate Test." Journal of Public Administration Research and Theory, Vol 10, no. 4., (2000), 713-727.

Howell, Jane M. and Christopher A. Higgins. "Champions of Change: Identifying, Understanding and Supporting Champions of Technological Innovations." Organizational Dynamics (Summer 1990), 40-55.

Howell, Jane M. and Christopher A. Higgins. "Champions of Technological Innovation." Administrative Science Quarterly 35, (1990), 317-341.

Hull, Frank. and Jerald Hage. "Organizing for innovation: Beyond Burns and Stalker organic type." Sociology 16, (1982), 564-577.

\section{I}

The Impact Group. The Roles of the Federal Government in Performing Science and Technology: the Canadian Context and Major Forces. Not Published, March 1999.

Industry Canada. Achieving Excellence Investing in People, Knowledge and Opportunity. Ottawa: Public Works and Government Services Canada, 2002.

Industry Canada. Science and Technology Advice: A Framework to Build On. Ottawa: Public Works and Government Services Canada, 2002.

Industry Canada. Investing in Excellence, 1996-2001 A Report on Federal Science and Technology 2001. Ottawa: Public Works and Government Services Canada, 2001.

Industry, Science and Technology Canada. Geomatics Industry Profile. Ottawa: Queen's Printer, 1991.

$J$

James, William M. "Best HR Practices for today's innovation management." Research Technology Management (January-February 2002), 57-60. 
JEH Associates. Scientific Advice in Government Decision Making the Canadian Experience. Unpublished, March 1999.

Joly, P.B. and V. Mangermatin. "Profile of Public Laboratories, Industrial Partnerships and organization of R\&D: the dynamics of industrial relationships in a large organizations." Research Policy Vol 25, no. 6 (1996), 901-922.

$\boldsymbol{K}$

Kanter, Rosabeth Moss. "When a thousand flowers bloom: structural, collective and social conditions for innovation in organization." Research in Organizational Behavior Vol 10, (1988), 169-211.

Kanter, Rosabeth Moss. "The middle manager as innovator." Harvard Business Review (July-August, 1982), 95-105.

Katz, Ralph. The Human Side of Managing Technological Innovation. Oxford: Oxford University Press, 1997.

Katzell, Raymond and Donna Thompson. "Work motivation: theory and practice." American Psychologist Vol 45, no. 2 (February 1990),144-153.

Keller, Robert and Winford Holland. "Communicators and innovators in research and development organizations." Academy of Management Journal Vol 26, no. 4 (December 1983), 742-749.

Keller, Robert and Winford Holland. "Individual characteristics of innovativeness and communication in research and development organizations." Journal of Applied Psychology 63, (1978), 759-762.

Kernaghan, Kenneth, Brian Marson and Sandford Borins. The New Public Organization. Toronto: Institute of Public Administration of Canada, 2000.

Khojasteh, Mak. "Motivating the private vs. public sector managers." Public Personnel Management Vol 22, no.3 (Fall 1993), 391-401.

Kimberly, John and Michael J. Evanisko. "Organizational Innovation: The Influence of Individual, Organizational and Contextual Factors on Hospital Adoption of Technological and Administrative Innovations." Academy of Management Journal Vol 24, (1981), 689-713.

Kimberly, John. "Issues in the creation of organizations: Initiation, innovation and institutionalization." Academy of Management Journal 22, (1979), 437-457.

Kimberly, John. "Environmental Constraints and organizational structure." Administrative Science Quarterly 20, (1975), 1-9.

Kinder, Jeff. "The Doubling of Government Science." In How Ottawa spends 2003-04: Regime Change and Policy Shift, Don Mills: Oxford University Press, 2003.

Kipnis, David and Stuart M. Schmidt, and Ian Wilkinson. "Intraorganizational influence tactics: Explorations in getting one's way." Journal of Applied Psychology Vol 65, no.4 (1980), 440-452.

Klein, Katherine and Joann Speer Sorra. "The challenge of innovation implementation." Academy of Management Review Vol 21, no. 4 (October 1996), 1055-1080.

Knight, E.E. "A descriptive Model of the intra-firm innovation process." Journal of Business 40, (1967), 478-496. 
Kohn, Alfie. "Why Incentive Plans Cannot Work." Harvard Business Review (September-October 1993), 54-63.

Kotter, John P. "Power, dependence, and effective management." Harvard Business Review (July-August 1977), 125-136.

KPMG Consulting. Measuring and Ensuring Excellence in Government Science and Technology: Canadian Practices. Not published, March 2001.

Kriesberg, Louis. "Careers, Organizational Size, and Succession." American Journal of Sociology (1962), 355-359.

Kruglanski, Arie W, Irith Friedman and Gabriella Zeevi. "The effects of extrinsic incentive on some qualitative aspects of task performance." Journal of Personality Vol 39, (1971), 606-617.

Kuczmarski, Thomas. Innovation Leadership Strategies for the Competitive Edge. Chicago: NTC Business Books, 1996.

Kumar, U. and V. Kumar. Incubating technology: best practices, Not Published, 1997.

$L$

Lachman, Ran. "Public and Private Sector Differences: CEO's Perceptions of Their Role Environments." Academy of Management Journal Vol 28, no. 3 (September 1985), 671-679.

Lambright, Henry. "Government and technological innovation: weather modification as a case in point." Public Administration Review Vol 32, (January-February 1972), 1-10.

Lawler, Edward E. and Douglas Hall. "Relationship of job characteristics to job involvement, satisfaction, and intrinsic motivation." Journal of Applied Psychology Vol 54, no. 4, (1970), 305-312.

Lawless, Michael and Linda L. Price. "An agency perspective on new technology champions." Organization Science Vol 3, no. 3 (August 1992), 342-354.

Lawson, Benn and Danny Samson. "Developing innovation capability in organizations: a dynamic capabilities approach." International Journal of Innovation Management Vol 5, no. 3 (September 2001), 377-400.

Lewis, Laurie and David Seibold. "Innovation modification during intraorganizational adoption." Academy of Management Review (April 1993), 323-353.

Leydesdorff, Loet and Henry Etzkowitz. "Triple Helix of innovation." Science and Public Policy Vol 25, no. 6 (1998), 358-364.

Lieberson, Stanley and James O'Connor. "Leadership and Organizational Performance: A Study of Large Corporations." American Sociological Review Vol 37, no. 2 (1972), 117-130.

Light, Paul. Sustaining innovation : creating nonprofit and government organizations that innovate Naturally. San Francisco: Jossey-Bass, 1998.

Litwak, Eugene. "Models of bureaucracy which permit conflict." American Journal of sociology Vol 67, (1961), 177-184.

Lodahl, Thomas and Mathilde Kejner. "The definition and measurement of job involvement." Journal of applied Psychology Vol 49, no. 1 (1965), 24-33. 
Lynton, Rolf P. "Linking an innovative subsystem into the system." Administrative Science Quarterly Vol 14, (September 1969), 398-416.

$M$

MacKinnon, D.W. "Personality and the realization of creative potential." American Psychologist Vol 20, (1965), 273-281.

Maidique, Modesto A. "Entrepreneurs, Champions, and Technological Innovation." Sloan Management Review Vol 21, no.2 (Winter 1980), 59-76.

Markham, Stephen and Lynda Aiman-Smith. "Product champions: truths, myths and management." Research Technology Management (May-June 2001), 44-50.

Markham, Stephen K. "A Longitudinal Examination of How Champions Influence Others to Support Their Projects." Journal of Product Innovation Management Vol 15, (1998), 490-504.

Markham, Stephen K. and Abbie Griffin. "The Breakfast of Champions: Associations Between Champions and Product Development Environments, Practices and Performance." Journal of Product Innovation Management Vol 15, (1998), 436-454.

McGrath, Rita Gunther. "Exploratory Learning, innovative capacity, and managerial oversight." Academy of Management Journal Vol 44, no.1 (2001), 118-131.

Mechanic, David. "Sources of Power of Lower Participants in Complex Organizations." Administrative Science Quarterly Vol 7, (1962), 349-364.

Merritt, Richard and Anna Merritt, eds., Innovation in the Public Sector. Beverly Hills: Sage, 1985.

Meyer, Alan and James Goes. "Organizational assimilation of innovations: a multilevel contextual analysis." Academy of Management Journal Vol 31, no. 4 (1988), 897-923.

Meyer, Marshall W. "Leadership and Organizational Structure." American Journal of Sociology Vol 81, no. 3 (1975), 514-542.

Meyer, Marshall W. "Two authority structures of bureaucratic organization." Administrative Science Quarterly Vol 13, (1968), 211-228.

Meyer, Marshall. "Size and Structure of Organizations: A Causal Analysis." American Sociological Review (1972), 434-40.

Miewald, Robert D. "The greatly exaggerated death of bureaucracy." California Management Review Vol 13, (Winter 1970), 65-69.

Miller, D. and Friesen P.H. "Innovation in conservative and entrepreneurial firms: two models of strategic momentum." Strategic Management Journal 3, (1982), 1-25.

Moch, Michael K. and Edward V. Morse. "Size, centralization and organizational adoption of innovations." American sociological Review Vol 42, (1977), 716-725.

Mohr, Lawrence. "Determinants of innovation in organizations." American Political Science Review 63, (1969), 111-116.

Monge, Peter, Michael Cozzens and Noshir Contractor. "Communication and Motivational Predictors of the Dynamics of Organizational Innovation." Organizational Science Vol 3, no. 2 (May 1992), 250-274. 
Morck, Randall. The Economic Determinants of Innovation. Ottawa: Public Works and Government Services Canada, 2001.

Mowday, Richard T. "The exercise of upward influence in organizations." Administrative Science Quarterly Vol, 23, (March 1978), 137-156.

Murray, Michael. "Comparing Public And Private Management: an exploratory essay." Public Administration Review (July/August 1975), 364-371.

$N$

Natural Resources Canada. CANMET Energy Technology Centre Brochure. Not Published, 2003.

Natural Resources Canada. Report on Plans and Priorities 2002-2003. Ottawa: Public Works and Government Services Canada, 2002.

Natural Resources Canada. Earth Sciences Sector Business Plan 2002-2005. Ottawa: Public Works and Government Services Canada, 2002.

Natural Resources Canada. Departmental Performance Report 2002. Ottawa: Public Works and Government Services Canada, 2002.

Natural Resources Canada. CANMET Building the future. Ottawa: Public Works and Government Services Canada, 2001.

Natural Resources Canada. Business Plan 1997-2000. Ottawa: Public Works and Government Services Canada, 1997.

Natural Resources Canada. CANMET making an impact on Canada. Ottawa: Public Works and Government Services Canada, 1997.

Natural Resources Canada. CANMET an Investment in Canada Achieving Sustainable Economic Growth And Sustainable Development. Ottawa: Supply and Services Canada, 1995.

Nelson, Richard R. and Sidney Winter. "In search of useful theory of innovation." Research Policy 6, (1977),36-76.

Nelson, Richard R. "The simple economics of basic research." Journal of political economy Vol 67, (1959), 297-306.

Nelson, Richard R. National Innovation Systems: A Comparative Analysis. New York: Oxford University Press, 1993.

Nicholson, Geoffrey. "Keeping Innovation Alive." Research Technology Management Vol 41, no. 3 (May-June 1998), 34-40.

Nohria, $\mathrm{N}$ and Gulati, R. "Is slack bad for innovation?" Academy of management Journal Vol 39, no. 5 (1996), 1245-1264.

Normann, Richard. "Organizational innovativeness: product variation and reorientation." Administrative Science Quarterly Vol 16, (1971), 203-215.

$\boldsymbol{O}$

OECD. Oslo manual: proposed guidelines for collecting and interpreting technological innovation data. Paris: Organisation for Economic Co-operation and Development, 1997. 
OECD. The changing role of government research laboratories.

Washington: Organisation for Economic Co-operation and Development, 1989.

Oldham, Greg. "The Motivational Strategies Used by Supervisors: Relationships to Effectiveness Indicators." Organizational Behavior and Human Performance Vol 15, (1976), 66-86.

Organ, Dennis. "The subtle significance of job satisfaction." In The Human Side of Managing Technical Innovation, edited by Ralph Katz, New York: Oxford University Press, 1997.

$\boldsymbol{P}$

Pelz, Donald C. "Some social factors related to performance in a research organization." Administrative Science Quarterly 1, (1956), 310-325.

Perrow, Charles. "The analysis of goals in complex organizations." American Sociological Review 26, (1961),854-866.

Perry, James and Lyman Porter. "Factors Affecting The Context for Motivation in Public Organizations." Academy of Management Review Vol 7, no. 1 (1982), 89-98.

Perry, James and Lois Recascino Wise. "The Motivational Basis of Public Service." Public Administration Review, (May June 1990),367-373.

Perry, James and Hal Rainey. "The public-private distinction in organization theory: a critique and research strategy." Academy of Management Review Vol 13, no. 2 (1988),182-201.

Peters, Tom. "Get innovative or get dead." California Management Review 33, (1990), 9-26.

Peters, Thomas and Robert Waterman, In Search of Excellence Lessons from America's Best Run Companies. New York: Warner Books, 1982.

Pierce, Jon and Andre Delbecq. "Organizational Structure, Individual Attitudes and Innovation." Academy of Management Review (January 1977), 27-37.

Porter, L.W. "Job attitudes in management I: Perceived deficiencies in need fulfillment as a function of job level.” Journal of Applied Psychology 42, (1962), 375-384.

\section{$Q R$}

Rainey, Hal and Paula Steinbauer. "Galloping Elephants: Developing Elements of a Theory of Effective Government Organizations." Journal of Public Administration Research and Theory Vol 9, no. 1 (1999), 1-32.

Rainey, Hal, Robert Backoff and Charles Levine. “Comparing Public and Private Organizations." Public Administration Review (March/April 1976), 233-246.

Rainey, Hal. "Public Agencies and private firms incentive structures, goals and individual roles." Administration and Society Vol 15, no. 2 (August 1983), 207-242.

Rainey, H.G. "Perceptions of Incentives in Business and Government: Implications for Civil Service Reform." Public Administration Review 39, (1979), 440-448.

Rice, Mark, Donna Kelley Lois Peters and Gina Colareli O'Connor. "Radical innovation: triggering initiation of opportunity recognition and evaluation." R\&D Management Vol 31,no. 4 (2000), 409-420. 
Roberts, Edward. "Managing Invention and Innovation." Research Technology Management Vol 31,no. 1 (1988), 11-29.

Roberts, Edward and Alan Fusfeld. "Staffing the Innovative Technology-Based Organization." Sloan Management Review (Spring 1981), 19-33.

Robertson, Thomas and Yoram Wind. "Organizational Cosmopolitanism and Innovativeness." Academy of Management Journal Vol 26, no. 2 (1983), 332-338.

Roessner David J. "Incentives to innovate in private and public organizations." Administration and society Vol 9, (November 1977), 341-365.

Rosner, Morris. "Administrative Controls and Innovations.” Behavioral Science 13, (1968), 36-43.

Rowe, Lloyd A. and William Boise. "Organizational Innovation: Current Research and Evolving Concepts." Public Administration Review Vol 34, (May/June 1974), 284-392.

Ruh, R.A. White, J.K. \& Wood R.R. "Job involvement, values, personal background, participation in decision making, and job attitudes." Academy of management journal Vol 18, no. 2 (June 1975), 300-312.

$S$

Sanger, Mary B. and Martin Levin. "Using old stuff in new ways: Innovation as a case of evolutionary tinkering." Journal of Policy Analysis and Management Vol 11, no. 1 (1992), 88-115.

Sapolsky, Harvey M. “Organizational Structure and innovation." Journal of Business 40, (1967), 497-510.

Schilit, Warren and Edwin Locke. "A Study of Upward Influence in Organizations." Administrative Science Quarterly 27, (1982), 304-316.

Schon, Donald A. "Champions for Radical New Inventions." Harvard Business Review Vol 41, (1963), 77-86.

Smith, M.E. "The Role of Federal Laboratories in the Technological Development of Canadian Industry." Journal of Canadian Studies Vol 17, no. 4 (Winter 1982) 10-19.

Solomon, Ester. "Private and public sector managers: an empirical investigation of job characteristics and organizational climate." Journal of Applied Psychology Vol 71, no. 2 (1986), 247-259.

Statistics Canada. 2000 Workplace and Employee Survey. Ottawa: Public Works and Government Services Canada, 2000.

Statistics Canada. Survey of Innovation 1999. Ottawa: Public Works and Government Services Canada, 1999.

Storey, John. "The management of innovation problem." International Journal of Innovation Management Vol 4, no. 3 (September 2000), 347-369.

Stringer, Robert. "How to manage radical innovation." California Management Review Vol 42, no. 4 (Summer 2000), 70-88.

$T$

Teece, David J. "The diffusion of administrative innovation." Management Science Vol 26, (1980), 464-470. 
Teofilovic, Nada." The reality of innovation in government." Innovation Journal Vol 7, no.3 (2002), 1-22.

Thompson, Victor. Bureaucracy and Innovation. Urbana: University of Alabama Press, 1976.

Thompson, Victor. "Bureaucracy and innovation." Administrative Science Quarterly Vol 10, no. 1 (1965), 1-20.

Thornton, Robert L. “Decisions to Innovate.” Personnel Administration 33, (May June 1970), 42-45.

Topalian, Alan. "The role of innovation leaders in developing long-term products." International Journal of Innovation Management Vol 4, no. 2 (June 2000), 149-171.

Tushman, Michael and David Nadler. "Organizing for innovation." California Management Review Vol XXVIII, no. 3, (Spring 1986), 74-92.

Tushman, M.L. and Nelson R.R. "Introduction technology, organizations and innovation." Administrative Science Quarterly Vol 35, (1990), 1-8.

Tushman, M.L. "Special boundary roles in the innovation process." Administrative Science Quarterly Vol 22, (1977), 587-605.

$U \boldsymbol{V}$

Van de Ven, Andrew, Douglas Polley, Raghu Garud and Sankaran Venkataraman. The Innovation Journey. New York: Oxford University Press, 1999.

Vroom, Victor. "Ego-involvement, job satisfaction and job performance.” Personnel Psychology Vol 15, (1962), 159-177.

$\boldsymbol{W}$

Walker, Jack. "The diffusion of innovations among the American states." American political science review Vol 73, (1969), 880-899.

Warner, Kenneth E. "The need for some innovative concepts of innovation: an examination of research on the diffusion of innovation." Policy Sciences 5, (1974), 433-451.

Warna, Jacek. Government Research Laboratories Finding the Right Chemistry for the Future. Ottawa: Conference Board of Canada, November 1999.

Webber, Alan and Polly LaBarre. "The innovation conversation." Research Technology Management (September-October 2001), 9-11.

Weissenberg, Peter and Leopold Gruenfeld. "Relationship between job satisfaction and job involvement." Journal of Applied Psychology (1968), 469-473.

Wernimont, Paul. "Intrinsic and extrinsic factors in job satisfaction." Journal of Applied Psychology Vol, 50, (1966), 41-50.

West, Michael and James Farr. Innovation and Creativity at work psychological and organizational structures. Toronto: John Wiley \& Sons, 1990.

White, Robert. “Motivation reconsidered.” Psychological review Vol, 66, no. 5 (1959), 297-323. 
Whorton, Joseph W. and Worthley John A. "A perspective on the challenge of public management: environmental paradox and organizational culture." Academy of Management Review 6 , (1981),357-362.

Wilkins, Alan L., Lee Tom Perry, and Alan G. Checketts. "Please Don't Make Me A Hero: A ReExamination of Corporate Heroes." Human Resource Management Vol 29, no. 3 (Fall 1990), 327-341.

Wolfe, Richard. "Organizational innovation: review, critique and suggested research directions." Journal of Management Studies Vol 31, no. 3 (May 1994) 405-431.

Woodman, Richard, John Sawyer and Ricky Griffin. "Toward a theory of organizational creativity." Academy of Management Review Vol 18, no. 2 (1993), 293-321.

Wright, Bradley. "Public-Sector Work Motivation: A Review of the Current Literature and a Revised Conceptual Model." Journal of Public Administration Research and Theory Vol 11, no. 4 (October 2001),559-586.

\section{$X Y Z$}

Yin, Robert K. "Production Efficiency Versus Bureaucratic Self-interest: Two Innovative Processes?" Policy Sciences Vol 8, (1977), 381-399. 


\section{APPENDIX A METHODOLOGY}

\section{Methodology and procedures}

To participate in this study, there were two general criteria. First, the lab had to be a federal government lab. Second, the lab had to be located in the national capital region. This was primarily to defray costs and increase accessibility. Choosing a single location controls for geographical differences between the labs. Also, since the majority of federal government labs are in the National Capital Region, this would not appear to be a major shortcoming. The labs could come from any federal department, and it was not intentional that all three are part of Natural Resources Canada.

This dissertation used three lines of evidence: literature review; survey; and focus groups. Several in-person meetings were held with the Directors of each lab, and they were used to provide background information, rather than a separate line of evidence. The literature review examined academic, lab and departmental (NRCan) documents, to improve the research focus, provide background information and set hypotheses. A new survey instrument was created to collect primary data. The survey was administered in three Canadian federal government labs. The third line of evidence comes from focus groups. Where possible, multiple lines of evidence were used to establish the findings. For example, information from focus groups was used with the results of the survey. Similarly, the literature review set some of the expectations for the results of the survey.

\section{The Literature Review}

The literature review is presented in the first two chapters of the dissertation. Two streams of literature were used: literature on innovation at the individual level; 
drawn from a fairly wide variety of fields including: innovation; public administration; political science; psychology; business and; organization theory; etc. The second stream related to institutional factors came from literature on government labs in Canada and the United States. This literature was used to provide the background for the discussion of innovation and all of the theoretical underpinnings of the dissertation. The literature review highlighted potential questions for the survey, and suggested some expected results. The researcher attempted to extend existing theories to advance our understanding of innovation in government labs. Lab documentation provided background of the labs, their operating environment; as well as information on the resources and cost recovery imperatives they face. Financial information from business plans and annual reports was also used.

\section{Innovation Survey}

Using the literature review in addition to the researcher's own questions, a survey instrument was crafted. Several steps were taken to bring the survey from concept to implementation. To identify labs to participate in the survey, a listing of all federal government labs and contacts was obtained from the Federal Partners in Technology Transfer. ${ }^{1}$ Using this list, an introductory email was sent out to Directors in all the labs in the national capital region. Several responded, and three agreed to enter discussions about participating. Their agreement to participate was tentative, until they and the researcher could meet to discuss the questionnaire. They were notified that the University Research Ethics Committee had to approve the questionnaire before it could be administered

\footnotetext{
${ }^{1}$ Federal Partners in Technology Transfer is a National Research Council bureau that provides information about federal labs. FPTT website: http://www.fptt-pftt.gc.ca/
} 
The questionnaire was sent to Directors in three government labs that had agreed to enter into discussions to participate. All three Directors had in-person meetings with the researcher to discuss the purpose of the research and to give their comments. All proposed modifications and clarifications to the survey. All Directors consented, and received approval to allow the survey to be distributed, after University Ethics Committee approval, on January 23, 2003.

In mid February and March 2003, a short presentation was given in each lab to describe the research project and allow for questions and answers. The presentations included the contents of the letter of information, as well as a summary of the research project. It was made clear that participation was voluntary and that all responses will be treated anonymously and there will be no identification of individual respondents in either the survey or the results. It was also made clear that there is no compensation for participation, nor were there any foreseen risks to participation.

The survey instrument was not handed out at this time, but rather delivered to all employees, managers and students through each lab's internal mail system shortly after the meeting to ensure the anonymity of the respondents. All potential participants received a paper questionnaire, complete with a letter of information explaining the research project and the purpose of the survey. Everyone was also given a pre-addressed postage paid return envelope to be sent back to a mailbox at Carleton University. A ten working day time limit was suggested to ensure timely completion. After a few days, an email was sent out as a reminder of the survey and to explain its content, in case some members of the lab were unable to attend the meeting. After receiving the anonymous surveys, the researcher coded them into SPSS. While there are no personal identifiers, 
each lab was identified to allow comparisons between the labs. The surveys distributed were identical, except the name of the lab was changed.

Potential participants were all individuals working for three Federal Government Labs: Canada Centre for Remote Sensing; CANMET Energy Technology Centre; and CANMET Materials Technology Laboratory. All three labs are part of Natural Resources Canada. In total, 605 surveys were distributed, and 88 were returned, for a total response rate of $14.5 \%$. The individual lab response rates are:

\begin{tabular}{|l|c|c|c|}
\hline \multicolumn{4}{|c|}{ Survey } \\
\hline \multicolumn{1}{|c|}{ Lab } & Surveys Returned & Lab Population & Proportion Returned \\
\hline CETC & 43 & 275 & $15.5 \%$ \\
\hline MTL & 21 & 130 & $16 \%$ \\
\hline CCRS & 24 & 200 & $12 \%$ \\
\hline TOTAL & 88 & 605 & $14.5 \%$ of the total \\
\hline
\end{tabular}

The recruitment is self-selecting, as those who choose to participate in the survey completed the questionnaire and sent it in, and those who did not wish to participate did not. There is no way to identify participants and non-participants. Participants formed their consent by completing the survey. Please refer to Appendix B for the survey instrument. After the completion of the survey period, the researcher placed the results of selected survey questions on a website that was accessible to everyone. After the completion of the survey, the next step was to hold focus groups.

\section{The Focus Groups}

In order to give another line of evidence, the researcher elected to run focus groups in each of the labs, and if possible to have one with managers and a separate one with employees. The purpose of the focus groups was threefold: first to validate (or repudiate) the survey findings; second to provide information to illuminate the findings 
and to explain some of the differences and results that were unexpected; third to answer additional questions.

After the completion of the survey, the logistics of the focus groups were to first create a potential question list and share it with the lab's Directors for input and suggestions. The questions were modified and the entire proposal for focus groups was sent to the Research Ethics Committee for approval. After approval from the Ethics Committee on May 22, 2003 a time and place for the group was set up. An email was sent out to recruit managers and employees to participate. The email included the focus group questions, as well as a link to a website containing the overall results of the survey. Participation was voluntary, and it was not necessary to have taken part in the survey to participate in the focus group, and since participation (in the survey) was anonymous, neither the lab employees, nor the researcher knows who returned a survey and who did not. Interested parties replied via email to the researcher and were told of the time and the place of the focus group.

The focus groups lasted approximately an hour and a half. The researcher shared the major results from the survey. For the results from each survey question presented, participants will be asked if the results seem to make sense. Next, participants were asked to provide any information that may explain or illuminate the findings. Finally, participants were asked if they think the results (for their lab) on this question would be similar to other Canadian federal government labs. The second part of the focus group was designed to provide the researcher with specific information related to the dissertation. 
Each focus group was tape-recorded, and participants had to sign a letter of consent before participating. The tape recording is to ensure the accuracy of the reporting. Participants may decline to answer any questions. Because the purpose of the focus group is to ascertain nuances and opinions participants may have about the survey findings, in the dissertation, individual comments were quoted. The identities of the participants were not anonymous because the researcher knew the participants from the email that confirms their attendance, and their signed consent form. However, the comments made were not attributed to individuals, but rather: "as one respondent noted..." There was no compensation for participation. Participants could withdraw consent to participate at any time during the focus group, without reprisal. There were no foreseen risks to participation.

Like the survey, the potential focus group participants were all individuals, including managers and employees working for the three Federal Government Labs that participated in the survey. In total we ran 5 groups with 25 participants in July of 2003. A sixth group was set up, but there was no attendance.

\begin{tabular}{|l|c|c|}
\hline \multicolumn{3}{|c|}{ Focus Groups } \\
\hline Cab & Total Groups & Number of Participants \\
\hline MTL & 2 & 13 \\
\hline CCRS & 2 & 7 \\
\hline TOTAL & 1 & 5 \\
\hline
\end{tabular}

\section{Potential Bias and Limitations of Data}

The methodology leaves potential for bias at two separate levels. The first is at the institutional level, as a selection bias may exist because the labs were self-selecting. The Directors who decided to participate may consider their labs to be more "innovative" than others. Labs that did not choose to participate may not be innovative. This bias is 
mitigated in part because the introductory email was sent out to all federal government labs identified in the National Capital Region, and there was no control over the labs chosen. Second, there is no reason to assume that innovative labs are any more likely to participate than non-innovative labs. Third, even in the case of a lab participating because they believe they are innovative, it is unlikely that the Director could predict the outcome of an anonymous survey of his or her employees.

There is also a potential study effect where some labs are studied often and they may or may not be typical of other labs. Because of the small number of labs in our study, and the relatively small size of our total sample $(\mathrm{N}=88)$, we cannot extrapolate the findings. The labs are all from one Department (NRCan). This means that the overall institutional environment is controlled for i.e.: same Minister, Deputy Minister, and same Departmental structure. However, other government labs in different departments may operate in a different environment. It is important to note that the labs were not specifically chosen because they were part of NRCan, they were just the ones who happened to participate. The difference between the labs is that none are in the same industry - one is in metals, the other energy and one in remote sensing. Also, the labs vary in size, from CANMET Materials Technology Lab with 130 employees, Canada Centre for Remote Sensing with 200 and CANMET Energy Technology Centre with 275.

The second possible bias occurs at the individual respondent level. It is possible that those who reply to an innovation survey are those that consider themselves innovative. Since we sent out the surveys to everyone in the lab, this should potentially allow both innovators and non-innovators to participate. If we received only responses from innovators or champions, this indicates a self-selection bias in the survey. Since our 
results identified a percentage of the respondents who were not innovative, this bias did not appear. A similar selection bias potentially existed in the focus group participation. In the groups, a wide varieties of opinions were expressed, which tend to discount this problem. 


\section{APPENDIX B INNOVATION SURVEY}

Before completing this survey, please be sure that you have read the attached letter of information. Your participation is completely voluntary and you are not required to give your name. This survey is directed to discovering information about individual innovation in government labs, focusing on both personal and institutional factors. By innovation, we mean the creation of new or improved products, process and services.

To begin, we would like to ask you about your work experience

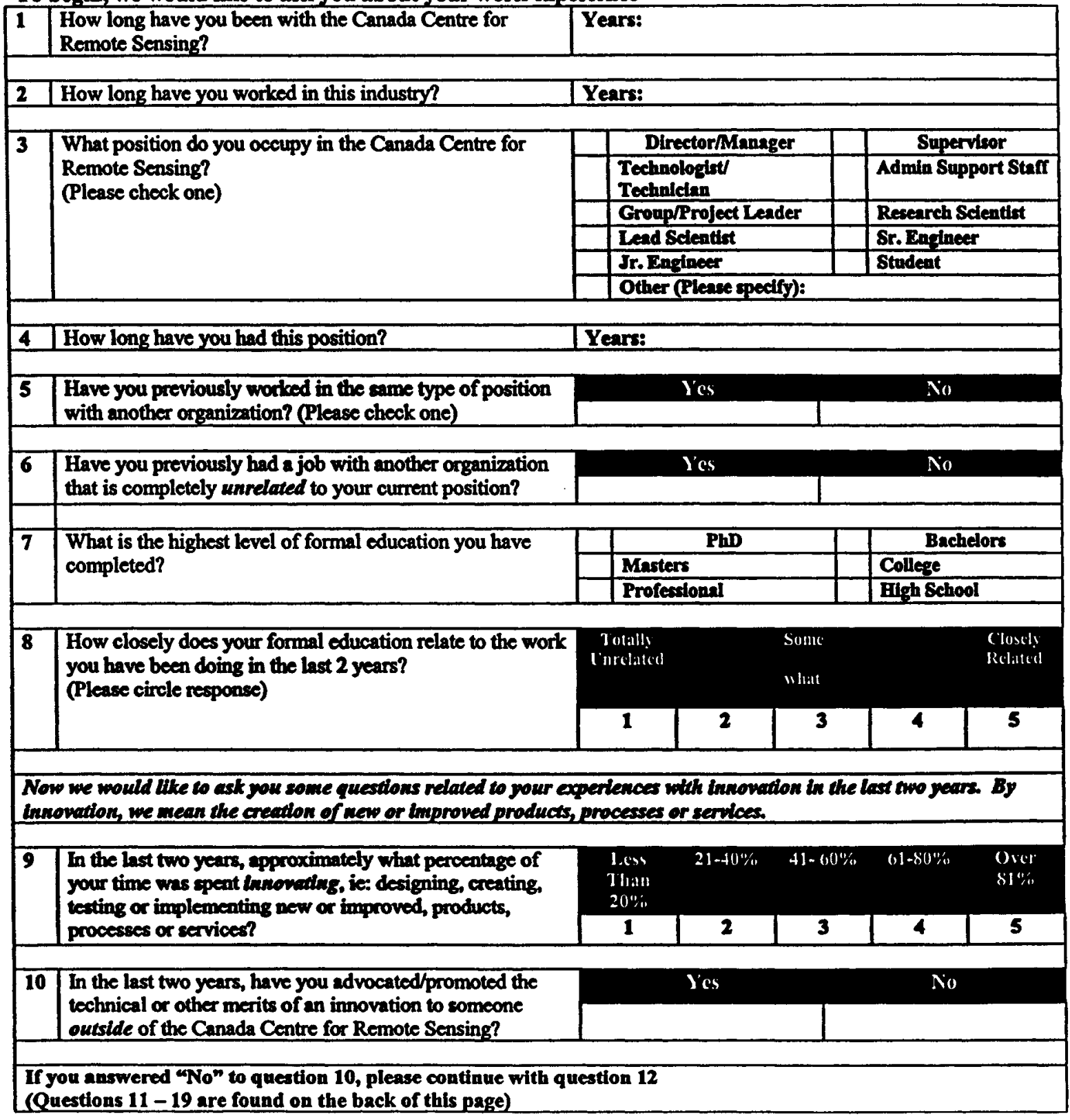




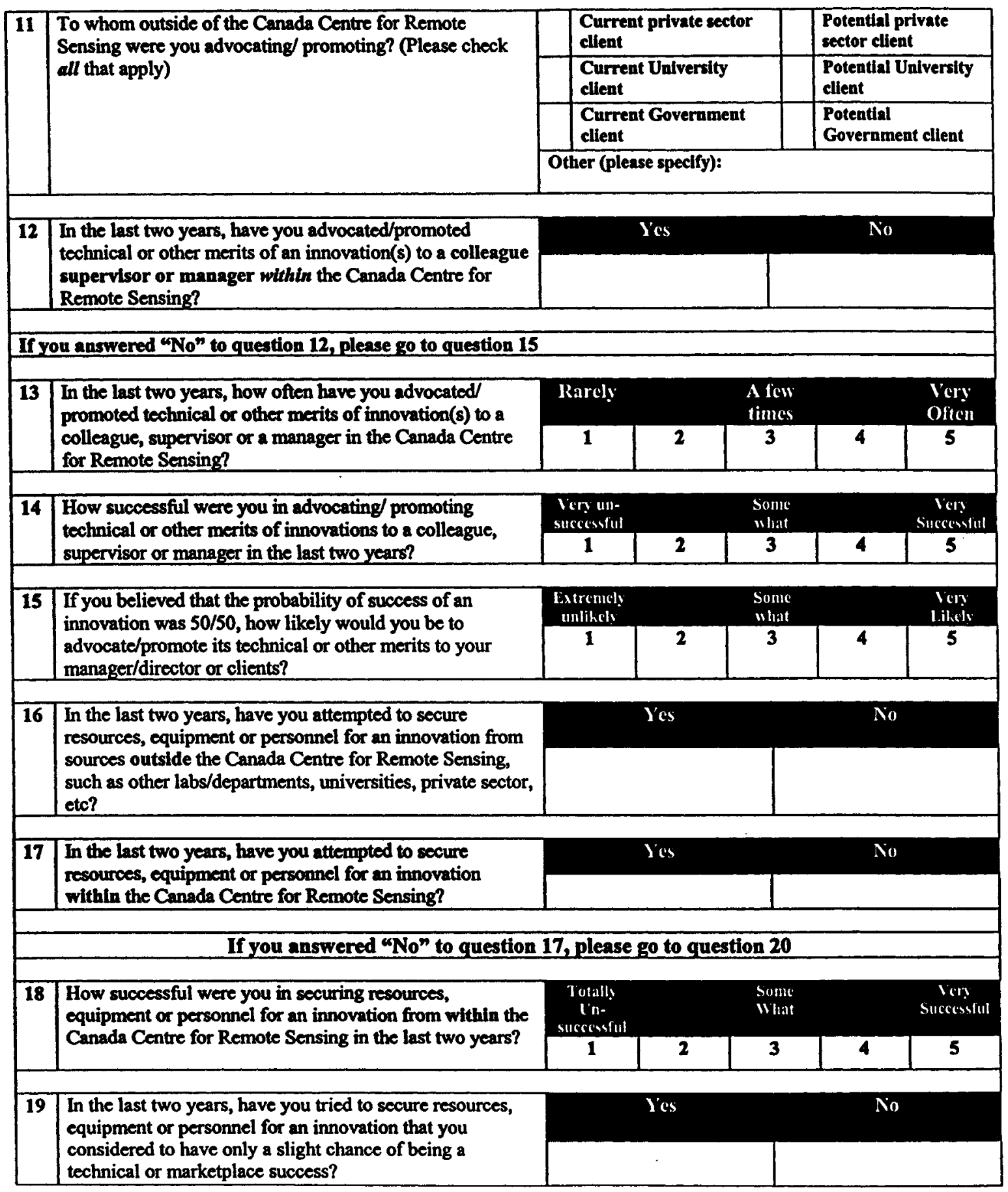




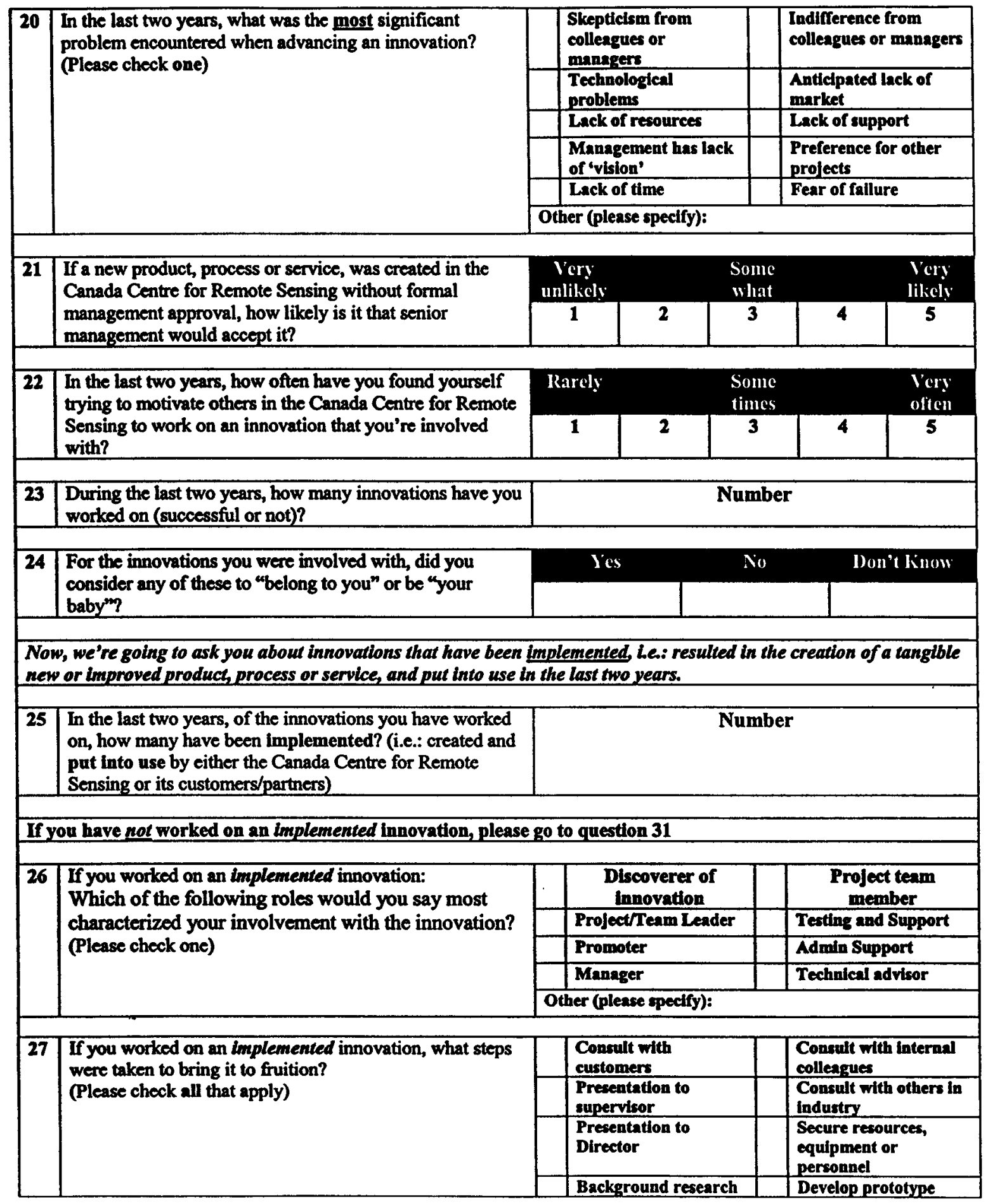




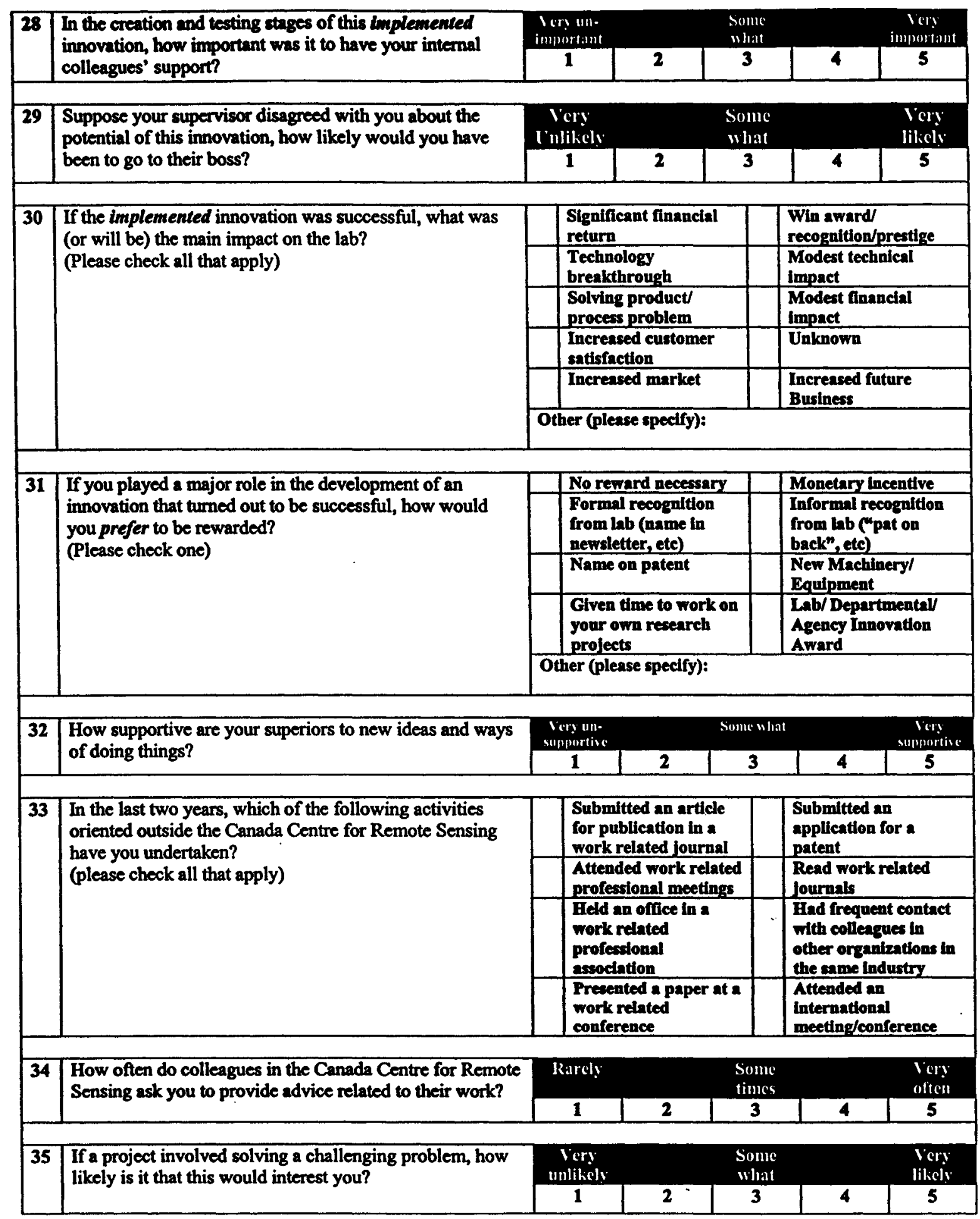




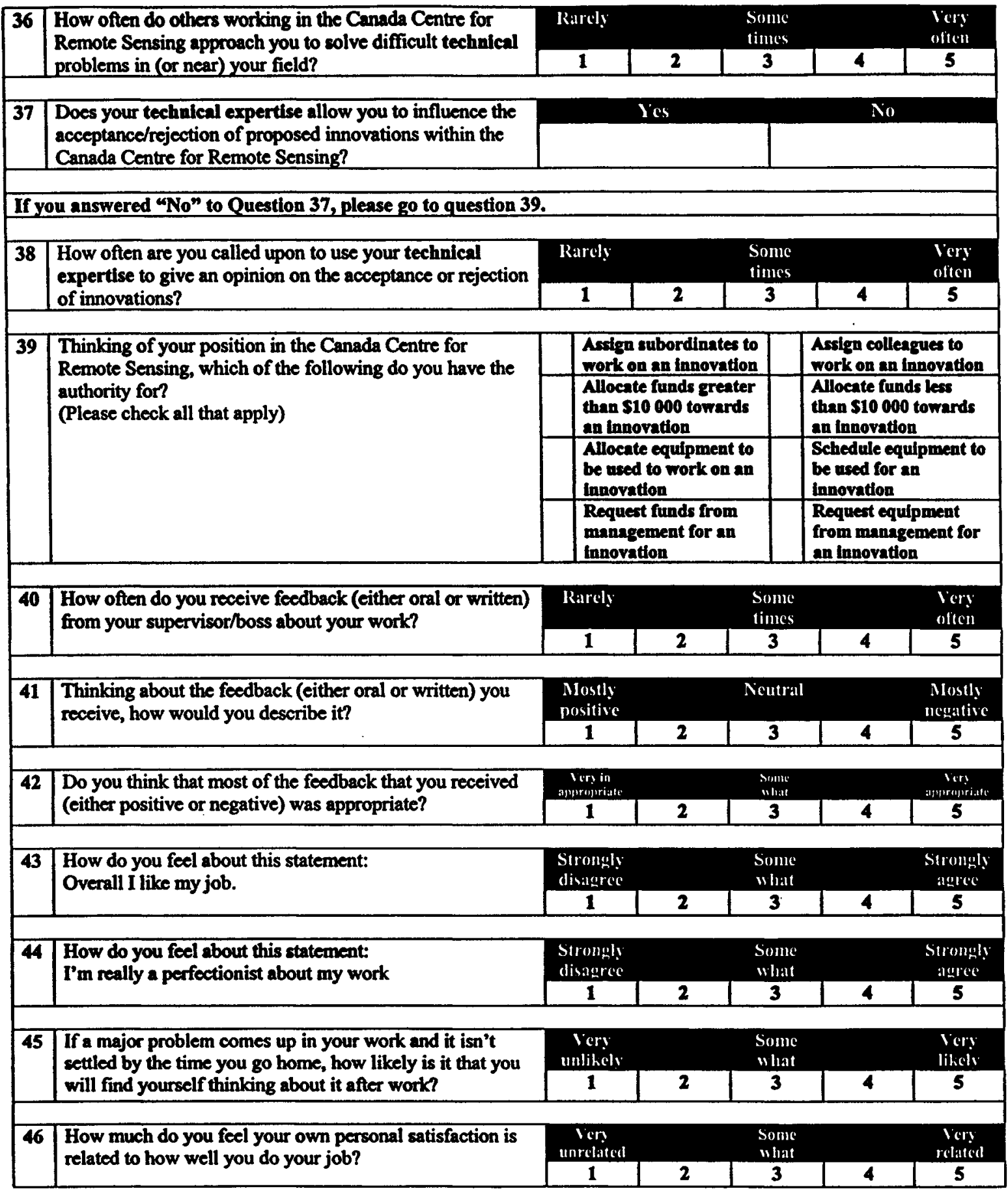




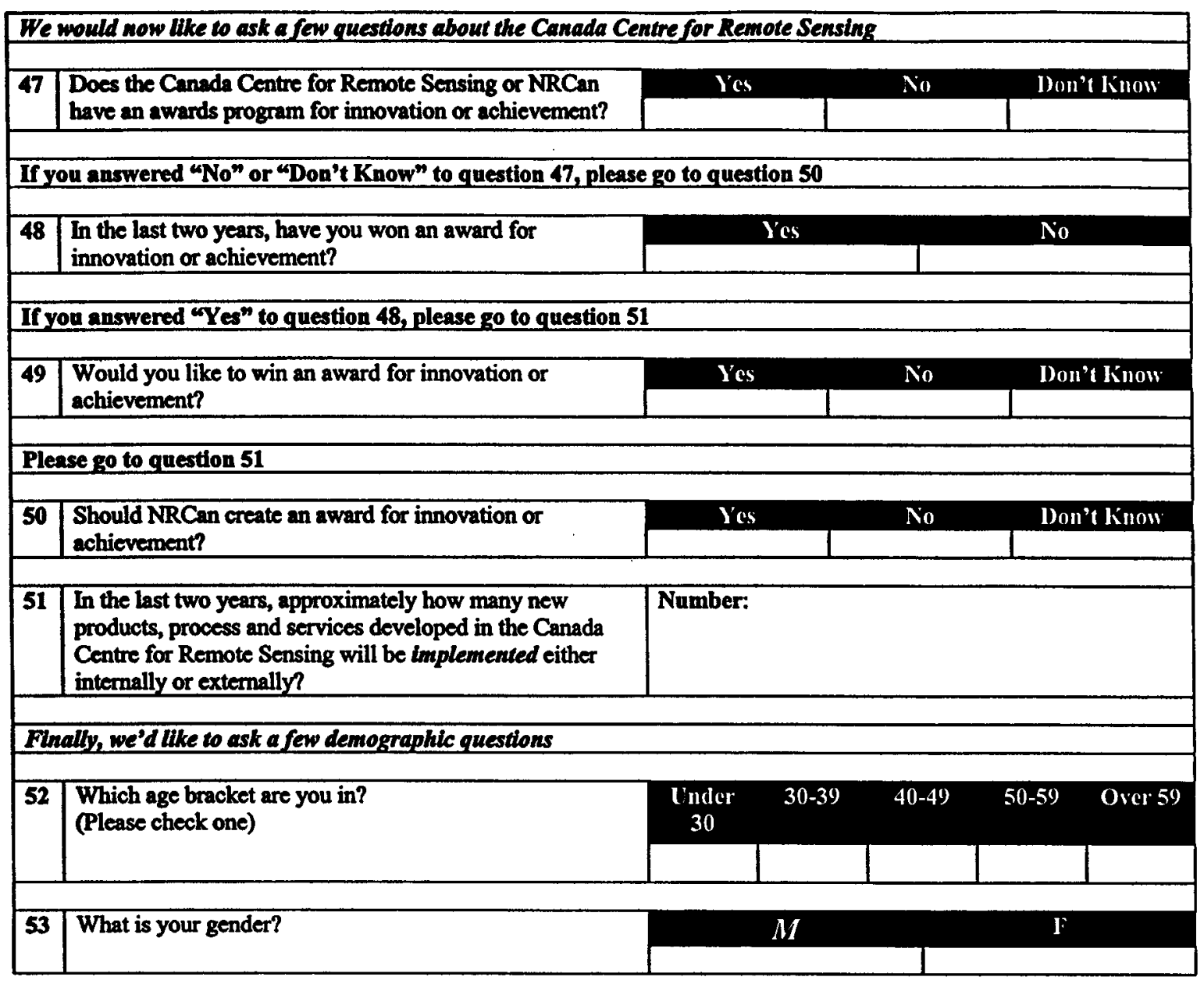

Thank you for your participation!

Please use the self addressed, postage-paid envelope that accompanied this survey to return it. 


\section{APPENDIX C FOCUS GROUP QUESTIONS}

\section{Part 1: Survey findings and discussion}

The results for selected survey questions will be presented, and participants will be asked if the results seem to make sense? Next, participants will be asked to provide any information that may explain or illuminate the findings. Finally, participants will be asked if they think the results (for their lab) on this question would be similar to other Canadian federal government labs?

For example: Suppose the survey results indicate that many respondents identify a "lack of funding" as a major barrier to innovation.

Focus group participants would be asked if they think that a lack of funding would seem to make sense as a major barrier to innovation in the lab? Participants would then be asked if they could provide any information as to why they think a lack of funding is (or is not) a barrier? Perhaps it will be discovered that this is a known problem and that the lab has been trying to secure new funding, for example. Finally, participants would be asked if they thought that other labs were facing funding barriers as well?

\section{Part 2: Additional focus group questions}

The second part of the focus group is designed to provide the researcher with specific information related to the dissertation, but not related to the results of the survey.

Lab funding and product mix

1. Does the source of funding (public or private) make any difference in the development and advancement of the innovation? Are there complications or difficulties, such as unwanted influence, interference or oversight, etc, which arise depending on the type of funding?

2. What difficulties or opportunities arise trying to balance the funding and product mix; ie: production of marketable goods, processes or service and conducting basic research, or research for the public good?

3. How strong are the imperatives towards cost recovery?

\section{Political Imperatives and Innovation}

4. How would you describe the relationship between your lab, the Department and Parliament (or the appropriate standing committee)?

5. Have you been involved with an innovation that was stopped for any reason? How often does this happen?

6. Have any of the lab's successful (or unsuccessful) innovations attracted media attention (media could include industry publications)?

7. Is the lab able to plan for long-term innovation? If not, what are the main barriers? 